\title{
Um arcabouço para \\ construção de sistemas multiagentes musicais
}

\author{
Leandro Ferrari Thomaz
}

TESE APRESENTADA

$\mathrm{AO}$

Instituto DE MATEMÁticA E EstatísticA

DA

Universidade De SÃo Paulo

PARA

OBTENÇÃO DO TÍTULO

$\mathrm{DE}$

Doutor EM CIÊNCIAS

Programa: Ciência da Computação

Orientador: Prof. Dr. Marcelo Gomes de Queiroz

Durante o desenvolvimento deste trabalho o autor recebeu auxílio financeiro da CAPES

São Paulo, junho de 2011 



\title{
Um arcabouço para construção de sistemas multiagentes musicais
}

\author{
Esta tese contém as correções e alterações \\ sugeridas pela Comissão Julgadora durante a defesa \\ realizada por Leandro Ferrari Thomaz em 13/06/2011. \\ O original encontra-se disponível no Instituto de \\ Matemática e Estatística da Universidade de São Paulo.
}

Comissão Julgadora:

- Prof. Dr. Marcelo Gomes de Queiroz (orientador) - IME-USP

- Prof. Dr. Fabio Kon - IME-USP

- Profa. Dra. Anna Helena Reali Costa - EP-USP

- Prof. Dr. Fernando Henrique de Oliveira Iazzetta - ECA-USP

- Prof. Dr. Regis Rossi Alves Faria - FFCLRP-USP 



\section{Agradecimentos}

Primeiramente, gostaria de agradecer ao meu orientador Prof. Marcelo Queiroz, pela inestimável ajuda e incentivo durante esses anos. Este trabalho não existiria se não fosse por ele. Agradeço também aos professores Fabio Kon e Fernando Iazzetta, que em diversos pontos do doutorado contribuiram de uma forma ou de outra.

Ao Prof. Jean-Gabriel Ganascia, da universidade Paris 6, pela oportunidade única oferecida de estagiar em Paris. E, é claro, aos grandes amigos que fiz na Maison du Brésil, Paula Monteiro, Paulo Sampaio, Rodrigo Ferracine, Rodrigo Minetto e Teresa Marques.

Aos velhos e queridos amigos Fernando Moya Orsatti, Luciana Dayoub e Rodrigo Carareto e cujas discussões, acadêmicas ou não, continuam sendo essenciais na minha vida. Aos meus grandes amigos ecanos, principalmente Arthur Tofani, Carolina Baliviera, Carina Castro, Guilherme Sparrapan e Renata Grazzini, pelo incentivo e pela companhia inestimável.

Finalmente, e não menos importante, à minha mãe, Diva Ferrari Thomaz, a quem devo toda essa jornada. 


\section{Resumo}

A área de sistemas multiagentes é um promissor domínio tecnológico para uso em performances musicais interativas. Em trabalhos recentes, essa tecnologia vem sendo utilizada para resolver problemas musicais de escopo específico e alcance limitado, como a detecção de pulsação, a simulação de instrumentos e o acompanhamento musical automático. Neste trabalho, apresentamos uma taxonomia desses sistemas multiagentes musicais e uma arquitetura e implementação de um arcabouço computacional que generaliza os trabalhos anteriores e aborda problemas usuais como a sincronização em tempo real, a comunicação sonora e a mobilidade espacial dos agentes. Através do arcabouço, um usuário pode desenvolver um sistema multiagente musical focado em suas necessidades musicais, enquanto deixa grande parte dos problemas técnicos a cargo do arcabouço. Para validar o arcabouço, implementamos e discutimos dois estudos de caso que exploram diversos aspectos de um sistema multiagente musical, como a comunicação simbólica, a troca de áudio digital, o uso de trajetórias espaciais, a simulação acústica e conceitos de vida artificial, como códigos genéticos e reprodução, demonstrando a usabilidade do arcabouço em uma grande variedade de aplicações musicais.

Palavras-chave: sistemas multiagentes, computação musical, arcabouços computacionais. 


\section{Abstract}

Multiagent system technology is a promising new venue for interactive musical performance. In recent works, this technology has been tailored to solve specific, limited scope musical problems, such as pulse detection, instrument simulation or automatic accompaniment. In this work, we present a taxonomy of such musical multiagent systems, and an implementation of a computational framework that subsumes previous works and addresses general-interest low-level problems such as real-time synchronization, sound communication and spatial agent mobility. By using it, a user may develop a musical multiagent system focusing primarily in his/her musical needs, while leaving most of the technical problems to the framework. To validate this framework, we implemented and discussed two cases studies that explored several aspects of musical multiagent systems, such as symbolic and audio communication, spatial trajectories and acoustical simulation, and artificial life concepts, like genetic codes and reproduction, thus indicating the usefulness of this framework in a variety of musical applications.

Keywords: computer music, multiagent system, software framework. 


\section{Sumário}

Lista de Abreviaturas $\quad$ xi

Lista de Símbolos $\quad$ xiii

Lista de Figuras $\quad$ xv

Lista de Tabelas $\quad$ xvii

1 Introdução $\quad 1$

1.1 Trabalhos Relacionados . . . . . . . . . . . . . . . . . . . . . 2

1.2 Motivação . . . . . . . . . . . . . . . . . . . . . . . . 4

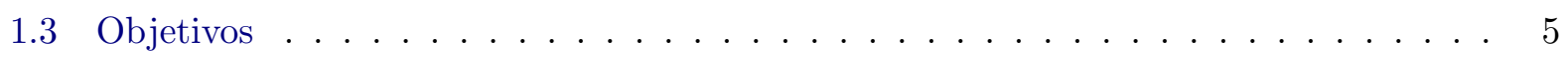

1.4 Requisitos da Arquitetura . . . . . . . . . . . . . . . . . . 6

1.5 Exemplo de uma aplicação musical: Concerto na Catedral . . . . . . . . . . . . 7

1.6 Sumário Estruturado da Tese . . . . . . . . . . . . . . . . . . . 8

2 Taxonomia de Agentes Musicais $\quad 9$

2.1 Ambiente Virtual . . . . . . . . . . . . . . . . . . . . . . . . . . . 10

2.1.1 Representação Física . . . . . . . . . . . . . . . . . . . . . . . . 11

2.1.2 Representação Ecológica . . . . . . . . . . . . . . . . . . . . . . . 13

2.2 Agente Musical . . . . . . . . . . . . . . . . . . . . . . . . . . . 14

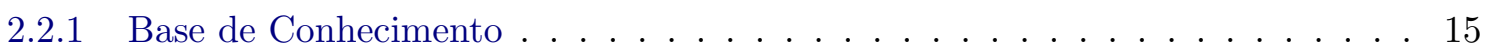

2.2 .2 Raciocínio . . . . . . . . . . . . . . . . . . . . 16

2.2 .3 Sensores . . . . . . . . . . . . . . . . . . . . . 20

2.2 .4 Atuadores . . . . . . . . . . . . . . . . . . . . . 21

2.3 Interações . . . . . . . . . . . . . . . . . . . . . . . . . 22

2.3 .1 Comunicação entre Agentes . . . . . . . . . . . . . . . . . . . 22

2.3 .2 Interações Físicas . . . . . . . . . . . . . . . . . . . . . . . . 23

2.3 .3 Interações Ecológicas . . . . . . . . . . . . . . . . . . . . . . . . 23

3 Arquitetura do Ensemble $\quad 25$

3.1 Atores do Ensemble . . . . . . . . . . . . . . . . . . 26

3.1 .1 Agente Musical . . . . . . . . . . . . . . . . . . . . 26

3.1 .2 Agente Ambiente . . . . . . . . . . . . . . . . . . . . 30

3.1 .3 Agente Externo . . . . . . . . . . . . . . . . . . . . . . . . 32

3.2 Tempo no Ambiente Virtual . . . . . . . . . . . . . . . . . . . 33 
3.3 Modos de Execução do Sistema . . . . . . . . . . . . . . . . . . . . . . . 34

3.3 .1 Processamento em Lote . . . . . . . . . . . . . . . . . . . 35

3.3.2 Processamento em Tempo Real . . . . . . . . . . . . . . . . . . . 35

3.4 Comunicação no Ambiente Virtual ． . . . . . . . . . . . . . . . . . . . 35

3.4.1 Roteamento de Comandos . . . . . . . . . . . . . . . . . . . . 37

3.5 Ciclo de Vida . . . . . . . . . . . . . . . . . . . . . . . . . . 40

3.5.1 Configuração e Execução de um Sistema . . . . . . . . . . . . . . . . . . . 40

3.5.2 Criação de um Agente Musical . . . . . . . . . . . . . . . . . . . 40

3.5.3 Ciclo de Vida de um Componente . . . . . . . . . . . . . . . . . . 41

3.5.4 Modo de Execução em Lote . . . . . . . . . . . . . . . . . . . . . . . . 42

3.5.5 Finalização de um Agente Musical . . . . . . . . . . . . . . . . . . . 44

3.6 Interação no Ambiente Virtual . . . . . . . . . . . . . . . . . . . . 45

3.6 .1 Tipos de Evento . . . . . . . . . . . . . . . . . 45

3.6.2 Formas de Troca de Eventos . . . . . . . . . . . . . . . . 46

3.6 .3 Interface de Comunicação . . . . . . . . . . . . . . . . . . . 46

3.6.4 Registro de Sensor e Atuador no Ambiente . . . . . . . . . . . . . . . 47

3.6 .5 Troca de Eventos . . . . . . . . . . . . . . . . . . 50

$4 \quad$ Implementação do Ensemble $\quad 57$

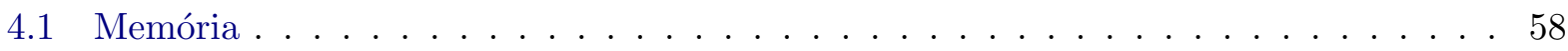

4.2 Movimentação do Agente . . . . . . . . . . . . . . . . . . . . . . . 59

4.3 Propagação Sonora . . . . . . . . . . . . . . . . . . . . . . . 61

4.3 .1 Cálculo da Frente de Onda . . . . . . . . . . . . . . . . . . . . 62

4.3 .2 Troca de Eventos de Áudio . . . . . . . . . . . . . . . . . . . . 67

4.4 Interfaces Externas . . . . . . . . . . . . . . . . . . . . . . 68

4.4.1 Interface com Bibliotecas Externas . . . . . . . . . . . . . . 68

4.4 .2 Interface com Sistemas Externos . . . . . . . . . . . . . . . . . . 70

4.4.3 Interface com Espaços de Escuta e Captura Reais . . . . . . . . . . . . . . . . 71

4.4 .4 Interface de controle . . . . . . . . . . . . . . . . . . . . 76

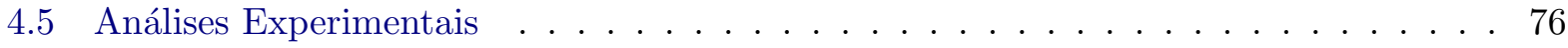

4.5.1 Troca de Eventos Periódicos . . . . . . . . . . . . . . . . . 76

4.5 .2 Propagação Sonora . . . . . . . . . . . . . . . . . . . . 80

5 Estudos de Caso $\quad \mathbf{8 3}$

5.1 Living Melodies . . . . . . . . . . . . . . . . . . . . . . . . 83

$5.1 .1 \quad$ Agente Musical . . . . . . . . . . . . . . . . . . . . 84

5.1 .2 Agente Ambiente . . . . . . . . . . . . . . . . . . 85

5.1 .3 Discussão . . . . . . . . . . . . . . . . . . . . . 88

5.2 Clapping Music . . . . . . . . . . . . . . . . . . . . . . . . 89

$5.2 .1 \quad$ Agente Musical . . . . . . . . . . . . . . . . . . . . 89

$5.2 .2 \quad$ Agente Ambiente . . . . . . . . . . . . . . . . . . . . . . . . 94

5.2 .3 Discussão . . . . . . . . . . . . . . . . . . . . . . . . 94 
6 Conclusões e Trabalhos Futuros $\quad 97$

6.1 Limitações do Java . . . . . . . . . . . . . . . . . . . . . . . . . 97

6.2 Considerações Finais . . . . . . . . . . . . . . . . . . . . . 98

6.3 Trabalhos Futuros . . . . . . . . . . . . . . . . . . . 99

$\begin{array}{ll}\text { A Tutorial } & 101\end{array}$

A.1 Requisitos do Ensemble . . . . . . . . . . . . . . . . . . . . . . 101

A.2 Configurando uma aplicação musical . . . . . . . . . . . . . . . . . . . 102

A.2.1 Criando um agente músico . . . . . . . . . . . . . . . . . . 103

A.2.2 Ouvindo o que acontece no ambiente virtual . . . . . . . . . . . . . . 104

A.2.3 Movimentando os agentes . . . . . . . . . . . . . . . . . . 105

A.2.4 Tocando junto com os agentes . . . . . . . . . . . . 106

A.2.5 Recriando um campo sonoro de escuta . . . . . . . . . . . . . . . . 107

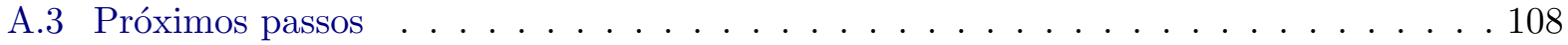

$\begin{array}{ll}\text { Referências Bibliográficas } & 109\end{array}$ 


\title{
Lista de Abreviaturas
}

\author{
API Application Programming Interface. \\ DS Directory Service. \\ GC Garbage Collector. \\ FIR Finite Impulse Response. \\ JADE Java Agent DEvelopment Framework. \\ JNI Java Native Interface. \\ IIR Infinite Impulse Response. \\ MIDI Musical Instrument Digital Interface. \\ FFT Fast Fourier Transform. \\ OSC Open Sound Control. \\ Pd Pure Data. \\ RTSJ Real-Time Specification for Java. \\ UML Unified Modeling Language.
}




\section{Lista de Símbolos}

$t \quad$ Instante no tempo correspondente a uma amostra da janela de áudio.

$\Delta \quad$ Duração de uma amostra, dependente da taxa de amostragem escolhida.

$c_{\text {som }}$ Velocidade do som no ambiente.

$S x(t) \quad$ Sinal de áudio do sensor sonoro.

$S p(t) \quad$ Posição do sensor sonoro.

$A x(t) \quad$ Sinal de áudio do atuador sonoro.

$A p(t)$ Posição do atuador sonoro.

$A v(t)$ Velocidade do atuador.

$t_{d} \quad$ Instante correspondente à saída da frente de onda do atuador que chega no sensor no instante $t$.

$g(t) \quad$ Ganho do sinal ao chegar no sensor com relação ao sinal original do atuador. 


\section{Lista de Figuras}

2.1 O Agente Musical e seu Ambiente Virtual . . . . . . . . . . . . . . . . . . . . 9

2.2 Taxonomia do Ambiente Virtual _ . . . . . . . . . . . . . . . . . . . 11

2.3 Taxonomia do Agente Musical . . . . . . . . . . . . . . . . . . . . . . . . 14

2.4 Taxonomia de Interações no Ambiente . . . . . . . . . . . . . . . . . . . 22

3.1 Diagrama de Classes do Agente Musical . . . . . . . . . . . . . . . . . . 27

3.2 Diagrama de Classes do Agente Ambiente . . . . . . . . . . . . . . . . . . . 31

3.3 Diagrama de Classes do Tempo Virtual . . . . . . . . . . . . . . . . . . 33

3.4 Agendamento de uma tarefa em modo controlado pelo relógio interno e pelo usuário 34

3.5 Comunicação no Ensemble . . . . . . . . . . . . . . . . . . . . 36

3.6 Inicialização de um Agente Musical no processamento em lote . . . . . . . . . . . . . 41

3.7 Processamento de um turno no processamento em lote . . . . . . . . . . . . . . 43

3.8 Finalização de um Agente Musical no processamento em lote . . . . . . . . . . . . . 44

3.9 Diagrama de Classes de Eventos . . . . . . . . . . . . . . . . . . . 46

3.10 Diagrama de classes da Interface de Comunicação . . . . . . . . . . . . . . . . . . 47

3.11 Diagrama de sequência do registro de um Sensor/Atuador . . . . . . . . . . . . . . 48

3.12 Diagrama de sequência da retirada do registro de um Sensor/Atuador . . . . . . . . 49

3.13 Diagrama de sequência de uma troca de eventos esporádicos . . . . . . . . . . . . 51

3.14 Linha do tempo de uma janela na troca de eventos periódicos . . . . . . . . . . . . 52

3.15 Diagrama de estados do Servidor de Eventos e do Atuador na troca de eventos

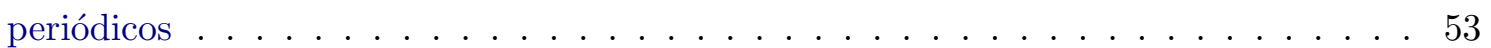

3.16 Diagrama de sequência de uma troca de eventos periódicos. . . . . . . . . . . . 54

3.17 Problemas na troca de eventos periódicos . . . . . . . . . . . . . . . 55

4.1 Diagrama de classes dos tipos de memória disponíveis no Ensemble . . . . . . . . . 58

4.2 Frente de onda sonora em duas situações: momento em que chega no sensor $(t)$ e momento em que foi produzida pelo atuador $\left(t_{d}\right) \ldots \ldots \ldots \ldots$

4.3 Variação do atraso $\left(t-t_{d}\right)$ para um par Atuador/Sensor em movimento . . . . . . . 64

4.4 Diagrama de classes do processamento através de bibliotecas externas . . . . . . . . 69

4.5 Interação entre o $\mathrm{Pd}$ e o Ensemble através do protocolo OSC $\ldots$. . . . . . . . . . 72

4.6 Atraso na captura e na reprodução de áudio no Ensemble . . . . . . . . . . . . . . 73

4.7 Interface entre o Ensemble, o Pd e a interface de áudio feita através do Jack . . . . . 74

4.8 Configurações de alto-falantes disponíveis para a recriação de campo sonoro através de Ambisonics . . . . . . . . . . . . . . . . . . . . . 76

4.9 Interface de controle gráfica do Ensemble . . . . . . . . . . . . . . . . 77 
4.10 Taxa de sucesso na troca de eventos periódicos entre Agentes Musicais e um Servidor de Eventos. . . . . . . . . . . . . . . . . . . . . . . 79

4.11 Tempo gasto para o cálculo da propagação sonora relativo ao tamanho da janela. . . 81

5.1 Diagrama de classes do Agente Musical da aplicação Living Melodies . . . . . . . . . 84

5.2 Diagrama de classes do Ambiente Virtual da aplicação Living Melodies . . . . . . . . 85

5.3 Interface gráfica na simulação do Living Melodies . . . . . . . . . . . . . . . 86

5.4 Propagação do som na simulação do Living Melodies . . . . . . . . . . . . . . . . 87

5.5 Padrão rítmico utilizado na peça Clapping Music, de Steve Reich . . . . . . . . . . . 89

5.6 Diagrama de objetos com os dois tipos de Agente Musical do Clapping Music . . . . 90

5.7 Execução de um ciclo completo do padrão do Clapping Music, onde a segunda voz defasa uma colcheia a cada compasso . . . . . . . . . . . . . . . . . 92

5.8 Posicão dos agentes a cada compasso na execução do Clapping Music utilizando o exemplo da figura anterior (sendo L o líder, F1 o Seguidor 1 e F2 o Seguidor 2) . . 93

5.9 Diagrama de objetos com o Agente Ambiente do Clapping Music . . . . . . . . . . . 94 


\section{Lista de Tabelas}

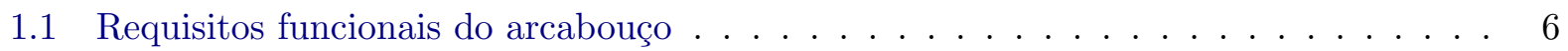

1.2 Requisitos não-funcionais do arcabouço $\ldots \ldots \ldots \ldots \ldots \ldots$

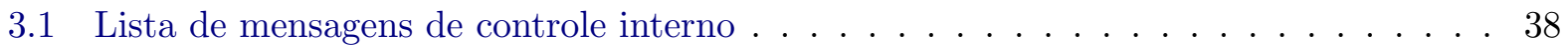

3.2 Lista de mensagens de controle do usuário . . . . . . . . . . . . . . . . . . 39

3.3 Ciclo de vida de um componente do arcabouço . . . . . . . . . . . . . . . . 42

3.4 Prazos na troca de eventos periódicos . . . . . . . . . . . . . . . 52

4.1 Instruções utilizadas para a interação com Servidor de Eventos de Movimentação . 60

4.2 Parâmetros aceitos pela lei de movimentação (MovementLaw) . . . . . . . . . . . . . 60

4.3 Parâmetros aceitos pelo servidor de áudio . . . . . . . . . . . . . . . . . . 62

4.4 Comandos utilizados para a interação com Servidor de Eventos de Movimentação . . 70

4.5 Taxa de sucesso no envio de eventos sonoros pelos Agentes Musicais . . . . . . . . 78

5.1 Parâmetros da aplicação Clapping Music . . . . . . . . . . . . . . . . . . . . . 91 


\section{Capítulo 1}

\section{Introdução}

O interesse no uso de algoritmos computacionais no âmbito da composição musical surgiu na década de 1950 e vem crescendo desde então. Este uso acompanha uma tendência artística que corresponde a valorizar o processo dinâmico de criação/realização/apreensão da arte em oposição à valorização do objeto de arte estático. A composição algorítmica pode ser vista, neste contexto, como um conjunto de técnicas que permite ao compositor controlar parâmetros musicais gerais, tais como densidade, textura e harmonicidade, e deixar algumas escolhas de parâmetros pontuais, tipicamente associados a eventos sonoros individuais, por conta de algum processo computacional, seja ele determinístico ou estocástico.

Segundo Whalley [Wha05], a exploração de novas ferramentas tecnológicas para a criação musical, embora tenha a capacidade de ampliar o horizonte estético, geralmente leva a caminhos sem saída. Os usuários da tecnologia acabam se perdendo no processo de aprendizagem e aplicação de ferramentas específicas, criando sistemas que são tecnologicamente complexos, mas cujo valor estético é pequeno. Assim, é necessário encontrar um caminho em que seja possível balancear a preocupação do músico com o aporte tecnólogico e o resultado musical do sistema sendo desenvolvido. A tecnologia de sistemas multiagentes parece ser uma dessas opções.

Um agente computacional é comumente descrito como sendo um sistema computacional que está situado em um ambiente (virtual ou não), interagindo com este através de sensores e atuadores, e que é capaz de tomar decisões e executar ações de forma autônoma a fim de alcançar seus objetivos [Wei99]. Um sistema multiagente é uma comunidade de agentes autônomos onde estes interagem, se organizam e se comunicam, competindo ou cooperando uns com os outros, a fim de alcançar o objetivo proposto para esse sistema. A tecnologia de agentes em inteligência artificial é particularmente apta a aplicações musicais pela possibilidade de associação do agente com a figura do intérprete ou instrumentista. Nesta identificação podem ser mapeadas características tais como performance, percepção, adaptação e improvisação de um lado e processos artificiais de outro.

A concentração do escopo em sistemas multiagentes permite, por um lado, a abstração de questões estéticas específicas à escolha dos algoritmos composicionais de cada agente e, por outro lado, um estudo mais aprofundado dos problemas de comunicação e interação (ou seja, da sociologia) dos sistemas multiagentes no contexto da produção musical [LCN90, Jen93, Wei99]. Através da associação de cada agente a uma parte musical e da dinâmica social do conjunto de agentes à estrutura da composição, podem-se definir processos musicais dinâmicos os quais, embora sempre refletindo a mesma estrutura abstrata que corresponde ao projeto do sistema, poderão ser distintos a cada nova realização ou simulação.

O projeto aqui apresentado corresponde à proposta de definição e implementação do Ensemble, um arcabouço computacional para sistemas multiagentes musicais, e ao estudo abrangente dos problemas intrínsecos a tais sistemas e técnicas de solução. Um arcabouço (framework), segundo 
Johnson e Foote [JF88], é um conjunto de classes cujo objetivo é abstrair um família de problemas relacionados, e assim permitir a reutilização com um escopo maior do que simplesmente utilizar as classes separadamente. Através da determinação de elementos comuns entre os sistemas existentes, e do levantamento de novas funcionalidades, objetivou-se neste trabalho o desenvolvimento de um arcabouço capaz de suprir as necessidades técnicas básicas de um potencial músico/usuário, permitindo a implementação de um sistema multiagente musical que se adapte à sua aplicação musical.

Um ponto importante a ser tratado é a espacialidade, um atributo musical de fundamental importância na composição musical contemporânea, especialmente na música eletroacústica, e que foi explorada superficialmente no contexto de sistemas multiagentes em trabalhos anteriores [DN01]. Assim, a simulação da propagação do som no ambiente virtual e a forma como cada agente recebe a informação sonora, dependendo de sua posição e forma de escuta, são um dos principais focos do trabalho. Além disso, a associação de trajetórias espaciais aos agentes musicais em um espaço virtual pode ser apreciada em um palco sonoro (soundstage) através de técnicas de auralização com um número escalável de fontes sonoras fixas, como o Ambisonics [MM95, Tho07] e o VBAP [Pul97].

A partir do estudo dos sistemas existentes, uma taxonomia de agentes musicais e de suas possíveis relações em sistemas multiagentes foi criada. Em seguida, a arquitetura do Ensemble foi desenvolvida utilizando-se o paradigma de orientação a objetos, baseando-se na taxonomia e nas funcionalidades genéricas. Para a implementação da arquitetura, foi escolhida a linguagem Java principalmente pela sua portabilidade, uma vez que pretende-se disseminar o Ensemble em diversas plataformas computacionais. Finalmente, para validar a generalidade e aplicabilidade do arcabouço, foi feito o mapeamento de uma aplicação já existente e foram criadas aplicações sonoras e musicais que exploram diversos aspectos das funcionalidades do Ensemble.

\subsection{Trabalhos Relacionados}

Vários trabalhos anteriores envolvendo computação musical e sistemas multiagentes tratam de sistemas bastante restritos em seu escopo, como deteç̧ão de pulso musical [Dix00], geração e avaliação de melodias [TW99, Mir02], simulação de um instrumento específico [RRG99, CVM08] e acompanhamento e performance coletiva no contexto específico do sistema tonal [WNV03]. Além desses, dois trabalhos de âmbito mais geral envolvendo agentes e composição algorítmica são o projeto Andante [UK04], que trata da construção de agentes móveis em sistemas distribuídos, e a arquitetura MAMA [MR07], um sistema multiagente musical cujo escopo está bem próximo do presente trabalho. Estes trabalhos são apresentados de forma resumida a seguir.

O problema de detecção de pulso musical em sinais de áudio é tratado por Dixon [Dix00] através do uso de um sistema multiagente. Neste trabalho os agentes não produzem música, mas são responsáveis por avaliar múltiplas hipóteses de pulso geradas por um algoritmo de agrupamento de forma competitiva. Novos agentes são criados em pontos de indecisão ao longo do processo, a fim de avaliar alternativas para a localização dos pulsos, e agentes que representem hipóteses não confirmadas são destruídos.

Todd e Werner [TW99] descrevem uma comunidade virtual para composição algorítmica inspirada no fato de que algumas espécies de pássaros usam melodias para atrair parceiros para o acasalamento. Neste modelo há dois tipos de agentes: machos que produzem melodias simples (sequências de notas) e fêmeas que decidem, ao escutar estas melodias, com quem vão acasalar e gerar a próxima geração (de machos compositores e fêmeas críticas), a partir de uma combinação das características de seus pais. A cada geração, os compositores tocam melodias determinadas por suas cargas genéticas, enquanto as críticas usam cadeias de Markov para dar notas aos possíveis parceiros. A coevolução destes dois grupos determinará, com o passar das gerações, o surgimento 
de padrões melódicos mais complexos. De vários métodos propostos de decisão de acasalamento por parte das fêmeas, o que produziu músicas mais interessantes na opinião dos autores foi aquele em que a fêmea privilegiava parceiros que mais a surpreendessem; depois de algumas gerações observa-se o surgimento de um espaço melódico com características complexas, sem a intervenção humana. Os trabalhos de Miranda [Mir03] e Langton [Lan95] fornecem mais informações sobre a emergência de características musicais em sistemas complexos.

Ramalho, Rolland e Ganascia [RRG99] propõem um agente musical artificial capaz de improvisar linhas de baixos em jazz, a partir da análise do som gerado pelos outros instrumentos e da adaptação de fragmentos de linhas melódicas previamente carregadas em sua base de conhecimento. Outro exemplo envolvendo síntese instrumental é um sistema multiagente desenhado para simular os sons rítmicos de performances de violão [CVM08], sendo sua saída traduzida para o protocolo MIDI e então sintetizada. O núcleo do sistema é composto por dois agentes, um responsável pelo ritmo (mão direita) e o outro pela melodia (mão esquerda). No sistema CInBalada [STR05], uma comunidade de agentes percussionistas interage de forma a criar ritmos musicais. Uma plataforma multiagentes compatível com o padrão FIPA [ON98] foi implementada na linguagem $\mathrm{C}++$ para ser utilizada como base para o sistema.

Wulfhorst, Nakayama e Vicari [WNV03] definem um sistema de agentes que simulam um grupo instrumental, desenhados e organizados para produzir sons intercoerentes. Propriedades como ritmo e padrão melódico, dentre outras, surgem como forma de sincronizar e padronizar o comportamento dos agentes, para que o som criado tenha um sentido musical tonal. Cada agente neste sistema possui características como liderança, performance, persuasão e improvisação, que determinam a atuação que ele terá no conjunto.

Em Living Melodies [DN01], os autores construíram um mundo artificial de agentes musicais, que habitam um espaço físico virtual, podendo se locomover dentro dele. Além disso, o som gerado pelos agentes se propaga por esse espaço virtual seguindo leis físicas simplificadas. O comportamento dos agentes é descrito em termos de um arcabouço de programação genética, que permite a comunicação entre os agentes através do som, sua movimentação no espaço e a reprodução entre agentes. De acordo com a intenção dos autores, o som gerado nesse mundo virtual poderia ser aproveitado pelo usuário do sistema como material base para composição musical.

De forma similar ao Living Melodies, Beyls [Bey07] desenvolveu uma sociedade de agentes musicais que se auto-organiza a fim de gerar música a partir do comportamento emergente do sistema, que pode funcionar de forma autônoma ou com uma entrada musical externa. O trabalho utiliza o protocolo MIDI como forma de troca de informação musical e apresenta alguns conceitos de vida artificial, como a existência de um mundo bidimensional onde os agentes habitam e se locomovem, consumindo energia durante o processo. Na mesma linha de sistemas emergentes, o trabalho proposto por Gimenes, Miranda e Johnson [GMJ06] utiliza um sistema multiagente musical para estudar a evolução de estilos musicais em nossa sociedade e outros caminhos que poderiam ter sido tomados.

Os próximos trabalhos almejam a definição de ferramentas mais complexas e flexíveis, permitindo a definição de diversos sistemas multiagentes em determinados contextos.

O projeto Andante [UK04] define o conceito de Agentes Móveis Musicais para criação e execução musical, utilizando o protocolo MIDI, em ambientes computacionais distribuídos. Neste trabalho foi especificado e implementado o sistema Andante, que permite a definição de agentes musicais com a capacidade de migração (dos programas correspondentes) dentro de uma rede de computadores. O sistema visa o desenvolvimento de obras artísticas distribuídas, onde vários artistas e ouvintes conectados em rede podem compartilhar experiências de composição e performance. 
O AALIVENET [Spi04] é um sistema distribuído de agentes musicais utilizado para composição em tempo real utilizando o protocolo MIDI. O seu foco é na troca de informação musical em redes de computadores, sendo que em cada nó da rede encontra-se um agente musical com alguma habilidade específica, por exemplo um baixista ou um baterista.

A arquitetura MAMA [MR07] compreende um sistema multiagente musical em que os agentes, através de uma representação de alto nível da peça musical sendo executada, interagem e assim determinam suas performances. O autor constrói uma teoria de atos musicais, baseada na teoria de atos da fala (speech act theory), para representar as interações entre agentes. Através do raciocínio sobre o estado atual da peça, das ações de outros agentes e do seu estado interno, o agente é capaz de construir um plano que irá guiar sua atuação musical no ambiente, decidindo por exemplo se irá acompanhar outro agente. O sistema transmite as informações musicais entre os agentes via MIDI, utilizando um agente centralizador (agente maestro) que tem o papel de juntar as informações recebidas a cada fragmento musical e repassar para os agentes musicais e para a renderização final em áudio.

O Swarm Orchestra [BNF08] é um sistema que trata de uma complexa população de agentes (swarms) que interage utilizando conceitos de vida artificial. Através da biblioteca ISO Flock, extensível pelo usuário, é possível criar simulações com uma grande quantidade de agentes virtuais e controlar seus diversos parâmetros de forma simultânea, criando complexos padrões de movimentação e de interação entre os agentes. O resultado da simulação pode ser acoplado à bibliotecas de síntese de áudio e de video tracking, disponíveis no sistema, ou redirecionadas a outros sistemas.

Pode-se observar que, em cada um dos trabalhos anteriores, aparecem várias restrições de ordem estrutural ou estética, tais como melodias isoladas, o uso do sistema tonal, a simulação de instrumentos específicos etc. Além disso, também existem restrições técnicas quanto à análise, síntese e codificação do som, como a frequente utilização do protocolo MIDI. Obviamente, essas restrições aparecem devido ao propósito do sistema e à dificuldade de se fazer um sistema capaz de comportar um grande número de funcionalidades.

Neste trabalho, por tratar-se de um arcabouço, não serão feitas hipóteses restritivas sobre materiais musicais, sistemas composicionais ou métodos específicos de síntese e processamento de sinais, possibilitando a implementação de qualquer um dos sistemas descritos acima. Por outro lado, os agentes deverão seguir um protocolo relativo à interface e modos de comunicação a fim de garantir a possibilidade de reutilização e extensibilidade do sistema.

\subsection{Motivação}

Alguns sistemas de criação de áudio tradicionalmente utilizados pelos músicos, como o Pure Data (Pd) [Puc96] e o CSound [VE90], podem, em princípio, ser comparados ao arcabouço aqui descrito. Se considerarmos que esses sistemas trabalham com blocos de processamento de áudio, com entradas e saídas (inlets e outlets, no caso do Pd), que são ligados entre si (patch) criando um fluxo de áudio processado ao longo do tempo, pode-se fazer um paralelo com o agente musical e seus sensores e atuadores. Assim, esse patch teria a mesma função de um sistema desenvolvido utilizando-se o Ensemble, onde os diversos blocos de processamento seriam os agentes.

Mas a semelhança é interrompida nesse ponto, pois os sistemas tradicionais trabalham de forma acoplada e sincronizada, além de seus blocos serem obrigados por definição a fazer o que foram programados, através da passagem de parâmetros e do áudio que chega em sua entrada. Já em um sistema multiagente, os agentes têm total autonomia (obviamente limitada pela complexidade de 
sua programação interna) para decidir o que fazer, baseando-se em mas não sendo regrados por suas entradas. Assim, existe um desacomplamento entre os diversos componentes do sistema e a possibilidade de colaboração entre os diversos agentes.

A utilização de sistemas multiagentes é particulamente conveniente em aplicações que envolvem diversos agentes musicais autônomos, sejam eles computacionais ou não, que interagem através da troca de informação musical, como no caso do acompanhamento e improvisação musicais automáticos [MRSE06, RRG99] e nas performances eletrônicas coletivas [BNF08, Spi04].

Outra área em que o Ensemble pode ser útil é no estudo do comportamento emergente de sociedades musicais inspiradas em conceitos biológicos. Estes sistemas vêm sendo utilizados para gerar material musical para composições [DN01, McC01, Bey07], ou ainda para estudar o surgimento e a evolução da música na sociedade humana [Mir02, GMJ06].

Finalmente, o Ensemble também poderia ser utilizado em aplicações não necessariamente musicais que envolvam a troca de áudio em um ambiente espacializado, por exemplo em jogos ou em ambientes de realidade virtual imersiva, onde a estrutura de propagação sonora em ambiente virtual poderia ser usada para simular fontes sonoras em movimento, acrescentando atrasos relativos, atenuação pela distância, efeito Doppler, etc.

Contudo, o principal público alvo desse trabalho é a comunidade de compositores que utiliza o computador como uma ferramenta de criação musical. A falta de uma arquitetura genérica de sistemas multiagentes musicais é o principal obstáculo para sua utilização pelo público não acadêmico, uma vez que o reaproveitamento de código é mínimo e a cada nova aplicação várias ferramentas devem ser refeitas. Também deve-se considerar que, não sendo a programação seu mister principal, o músico poderia usufruir de uma ferramenta de fácil programação e execução. Indo mais além, a utilização de uma plataforma comum também permite uma troca maior de idéias e ferramentas entre os seus usuários. Com o Ensemble, o compositor pode utilizar os componentes e agentes já prontos, apenas parametrizando-os, ou então, caso seja necessário, programar novos componentes e agentes.

\subsection{Objetivos}

A principal contribuição original deste trabalho de pesquisa é a disponibilização de um arcabouço de sistemas multiagentes musicais, em particular capaz de tratar as questões da propagacão sonora e da espacialidade dentro do ambiente virtual. Os objetivos do trabalho são os seguintes:

- Levantamento e classificação, através de uma taxonomia, de sistemas multiagentes musicais, a partir de sistemas existentes na literatura;

- Definição e implementação de um arcabouço computacional para comunidades virtuais musicais baseadas em sistemas multiagentes a partir da taxonomia e dos requisitos funcionais levantados na seção 1.4;

- Validação da generalidade do arcabouço através do mapeamento de sistemas existentes no Ensemble, além da validação das funcionalidades do Ensemble através da criação de novas aplicações; 


\subsection{Requisitos da Arquitetura}

Os requisitos funcionais do arcabouço foram levantados a partir do estudo dos sistemas existentes, de suas funcionalidades e limitacões, e da definição da taxonomia. Estes requisitos são considerados essenciais para que o arcabouço seja genérico o suficiente a fim de permitir o mapeamento desses sistemas, além de permitir a criação de novas aplicações cujos requisitos não foram levantados anteriormente. A tabela 1.1 enumera esses requisitos.

Tabela 1.1: Requisitos funcionais do arcabouço

\section{RF Seção Descrição}

1. Arcabouço (funcionalidades genéricas)

$\begin{array}{lll}1.1 & 3.2 & \text { deve fornecer um serviço de relógio capaz de agendar tarefas }\end{array}$

$1.2 \quad 3.4$ deve gerenciar a transmissão de mensagens entre os agentes musicais

$1.3 \quad 3.1 \quad$ deve prover um gerenciamento comum do ciclo de vida para os agentes e seus componentes

$1.4 \quad 3.1$ deve prover um conjunto de métodos que podem ser implementados pelo usuário a fim de prover funcionalidades específicas para o sistema

1.5 3.1.3 deve permitir a interação de agentes externos (usuário ou outros sistemas) com o ambiente virtual e os agentes nele inseridos

1.6 3.6 deve prover meios para que os agentes musicias recebam sensações do ambiente virtual e atuem neste ambiente

1.7 $3.5 \quad$ deve ser capaz de inicializar um sistema e criar o ambiente virtual e os agentes musicais através de um arquivo de configuração

$1.8 \quad 3.5$ deve permitir a criação e destruição de agentes musicais bem como a inserção ou remoção de seus componentes, tanto durante a inicialização quanto em tempo de execução

$1.9 \quad 3.3 \quad$ deve permitir tanto a execução de um sistema em tempo real quanto a utilização de processamento em lote

2. Ambiente Virtual

$2.1 \quad 3.1 .2 \quad$ deve ser capaz de criar e destruir agentes musicais, mantendo um registro dos agentes presentes no ambiente

$2.2 \quad 3.6 \quad$ deve gerenciar a troca de sensações e atuações entre os agentes musicais

$2.3 \quad 3.1 .2 .2$ deve ser capaz de criar um mundo virtual parametrizado

$2.4 \quad 3.1 .2 .2$ deve manter o estado do mundo virtual e fornecer meios para que esse estado seja atualizado

2.5 3.6.5.2 deve ser capaz de manter a sincronização na troca de eventos periódicos e permitir a mudança na periodicidade de tais eventos em tempo de execução

2.6 4.2 deve dispor de meios para que os agentes possam se locomover dentro do mundo virtual

2.74 .3 deve ter um componente capaz de calcular a propagação sonora dentro do ambiente virtual de forma realística, permitindo a configuração dos parâmetros físicos envolvidos

3. Agente Musical

3.13 .1 .1 deve gerenciar o ciclo de vida de seus componentes, incluindo a inserção e remoção destes em tempo de execução

(Continua na próxima página...) 
Tabela 1.1 - Continuação

\begin{tabular}{|c|c|c|}
\hline $\mathbf{R F}$ & Seção & Descrição \\
\hline 3.2 & 3.1 .1 .3 & $\begin{array}{l}\text { deve fornecer meios para atuar no ambiente e para ser informado das sensações } \\
\text { que recebe }\end{array}$ \\
\hline 3.3 & 3.1.1.2 & $\begin{array}{l}\text { deve fornecer meios para que raciocínios genéricos sejam implementados pelo } \\
\text { usuário, permitindo que estes executem de forma reativa, periódica ou cíclica }\end{array}$ \\
\hline 3.4 & 3.1.1.1 & $\begin{array}{l}\text { deve fornecer meios para armazenar seu estado interno de forma acessível a } \\
\text { todos seus componentes, inclusive mantendo um histórico destes estados }\end{array}$ \\
\hline 3.5 & 3.4 .1 & deve ser capaz de promover a comunicação entre os seus diversos componentes \\
\hline 3.6 & 3.1.1.1 & $\begin{array}{l}\text { deve ser capaz de disponibilizar ao mundo exterior alguns aspectos do seu } \\
\text { estado interno }\end{array}$ \\
\hline 3.7 & 3.6 .4 & deve permitir o posicionamento de sensores e atuadores no seu corpo virtual \\
\hline
\end{tabular}

Além disso, alguns requisitos não-funcionais foram levantados e estão enumerados na tabela 1.2.

Tabela 1.2: Requisitos não-funcionais do arcabouço

\begin{tabular}{lll}
\hline RNF & Seção & Descrição \\
\hline \hline 1 & 4 & deve ser de código aberto e multi-plataforma \\
2 & 4.3 & $\begin{array}{l}\text { deve permitir a troca de áudio com janelas de pelo menos } 50 \text { ms e taxas de } \\
\text { amostragem variáveis }\end{array}$ \\
\hline
\end{tabular}

\subsection{Exemplo de uma aplicação musical: Concerto na Catedral}

Como uma forma de motivar o leitor e melhor ilustrar o domínio de aplicação do Ensemble, um exemplo de aplicação musical é aqui apresentado e reaparecerá em outros pontos do trabalho à medida que novos conceitos da taxonomia forem introduzidos. Essa aplicação, que não foi implementada e visa exclusivamente ilustrar conceitos relativos a sistemas multiagentes musicais, deve abranger um grande número de funcionalidades disponíveis no Ensemble, explorando principalmente o conceito da espacialiade.

O ambiente escolhido é o interior de uma catedral virtual onde uma pequena orquestra está posicionada no presbitério e um grupo coral no coro da catedral. Além dos instrumentistas e coralistas, um regente está posicionado à frente da orquestra e é responsável por coordenar a execução musical de ambos os grupos. Peças musicais estão sendo executadas continuamente pelos músicos.

Os ouvintes estão separados em dois grupos, o primeiro está parado na nave, enquanto que o segundo anda livremente pela catedral. Baseado na posição de cada ouvinte, nos obstáculos presentes no ambiente e em suas características acústicas, o som chega de forma diferente para cada ouvinte. Da mesma forma, os músicos conseguem ouvir os murmúrios e passos das pessoas que estão na catedral.

Cada um dos músicos e dos ouvintes, dentro do contexto do Ensemble, é representado por um agente musical autônomo. Através das sensações que eles recebem do ambiente, tanto sonoras 
quanto visuais, cada agente irá agir de acordo com seu papel dentro da aplicação. Assim, o regente deve coordenar os músicos de forma a obter uma apresentação homogênea e o mais próxima possível da partitura musical, cada músico deve executar a sua parte em sincronia com os outros e respondendo às solitações do regente e, finalmente, os ouvintes irão apreciar a execução.

Assim, várias interações, musicais ou não, são possíveis. Por exemplo, os coralistas devem sincronizar sua execução com a orquestra através da observação dos gestos do regente, os ouvintes serão afetados emocionalmente pela execução, aplaudindo ou indo embora da catedral, e, da mesma forma, os músicos podem ser afetados emocionalmente pela reação do público interferindo na execução. Todos estes aspectos serão abordados ao longo do trabalho, em re-exposições e variações desta aplicação.

\subsection{Sumário Estruturado da Tese}

Os próximos capítulos desta tese estão organizados da seguinte forma:

- Capítulo 2 - apresenta uma taxonomia de sistemas multiagentes musicais, baseada na literatura disponível;

- Capítulo 3 - apresenta, tomando como base a taxonomia e utilizando o paradigma de orientação a objetos, a arquitetura do arcabouço computacional para o desenvolvimento de sistemas multiagentes musicais;

- Capítulo 4 - trata da implementação da arquitetura, apresentando a plataforma tecnológica utilizada (Java e JADE) e os detalhes mais importantes da implementação, além de descrever como a arquitetura faz a interação com outros sistemas existentes, como o Pd, e com bibliotecas externas de processamento de áudio;

- Capítulo 5 - descreve a implementação de dois sistemas utilizando o arcabouço desenvolvido, a fim de testá-lo e validar sua generalidade. O primeiro estudo de caso é um mapeamento de um sistema existente, o Living Melodies, e o segundo é uma extrapolação da peça Clapping Music, de Steve Reich;

- Capítulo 6 - encerra o texto, apresentando dificuldades encontradas, as considerações finais e possíveis trabalhos futuros relacionados com o sistema. 


\section{Capítulo 2}

\section{Taxonomia de Agentes Musicais}

Esta capítulo apresenta uma taxonomia para sistemas multiagentes musicais, construída a partir da generalização de diversos trabalhos anteriores [DN01, MRSE06, UK04, CVM08, RRG99, STR05, WNV03, Dix00, BNF08, McC01] de forma a contemplar as principais características apresentadas pelos agentes musicais, pelo ambiente virtual em que estes residem, e pelas interações entre agentes ou entre agente e ambiente. Além disso, foram considerados também outros trabalhos de computação musical [Mir02, Mir01, TW99, CDK00, Dan93, DBT ${ }^{+}$04, Dre05, GD05, PMC06, RS04, SGVT04, Sup01, TC02, MMH99] que, embora não tratem especificamente de agentes musicais, possuem componentes que se encaixam na estrutura de um sistema multiagente musical.

Dentro deste contexto, dividiu-se a taxonomia em três grandes categorias: o Agente Musical; o Ambiente Virtual; e as interações entre Agentes e entre Agente e Ambiente Virtual. Com base nessa divisão, a Figura 2.1 mostra uma visão geral de um Sistema Multiagente Musical genérico, onde os diversos Agentes Musicais habitam e compartilham um Ambiente Virtual e interagem.

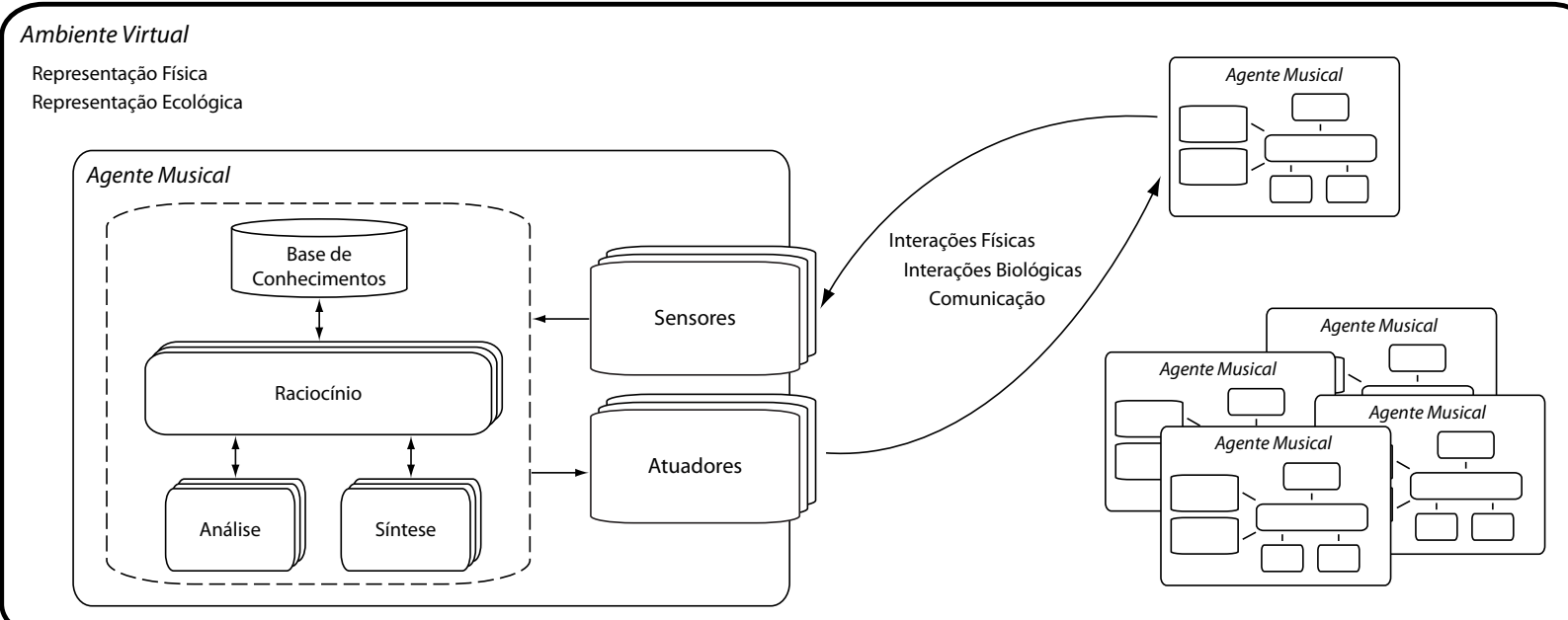

Figura 2.1: O Agente Musical e seu Ambiente Virtual

A seguir, o texto entra em detalhes de cada uma das categorias, expondo as diversas classificações dos componentes de um Sistema Multiagente Musical. É importante frisar que, dado o escopo deste trabalho, uma ênfase maior é dada aos atributos ligados ao som e a certos atributos que podem influenciar o comportamento sonoro dos agentes. Essa taxonomia poderia ser complementada se considerarmos outros domínios de aplicação que não o sonoro. À medida que as diversas classificações forem apresentadas no texto, exemplos específicos de trabalhos anteriores serão utilizados para ilustrar como o conceito em questão foi explorado anteriormente, e as caixas de texto mostrarão como o mesmo conceito poderia ser aplicado ao concerto na catedral. 
É importante frisar que a taxonomia é uma base teórica para o desenvolvimento da arquitetura do arcabouço. Assim, nem todas as funcionalidades que derivam das classificações de um sistema multiagente musical descritas neste capítulos foram implementados no Ensemble, mas optou-se por deixá-lo genérico o suficiente a fim de que todos os aspectos aqui discutidos possam vir a ser implementados.

\subsection{Ambiente Virtual}

Um ambiente no contexto de sistemas multiagentes musicais pode ser definido como um mundo virtual em que o agente computacional está inserido e com o qual interage através de sensores e atuadores [Woo02]. Todas as entidades presentes no sistema multiagente estão inseridos nesse ambiente, sejam Agentes Musicais ou objetos inanimados.

O Ambiente pode representar um mundo similar à nossa realidade ou então mundos hipotéticos, como por exemplo o mundo bidimensional Flatland, de Edwin Abbott, ou os mundos em laço de M. C. Escher. Outro exemplo de representação do mundo, muito comum em jogos computacionais, é o baseado em tabuleiro. Enfim, a definição do Ambiente Virtual é aberta e depende da aplicação musical do usuário.

Segundo Russell e Norvig [RN03], um ambiente virtual pode ser classificado de acordo com vários critérios, como por exemplo se o estado do mundo é acessível ou inacessível aos agentes, se a evolução do mundo é determinística ou se existem ingredientes aleatórios, se o comportamento dos agentes é ou não dividido em episódios, se o ambiente pode ou não mudar de configuração enquanto o agente planeja sua próxima ação, e se o espaço de sensações e ações possíveis é contínuo ou discreto. No arcabouço aqui proposto, não existem restrições quanto às configurações do ambiente em relação a estes critérios, e todas as possíveis combinações dos mesmos devem ser passíveis de implementação.

A representação de um Ambiente Virtual é composta de atributos, estados e de leis. Os atributos são características geralmente imutáveis que definem a qualidade do mundo e são usadas como parâmetros em todas as transformações que ocorrem nesse mundo. Por exemplo, no mundo real, estes atributos seriam as constantes físicas.

O estado do Ambiente é um conjunto de propriedades do mundo virtual que podem mudar ao longo do tempo. Este estado pode ser alterado através da atuação dos agentes, como a emissão de um som por um agente ou sua mudança de posição, ou por processos independentes que podem ter sido originados de atuações mas que se desenrolam de forma autônoma, como a propagação sonora ou a simulação de um vento. O Ambiente tem conhecimento de todas as entidades presentes nele e de seus respectivos estados externos (ou fenótipo), ou seja, aquelas características que podem ser percebidas por outras entidades. Os estados passados também podem ser mantidos como uma forma de histórico do Ambiente, útil na simulação de fenômenos que não dependem apenas do estado atual, como a propagação sonora.

As mudanças de estado no Ambiente são feitas através de aplicações de leis que, baseadas no estado atual, nos atributos do Ambiente e em alguma condição de transição, como a atuação de um agente ou a passagem do tempo, geram um novo estado. Por exemplo, quando um agente inicia sua movimentação através da aplicação de uma aceleração, as leis da mecânica são usadas para calcular a sua posição a cada instante, com base na gravidade e coeficiente de atrito do terreno.

A figura 2.2 mostra a taxonomia do Ambiente Virtual, que foi classificada em representação 


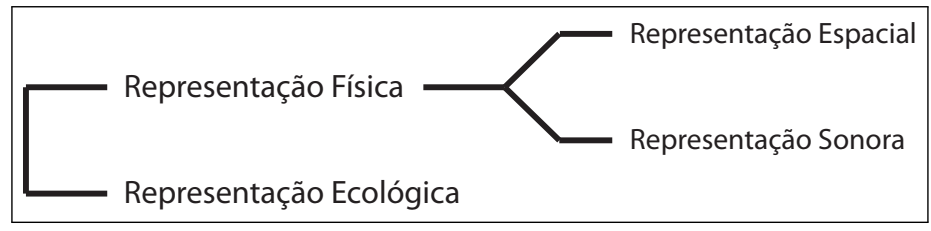

Figura 2.2: Taxonomia do Ambiente Virtual

física e em representação ecológica. A primeira trata de todos os aspectos físicos do Ambiente, principalmente de como é descrito o espaço e o som dentro do mundo. Já a segunda trata da descrição de aspectos ecológicos, ligados aos conceitos de vida artificial.

\subsubsection{Representação Física}

A representação física do ambiente envolve a definição de um mundo físico virtual, onde os agentes habitam, se locomovem e interagem fisicamente. Esse mundo físico virtual é regido por leis físicas também definidas aqui, e mais especificamente para o presente trabalho, as leis de propagação do som no ambiente.

Dividiu-se a representação física do Ambiente Virtual em representação espacial e em representação sonora, pois estas são duas categorias importantes para o sistema em questão: a primeira trata da questão da espacialidade, ou seja, de como os agentes percebem o espaço e se locomovem nele; e a segunda trata da codificação e da propagação sonora no ambiente.

\subsubsection{Representação do Espaço}

A representação do espaço define o mundo físico virtual, onde os agentes habitam e onde possivelmente se locomovem. Ela possui necessariamente, porém não exclusivamente, os seguintes atributos:

\section{- Dimensão}

A dimensão do espaço se refere neste contexto ao número de coordenadas independentes utilizadas na representação de uma posição qualquer do espaço. Dois exemplos de espaços bidimensionais são o plano, representado por coordenadas Euclideanas $(x, y)$, e um plano sonoro estéreo representado por um valor de intensidade total e outro de panorama (relação entre intensidades nos canais esquerdo e direito).

\section{- Estrutura}

A estrutura do espaço compreende o conjunto de valores usado para representar cada posição, bem como medidas de distância e possivelmente estrutura de adjacências. O espaço tridimensional usual pode ser representado pelo $\mathbb{R}^{3}$ munido da distância Euclideana, sem estrutura de adjacências. Um exemplo de espaço com estrutura discreta é o conjunto $\mathbb{N}^{n}$, munido da distância de Hamming $d(x, y)=\sum_{i=1}^{n}\left|x_{i}-y_{i}\right|$ e da estrutura de adjacências definida por $N(x)=\left\{y|| x_{i}-y_{i} \mid=1\right\}$. Um tabuleiro de xadrez é um exemplo de espaço bidimensional onde as posições possíveis são definidas por um conjunto finito de valores.

- Forma

A forma do espaço diz respeito a limitações impostas às posições dos objetos, normalmente definidas por restrições de desigualdade, tais como $a_{i} \leq x_{i} \leq b_{i}$ (uma sala retangular) ou $\sqrt{\sum_{i=1} x_{i}^{2}} \leq R$ (um espaço circular). Um espaço também pode ser ilimitado, ou seja, não possuir restrições nos valores de posição dos objetos. 
No sistema multiagente musical Living Melodies [DN01], os autores definem um mundo virtual que corresponde a um tabuleiro quadriculado bidimensional, em que o agente está livre para locomover-se em oito direções, sendo que apenas um agente pode ocupar cada quadrado por vez. Os limites do tabuleiro podem ser definidos como uma barreira que os agentes não podem atravessar, ou alternativamente o tabuleiro poderia ser concebido em forma de torus, em que um agente que sai por um lado do tabuleiro aparece instantaneamente do outro lado.

Murray-Rust [MRS05] distribui os agentes em um palco sonoro de forma que a música gerada tenha um panorama estéreo e de atenuação por distância. Porém esta disposição é utilizada apenas para renderização do resultado sonoro, ou seja, os agentes não são afetados por essa separação espacial. Alguns sistemas não apresentam a modelagem de um mundo físico e os agentes inseridos neste ambiente não têm a noção de um espaço físico [MRS05, WNV03, Mir02].

Com o espaço definido, o Ambiente Virtual pode possuir leis físicas que regem as interações mecânicas entre suas entidades. Elas podem ser extremamente simples, como no Living Melodies, ou simular as interações reais como gravidade, colisão de corpos, inércia, entre outras [ES04]. Em casos mais complexos, o ambiente necessita de atributos, como constantes físicas, que vão ser usadas por essas leis físicas.

Na aplicação Concerto na Catedral, o ambiente é o interior de uma catedral e deve simular o mundo real. Assim, o ambiente tem três dimensões sem estrutura de adjacências. Obstáculos incluem as colunas da nave e outros pequenos objetos como cadeiras, além dos corpos dos participantes.

\subsubsection{Representação Sonora}

A representação sonora é um caso especial da representação física que define a forma como o som é codificado, os atributos acústicos e a lei que rege a propagação sonora no Ambiente Virtual.

A codificação do som refere-se ao formato como o som é transmitido entre os agentes. O som pode ser codificado, por exemplo, no formato de áudio digital, ou seja, uma representação do sinal sonoro com certa frequência de amostragem e resolução de quantização de cada amostra. Alternativamente, o som pode ser codificado simbolicamente, por exemplo, em MIDI ou MusicXML, de forma que mesmo sem a representação de uma onda sonora real seja possível utilizar as leis de propagação para transmissão de som no ambiente virtual descritas a seguir. Dannenberg [Dan93] apresenta estas e outras formas usuais de representação de música e som.

Uma forma comum de se transmitir informações musicais no ambiente é através do formato MIDI [DN01, MRSE06, WNV03]. Esta forma traz a vantagem de que poucos eventos são normalmente transmitidos por segundo, o que é computacionalmente vantajoso. Em contrapartida, sacrifica-se o fenômeno acústico em prol de uma notação simbólica simplificada, limitando assim o controle do resultado final.

O padrão de propagação sonora pode ser simples, como uma transmissão direta e instantânea entre dois agentes, ou bastante complexo, por exemplo através da simulação das leis de propagação do som no mundo real. O Ambiente virtual pode estar dotado de atributos acústicos que irão influenciar no padrão da propagação sonora, como coeficientes de absorção dos materiais presentes, modos de vibração de salas, velocidade do som, fatores de atenuação da energia sonora, entre outros.

Na natureza, as ondas sonoras estão sujeitas a fenômenos acústicos como a reflexão, refração, difração, interferências, absorção do som no meio, reverberação e efeito Doppler. Em sistemas mais complexos, nos quais seja importante simular de forma mais realista a acústica do espaço virtual, 
esses efeitos podem ser levados em consideração na propagação das ondas sonoras.

Deve-se notar que a propagação sonora realista é apenas uma das alternativas para o funcionamento das leis acústicas dentro do mundo virtual. Alguns sistemas multiagentes [DN01, MMH99, $\mathrm{McC} 01]$ utilizam outras formulações para o espaço virtual, como espaços bidimensionais discretos com frentes de onda planares ou quadradas. Esquemas de propagação de onda irreais poderiam ser usados para experimentações sonoras, por exemplo frentes com velocidades diferentes saindo de uma mesma fonte sonora.

Um ambiente virtual pode contar com uma simulação de reverberação genérica, sem a necessidade de calcular as reflexões das ondas sonoras nos obstáculos. A simulação deste efeito pode ser obtida com o uso de filtros IIR [Roa96]. Chowning [Cho71] apresenta uma forma simples e computacionalmente eficiente de simular uma fonte sonora em movimento, considerando o efeito Doppler e a reverberação.

O Living Melodies [DN01] é o único dentre os sistemas estudados a definir algumas regras físicas, mesmo que simplistas, para a propagação sonora. O som, ao ser emitido por um agente, se propaga em todas as direções em frentes de ondas quadradas, ocupando os quadrados do tabuleiro com informações de nota, amplitude e direção. O som decai linearmente com o tempo e um som mais forte sempre mascara os outros em um mesmo quadrado.

Dentro da catedral, o som deve se propagar de forma similar ao mundo real, porém algumas simplificações são necessárias devido ao custo computacional da simulação em um ambiente estruturalmente complexo como este. Uma solução simples para essa aplicação é calcular as ondas sonoras diretas entre a fonte sonora e o receptor, considerando o atraso e a atenuação por distância, e aplicar um efeito de reverberação diretamente nessas ondas, uma vez que a ambiência é uma característica marcante dentro do ambiente escolhido. Em alguns casos especiais, como quando existir um grande obstáculo entre a fonte e o receptor, pode-se aplicar alguma forma de atenuação. Como forma de codificação, deve-se utilizar o áudio digital.

\subsubsection{Representação Ecológica}

A representação ecológica leva em conta todos os aspectos biológicos dos Agentes e sua relação biológica com o Ambiente, geralmente inspirados em conceitos de Vida Artificial [Lan95]. Assim, pode-se modelar ciclos de vida em que os agentes nascem, se reproduzem e morrem, variando assim o número de agentes na comunidade e sua variedade genética. O ciclo de vida é regulado por atributos como a expectativa de vida e a taxa de reprodução e por uma lei que rege esse ciclo.

Pode-se adotar alguma representação de energia para regular certos aspectos da vida dos agentes, entre eles a alimentação, a movimentação, o envelhecimento, etc. Quantidades específicas de energia podem ser requisito para que os agentes mantenham-se vivos ou realizem determinadas tarefas, enquanto certas atividades podem ter por finalidade a aquisição de energia, como ingerir um alimento ou descansar.

Em Living Melodies [DN01], o ambiente é dotado de uma quantidade constante de energia, que é representada na forma de alimento e consumida pelas criaturas. A energia é utilizada para a procriação, sendo compartilhada com a prole. Quando uma criatura morre, sua energia é devolvida ao ambiente que a transforma em alimento.

Na sociedade de agentes musicais descrita por Beyls [Bey07], o agente musical tem um nível de energia que é gasto à medida que ele se desloca dentro do mundo virtual. Quando esse nível atinge 
um limite inferior, o agente entra em um estado de hibernação até recuperar a energia.

A execução musical exige um dispêndio de energia por parte dos músicos, assim como a concentração exigida dos ouvintes. Assim, o nível de energia de cada agente vai caindo à medida que o tempo passa, podendo afetar a capacidade de execução do músico (sua performance, sincronização com os outros e capacidade de seguir as indicações do regente) e a apreciação da peça pelo ouvinte, diminuindo sua resposta emocional. Pausas no concerto são momentos em que a energia poderia ser recuperada.

\subsection{Agente Musical}

O Agente Musical é um agente computacional especializado em processar informações musicais e sonoras. Tipicamente, esse agente é capaz de analisar o som presente em seu ambiente, efetuar algum tipo de raciocínio musical e gerar uma resposta através de síntese e processamento sonoro. Pressupõe-se que o Agente Musical reside em um espaço acústico, que é o meio condutor das informações sonoras e musicais, e que os agentes têm mobilidade dentro deste espaço, o que é entendido como uma dimensão adicional do próprio fenômeno sonoro. Além destas características, centrais para este trabalho, o agente musical inclui aspectos do agente computacional geral, podendo possuir características não-musicais como visão, tato, alimentação, realização de tarefas motoras, etc.

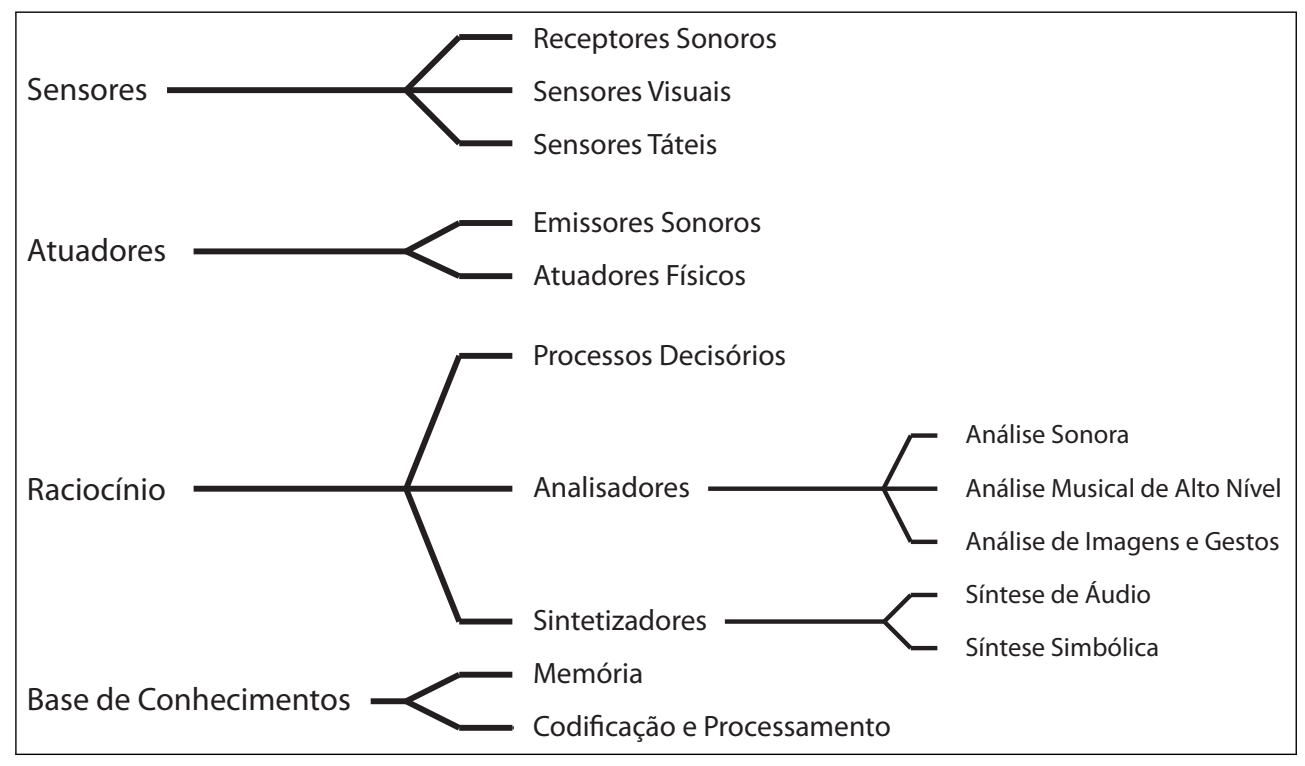

Figura 2.3: Taxonomia do Agente Musical

O Agente Musical é composto de diferentes componentes, que se relacionam de forma coordenada para atingir o objetivo proposto do Agente: a base de conhecimento, os raciocínios, os sensores e os atuadores. A figura 2.3 mostra a taxonomia do agente musical, com seus componentes básicos e suas diversas classificações.

A representação física do agente indica o espaço ocupado pelo mesmo no mundo virtual e, possivelmente, sua forma, para um melhor posicionamento dos sensores e atuadores. Essa definição pode ser importante, por exemplo, para caracterizar quando dois agentes ocupam o mesmo lugar no espaço, situação esta que pode (ou não) ser permitida pelas regras que caracterizam o mundo virtual. 
Existem três tipos de Agentes Musicais no Concerto na Catedral: o músico, o regente e o ouvinte. Várias instâncias distintas da categoria "agente músico" habitam o ambiente, cada um responsável pela execução de sua parte na peça musical, levando em consideração a regência e a reação do público. O agente regente é único no sistema e tem o objetivo de coordenar a execução dos agentes músicos. Finalmente, os ouvintes têm o objetivo de apreciar a peça musical, podendo fornecer algum tipo de resposta emocional aos músicos.

\subsubsection{Base de Conhecimento}

Uma base de conhecimentos, no contexto de agentes computacionais, é um banco de dados que armazena fatos sobre o mundo e sobre o estado interno do agente. Essa base de dados é atualizada pelo agente à medida que seus sensores percebem alterações no estado do mundo, seus atuadores agem, ou quando existe algum processo de raciocínio feito pelo próprio agente.

Dois aspectos são levados em consideração na base de conhecimento de um agente musical: como a informação musical é codificada (codificação/linguagem/ontologia) e quais são os fatos que o agente conhece (memória de sons, de teorias musicais, de técnicas de síntese e análise, além de fatos não-musicais).

A codificação musical indica o formato no qual a informação musical é armazenada na base de conhecimento do agente. Similar à codificação do som, esta pode ser em formato de áudio, ou em alguma notação simbólica, como MIDI, MusicXML, ou mesmo outras notações mais simples. Além disso, como é comum em implementações de agentes computacionais, pode-se utilizar alguma notação de lógica, como a lógica proposicional ou de primeira ordem [RN03].

A base de conhecimento também pode funcionar como uma base de dados inteligente, capaz de não apenas armazenar fatos, mas também efetuar processamentos destes dados. Os dados armazenados podem ser de conteúdo musical, como notas, trechos musicais, partituras completas, sequências harmônicas, técnicas de transformação do sinal da entrada (processadores de efeitos, acompanhamento automático [Row92]), além de teorias musicais, como por exemplo sistemas de referência composicionais (esquemas de improvisação de jazz [RRG99], regras de serialismo integral [SB68]) e técnicas de análise e segmentação da entrada (fraseologia tonal [LJ83], reconhecimento de estilos [TC02]). Além disso, um agente também pode armazenar em sua base de conhecimento outros fatos não-musicais relevantes, como sua posição no mundo, outros agentes conhecidos, códigos genéticos etc.

O agente de Ramalho, Rolland et al. [RRG99] dispõe de uma base de dados de fragmentos musicais, juntamente com uma descrição de suas propriedades rítmicas e harmônicas. No momento que o agente necessita de um novo fragmento, ele envia as propriedades desejadas à base de conhecimento que devolve o melhor fragmento utilizando a técnica Case Based-Reasoning [Kol93].

Em Living Melodies [DN01] a codificação é feita através de doze caracteres que representam as notas ou intervalos, e cada agente armazena em sua base de conhecimento um genoma musical que contém uma sequência de notas. Além disso, o agente armazena informações como sua idade, energia disponível, direção de movimentação e um valor que representa o prazer auditivo da última nota por ele ouvida, valor este que será determinante na biologia dos agentes.

Os agentes musicais do sistema de Murray-Rust [MR07] armazenam a peça musical sendo executada em sua base de conhecimento, codificada em uma estrutura de alto nível em formato textual (baseada em Lisp), que indica informações gerais da peça. Essas informações incluem o andamento e fórmula de compasso, as seções em que a peça está dividida, incluindo a ordem de execução e repetições, e eventos temporais (notas), descritas por sua altura, duração e intensidade. Além disso, a base contém uma biblioteca de estilos, que podem corresponder a progressões harmônicas, ritmos, 
padrões de ornamentação, etc.

Na catedral, os músicos e o regente contêm em sua base de conhecimento a partitura das peças a serem executadas, além de informações sobre o estilo musical e técnicas de execução correspondentes.

\subsubsection{Raciocínio}

O Raciocínio de um agente é o conjunto de mecanismos pelos quais o agente decide suas próximas ações, musicais ou não, baseados no seu objetivo dentro do sistema. Estes mecanismos utilizam tanto os dados perceptuais recém-obtidos quanto informações contidas na base de conhecimento.

\subsubsection{Processos Decisórios}

Existem diversos paradigmas de raciocínio para agentes que podem ser utilizados em seus processos decisórios: entre os mais comuns estão o raciocínio dedutivo, que se vale de deduções lógicas a partir do seu conhecimento do ambiente; o raciocínio prático ou intencional, em que o agente delibera sobre as possíveis consequências de suas ações, baseado em suas intenções e no seu conhecimento do mundo; e o raciocínio reativo, mais simples, em que uma sensação do ambiente dispara uma atuação do agente [Woo02]. Muitas vezes uma mescla de paradigmas é utilizada, principalmente no caso do raciocínio reativo, a fim de não limitar demais as reações de um agente.

No caso de agentes que geram música, como parte de seu processo decisório estão os algoritmos composicionais. Este algoritmos são blocos de processamento que criam música a partir de alguma técnica, como cadeias de Markov, gramáticas formais, fractais, redes neurais ou algoritmos genéticos [Mir01]. A produção musical do agente pode combinar vários algoritmos composicionais, desde a reutilização de fragmentos musicais pré-armazenados, passando por técnicas de composição reativa ao contexto (produção de acordes de acompanhamento ou improvisações a partir do material de entrada), até o uso de técnicas sofisticadas de análise de áudio e produção de som articuladas com uma intenção composicional e um projeto estrutural [Sup01, Mir01, Cop00].

Em Living Melodies [DN01], quando o agente escuta um som, ele compara a nota recebida com o seu genoma musical (uma sequência de notas armazenadas na sua base de conhecimento), gerando um valor de prazer auditivo. Dependendo desse valor, o agente executa alguma outra ação programada, como andar, cantar ou descansar.

No trabalho de Wulfhorst, Nakamaya e Vicari [WNV03], o raciocínio musical do agente é baseado em uma técnica nebulosa para seleção de ações. O objetivo de cada agente é acompanhar os outros agentes, que podem ser artificiais ou humanos, através de padrões musicais pré-estabelecidos, tentando seguir a pulsação e a harmonia que está sendo tocada.

Murray-Rust [MR07] define um sistema deliberativo responsável por criar um plano para a execução musical do agente, que toma como entrada o contexto musical atual da peça e a comunicação com os outros agentes através dos chamados atos musicais, gerando como saída novos atos musicais e modificações na execução musical do agente, com base em suas intenções musicais. Para guiar o processo de deliberação, o agente utiliza como função de utilidade a satisfação dos seus objetivos internos (dados pelo compositor, por exemplo), e a reação dos outros agentes como, por exemplo, aceitar uma sugestão musical dada por ele.

Os agentes de Ramalho e Ganascia [RRG99] utilizam um tipo de raciocínio baseado em casos, ou seja, a base de conhecimento do agente contém vários trechos musicais conhecidos (casos) e, à medida que o agente percebe o contexto musical que está sendo executado, ele escolhe um desses 
casos, adaptando-o e executando-o.

O objetivo dos músicos é ler a partitura musical presente em sua base de conhecimento e executá-la da melhor maneira possível, utilizando como entrada a análise do som emitido pelos outros músicos, os gestos enviados pelo regente e a reação do público. Por ser uma tarefa complexa, pode-se utilizar diversos raciocínios, um para análise sonora e outro para a execução da peça, cada um com uma tarefa específica trocando informação através da base de conhecimento. O objetivo do regente é seguir a partitura musical e dirigir a orquestra, controlando sua expressividade e sincronização. Um raciocínio deve analisar o som vindo da orquestra, comparar com a partitura e controlar os braços gerando uma sequência de gestos necessárias para a condução da orquestra. O ouvinte tem raciocínios responsáveis por ouvir a música e dar alguma resposta emotiva e por se locomover pela catedral seguindo algum percurso, sem se chocar em algum obstáculo.

\subsubsection{Analisadores}

A análise feita pelo agente musical pode ser utilizada para extrair dados importantes a partir da informação captada pelos seus sensores, que irão complementar o raciocínio do agente, possivelmente atualizando sua base de conhecimento. Embora as análises sonoras e musicais correspondam às técnicas mais importantes neste contexto, outras análises são possíveis, como a análise de imagens e de gestos.

Análise Sonora Corresponde à análise de todos os aspectos físicos dos som.

\section{- Análise Temporal}

A análise temporal do som é feita a partir da representação do sinal sonoro, ou seja, da variação da pressão sonora ao longo do tempo. Algumas das aplicações deste tipo de análise são as detecções de ataques ou dos instantes em que há silêncios, o cálculo da defasagem entre sinais correlacionados (para detectar a direção de origem de um som, por exemplo) e o cálculo da função de autocorrelação do sinal, para detectar uma frequência fundamental de oscilação.

\section{- Análise Espectral}

A análise espectral fornece uma representação do som que corresponde a uma decomposição em sinais mais simples, como senóides, através da transformada de Fourier, ou utilizando Wavelets [KMMG87]. Ela é utilizada em todos os contextos em que são necessárias informações sobre a frequência do som, como na análise melódica e harmônica. Além disto, ela também pode ser usada para aumentar a precisão de informações temporais, como na localização de ataques, e na detecção de eventos com ataques não-percussivos.

- Análise Simbólica

A análise simbólica extrai os aspectos musicais do som. Assim, a análise simbólica pode utilizar as ferramentas de análise física para extrair parâmetros musicais, como altura e valor rítmico de notas, encaminhamento harmônico da peça musical, entre outros. A análise sonora simbólica pode ser:

- Análise de Altura

A análise de altura é responsável basicamente por encontrar uma ou mais notas musicais presentes em um som. A detecção pode ser feita através da análise no domínio do tempo, utilizando a autocorrelação [BP89] ou filtros adaptativos [Moo73], ou no domínio da frequência, como com a estimação da frequência fundamental [PMC06, EP06, Dre06, RK06]. Algumas técnicas mais avançadas incluem modelos da audição humana [PAG95] e análises polifônicas, que tentam identificar diversas notas que soam simultaneamente [PMC06]. 
A partir da análise de altura, pode-se fazer uma análise horizontal da música, extraindo assim o perfil melódico, que pode ser usado para a transcrição automática de músicas e para a análise do material musical utilizado, detectando similaridade entre melodias, inversões, retrogradações etc. Alguns trabalhos que tratam da análise melódica são a extração de um contorno melódico em um som polifônico [Dre05] e a extração melódica a partir de uma música cantarolada $\left[\mathrm{DBT}^{+} 04\right]$.

- Análise Harmônica

A análise harmônica, muito utilizada em sistemas de acompanhamento musical, determina os acordes de um trecho musical, extraindo assim a progressão harmônica. Por exemplo, o sistema de Pardo e Birmingham [PB02] faz a extração de acordes, enquanto que o de Raphael e Stoddard [RS04] faz a análise harmônica funcional de uma peça tonal.

O sistema multiagente descrito por Wulfhorst, Nakamaya e Vicari [WNV03] contém um analisador harmônico, que é capaz de detectar mudanças de acordes, um analisador rítmico, capaz de detectar a pulsação da música sendo executada, e um analisador de intensidade sonora. Murray-Rust [MR07] faz em seu trabalho análise da dinâmica e a detecção de síncopas.

- Análise Rítmica

Corresponde à análise da pulsação e da métrica de uma música, podendo ser usada para extrair dados como andamento, figuras rítmicas utilizadas, entre outros. Roads [Roa96] categoriza a análise rítmica em três tipos: análise de baixo nível, responsável pela deteç̧ão de eventos; análise de nível médio, que faz a transcrição do rítmo em notação musical; e análise de alto nível ou análise de estilo. Gouyon e Dixon [GD05] fazem uma análise de vários métodos de transcrição rítmica [CDK00].

- Análise de Timbre

A partir da análise espectral e de outros parâmetros é possível obter informações sobre os instrumentos que estão sendo utilizados numa execução musical, ou ainda obter dados sobre a evolução temporal de aspectos timbrísticos (como o envelope dinâmico de cada parcial isoladamente) [Fuj98, Ris91, Zha01]. Fatores importantes para a análise do timbre são a forma de ataque e o envelope de amplitude do som, efeitos de vibrato e tremolo, formantes do som, intensidade percebida, duração e variação do espectro durante o tempo.

Análise Musical de Alto Nível Vários outros tipos de análise podem ser aplicados a uma entrada musical, sonora ou simbólica, permitindo o reconhecimento de estruturas musicais, gênero e estilo, textura e expressão. Estas análises fazem parte do métier do músico, porém existem alguns poucos métodos automáticos para obtenção de informações deste tipo.

- Análise Estrutural

Corresponde à análise da estrutura musical de uma peça ou trecho dela, permitindo reconhecer frases musicais, motivos, seções musicais, ou mesmo definir a forma da peça (sonata, rondó etc.).

- Análise do Gênero e Estilo

Permite obter, a partir da estrutura, harmonia e textura, entre outros, o possível gênero e estilo da peça sendo executada, ou ainda informações como o período histórico, o compositor ou a formação instrumental (por exemplo orquestra sinfônica, banda de rock ou instrumento solo). Scaringella, Zoia et al. [SZM06] apresentam um sistema que classifica automaticamente gêneros musicais.

- Análise de Expressividade e Performance

Permite a identificação de elementos expressivos da interpretação de um trecho musical, indicados ou não na partitura musical, como por exemplo rubato e cantabile, entre outros. 
O sistema de Widmer [Wid96] extrai e aprende a utilizar padrões de expressividade a partir da análise de peças ao piano. Muller e Mazzola [MM03] também tratam a questão de como a expressividade pode ser extraída de uma performance musical.

Análise de Imagens e Gestos O Agente Musical dotado de um sensor de imagens pode ter o interesse de analisar essas informações e extrair parâmetros que o auxiliem a determinar a posição e gestos de outros agentes no ambiente virtual, ou obstáculos a serem evitados, por exemplo.

Os projetos Eyesweb $\left[\mathrm{CHR}^{+} 00\right]$ e MEGA $\left[\mathrm{CDPF}^{+} 05\right]$ desenvolvem técnicas para a análise gestual que podem ser utilizadas no contexto musical para obter informações tanto de humanos interagindo com o sistema como de imagens virtuais que os próprios agentes venham a sintetizar. Técnicas desse tipo poderiam ser embutidas em um agente musical para analisar os gestos de um outro agente dentro do mundo virtual, ou então, através de um atuador ligado a uma câmera, o gesto de um usuário interagindo com o sistema.

Para poder ser capaz de tocar em conjunto, o agente musical e o regente devem ser dotados de vários analisadores sonoros e musicais. Assim, para entender o que os outros músicos estão tocando, um agente musical deve ser dotado de analisadores harmônicos, rítmicos e de timbre. Analisadores gestuais são imprescindíveis para que os músicos possam seguir o regente. Os ouvintes podem ser dotados de analisadores de expressividade e performance, para melhor apreciar a execução.

\subsubsection{Sintetizadores}

A síntese do som é o componente mais fundamental de um agente musical, pois é a partir dela que o agente participa musicalmente da performance coletiva. Podem ser utilizadas técnicas de síntese simbólica, que representam o som através de eventos abstratos (como no protocolo MIDI ou em MusicXML), ou técnicas de síntese e processamento de sinais de áudio, que geram diretamente a forma de onda, bem como combinações destas. Além disso, outras informações podem ser sintetizadas pelo agente, como trajetórias espaciais (para definir sua movimentação), imagens (como parte da performance), etc.

Um agente musical imerso em um ambiente interativo pode utilizar vários tipos de informação para modificar seus métodos de composição, entre estes os fatos de sua base de conhecimento e os dados correspondentes às informações sensoriais recebidas. Dentre estas, os sons produzidos pelos outros agentes estão entre as mais importantes, pois é a consideração destes sons que permitirá uma interação musical entre os agentes. Assim sendo, os métodos de síntese (tanto simbólica quanto de áudio) devem prever formas de utilização destes dados externos ao agente.

Síntese Simbólica A síntese simbólica gera uma sequência de símbolos, cujo significado os agentes do ambiente devem saber interpretar. Esses símbolos geralmente são uma sequência de caracteres (string) [MR07] ou uma sequência de bytes, muitas vezes seguindo padrões que definem instruções especiais e seus possíveis parâmetros, como o MIDI [WNV03] e o OSC [BNF08].

Síntese e Processamento de Áudio Vários métodos de síntese de áudio podem ser utilizados na produção de som pelo agente, como por exemplo as sínteses aditiva, subtrativa, FM, waveshaping, modelagem física, etc. $\left[\mathrm{B}^{+} 00, \mathrm{Mir} 01\right]$. Dado o contexto interativo no qual o agente se insere, tais técnicas podem ser adaptadas para estabelecer um relacionamento com os outros agentes, seja este colaborativo ou competitivo. A síntese também pode incluir a aplicação de efeitos sonoros, alterando a qualidade do som, atributos interessantes para a simulação de instrumentos musicais modernos, como guitarra e sintetizadores. Através da aplicação de filtros que implementam linhas de atrasos únicas, os chamados FIR Comb Filters, pode-se criar efeitos usuais como chorus, flanger 
e eco [ZA02].

O agente de Miranda [Mir02] tem um sintetizador de voz baseado em formantes, equipado com um articulador capaz de simular a posição da língua, o formato dos lábios e a abertura da mandíbula. O sintetizador necessita de 12 parâmetros para produzir o som.

Os agentes musicais são dotados de sintetizadores de áudio, cada qual adaptado ao seu instrumento, que geram um sinal de áudio com o timbre correto a partir de informações simbólicas passadas (como a altura e duração da nota musical).

\subsubsection{Sensores}

Os sensores do agente musical fazem a captura de informações do ambiente e, após um possível pré-processamento, repassam a informação para a parte cognitiva do agente. No caso dos agentes musicais, o principal sensor é o auditivo, que recebe informações sonoras presentes no ambiente. Outros sensores, como o tátil e o de visão, podem ser usados para obter informações adicionais utilizadas no processamento musical, ou em outras tarefas, como a locomoção no espaço virtual.

\subsubsection{Sensores de Audição}

Os sensores de audição correspondem ao mecanismo sensorial pelo qual o agente capta o som presente no ambiente. Os atributos dos sensores de audição mais comuns são:

- Quantidade e Posição

Esse atributo define o número de sensores auditivos disponíveis em um agente e suas posições. Em um espaço físico multidimensional esse atributo é importante, pois define os pontos em que o agente recebe a informação sonora. Por exemplo, é possível simular uma cabeça humana, com dois ouvidos posicionados em locais distintos do agente, permitindo ao agente localizar a direção de origem de um som.

- Padrão de captação

O padrão de captação é definido de maneira análoga ao de um microfone. Assim, um sensor auditivo pode captar o som unicamente da direção para qual ele está apontado, pode ser onidirecional, ou seja, perceber o som em toda a sua volta, ou ainda possuir qualquer padrão intermediário de captação.

- Pré-processamento

O pré-processamento auditivo do agente musical está relacionado com qualquer tipo de processamento obrigatório no som captado do ambiente que seja independente da vontade do agente. Assim, é possível prover o sistema auditivo do agente de qualidades ou defeitos específicos, como por exemplo através da simulação das curvas de audição humana [Roe99].

Miranda [Mir02] diz que seus agentes possuem um aparato auditivo, mas não dá detalhes sobre o seu funcionamento. O som é recebido diretamente do outro agente com quem a comunicação está sendo feita. No Living Melodies [DN01], cada agente ouve apenas o som mais forte presente no seu quadrado do tabuleiro.

\subsubsection{Sensores de Visão}

Correspondem ao mecanismo sensorial pelo qual o agente capta imagens do ambiente em que reside, podendo ser estas imagens captadas por câmeras no mundo real (em robôs, por exemplo), ou geradas por algum tipo de simulação de propagação de luz no mundo virtual. O agente pode 
utilizar essa informação musicalmente, por exemplo ao seguir os gestos de outro agente, ou pode utilizá-la para sua locomoção no mundo virtual, por exemplo desviando de obstáculos.

\subsubsection{Sensores de Tato}

Correspondem ao mecanismo sensorial pelo qual o agente musical identifica o contato de um elemento presente no ambiente. Por exemplo, um sensor de tato pode servir como um detector de colisão ou um sensor de proximidade, como os tentáculos das criaturas do Living Melodies, capazes de perceber a presença de uma outra criatura próxima [DN01].

Todos os agentes presentes no ambiente são dotados de dois sensores de áudio, posicionados de forma similar aos ouvidos humanos. Dessa forma, é possível efetuar cálculos para descobrir a origem de fontes sonoras. Eles também são dotados de sensores visuais para saber onde estão os músicos, para ver os gestos do regente e para poder se locomover dentro da catedral sem se chocar com obstáculos.

\subsubsection{Atuadores}

Os atuadores do agente musical recebem as instruções geradas através do raciocínio musical e outras informações geradas na síntese, e interagem com o ambiente, modificando-o. Essa interação é, principalmente, musical, através da emissão do som gerado, mas também pode se dar pela utilização de mecanismos de locomoção ou pela interação física entre agentes, através de atuadores táteis.

\subsubsection{Emissores Sonoros}

São os atuadores através dos quais o agente musical emite no ambiente o som gerado internamente, para que seja captado por outros agentes. Os atributos dos emissoros sonoros mais comuns são:

- Quantidade e Posição

Define o número de emissores sonoros disponíveis em um agente e suas posições. Em um espaço físico multidimensional esse atributo é importante, pois determina a forma de espacialização do som produzido pelos agentes e afeta a paisagem sonora gerada.

- Padrão de Emissão

O mecanismo emissor do agente musical pode utilizar um padrão específico de emissão do som gerado, definido de forma análoga ao de um alto-falante.

- Pós-processamento

O pós-processamento do emissor sonoro está relacionado com qualquer tipo de processamento obrigatório no som emitido pelo agente que seja característico do mecanismo de emissão e independente da vontade do agente. Assim, é possível prover o sistema de emissão do agente com características particulares, como por exemplo limitações na faixa dinâmica ou na banda de frequências possíveis de serem emitidas.

Em [Mir02], o agente possui um instrumento emissor que imita o trato vocal humano, através de geradores harmônicos e filtros de formantes. No entanto, a transmissão do som é feita de forma instantânea e direta para outro agente, uma vez que o sistema utiliza turnos de interação entre os agentes. Em [DN01], o agente emite o som na mesma direção em que está orientado (direção de movimento), através de três aparelhos de emissão que ficam apontados para frente e para os lados. 


\subsubsection{Atuadores Físicos}

São os mecanismos pelos quais o agente efetua interações físicas com o ambiente, como a locomoção. Por exemplo, no Living Melodies [DN01], o agente é dotado de atuadores de locomoção e pode se mover em qualquer uma das oito diferentes direções de uma grade bidimensional.

Os agentes músicos são dotados de emissores sonoros de forma a enviar ao ambiente o som gerado pelo seu instrumento. O regente deve ter um atuador gestual, seus braços, utilizado para enviar sinais aos seus músicos. Os agentes ouvintes têm atuadores físicos de movimentação, similares a pernas, para poderem se locomover dentro da catedral.

\subsection{Interações}

A interação entre agentes musicais dentro do mundo virtual pode ser feita de diversas formas, entre elas a comunicação e outras formas de interação física ou ecológica. A principal forma de comunicação entre agentes musicais é através da troca de informação sonora, o que não exclui outras formas de comunicação, como por exemplo usando mensagens, gestos ou imagens. Exemplos de interações físicas e ecológicas entre agentes são colisões e reprodução, entre outros. São consideradas também as interações entre os agentes e o ambiente, como no caso do consumo de algum material (e.g. comida) ou no caso do agente estar sujeito a alguma lei natural (e.g. gravidade). A figura 2.4 mostra as interações entre agentes no ambiente.

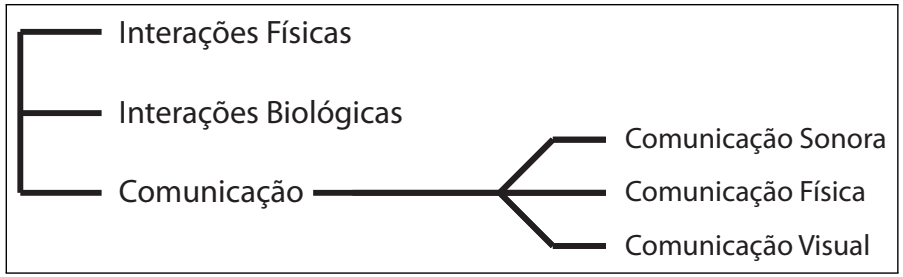

Figura 2.4: Taxonomia de Interações no Ambiente

\subsubsection{Comunicação entre Agentes}

A comunicação entre agentes pode ser feita através da emissão de som no ambiente, visualmente ou diretamente através de um esquema de troca de mensagens.

\subsubsection{Comunicação Sonora}

Os agentes musicais têm como forma primária de comunicação o som. Assim, a interação musical é feita através dos sons que cada agente gera, levando em consideração os sons presentes no ambiente e seu raciocínio musical. A comunicação sonora entre agentes respeita as leis de propagação do som no ambiente virtual, baseadas na representação física do som no espaço.

\subsubsection{Comunicação por Mensagens}

A comunicação através de mensagens é utilizada para que os agentes possam trocar outras informações que, embora não codificadas do mesmo modo que o som (por exemplo, em áudio ou MIDI), possam ser úteis do ponto de vista musical. Por exemplo, um agente pode enviar uma mensagem ao outro solicitando uma mudança de tonalidade, informando uma intenção de performance futura ou compartilhando seu algoritmo de composição. A codificação utilizada na mensagem é 
definida pela implementação e pode ser negociada entre os agentes.

Várias técnicas podem ser utilizadas para a troca de mensagens, como o uso de Blackboard [WNV03], o envio de pacotes de mensagens através de um agente centralizador, ou diretamente entre os agentes.

\subsubsection{Comunicação Visual}

A comunicação visual e, consequentemente, a gestual, é muito importante em grupos musicais, seja entre um maestro regendo uma orquestra, ou em um quarteto de cordas. Assim, é interessante que os agentes musicais possam trocar informações também através dos gestos.

Em um sistema completamente composto de agentes computacionais, a visão ou o gesto podem ser reduzidos a uma mensagem, mas quando o sistema interage com um músico humano, essa comunicação pode ser feita gestualmente, pelas duas partes. Por exemplo, um sistema mais avançado pode ser capaz de analisar o gesto de um agente humano através da captura e processamento de imagens, e o gesto do agente musical pode ser renderizado graficamente em uma tela, alterando assim a interpretação da música [SGVT04].

\subsubsection{Interações Físicas}

As interações físicas entre agentes ou entre agente e ambiente dizem respeito a como as leis da física definidas para o ambiente interferem nos agentes. Por exemplo, os agentes musicais que se movimentam no ambiente podem colidir em obstáculos presentes nesse ambiente, como paredes ou outros agentes, sendo forçados a respeitar as leis físicas definidas para o ambiente.

\subsubsection{Interações Ecológicas}

As interações ecológicas entre agentes ou entre agentes e o ambiente, como a reprodução e a alimentação, podem ser utilizadas para simular um ecossistema artificial. Estes aspectos podem ser implementados tendo em vista um resultado musical, através do aumento ou diminuição do número de agentes produzindo sons, ou através da combinação e modificação de materiais ou métodos musicais (representado por um material genético) de dois ou mais agentes.

No trabalho de Miranda [Mir02], tais formas de interação são utilizadas com o objetivo de renovar constantemente a população de agentes, ocasionando uma seleção natural de melodias, na expectativa de que características musicais interessantes sejam preservadas ou venham a emergir. Em Living Melodies [DN01], os agentes são capazes de se reproduzir no caso de se encontrarem no tabuleiro e respeitarem certas condições. Após a interação, um filho é gerado a partir da recombinação do genoma musical e procedural dos pais, subtraindo de ambos uma certa quantidade de energia.

Uma outra forma de interação é a emocional, em que as ações dos agentes podem ser modificadas devido à estímulos emocionais recebidos do Ambiente. Por exemplo, no caso do Living Melodies, os agentes possuem um nível de felicidade que é aumentado quando eles escutam uma nota musical que gostam, e estar feliz é essencial para que a reprodução aconteça. 
A comunicação entre os agentes musicais é ao mesmo tempo sonora e visual, pois os músicos devem seguir os gestos do maestro. Alternativamente, este pode enviar instruções específicas para um músico através de mensagens. As interações físicas são feitas a partir da geração de som pelos músicos e da movimentação dos ouvintes pelo ambiente. Existe uma interação ecológica emocional entre os músicos e os ouvintes, onde os primeiros são afetados pela recepção da platéia e os ouvintes pela qualidade da performance musical. 


\section{Capítulo 3}

\section{Arquitetura do Ensemble}

Baseado na taxonomia descrita no capítulo anterior, o presente capítulo descreve a arquitetura do Ensemble, que fornece a base para a construção de Agentes Musicais e do Ambiente onde eles habitam. O Ensemble é responsável por disponibilizar alguns serviços essenciais para um sistema multiagente musical, como a transmissão de som entre os agentes. A partir do Ensemble, o usuário pode programar funcionalidades específicas para seu objetivo musical como, por exemplo, algoritmos de composição, análise e síntese sonoras.

É importante observar que a implementação do Ensemble corresponde a um arcabouço, e não a uma biblioteca. Em um arcabouço, o controle do fluxo de execução é retirado do usuário e mantido pelo seu código interno. Assim, ao invés do usuário utilizar as funcionalidades do arcabouço como em uma biblioteca, ele implementa certos métodos que serão chamados em um momento oportuno pelo arcabouço. Por esta razão, implementações específicas do usuário e extensões do sistema devem seguir algumas convenções internas, uma vez que o arcabouço funciona como um programa principal, responsável por chamar métodos implementados pelo usuário, entre outros.

Algumas das vantagens da utilização de um arcabouço são: a reutilização de código que foi testado a priori pelo desenvolvedor do arcabouçou e por seus atuais usuários; a redução da tarefa de programação, uma vez que várias funcionalidades do domínio de aplicação em questão já estão presentes no arcabouço; e a possibilidade de estender suas funcionalidades através de novas atualizações ou programação do usuário. Por outro lado, um arcabouço pode apresentar uma curva de aprendizado mais lenta que a simples utilização de uma biblioteca de funções, uma vez que deve-se compreender alguns aspectos do seu funcionamento interno. O seu uso também pode causar degradação no desempenho devido ao código extra que controla o arcabouço e deve ser executado independentemente da aplicação do usuário.

O arcabouço aqui apresentado pode ser classificado, de acordo com Johnson e Foote [JF88], como do tipo caixa-branca, uma vez que o usuário deve ter um conhecimento mínimo de sua implementação interna. Contudo, o Ensemble disponibiliza um número razoável de componentes reutilizáveis (como ferramentas de análise e síntese) que podem facilitar consideravelmente a especificação e parametrização de um agente musical pelo o usuário, a ponto de nenhuma programação ser necessária. Assim, nessa situação, ele pode ser considerado também como um arcabouço caixapreta.

É importante ressaltar que uma aplicação que utilize o Ensemble não precisa necessariamente utilizar todos os itens aqui descritos e, geralmente, será constituída de um subconjunto destes. Por exemplo, um sistema pode necessitar da definição do espaço físico, mas escolher por não integrar a simulação de propagação do som. Ou ainda, utilizar funcionalidades programadas por outros usuários e que não fazem parte do núcleo do sistema. 
A arquitetura foi projetada de forma a ser plugável, ou seja, deve ser possível para o usuário acrescentar novos componentes ao agente em tempo de execução do sistema. Por exemplo, o usuário poderia querer construir um agente musical antropomórfico, e assim programar um sensor que tenha a função de um ouvido para o agente, com certa posição espacial no corpo do agente e capaz de receber o som presente no ambiente virtual. Em seguida, o usuário poderia simular a escuta de um ser humano plugando mais um ouvido no agente, em outra posição; este agente agora poderia, utilizando um raciocínio capaz de analisar o som captado pelos dois ouvidos, deduzir a direção da fonte sonora captada.

A arquitetura do Ensemble não está ligada a nenhum tipo de tecnologia específica, mas a certas estratégias de modelagem de software. Ela segue o paradigma de programação orientada a objetos e, portanto, necessita de uma linguagem capaz de implementá-los (como Java ou C++). Além disso, o Ensemble pressupõe o uso de um middleware de sistemas multiagentes que disponha das funcionalidades básicas não relacionadas com a área musical. Mais informações sobre as escolhas feitas para a implementação do sistema estão no capítulo 4.

As próximas seções deste capítulo descrevem em detalhes os componentes da arquitetura e o modo de funcionamento dos serviços essenciais fornecidos pelo Ensemble, baseados nos requisitos funcionais apresentados na seção 1.4. Para auxiliar na visualização, utiliza-se a linguagem de modelagem Unified Modeling Language (UML), em sua segunda versão.

\subsection{Atores do Ensemble}

Existem três atores principais dentro da arquitetura: o Agente Musical (classe MusicalAgent), especializado em processar a informação sonora e musical e habitante do mundo virtual; o Agente Ambiente (classe EnvironmentAgent), que representa o Ambiente Virtual e controla todas as interações entre os Agentes Musicais; e o Agente Externo, que representa qualquer sistema externo ou usuário que queira interagir com os agentes do Ensemble.

Os dois primeiros agentes são baseados em um agente genérico do arcabouço (classe EnsembleAgent) que, por sua vez, é baseado no agente básico disponível no middleware de sistema multiagente sendo utilizado. O agente genérico disponibiliza os serviços mais básicos de um agente computacional, como o controle do ciclo de vida do agente, a troca de mensagens e o acesso a serviços comuns, como o diretório de agentes presentes no sistema e ao relógio interno e agendador de tarefas. Além disso, mantém alguns atributos básicos como o nome do agente e seus parâmetros de configuração. O Agente Externo é um caso especial, que pode ser mapeado em um Agente Musical ou então se comunicar com os agentes do sistema através do envio de dados.

A seguir, o texto descreve com mais detalhes cada um dos atores do sistema e, quando for o caso, dos seus componentos internos.

\subsubsection{Agente Musical}

Um Agente Musical é composto por diversos componentes interligados: Base de Conhecimento, Raciocínios, Sensores e Atuadores. A construção de um Agente Musical é feita através da extensão de seus componentes básicos, ou do reaproveitamento de componentes existentes, e da especificação de como eles interagem uns com os outros e com o Ambiente. A figura 3.1 apresenta o diagrama de classes do Agente Musical. 


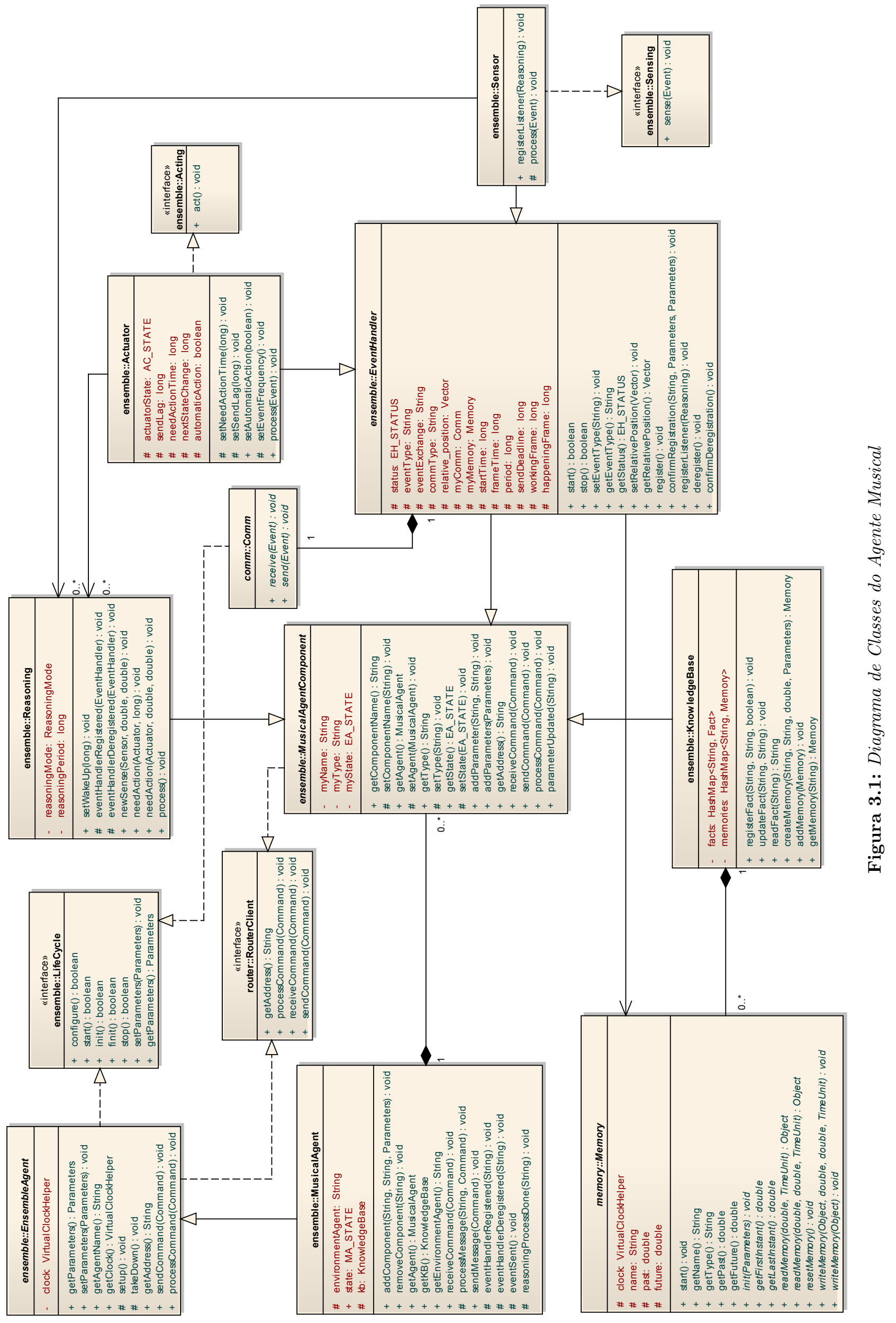


A classe MusicalAgent representa a parte fundamental de um Agente Musical. Ela é responsável por controlar o ciclo de vida de seus componentes, que podem ser agregados no momento da inicialização do sistema ou em tempo de execução através dos métodos addComponent(String compName, String className, Parameters parameters) e removeComponent(String compName), e por manter internamente uma lista com o tipo e nome de cada componente, que deve ser único. Além disso, ela gerencia a comunicação de controle (seção 3.4) necessária para que o agente e seus componentes possam participar do sistema.

Todos os componentes são baseados na classe abstrata MusicalAgentComponent, que dispõe dos métodos necessários para que um componente se comunique com o seu Agente Musical (acessado através do método getAgent()), além de armazenar atributos como o nome do componente, seu estado, seu tipo e seus parâmetros de configuração.

\subsubsection{Base de Conhecimentos}

A Base de Conhecimento (classe KnowledgeBase) de um Agente Musical armazena o conjunto de informações necessárias para representar o estado interno atual do Agente, chamadas de fatos. Além disso, áreas especiais, chamadas de memórias, podem ser criadas pelos componentes para manter informações mais complexas e que necessitem de um histórico. Todas essas informações, sejam fatos ou memórias, podem ser compartilhadas entre os componentes do agente. A classe tem uma instância única dentro do Agente Musical, e pode ser acessada pelos seus componentes através do método $\operatorname{get} K B()$.

Os fatos são dados simples, como uma sequência de caracteres ou um número, compostos de um nome e de um valor. Por exemplo, pode-se armazenar o nome de um arquivo de áudio, uma sequência de notas musicais ou o nível de energia disponível. No momento da criação do agente e de seus componentes, deve-se reservar um espaço para o fato através do método registerFact(String fact, String value, boolean isPublic). Durante a execução, o valor de um fato pode ser atualizado através do método updateFact(String fact, String newValue).

Um fato pode ser marcado como sendo público, que indica que esse fato está disponível para ser lido por um outro agente. Assim, o fato e seu valor são repassados para o ambiente, que os mantém em uma tabela. A cada atualização do fato marcado como público, o ambiente é informado do novo valor. Os fatos privados podem ser vistos como o genótipo do Agente Musical, enquanto que os públicos, como seu fenótipo.

Enquanto os fatos são apenas uma foto atual do estado interno do agente, algumas informações precisam ser situadas em algum instante no tempo. Por exemplo, pode ser importante para o raciocínio do agente conhecer os eventos sonoros recebidos nos últimos segundos a fim de gerar uma saída sonora compatível. Para isso, utiliza-se uma memória, que pode ser criada por um componente através do método createMemory(String name, Parameters parameters), informando o horizonte de tempo passado e futuro que ela deve armazenar. O registro em uma memória de informações futuras deve ser entendido como parte do planejamento de ações do agente. Uma mémoria é recuperada da Base de Conhecimento através do método getMemory(String name).

O acesso ao conteúdo da memória é feito através de sua interface Memory. A interface permite um acesso aleatório às informações armazenadas através dos métodos genéricos writeMemory(Object object, double instant, double duration, TimeUnit unit) e readMemory(double instant, double duration, TimeUnit unit). Pode-se obter a informação de um instante exato no tempo, ou então um conjunto de informações em um determinado intervalo de tempo. A unidade de tempo (TimeUnit) deve ser informada e pode ser especificada em segundos (e suas derivações), amostras ou eventos. 


\subsubsection{Raciocínio}

Um componente essencial é o Reasoning, que corresponde ao raciocínio do agente e executa as tarefas musicais, como a composição algorítmica, e que deve processar os estímulos recebidos pelos sensores do agente e enviar estímulos através dos seus atuadores. Um Agente Musical pode ter mais de um raciocínio, cada um responsável por um conjunto de sensores e atuadores, os quais podem trabalhar simultaneamente, em cooperação ou não.

O processamento do raciocínio é feito através da chamada de métodos padrões que devem ser implementados pelo usuário (process(), needAction(Actuator sourceActuator, double instant, double duration) e newSense(Sensor sourceSensor, double instant, double duration)). Esses métodos são executados automaticamente pelo arcabouço, através de chamadas do Sensor ou do Atuador ou das funções de agendamento do relógio interno do arcabouço. Existem três modos de processamento, que podem ser configurados de acordo com o objetivo do raciocínio e o custo computacional do código executado. São eles:

- reativo, em que só existe processamento quando uma sensação é recebida do ambiente por um sensor, através do método newSense(), ou então quando um atuador necessita de atuação, através do método needAction();

- periódico, em que o método process() é executado em intervalos de tempos parametrizados pelo usuário, além de acumular as funções do modo reativo;

- cíclico, em que o método process() é executado em laço, sem pausas, além de acumular as funções do modo reativo.

Os processadores (interface Processor) são ferramentas do Ensemble que podem ser usadas pelo raciocínio para manipular a informação recebida e gerar a resposta para o ambiente e são, em sua maioria, analisadores e sintetizadores de áudio. Essas ferramentas funcionam como caixaspretas, independentes do estado do Agente Musical, que recebem um conjunto de dados e parâmetros como entrada e fornecem um outro conjunto processado como saída através do método process(Parameters parameters, Object in). Como exemplo, temos analisadores de espectro, sintetizadores de ondas sonoras, detectores de onsets, entre outros. A seção 4.4.1 fornece mais informações sobre as ferramentas disponíveis. A interação entre os raciocínios e os sensores e atuadores, e os métodos relacionados, será melhor detalhada na seção 3.6.

\subsubsection{Sensores e Atuadores}

Os componentes responsáveis pela interação do Agente Musical com o Ambiente são os Sensores (classe Sensor), que recebem os estímulos do ambiente virtual, e os Atuadores (classe Actuator), que os enviam. Esses estímulos, ou acontecimentos no ambiente virtual, são chamados de eventos. Cada evento tem um tipo que indica sua natureza, como som, movimentação, etc.

Os sensores e atuadores são subclasses dos manipuladores de eventos (EventHandler), que implementam as interfaces Sensing e Acting. Cada manipulador de evento contém uma interface de comunicação (classe abstrata Comm), responsável pelo mecanismo de troca desses eventos com o ambiente virtual (ver seção 3.6.3).

O arcabouço executa automaticamente o método process() imediatamente após a recepção de um evento, no caso do Sensor, e antes de enviar um evento, no caso do Actuator. O usuário pode implementar esse método para fazer qualquer tipo de pré- ou pós-processamento no evento. 
Visto que esses são os únicos componentes do Agente Musical que têm contato com o mundo virtual, é possível posicioná-los no corpo virtual do Agente. Assim, pode-se criar um agente com duas pernas, ou duas orelhas, em que a posição do sensor/atuador vai influenciar no seu funcionamento. O funcionamento dos Sensores e Atuadores e a troca de eventos serão melhor detalhados na seção 3.6.

\subsubsection{Agente Ambiente}

O Ambiente Virtual em que os Agentes Musicais residem e trocam eventos é representado no Ensemble por um agente especial, de instância única no sistema, chamado de Agente Ambiente (EnvironmentAgent). Ele é composto de um Mundo Virtual (World), que contém a representação física do Ambiente Virtual, e de vários Servidores de Eventos (EventServer), responsáveis por mediar a troca de evento entre os Agentes Musicais. Da mesma forma que o Agente Musical, seus componentes básicos devem ser estendidos pelo usuário para dar a funcionalidade desejada. A figura 3.2 apresenta o diagrama de classes do Agente Ambiente.

A classe EnvironmentAgent é responsável por controlar o ciclo de vida do Mundo Virtual e dos Servidores de Eventos. Os servidores podem ser agregados no momento da inicialização do sistema, ou em tempo de execução através do método addEventServer(String className, Parameters esParam) e removidos com o método removeEventServer(String eventType). Tanto o Mundo quanto os Servidores podem ter acesso a todos os componentes que compõem o Agente Ambiente através dos métodos getWorld() e getEventServer(String eventType).

Além dos Servidores de Eventos, o Agente Ambiente tem um papel importante no gerenciamento do ciclo de vida dos Agentes Musicais. Através dos métodos createMusicalAgent(String agentName, String agentClass, Parameters parameters) e destroyAgent(String agentName) é possível, respectivamente, criar e destruir um Agente Musical. O Agente Ambiente também centraliza todos os comandos de controle enviados pelos Agentes Musicais, que são obrigados a se registrar caso queiram participar da comunidade virtual (ver a seção 3.4.1).

\subsubsection{Servidores de Eventos}

O Agente Ambiente é composto de Servidores de Eventos (classe EventServer), componentes cuja função principal é a de processar os eventos recebidos pelo Agente Ambiente, atualizar o estado do mundo através de suas leis, e enviar eventos de resposta. Assim, um Servidor de Eventos incorpora funções análogas aos Sensores, Atuadores e Raciocínios dos Agentes Musicais. Para cada tipo de evento que o Ambiente controla, deve existir um objeto da classe EventServer associado.

O Servidor de Eventos é capaz de receber e enviar eventos através das interfaces Sensing e Acting e, para isso, conta com uma interface de comunicação (Comm). Assim como Sensor e Actuator, ele tem dois métodos correspondentes para tratar os eventos recebidos, processSense(Event evt), e eventos a serem enviados, processAction(Event evt), ambos implementados pelo usuário. Além disso, o método process() é responsável por qualquer processo cíclico efetuado pelo servidor, cuja peridiocidade pode ser parametrizada pelo usuário. O funcionamento dos Servidores de Eventos será melhor detalhado na seção 3.6.

\subsubsection{Mundo Virtual}

O Agente Ambiente tem associado a ele um Mundo Virtual (classe World), que representa o mundo físico onde os Agentes Musicais vivem e interagem. Ele é responsável por manter o estado do 

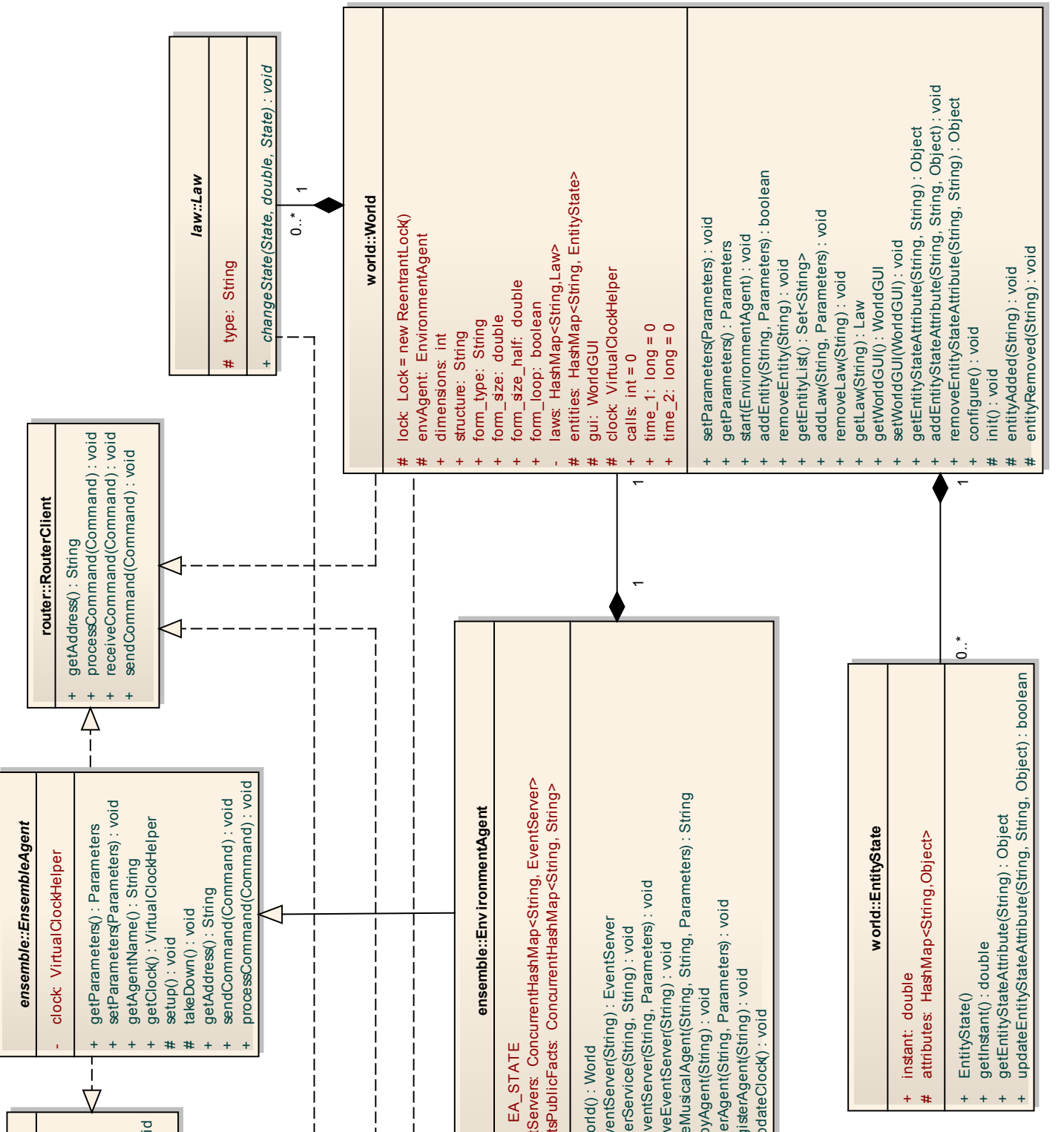

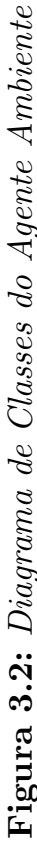
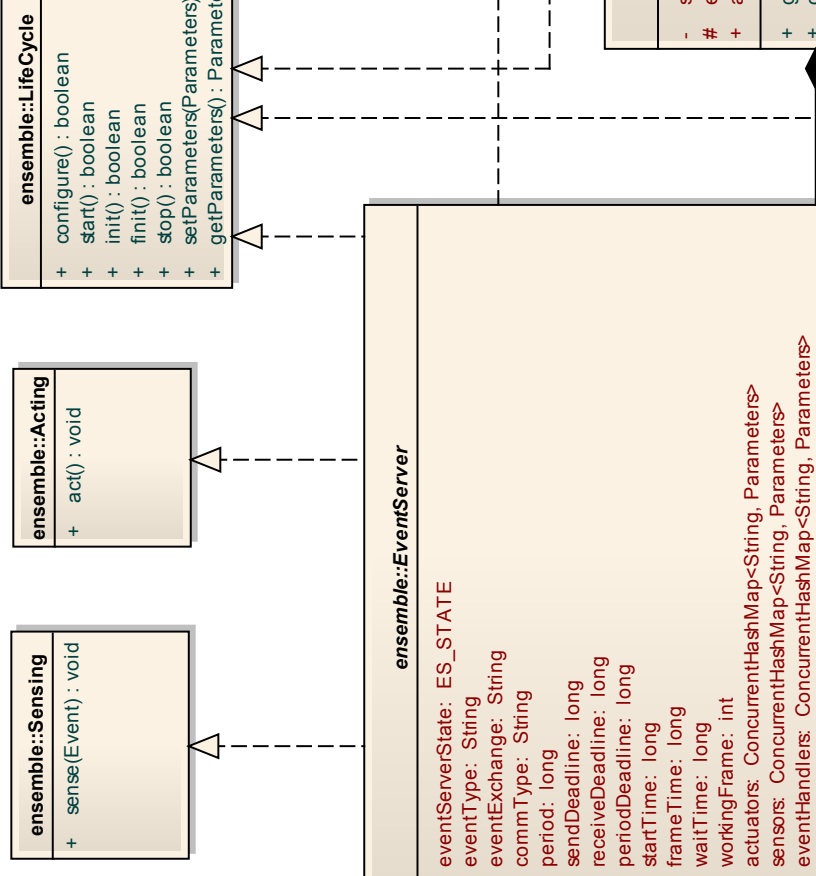

뭉

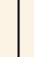

娄

क क

का

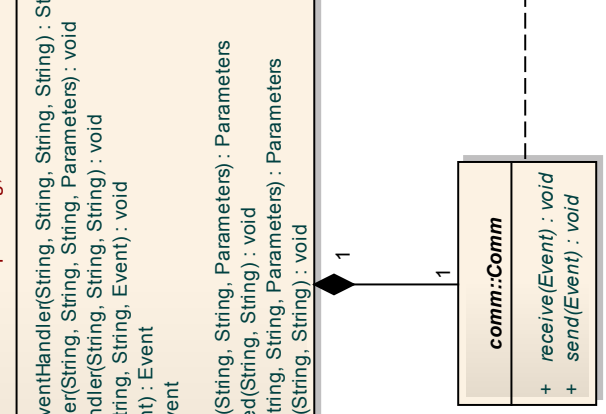

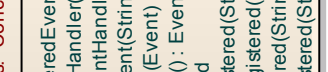

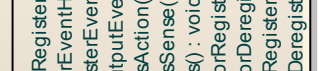

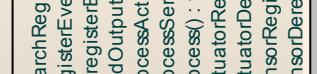


mundo através da representação da posição dos agentes, frentes de onda sonora, energia disponível, etc.

O Mundo Virtual (classe World) contém a descrição física do espaço virtual, que é definida no momento de sua inicialização, e uma lista de todas as entidades (agentes ou qualquer outro objeto físico presente no Ambiente), que são manipuladas pelo Agente Ambiente através dos métodos addEntity(String entityName, Parameters parameters), getEntityList() e removeEntity(String entityName).

A descrição física inclui obrigatoriamente o número de dimensões, a forma e o tamanho do espaço, mas pode conter ainda qualquer outro atributo desejado. Todas as informações vetoriais (como coordenadas no espaço, velocidade, etc.) são armazenadas em objetos da classe Vector e manipuladas tanto pelo Mundo Virtual como pelos outros componentes. Um objeto do tipo Vector é configurado para trabalhar com o número de dimensões parametrizado no World.

Uma instância do tipo World também armazena o estado atual de todos as entidades (como posição, intenções de movimentos, som produzido e recebido, etc.) através de instâncias da classe EntityState. Análogos à Base de Conhecimentos do Agente Musical, esses estados podem ser apenas fatos atuais do estado do mundo, ou então podem conter objetos do tipo Memory, quando um controle temporal é necessário.

As Leis, acessadas através da interface Law, definem o modo como o estado do Mundo Virtual é alterado, isto é, elas descrevem como atualizar a descrição do objeto World dado um estado passado, o instante de tempo atual e todas as ações efetuadas pelos agentes envolvidos. Por exemplo, uma propagação sonora tridimensional realística é definida através de uma lei particular que recebe todos os sons produzidos dentro do ambiente e retorna uma mistura para cada sensor sonoro de acordo com sua posição relativa a cada atuador sonoro.

Assim, para efetuar a alteração do estado de uma entidade, o Servidor de Eventos responsável pela recepção de um evento deve acessar o Mundo Virtual para obter o estado anterior através do método getEntityStateAttribute(), obter a Lei apropriada ao tipo de evento através do método getLaw(String lawType) e executar o método changeState(EntityState oldState, double instant, EntityState newState), informando o estado antigo e o instante para o qual se quer calcular o novo estado.

Associada a esse Mundo Virtual, pode-se ter uma interface (textual ou gráfica) que permita ao usuário visualizar o estado atual do mundo e também efetuar alterações nesse estado, sempre através do Agente Ambiente. Alternativamente, o estado do mundo pode ser enviado periodicamente a um sistema externo, responsável pela visualização dos dados.

\subsubsection{Agente Externo}

Um Agente Externo é um sistema externo ou usuário humano que interage, em tempo de execução, com o Ensemble. Para os Agentes Musicais e o Agente Ambiente do arcabouço, o funcionamento do Agente Externo deve ser transparente e ele deve aparentar ser simplesmente mais um Agente Musical presente no ambiente. O usuário deve fazer o mapeamento do Agente Externo, dependendo de sua natureza, para um Agente Musical.

Por exemplo, uma aplicação musical desenvolvida em PureData [Puc96], que implementa um algoritmo composicional, pode se comunicar com o Ensemble recebendo o estado do ambiente e devolvendo um conjunto de notas musicais a serem tocadas. Ou então, um músico humano pode interagir com a música sendo executada pelo sistema, tocando seu instrumento, cujo som é captado 
e inserido no sistema através de um Agente Musical (Avatar).

Alternativamente, um Agente Externo pode trocar informações diretamente com os agentes do Ensemble, sem a necessidade de um mapeamento, através de mensagens de controle enviadas a um agente especial, responsável por gerenciar o roteamento dessas mensagens. Nesse caso, os agentes interno e externo devem conhecer o formato do conteúdo das mensagens para permitir a interação. A seção 3.4.1 contém mais informações sobre a forma de comunicação entre o Ensemble e os sistemas externos.

\subsection{Tempo no Ambiente Virtual}

O tempo no ambiente virtual é controlado através de um relógio virtual, que permite aos Agentes obterem o tempo virtual atual e também programarem um despertador para agendar tarefas a serem executadas. O relógio virtual pode funcionar em dois modos:

- Controlado pelo Relógio Interno, em que o relógio virtual está vinculado ao relógio interno do computador, e dessa forma, ao fluxo do tempo natural. Pode-se definir uma proporção para o relógio interno, fazendo ele andar mais rápido ou mais devagar que o tempo natural.

- Controlado pelo Usuário, cabendo a algum agente, em geral ao Agente Ambiente, atualizar o relógio interno. Nesse tipo de processamento a noção do tempo existe, embora a duração entre duas unidades de tempo não seja sempre a mesma, como no caso do processamento em tempo real.

O relógio virtual deve ser acessível por todos os agentes do ambiente, na forma de um serviço do middleware. A figura 3.3 mostra o diagrama de classes do relógio interno. No momento de inicialização do sistema, deve-se configurar o modo de funcionamento do relógio, ou seja, se é controlado pelo relógio interno ou pelo usuário.
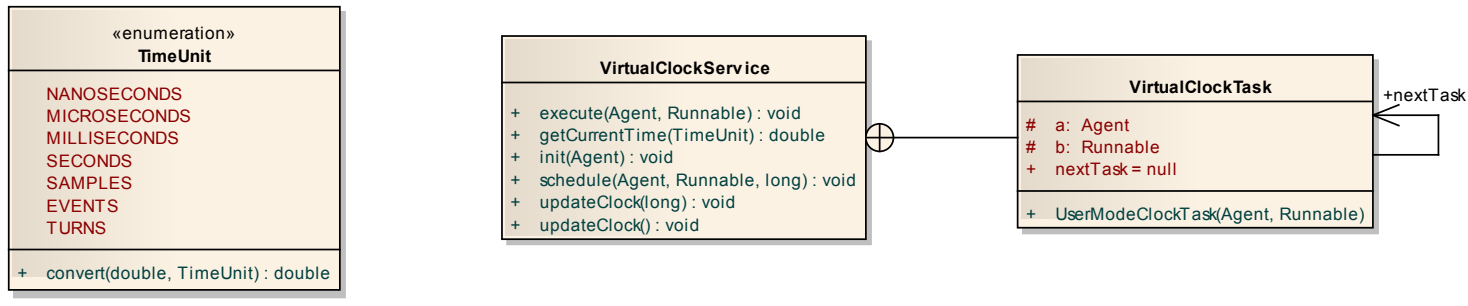

Figura 3.3: Diagrama de Classes do Tempo Virtual

Uma quantidade de tempo deve ser sempre seguida de sua unidade de medida, representada pela enumeração TimeUnit. Assim, todos os métodos que trabalham com a noção de tempo virtual, tanto no serviço de relógio como em outras classes, devem ter a indicação da unidade. Além das unidades que representam o tempo de forma contínua, como segundos e milissegundos, é possível utilizar unidades de tempo discretas, como amostras, eventos e turnos. O método convert(double sourceDuration, TimeUnit sourceUnit) permite a conversão entre medidas. No caso de conversões entre o tempo contínuo e discreto, a conversão é possível desde que informações extras sejam passadas, como por exemplo a taxa de amostragem.

O relógio virtual pode ser acessado através de um objeto da classe VirtualClockService, e cada tarefa agendada é representada por um objeto da classe VirtualClockTask. Este serviço disponibiliza três métodos que podem ser acessados pelos agentes:

- getCurrentTime(), que retorna o valor atual do relógio virtual; 
- schedule(EnsembleAgent a, Thread b, long wakeupTime), utilizado pelos agentes como um despertador. No momento em que o relógio atingir o tempo programado através da variável wakeup Time, uma tarefa do tipo VirtualClockTask é executada. No caso do wakeupTime ser menor que o tempo atual, a tarefa é imediatamente executada;

- updateClock(long units), que atualiza o relógio virtual em um certo número de unidades de tempo. Este método só tem efeito no modo de funcionamento controlado pelo usuário.

No modo de funcionamento controlado pelo relógio interno, o serviço funciona como uma interface para os serviços de tempo e agendamento oferecidos pelo sistema operacional. O diagrama de sequência da Figura 3.4 mostra como esse agendamento é feito por um componente de um agente, no fragmento alt internal clock, utilizando uma classe hipotética Timer disponível no sistema operacional. O Timer dispara a tarefa agendada preferencialmente após $\Delta t$ unidades de tempo, dependendo da precisão e disponibilidade da plataforma.

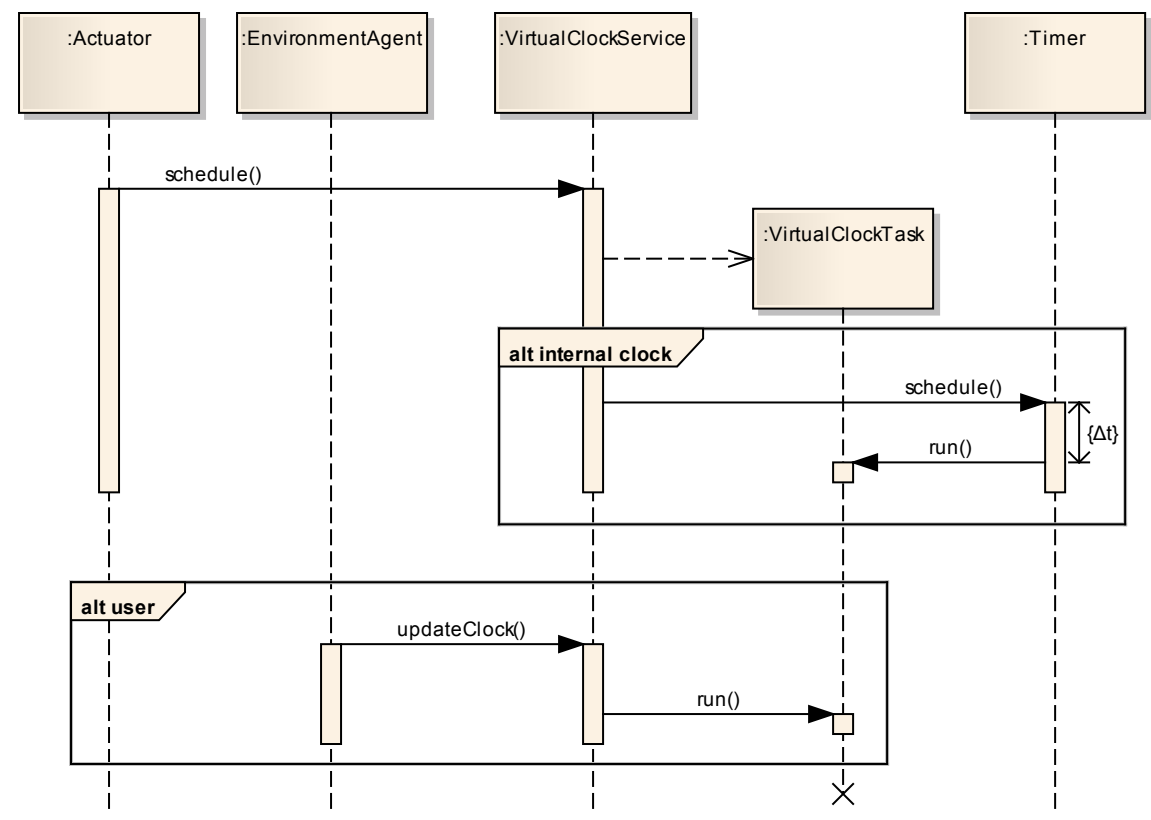

Figura 3.4: Agendamento de uma tarefa em modo controlado pelo relógio interno e pelo usuário

No modo de funcionamento controlado pelo usuário, o valor do tempo é armazenado em uma variável interna, que é atualizada através do método updateClock(). O serviço mantém uma fila de prioridades de tarefas (VirtualClockTask), ordenada pelo tempo em que elas devem ser executadas. A cada atualização do relógio virtual, a fila é consultada e as tarefas que têm o horário agendado menor ou igual ao atual são executadas. $\mathrm{O}$ agendamento é mostrado no diagrama de sequência da Figura 3.4, no fragmento alt user.

\subsection{Modos de Execução do Sistema}

Existem dois modos de execução possíveis: processamento em lote, em que o tempo é discreto, dividido em turnos e sem nenhum tipo de restrição temporal, sendo atualizado pelo Agente Ambiente; e processamento em tempo real, em que o tempo é contínuo, controlado pelo relógio interno do computador, e podem existir restrições temporais na execução de uma certa tarefa. As seções a seguir detalham o funcionamento de cada modo de execução. 


\subsubsection{Processamento em Lote}

No modo de funcionamento em Lote (Batch), o tempo é discretizado em turnos e só é atualizado quando todos os agentes finalizam suas tarefas do presente turno, sem existir nenhum tipo de restrição temporal. O controle do tempo está a cargo do Agente Ambiente. Esse modo de execução deve ser utilizado quando é necessário controlar a sequência de ações dos agentes, ou então em processos não interativos cujo custo computacional é intenso, criando uma saída sonora que será apreciada posteriormente.

Basicamente, ao início de cada turno, os Agentes Musicais executam suas tarefas enviando eventos para o Ambiente, avisam o Ambiente sobre o término das tarefas e aguardam o fim do turno. Em seguida, o Agente Ambiente processa os eventos recebidos, atualiza o estado do mundo virtual, se necessário enviando eventos de volta aos Agentes Musicais e, finalmente, atualiza o tempo, iniciando um novo turno.

Embora exista um controle na ordem do processamento, alternado entre agentes musicais e agente ambiente, os Agentes Musicais efetuam o seu processamento interno de forma paralela. $\mathrm{O}$ mecanismo de processamento em lote serve assim simplesmente para restringir algumas liberdades dos sistemas multiagentes, ganhando em tempo de processamento.

A duração real de um turno pode variar, uma vez que depende do tempo de execução utilizado pelos Agentes Musicais e pelo Agente Ambiente. O usuário do Ensemble pode especificar através de parâmetros qual é o tempo mínimo que deve durar um turno e se existe um tempo máximo para um agente enviar sua mensagem de fim de turno. O primeiro parâmetro é útil em casos que se deve atualizar uma interface gráfica, já o segundo impede que a simulação fique paralisada devido a algum agente que não consegue terminar suas tarefas e enviar sua mensagem de fim de turno.

Devido à sua natureza dual, exigindo um controle centralizado das ações de vários agentes autônomos, o processamento em lote exige uma complexa troca de comandos entre os agentes e uma sincronização de ações, principalmente na inicialização e finalização de um agente musical e no controle da troca de turno.

\subsubsection{Processamento em Tempo Real}

O processamento em Tempo Real não pressupõe nenhuma ordem na execução dos Agentes Musicais e do Agente Ambiente, assim os eventos podem ser enviados e recebidos a qualquer tempo (exceto quando existir alguma troca de evento periódico, que será detalhada na seção 3.6.5.2). O modo de funcionamento do Tempo virtual é o controlado pelo relógio interno.

Além disso, uma característica desse modo de execução é a possível existência de prazos para a execução de tarefas dependentes do relógio interno do computador e, desse modo, do decorrer do tempo no mundo real. Aplicações desse tipo são chamadas tecnicamente de tempo real e um exemplo de uma aplicação típica é a troca de áudio digital (mostrada na seção 4.3). O modo de execução em lote também permite o agendamento de tarefas mas o controle do tempo está na mão do usuário, e não do relógio interno do computador.

\subsection{Comunicação no Ambiente Virtual}

Existem duas formas de comunicação entre atores no Ensemble: a troca de eventos, que representam sensações e atuações no ambiente virtual e serão discutidas com mais detalhe na seção 3.6; 
e a troca de mensagens, através do uso do Canal de Comunicação.

O Canal de Comunicação é um módulo especial presente em todo Agente Musical e no Agente Ambiente, utilizado para trocar mensagens entre os agentes, seus componentes, aplicações externas e o usuário. Este módulo está ligado diretamente ao agente, e pode ser utilizado por todos os seus componentes internos. A figura 3.5 ilustra os possíveis modos de comunicação entre os diversos agentes e sistemas.

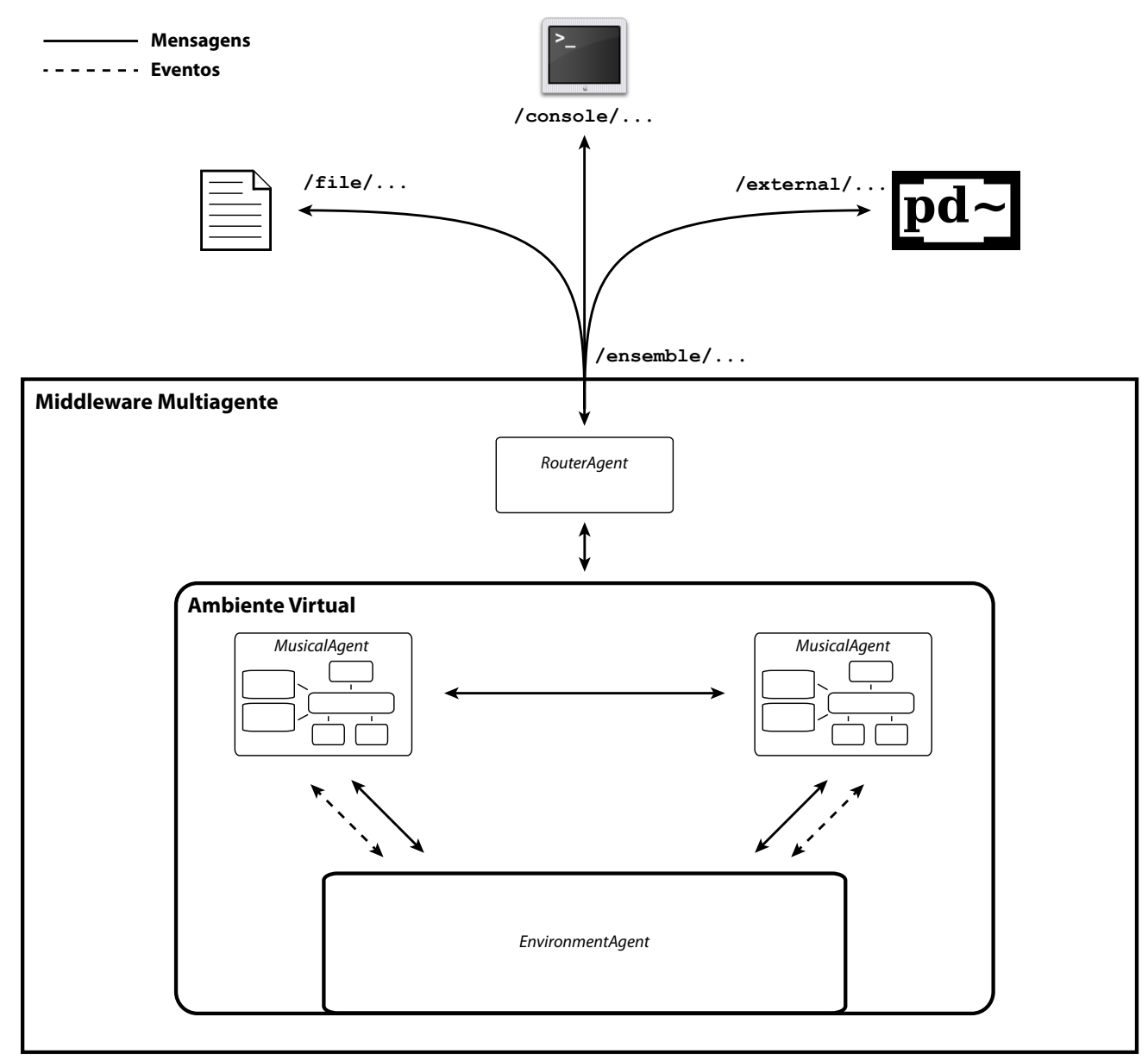

Figura 3.5: Comunicação no Ensemble

Este canal é utilizado entre Agentes Musicais, o Agente Ambiente e Agentes Externos para envio de mensagens de controle e instruções/parâmetros diversos, por exemplo, para indicar o fim de um turno ou a atualização de um fato público. Além disso, pode ser utilizado para troca de mensagens diretamente entre Agentes Musicais, sem a necessidade de ser tratado pelo Agente Ambiente como um evento.

As mensagens podem ser classificadas em três tipos:

- mensagens de controle interno

Uma série de comandos utilizados para o controle interno do arcabouço, como o registro de componentes, sincronização de troca de eventos e controle do processamento em lote. Estes comandos não estão disponíveis ao usuário. A tabela 3.1 mostra todos os comandos utilizados internamente no arcabouço;

- mensagens de controle do usuário 
Certos comandos que controlam o ciclo de vida do sistema. Eles podem ser utilizados pelo usuário, em tempo de execução, para criar e destruir agentes, adicionar e remover componentes, alterar parâmetros e controlar a simulação. A tabela 3.2 mostra todos estes controles;

- mensagens do usuário

São comandos ou mensagens definidos pelo usuário para uso em componentes customizados.

\subsubsection{Roteamento de Comandos}

O Ensemble disponibiliza um serviço de roteamento de mensagens capaz de efetuar a troca de mensagens entre Agentes Musicais, Agente Ambiente e Agentes Externos. Todos os agentes do sistema e seus componentes internos são capazes de receber e enviar mensagens através de um serviço de roteamento de mensagens. Esse serviço é responsável pela entrega de cada mensagem ao seu correto destinatário utilizando o mecanismo interno de troca de mensagens do middleware.

O roteador de comandos utiliza um esquema de endereçamento baseado em uma sequência de caracteres (string) que contém o nome do sistema, e seu componente interno quando for o caso. Por exemplo, pode-se enviar uma mensagem a um sensor /ensemble/pianist/right_ear, ou para um programa externo, como o Pd, usando o endereço /external/pd. Estes endereços podem ser:

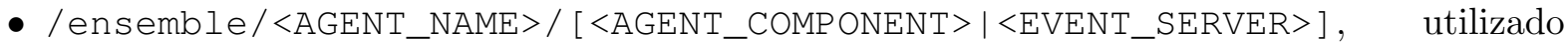
quando o destino é algum elemento que está sendo executado no arcabouço, ou seja, agentes musicais, seus componentes, o agente ambiente e seus servidores de eventos;

- /external/<APPLICATION_ADDRESS>, utilizado para se comunicar com outras aplicações, o Pd por exemplo;

- / console/<CONSOLE_NAME>, utilizado para que o usuário possa digitar comandos diretamente no console de um terminal, e também para que o arcabouço posso informar o usuário de eventos importantes;

- /file/<FILE_NAME>, utilizado para armazenar mensagens do arcabouço ou para ler um script.

A mensagem enviada através do canal de comunicação é encapsulada em uma estrutura de dados que armazena o nome do comando e seus parâmetros, representada no arcabouço através de um objeto da classe Command. Esse identificador de comando é importante no momento do tratamento da mensagem, facilitando a filtragem das mensagens de controle. Cada parâmetro é composto por um identificador e um valor associado, e ambos são obrigatoriamente sequências de caracteres.

Para acessar o roteador de comandos, os agentes e seus componentes implementam a interface RouterClient. Ela dispõe de um método que devolve o endereço do componente (getAddress()), facilitando a identificação de cada componente.

O envio de mensagens é feito através do método sendCommand(Command $\mathrm{cmd}$ ), que deve identificar o destinatário e informar o comando a ser enviado. No caso de se tratar de uma mensagem interna do ambiente, entre agentes, basta enviar diretamente a mensagem através do serviço de mensagens do arcabouço. Caso contrário, a mensagem é encaminhada para um serviço especial de roteamento que fará a interface com o mundo exterior.

O recebimento de mensagens do canal de comunicação é feita através do método receiveCommand(Command $\mathrm{cmd}$ ), que roda de forma independente. Esse método é responsável 


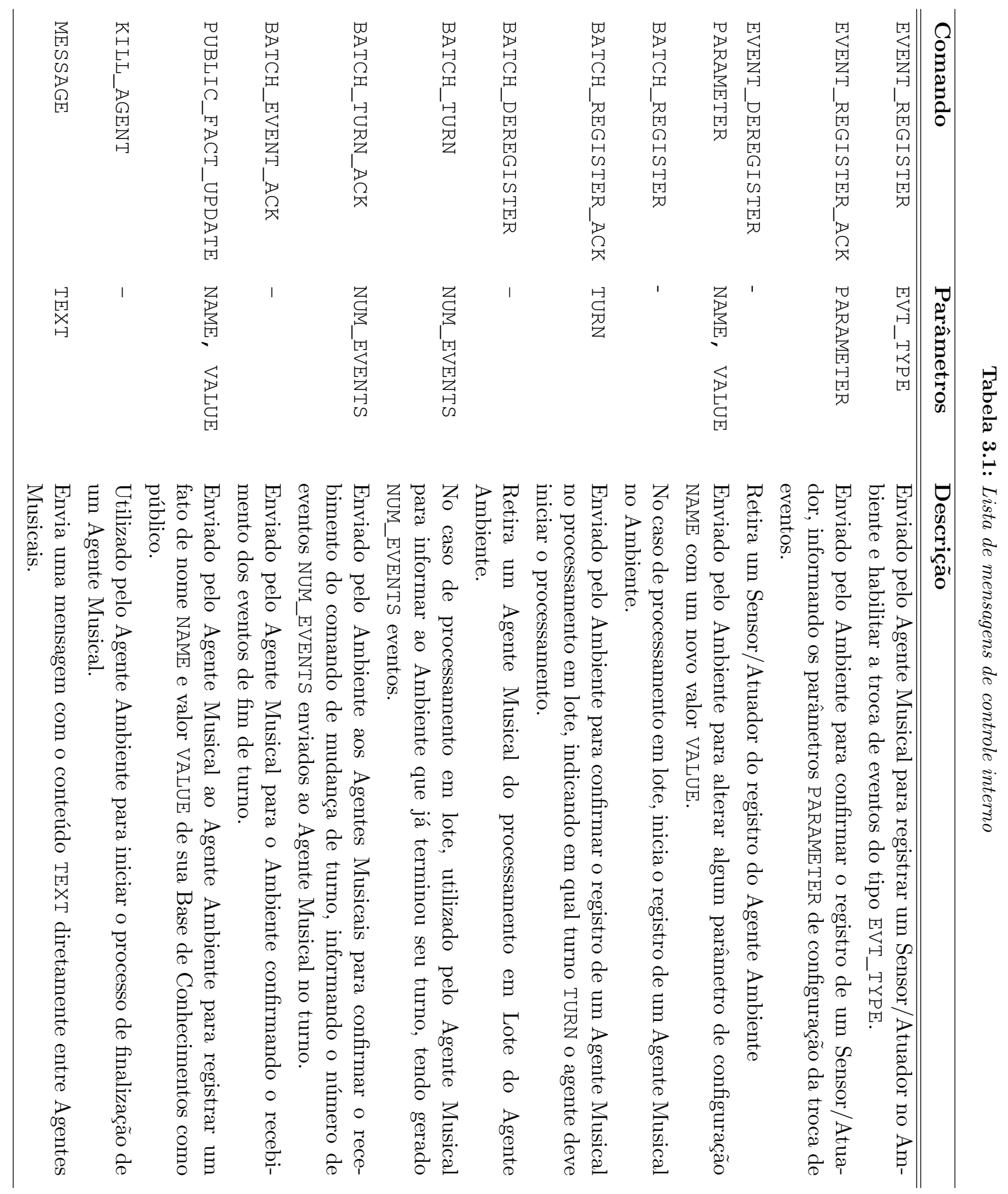




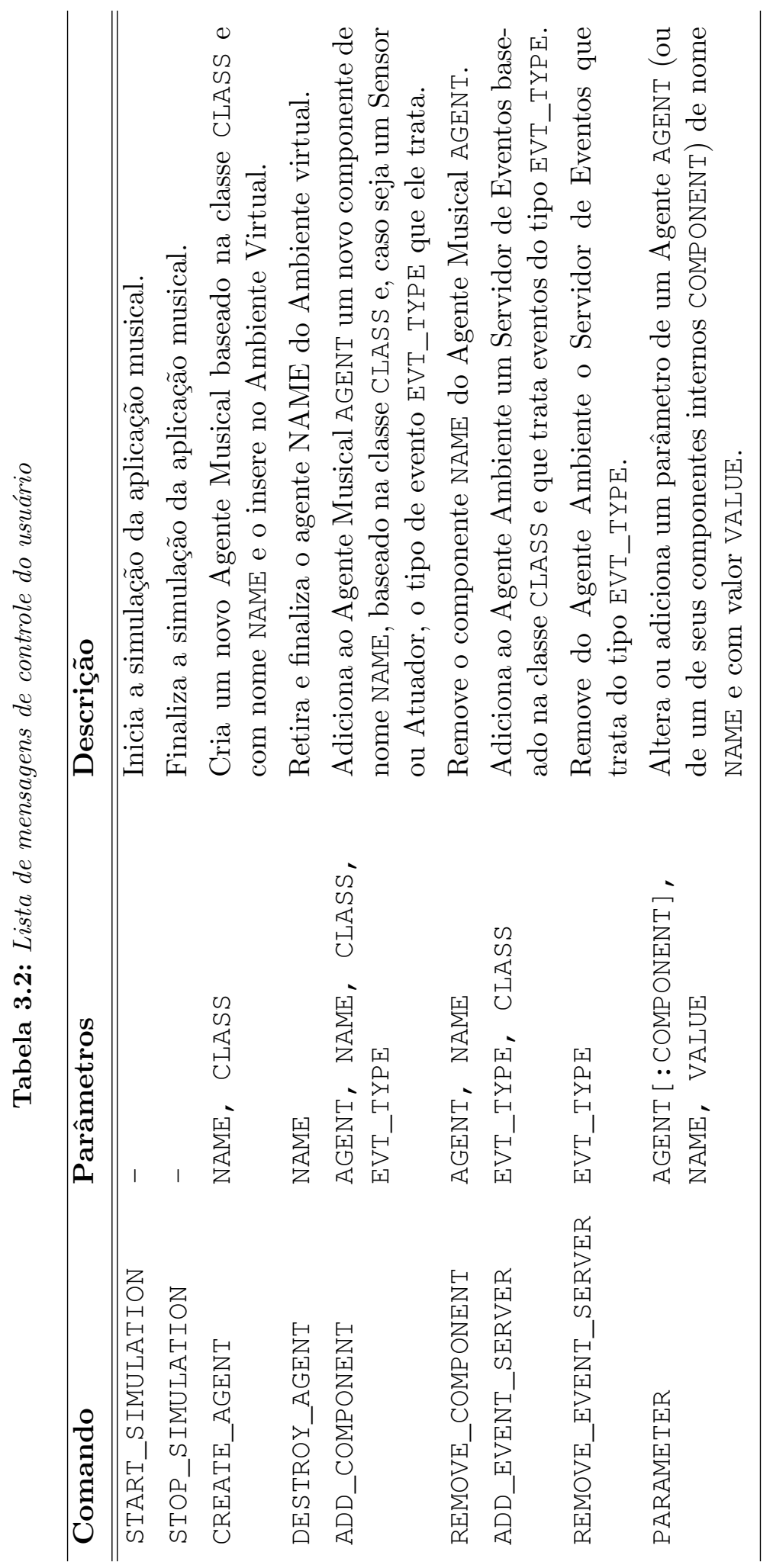


por identificar o destinatário da mensagem, rencaminhando-a caso não seja o destinatário final, ou processando-a caso contrário. O processamento da mensagem implica em filtrar as mensagens de controle, processando-as diretamente, ou executando o método processCommand(Command cmd). Esse método, implementado pelo usuário, permite que comandos específicos do componente sejam executados. Por exemplo, um Servidor de Eventos de movimentação pode tratar uma mensagem do agente solicitando uma mudança de posição.

\subsection{Ciclo de Vida}

Nesta seção é detalhado o funcionamento interno da arquitetura e de seus componentes com relação ao ciclo de vida, ou seja, a configuração e execução de um sistema, a inicialização e finalização de Agentes Musicais e o ciclo de execução dos componentes implementados pelo usuário. O caso do funcionamento durante o modo de execução de lote, que requer um tratamento especial por parte do arcabouço, também é comentado.

\subsubsection{Configuração e Execução de um Sistema}

Um Agente Musical pode ser criado de duas formas: no início da simulação, através de um arquivo de configuração que indica quais os tipos, nomes e quantidade dos Agentes, ou em tempo de execução, através do Agente Ambiente. A inicialização de um Agente Musical consiste em se registrar no Agente Ambiente, e registrar seus fatos públicos e seus Sensores e Atuadores nos respectivos Servidores de Evento. Da mesma forma, ao ser finalizado, os registros e fatos devem ser retirados dos Servidores de Eventos. Durante a execução, é possível adicionar ou remover componentes de um Agente Musical, assim como alterar qualquer parâmetro de seus componentes ou fatos armazenados em sua Base de Conhecimento.

Uma classe especial, chamada Loader, é responsável pela configuração inicial do sistema. Ela deve inicializar os serviços genéricos do sistema, como o relógio virtual e o envio de mensagens, e criar e inicializar os agentes. A critério do usuário, esta classe pode ser utilizada para inicializar a simulação. A entrada do Loader é dada por arquivo de configuração em formato texto, que contém todos os dados necessários para a definição de uma aplicação musical e sua inicialização. Esse arquivo deve ser criado pelo usuário e é composto de quatro seções (o apêndice A mostra exemplos de como criar esse arquivo no formato XML):

- parâmetros globais: o nome da aplicação musical e configuração dos parâmetros que afetam todos os agentes do sistema, como o modo de execução (ver seção 3.3), o modo de funcionamento do relógio virtual (ver seção 3.2) e os serviços que estarão disponíveis;

- definição do Agente Ambiente: composição do Agente Ambiente, com seu Mundo, suas Leis e seus Servidores de Eventos, além de quaisquer outros parâmetros necessários;

- definição dos Agente Musicais: composição das classes dos Agentes Musicais que poderão ser instanciados no ambiente, com seus componentes e diversos parâmetros, e os fatos a serem armazenados na Base de Conhecimento;

- instâncias de Agentes Musicais: indicação de todas as instâncias de Agentes Musicais a serem inicializadas, baseadas nas definições da seção anterior, com seus respectivos nomes no ambiente e parâmetros específicos.

\subsubsection{Criação de um Agente Musical}

A inicialização de um Agente Musical depende do correto registro de todos os seus atuadores e sensores. A figura 3.6 mostra o diagrama de sequência do procedimento feito por cada Agente 
Musical (o registro do EventHandler é mostrado de forma simplificada, mais detalhes podem ser encontrados na seção 3.6.4).

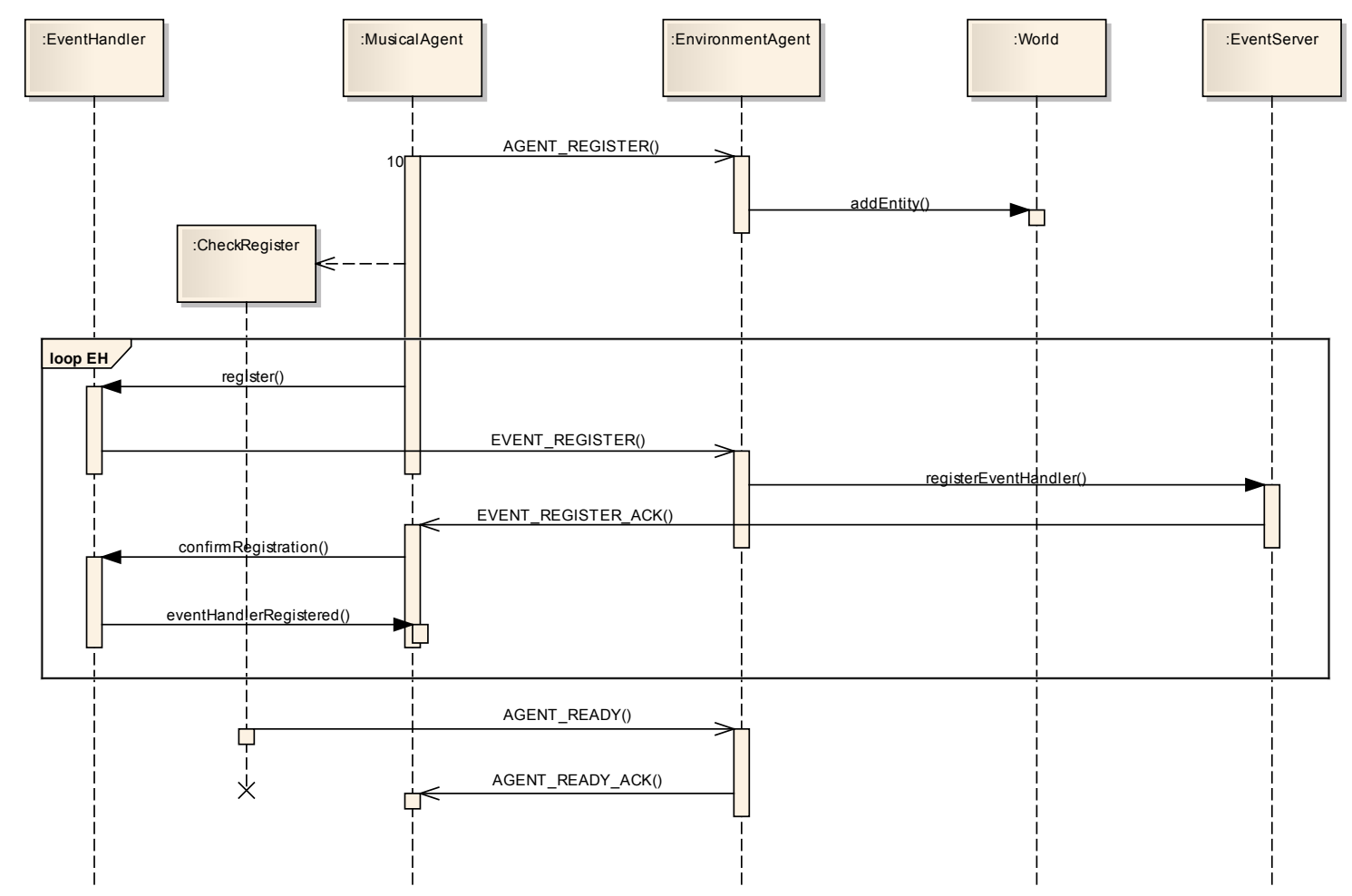

Figura 3.6: Inicialização de um Agente Musical no processamento em lote

Inicialmente, o agente envia uma solicitação de registros ao Agente Ambiente através do comando AGENT_REGISTER, que irá adicionar o agente ao mundo virtual (método addEntity()). Em seguida, o agente inicia um processo paralelo CheckRegister, responsável por verificar que todos os EventHandlers foram registrados, e começa a registrar cada um de seus atuadores e sensores (repetições do fragmento loopEH).

Para cada EventHandler, um comando EVENT_REGISTER é enviado ao ambiente, que irá registrar o Atuador ou Sensor correspondente no respectivo EventServer e retornar um comando EVENT_REGISTER_ACK confirmando o registro. O Agente Musical avisa o EventHandler em questão da confirmação no ambiente, que termina sua configuração e indica o fato ao agente, para que o processo CheckRegister consiga controlar quais objetos EventHandler foram registrados.

Finalmente, depois que todos os objetos do tipo EventHandler tenham sido registrados no ambiente, um comando AGENT_READY é enviado ao ambiente. Este confirma o recebimento através do comando EVENT_REGISTER_ACK, fazendo com o que o Agente Musical aguarde o início do próximo turno para iniciar o seu processamento.

\subsubsection{Ciclo de Vida de um Componente}

Todos os componentes do Ensemble (agentes, componentes musicais, servidores de eventos, interfaces de comunicação, representações do mundo e leis) implementam a interface LifeCycle como forma de uniformizar o ciclo de vida desses componentes. Essa abordagem permite uma maior flexibilidade para a extensão de componentes, enquanto assegura o controle que o arcabouço necessita.

A execução dos métodos fica a cargo de quem está criando o componente. Por exemplo, ao se 
Tabela 3.3: Ciclo de vida de um componente do arcabouço

\begin{tabular}{|c|c|}
\hline \multicolumn{2}{|r|}{ setParameters ()$\rightarrow$ configure ()$\rightarrow \operatorname{start}() \rightarrow$ init ()$\rightarrow$} \\
\hline$<$ Todos $>$ & $\begin{array}{l}\text { process Command () } \\
\text { parameter Updated () }\end{array}$ \\
\hline Reasoning & $\begin{array}{l}\text { process() } \\
\text { newSense(), needAction() } \\
\text { eventHandlerRegistered (), eventHandlerDeregistered () }\end{array}$ \\
\hline Sensor, Actuator & $\begin{array}{l}\text { process() } \\
\text { registerListener (), deregisterListener() }\end{array}$ \\
\hline EventServer & $\begin{array}{l}\operatorname{process}() \\
\text { processAction }(), \text { actuatorRegistered }(), \text { actuatorDeregistered }() \\
\text { processSense (), sensorRegistered }(), \text { sensorDeregistered }()\end{array}$ \\
\hline
\end{tabular}

adicionar um Sensor a um MusicalAgent, o último é responsável pela correta chamada de todos os métodos da interface LifeCycle. Os métodos da interface são os seguintes, em ordem de chamada:

- setParameters(Parameters parameters): responsável por passar os parâmetros necessários para a configuração do componente, armazenando um objeto da classe Parameters;

- configure(): implementado pelo usuário para fazer qualquer tipo de mudança na configuração do componente antes de sua inicialização;

- start(): chamado pelo arcabouço para executar as tarefas internas de inicialização do componente;

- init(): inicialização implementada pelo usuário, chamada automaticamente por start();

- parameterUpdate(String name, String newValue): chamado pelo arcabouço quando o valor de um parâmetro de nome name é atualizado com um novo valor newValue;

- stop(): usado pelo arcabouço para executar as tarefas internas de finalização do componente;

- finit(): finalização implementada pelo usuário, chamada automaticamente por stop().

Durante a execução de uma simulação, é possível controlar vários aspectos do sistema através de comandos de controle, como criar agentes musicais, adicionar componentes, ou alterar parâmetros de execução. Os comandos podem ser emitidos internamente pelos próprios agentes, ou então por um agente externo. O mecanismo utilizado para essa troca de comandos está detalhado na seção 3.4.1.

A tabela 3.3 ilustra a ordem com que os métodos da interface LifeCycle são chamados e os métodos (em negrito) que podem ser implementados pelo usuário em cada tipo de componente de forma a customizar sua aplicação.

\subsubsection{Modo de Execução em Lote}

No caso do início da simulação, quando o Agente Ambiente está esperando o registro de todos os agentes, ele também mantém um processo paralelo do tipo CheckRegister. Assim que todos os Agentes Musicais foram registrados, o relógio virtual é atualizado, iniciando a simulação. 
O fluxo de funcionamento do processamento em lote durante um turno é ilustrado no diagrama de sequência da figura 3.7. De forma a simplificar o diagrama, apenas um agente está presente, mas o fragmento par Agents indica que o mesmo procedimento é feito para todos os Agentes Musicais de forma paralela.

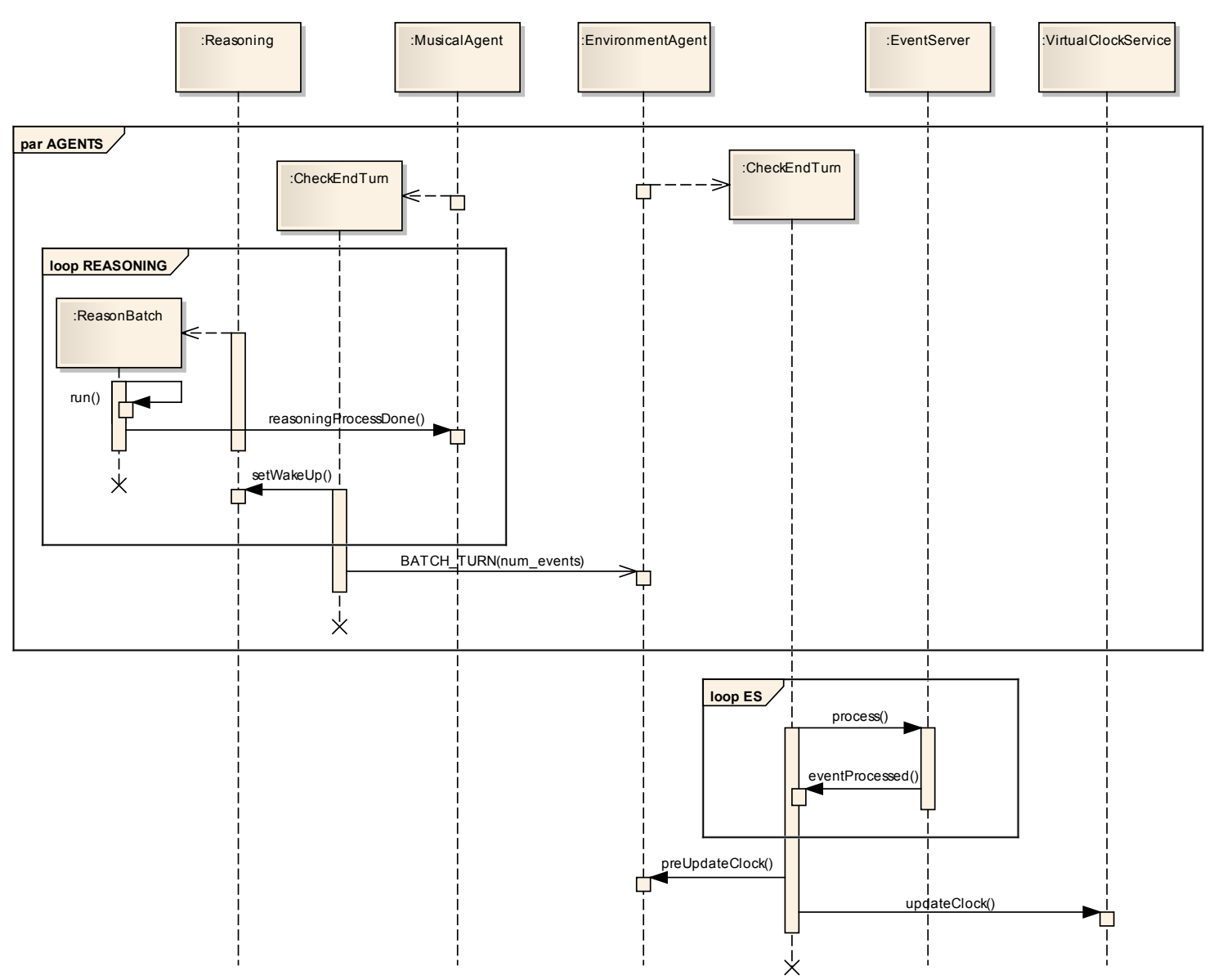

Figura 3.7: Processamento de um turno no processamento em lote

Ao início de um novo turno, as tarefas dos raciocínios programadas para executar nesse turno (ReasonBatch) são despertadas pelo serviço de agendamento de tarefas do relógio virtual, e executam o respectivo método process() de seu raciocínio. Os raciocínios, ao terminarem o processamento e possívelmente atuarem no ambiente enviando eventos, avisam o seu Agente Musical através do método reasoningProcessDone().

O Agente Musical mantém um processo paralelo CheckEndTurn que aguarda a finalização do processamento de todos os raciocínios, enviando um comando BATCH_TURN ao ambiente para indicar que o processamento do agente nesse turno terminou. Ele também é responsável por agendar a execução do raciocínio para o próximo turno, através do método setWakeUp().

Assim que todos os Agentes Musicais informaram que terminaram o turno e os Eventos foram processados, o Agente Ambiente inicia o processamento de cada Servidor de Eventos, indicado pelo fragmento loop ES, através da chamada ao método process(). Durante o processamento, os Servidores podem enviar eventos de resposta para os Agentes Musicais, caso necessário.

Em seguida, o Agente Ambiente deve aguardar o final do processamento, por parte dos Agentes Musicais, de todos os eventos de resposta enviados pelos Servidores de Evento. Esse passo pode ser omitido caso não existam eventos de resposta. 
Finalmente, o Agente Ambiente executa o método preUpdateClock(), em que pode ser feita a atualização da interface gráfica ou algum processamento global, e executa o método updateClock(), finalizando esse turno.

\subsubsection{Finalização de um Agente Musical}

A finalização de um Agente Musical deve retirar do registro todos os seus sensores e atuadores antes de eliminá-lo do ambiente. A figura 3.8 mostra o diagrama de sequência do procedimento feito por cada Agente Musical.

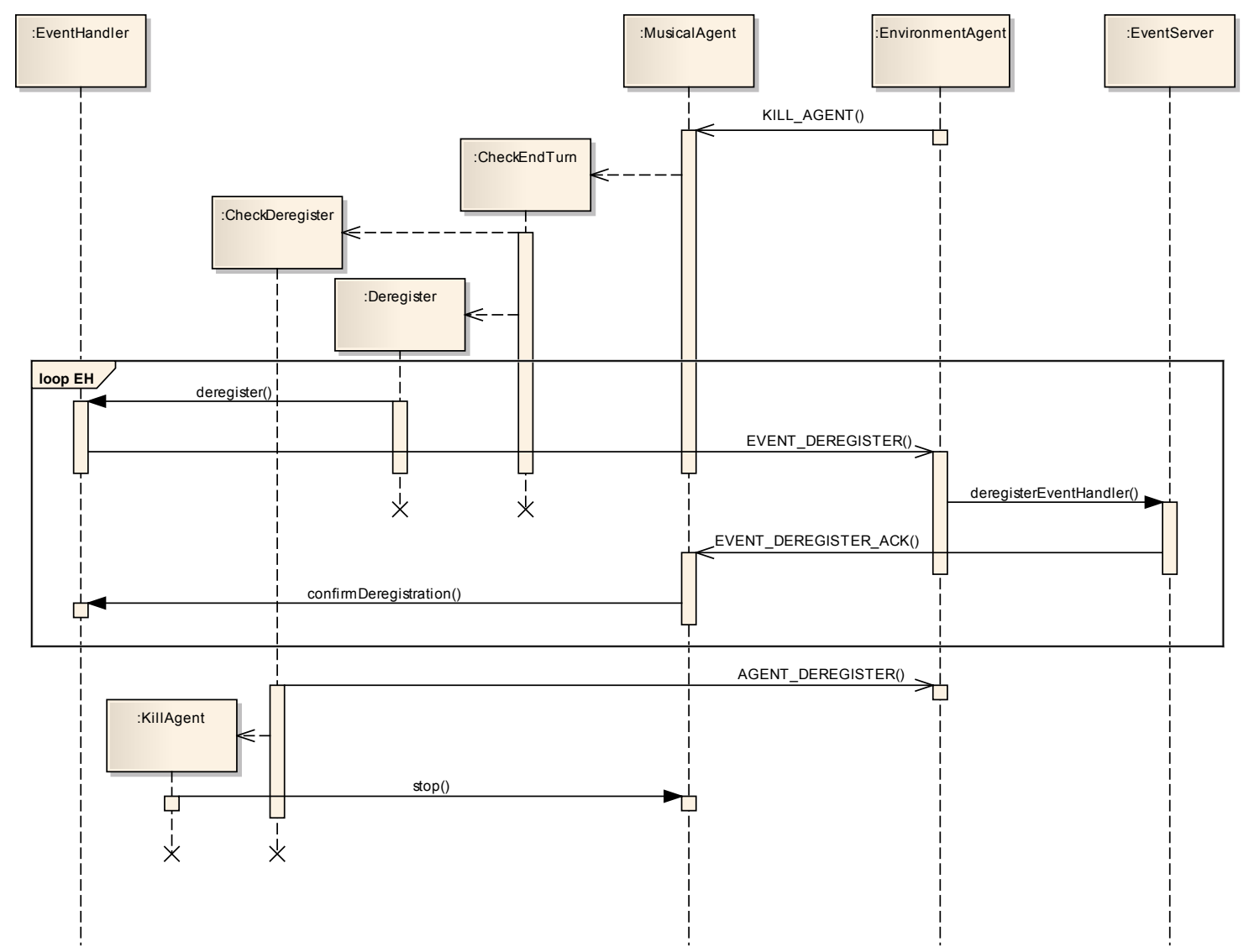

Figura 3.8: Finalização de um Agente Musical no processamento em lote

O Agente Ambiente inicia o processo de finalização de um agente ao enviar o comando KILL_AGENT ao agente em questão. O Agente Musical, ao receber o comando, cria um processo paralelo, CheckEndTurn, para aguardar a finalização do turno atual. Este processo, por sua vez, ao detectar o fim do turno, cria dois novos processos paralelos, CheckDeregister e Deregister. O primeiro é responsável por aguardar a retirada do registro de todos os sensores e atuadores e o segundo pela retirada propriamente dita.

O fragmento loop EH, executado para cada sensor e atuador, chama o método deregister() do EventHandler, que envia o comando EVENT_DEREGISTER para o Agente Ambiente. Este, por sua vez, informa o Servidor de Eventos responsável, que retira o EventHandler do registro e confirma a ação enviando o comando EVENT_DEREGISTER_ACK para o Agente Musical.

Uma vez que todos os EventHandler foram retirados do registro, o processo CheckDeregister aciona um novo processo KillAgent que irá finalizar o ciclo de vida do Agente Musical, retirando-o 
do sistema.

\subsection{Interação no Ambiente Virtual}

A interação entre Agentes Musicais e entre Agente Musical e o Agente Ambiente é feita através do envio e recepção de eventos, cujo fluxo é sempre controlado pelo Agente Ambiente através de seus Servidores de Eventos. Nesse contexto, um evento pode ser um fragmento de áudio, uma colisão de um agente com um obstáculo, uma interação biológica, e assim por diante.

Alguns tipos de eventos podem necessitar de resposta do ambiente para confirmar uma ação de um Atuador. Por exemplo, um Atuador responsável pelo movimento envia um evento indicando que quer andar em uma direção e aguarda a resposta do Ambiente que confirmará ou não a nova posição do Agente. Essa resposta do Ambiente é enviada através de um evento para o Sensor responsável pelo mesmo tipo de evento do Agente, e deverá ser tratado pelo usuário. No caso do Agente não ter um sensor desse tipo para receber a resposta, seria como se ele não soubesse avaliar os efeitos de suas ações.

Da mesma forma, certos tipos de eventos podem levar certo tempo para que suas ações tenham efeito, por exemplo, um agente que anda em uma direção com certa velocidade deve esperar uma confirmação de sua nova posição para que possa andar novamente. Esse controle depende da implementação do usuário para o tratamento do tipo de evento.

\subsubsection{Tipos de Evento}

Todo evento pertence a um tipo e cada Servidor de Eventos é responsável por gerenciar um determinado tipo de evento. Esse tipo é definido pelas seguintes informações:

- Nome, que é uma cadeia de caracteres cujo papel é ser o identificador único no sistema para um tipo de evento (por exemplo, SOUND ou MOVEMENT);

- Forma de troca de evento, que indica se é esporádico ou periódico, e quais parâmetros são necessários para essa forma de troca de evento;

- Estrutura de dados do evento, que armazena os dados que circulam pelo Ambiente, composta de:

- Informações básicas: nome do agente de origem e destino, ponto de acesso do agente origem e destino, tipo do evento, timestamp (baseado no clock virtual), janela à qual pertence o evento (no caso de eventos periódicos), campo de texto para instruções simples;

- Informações específicas: depende do tipo de evento, por exemplo, um evento sonoro pode conter o fragmento de áudio, a taxa de amostragem e o número de bits por amostra.

Eventos simples, que necessitam apenas das informações básicas, podem utilizar diretamente a classe Event disponível no arcabouço, enquanto que eventos mais complexos devem estender essa classe para acrescentar as informações específicas. A figura 3.9 mostra o diagrama de classes de eventos. No caso de eventos simples, pode-se utilizar diretamente o campo de conteúdo (objContent), indicando alguma instrução simples como "dar passo a frente" ou "cantar a nota lá".

No caso de um evento sonoro (AudioEvent), mais especificamente de áudio digital, este contém um fragmento do áudio (chunk), seu identificador (chunkID), o tamanho da fragmento (chunkLength), 


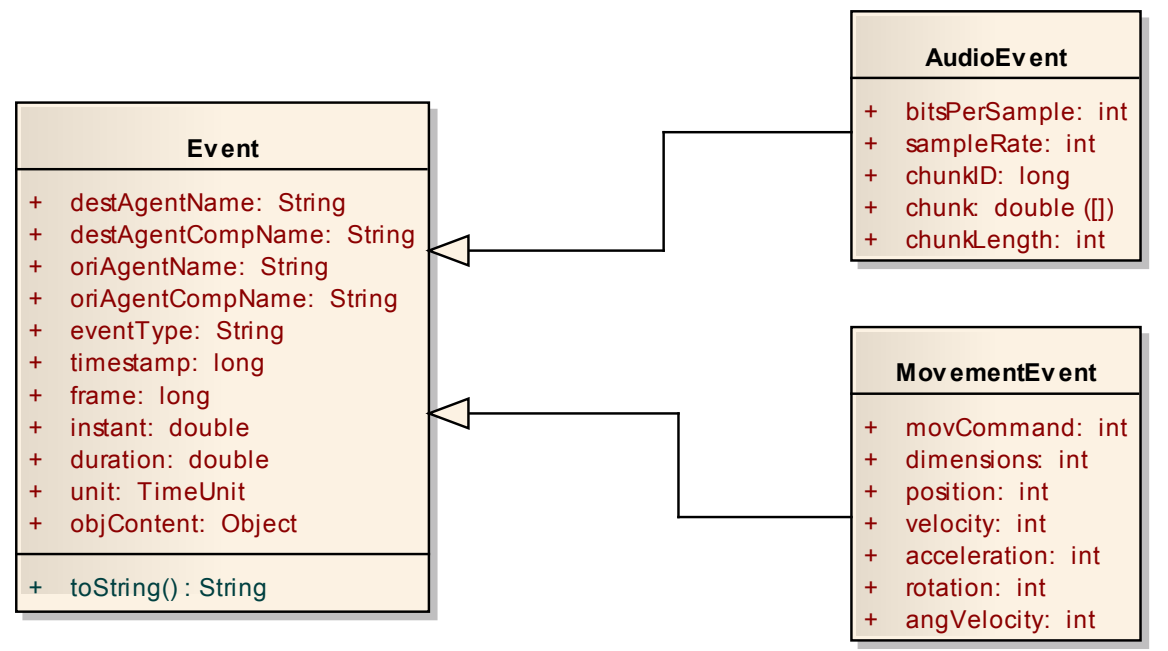

Figura 3.9: Diagrama de Classes de Eventos

sua taxa de amostragem (sampleRate) e o número de bits por amostra (bitsPerSample).

Um evento de movimentação (MovementEvent) contém uma instrução de movimentação (movCommand), como andar ou girar, e possíveis vetores de posição, velocidade, aceleração, grau de rotação e velocidade angular necessários para a execução da instrução (respectivamente position, velocity, acceleration, rotation e ang Velocity).

\subsubsection{Formas de Troca de Eventos}

O Ensemble oferece duas formas de troca de eventos no mundo virtual, esporádica ou periódica, cuja escolha depende do tipo de evento e de suas necessidades. Um sistema, dependendo dos sensores e atuadores presentes nos Agentes Musicais, pode comportar as duas formas de envio de eventos.

- Troca de eventos esporádicos

Eventos que podem ser enviados a qualquer instante e com qualquer frequência, por exemplo, mudança da posição de um agente ou o envio de uma mensagem MIDI;

- Troca de eventos periódicos

Algumas aplicações necessitam de um fluxo contínuo de dados, como a troca de áudio e de vídeo, e para isso utiliza-se a troca de eventos de forma periódica. O funcionamento exige que o Ambiente e o Agente estejam de acordo com a frequência de envio do evento. Além disso, tipos especiais de eventos podem exigir que os Agentes respeitem uma sequência de envio.

\subsubsection{Interface de Comunicação}

O envio e recebimento de eventos é feito através de uma interface de comunicação (Comm), utilizado por Sensores e Atuadores bem como pelos Servidores de Evento do Agente Ambiente. A implementação dessa interface depende do tipo de evento a ser enviado, por exemplo, eventos que necessitam de baixa latência, como o envio de áudio, podem usar uma implementação baseada em Blackboard ou em chamada direta de métodos, enquanto que eventos menos sensíveis podem utilizar o mecanismo de mensagens disponível no middleware.

Cada Sensor e Atuador tem uma Interface de Comunicação agregada e, no momento de sua especificação, se parametriza a implementação da interface Comm que será utilizada. Os eventos que chegam à Interface de Comunicação são repassados para o Sensor através da chamada de callback 
do método receive(Event evt), e o Atuador utiliza o método send(Event evt) para enviar eventos.

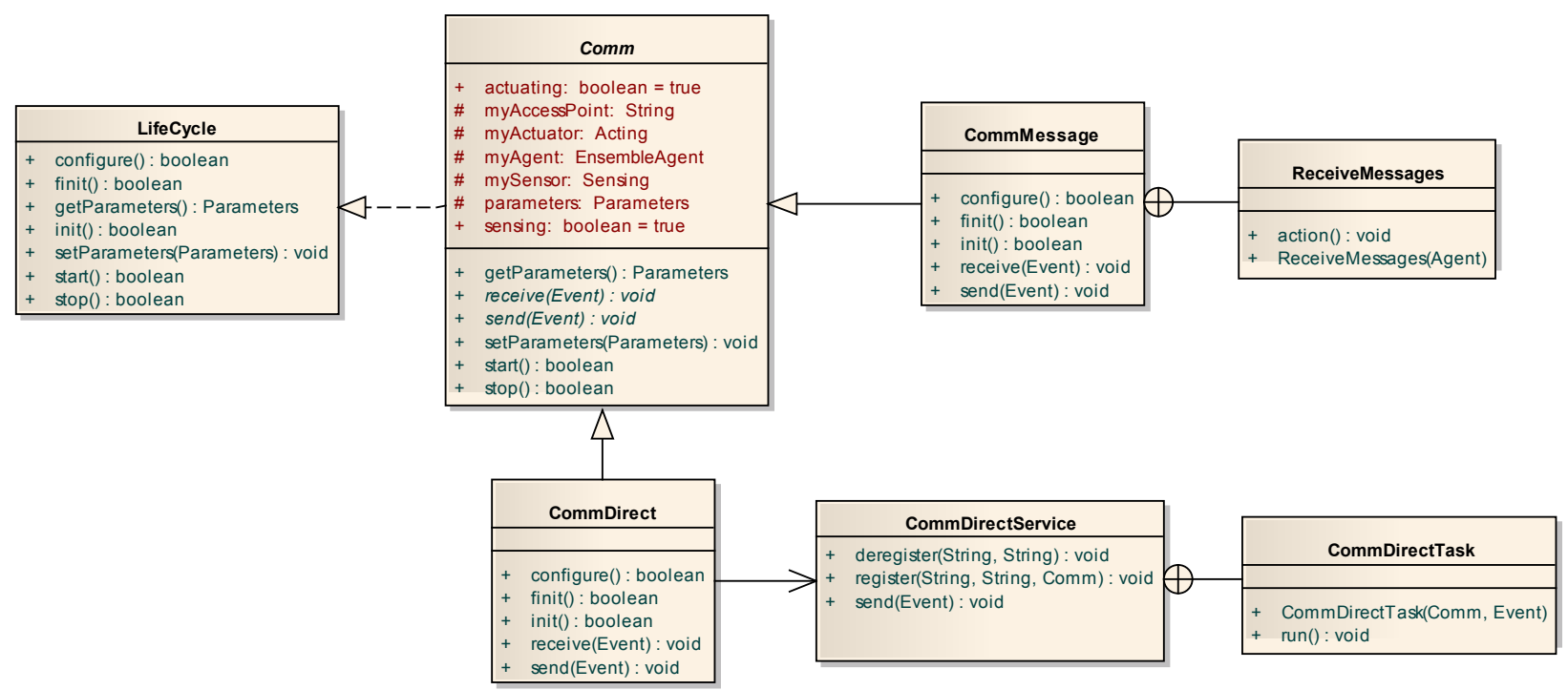

Figura 3.10: Diagrama de classes da Interface de Comunicação

A figura 3.10 mostra o diagrama de classes da Interface de Comunicação, com a interface Comm e suas implementações disponíveis, que são:

\section{- Comunicação via Mensagens}

Esta implementação funciona como uma casca para o sistema de comunicação do middleware multiagentes e simplesmente encapsula o evento, que é serializado (transformado em uma sequência de bytes) para ser enviado ao agente destino. Uma de suas vantagens, além da simplicidade de implementação, é permitir o envio de mensagens via redes de computadores, possibilitando que o sistema multiagente execute em um ambiente distribuído.

A natureza assíncrona deste tipo de comunicação implica em falta de garantias sobre a chegada da mensagem, uma vez que está suscetível ao roteamento de mensagens na rede de computadores e ao mecanismo interno do sistema middleware. Esses problemas podem deixar o tempo de resposta extremamente lento e não determinístico para a troca de áudio. Desta forma, torna-se inviável o uso de um mecanismo de troca de mensagens para áudio digital.

\section{- Comunicação via Chamada Direta}

A comunicação via chamada direta é uma forma rápida de passar o controle para o agente processar um evento. Ela é implementada como um serviço do sistema multiagente por uma mesma instância que pode ser acessada de qualquer agente. No momento do registro do Sensor, o método receive() de cada interface de comunicação fica registrada no serviço e, quando um evento é enviado, o serviço simplesmente repassa a chamada para o método que irá receber o evento.

Esta implementação tem a desvantagem de bloquear o processamento da Interface de Comunicação enquanto o método sense() não retorna. Assim, esse método deve ser processado rapidamente para que outros eventos, chegando na mesma interface, não fiquem aguardando.

\subsubsection{Registro de Sensor e Atuador no Ambiente}

Para que um evento de certo tipo possa ser processado no Ambiente Virtual, alguns procedimentos devem ser efetuados pelo Servidor de Eventos responsável pelo tipo de evento e pelos 
Agentes Musicais interessados em enviar e receber os eventos. O diagrama da figura 3.11 ilustra este processo. Para evitar um diagrama mais complexo, não aparecem as chamadas aos métodos da interface LifeCycle, nem os mecanismos internos de envio de mensagens.

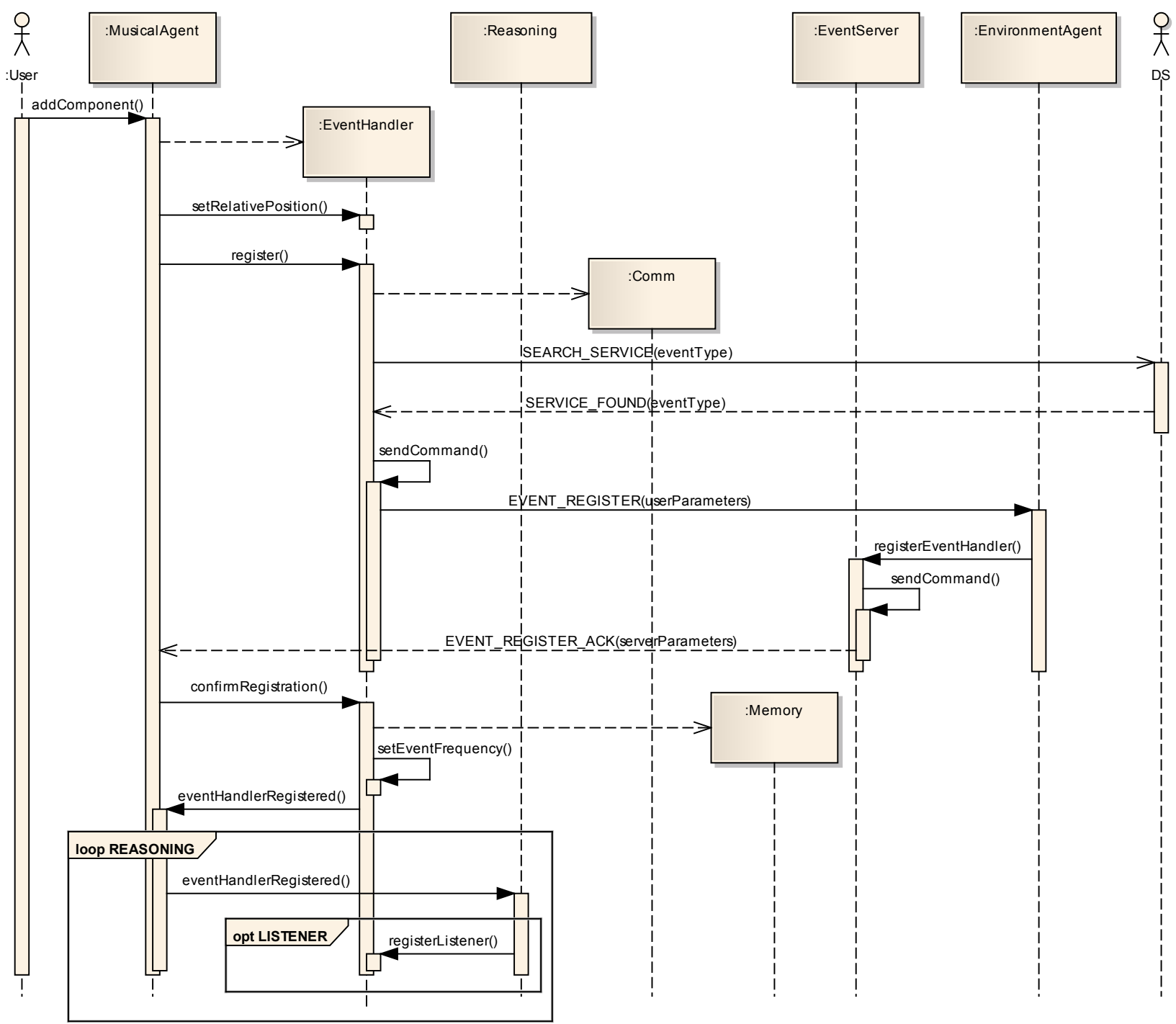

Figura 3.11: Diagrama de sequência do registro de um Sensor/Atuador

Quando um Sensor ou Atuador é agregado ao Agente Musical, através do método addComponent(), os parâmetros do usuário são passados, a sua posição relativa no corpo virtual do agente é configurada (setRelativePosition()) e o método register() é executado, iniciando o processo de registro.

O EventHandler consulta o diretório do sistema multiagente $(D S)$ para saber qual é o Servidor de Eventos responsável por certo tipo de evento (SEARCH_SERVICE). O diretório envia a resposta sobre a consulta (SERVICE_FOUND) indicando, caso exista, o Servidor de Eventos responsável.

Ao receber a resposta do diretório, o EventHandler cria uma interface de comunicação (Comm) para poder enviar eventos, e se registra no Servidor de Eventos responsável, enviando os parâmetros necessários (nome do componente, tipo do componente, tipo de evento e parâmetros do usuário), utilizando o canal de comunicação do Agente Musical através do comando EVENT_REGISTER.

Ao receber o pedido de registro, o Servidor de Eventos armazena em uma lista o nome do Agente 
Musical e o nome do componente registrado, junto com os parâmetros que foram passados. Em seguida, envia ao Agente Musical uma confirmação do registro, utilizando o canal de comunicação através do comando EVENT_REGISTER_ACK, com os parâmetros necessários para a configuração do Sensor ou Atuador. Tratando-se de uma troca periódica, o tempo inicial, período e prazos são informados. Parâmetros específicos de certo tipo de evento também são passados como, por exemplo, no caso da troca de áudio, a taxa de amostragem e o número de amostras esperadas por fragmento.

Ao receber a confirmação do registro, o Agente Musical repassa ao Sensor ou Atuador os parâmetros sobre o tipo de evento através do método confirmRegistration(). O EventHandler irá criar uma Memória para armazenar seus eventos e, caso se trate de um Atuador em uma troca periódica, irá executar o método setEventFrequency() para inicializar a máquina de estados que controla a troca (mais detalhes na seção 3.6.5.2).

Todos os Raciocínios registrados são informados sobre o novo Sensor ou Atuador através do método eventHandlerRegistered(), implementado pelo usuário. Assim, o Raciocínio que tenha interesse em um determinado tipo de evento pode se registrar no Sensor, para ser informado da recepção de um evento, ou no Atuador, para poder enviar eventos. Este registro é feito através do método registerListener().

Finalmente, a troca de eventos entre o Sensor ou Atuador do Agente Musical com o Agente Ambiente pode começar.

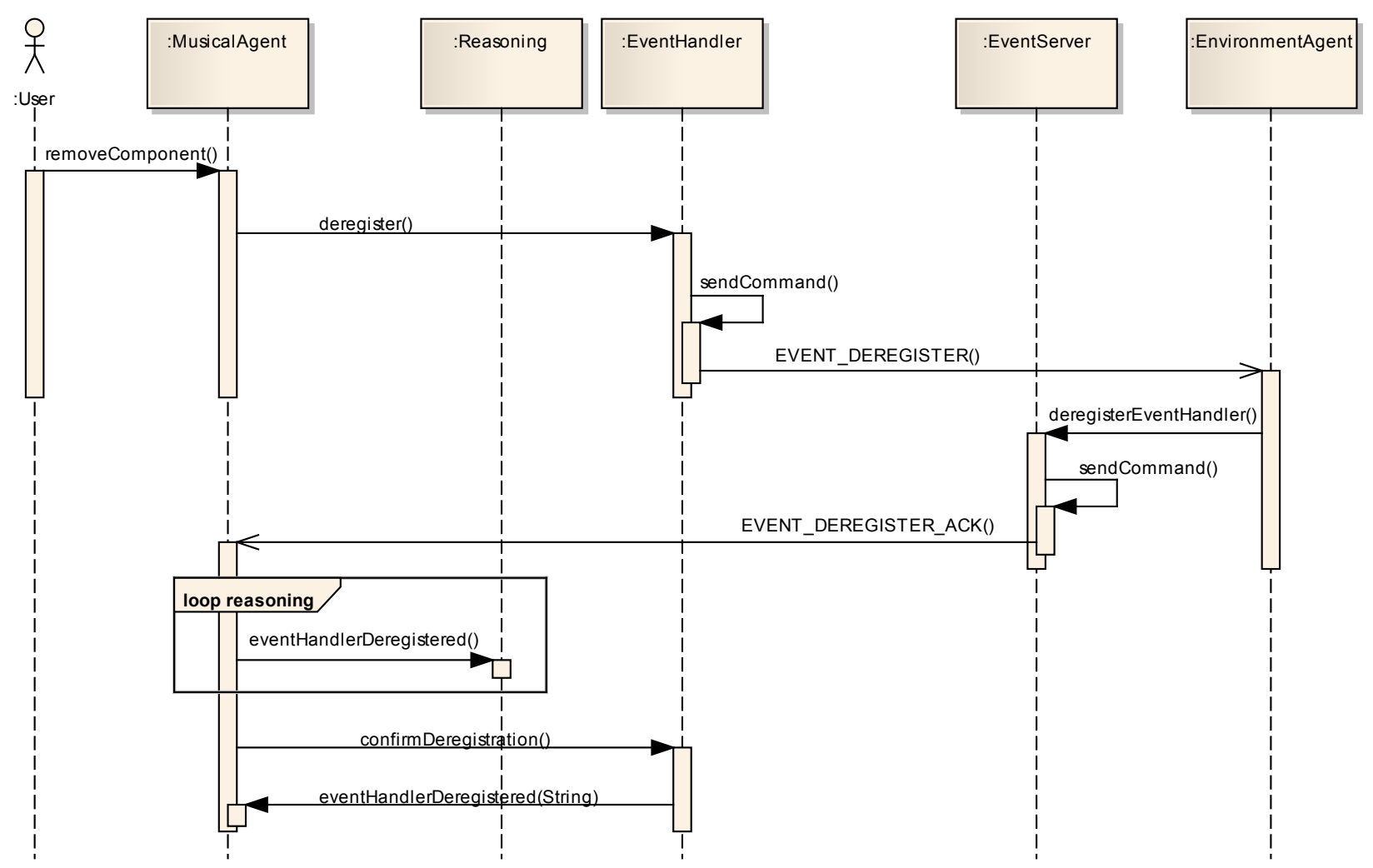

Figura 3.12: Diagrama de sequência da retirada do registro de um Sensor/Atuador

O diagrama da figura 3.12 ilustra a retirada do registro de um Sensor ou Atuador. No momento em que um Sensor ou Atuador é retirado do Agente Musical através do método removeComponent(), o método deregister() é executado, iniciando o processo através do envio do comando de controle EVENT_DEREGISTER.

O Agente Ambiente, ao receber o pedido, executa o método deregisterEventHandler() do Servi- 
dor de Eventos responsável pelo tipo de evento em questão. Este retira o registro do EventHandler de sua lista para que não seja mais processado, executando qualquer outro tipo de limpeza necessária, e enviando uma mensagem de controle EVENT_DEREGISTER_ACK.

O Agente Musical, ao receber a confirmação da retirada do registro, informa todos seus raciocínios sobre o fato através do método eventHandlerDeregistered() e informa o EventHandler do sucesso da operação através do método confirmDeregistration(). Finalmente, o EventHandler faz qualquer tipo de limpeza necessária, como finalizar o Comm, e fecha o ciclo informando o Agente Musical de sua finalização através do método eventHandlerDeregistered().

\subsubsection{Troca de Eventos}

\subsubsection{Troca de Eventos Esporádicos}

O processo de uma troca de eventos esporádicos é ilustrado pelo diagrama da figura 3.13. Embora o envio e recebimento do evento apareçam em sequência no diagrama, eles podem acontecer em qualquer momento.

O envio de eventos é iniciado pelo Raciocínio que deve, primeiramente, armazenar os dados a serem enviados na Memória do respectivo Atuador. Em seguida, deve executar o método act() do Atuador responsável por enviar o evento. Este, por sua vez, recupera automaticamente da Memória os dados a serem enviados e cria um objeto da classe Event, ou de alguma classe específica como AudioEvent ou MovementEvent. Em seguida, ele executa o método process(), caso tenha sido implementado pelo usuário para efetuar algum processamento no evento, e o envia através de sua interface de comunicação Comm.

O evento é recebido pela interface de comunicação do Servidor de Eventos responsável por este tipo de evento, que irá processá-lo através do método processSense(). Caso o Servidor de Eventos queira enviar um evento, basta criá-lo e enviá-lo através do método act().

Ao receber um evento, o método sense() do Sensor é executado pelo objeto Comm associado. Caso o usuário tenha implementado o método process(), o evento é repassado primeiramente para ser processado e, em seguida, seus dados são armazenados na Memória. Finalmente, o Sensor avisa todos os raciocínios registrados sobre o novo Evento recebido, através do método newSense(). Caso interesse ao Raciocínio, os dados podem ser buscados na Memória do Sensor.

\subsubsection{Troca de Eventos Periódicos}

A troca de eventos periódicos é um processo que ocorre em conjunto, e de forma sincronizada, entre os Atuadores e o Servidor de Eventos responsável por certo tipo de evento. O tempo, neste caso, está dividido em janelas (frames) de mesmo duração. Os Agentes Musicais sempre geram eventos relativos à próxima janela, ou janela de trabalho (workingFrame), enquanto os eventos da janela presente estão acontecendo no Ambiente Virtual (currentFrame).

Na inicialização de um Servidor de Eventos, deve-se informar a duração de uma janela (period), o prazo para os Agentes Musicais enviarem os eventos para a próxima janela (agentDeadline), o prazo para os eventos chegarem ao Ambiente (receiveDeadline), o prazo para o Servidor de Eventos processar todos os eventos e gerar as respostas necessárias (sendDeadline).

Um Atuador, ao ser registrado em um Servidor de Eventos, recebe os seguintes parâmetros: startTime, que indica o momento em que se inicia a troca de eventos periódicos, baseado no Tempo Virtual; period, que indica a duração de uma janela; receiveDeadline, que indica o limite de tempo 


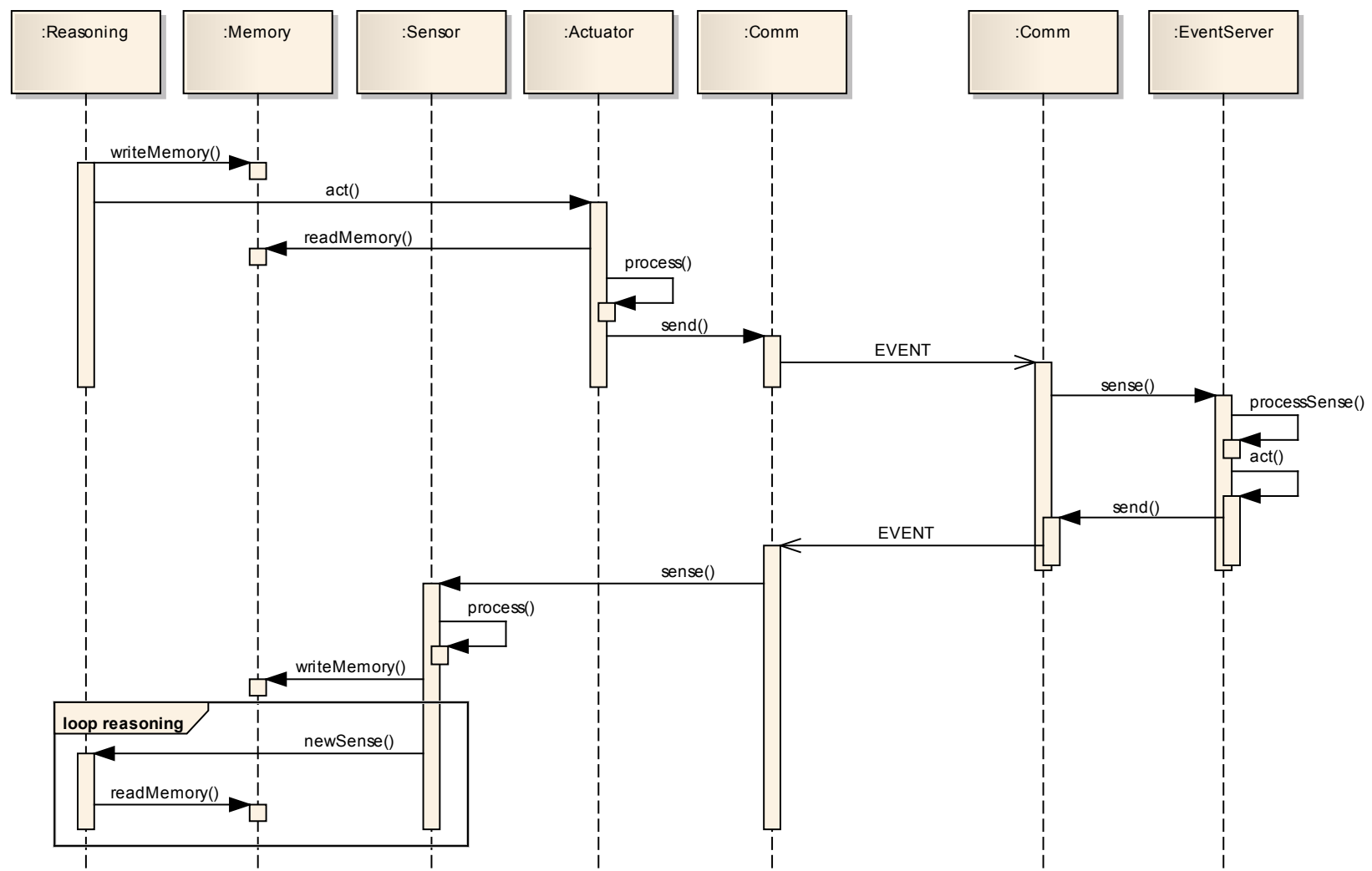

Figura 3.13: Diagrama de sequência de uma troca de eventos esporádicos

dentro da janela que o Agente Musical tem para enviar o evento; e workingFrame, que corresponde ao número da janela de trabalho. Cabe ao, se desejar, avisar os Raciocínios registrados da necessidade de uma atuação devido à proximidade do prazo de envio do evento (needAction), e em que momento o fará.

A utilização de um tempo inicial (startTime) baseado no relógio virtual central, aliado à duração de uma janela, permite que os diversos Atuadores e o Servidor de Eventos sejam executados em sincronia. A troca de eventos periódicos independe do modo de funcionamento do tempo virtual, ou seja, ela está disponível tanto no processamento em tempo real como no processamento em lote.

Os prazos envolvidos na troca de eventos periódicos estão sumarizados na tabela 3.4 e devem respeitar a seguinte ordem:

$$
0 \leq \text { needAction }<\text { agentDeadline } \leq \text { receiveDeadline }<\text { sendDeadline } \leq \text { period }
$$

Todos os prazos e a duração de uma janela são definidos pelo usuário, e dependem de fatores como a latência na troca de mensagens, o tempo de resposta esperado do sistema e a carga de processamento dos Agentes Musicais e do Ambiente. Os parâmetros podem mudar ao longo da execução de uma simulação, por exemplo, o Agente Ambiente responsável pode querer diminuir o número de amostras de áudio, e assim diminuir o período entre a troca de eventos.

A troca do período pode ser feita em tempo de execução pelo Servidor de Eventos através de uma solicitação do usuário feita através do comando PARAMETER ou internamente pelo próprio Servidor de Evento. A informação sobre os novos parâmetros do período é propagada para os atuadores e sensores envolvidos, indicando em que janela ocorrerá a troca.

A janela de trabalho, de duração $\Delta t_{P E R}$, pode ser vista na linha do tempo da figura 3.14 , com os prazos indicados. O período $\Delta t_{A G T}$ é aquele em que o Agente Musical processa o evento a ser 
Tabela 3.4: Prazos na troca de eventos periódicos

\begin{tabular}{|c|c|c|}
\hline Prazo & Nome & Descrição \\
\hline$\overline{t_{1}}$ & "needAction & $\begin{array}{l}\text { Nesse instante, o método needAction() do Raciocínio é cha- } \\
\text { mado automaticamente pelo arcabouço, indicando que se } \\
\text { deve disponibilizar na base de conhecimento o evento que } \\
\text { será enviado }\end{array}$ \\
\hline$t_{2}$ & agentDeadline & $\begin{array}{l}\text { Prazo para o Agente Musical atuar, enviando um evento } \\
\text { para o Ambiente }\end{array}$ \\
\hline$t_{3}$ & receiveDeadline & $\begin{array}{l}\text { Prazo para os eventos enviados pelos Agentes Musicais che- } \\
\text { garem ao Ambiente; após esse prazo, os eventos que chegam } \\
\text { são descartados }\end{array}$ \\
\hline$t_{4}$ & sendDeadline & $\begin{array}{l}\text { Prazo para o Ambiente enviar eventos para os Agentes } \\
\text { Musicais }\end{array}$ \\
\hline$t_{5}$ & period & Fim da janela \\
\hline
\end{tabular}

enviado, $\Delta t_{A M B}$ é o período que o Servidor de Eventos processa os eventos recebidos e $\Delta t_{L A G}$ é a latência máxima permitida da comunicação de eventos no sistema.

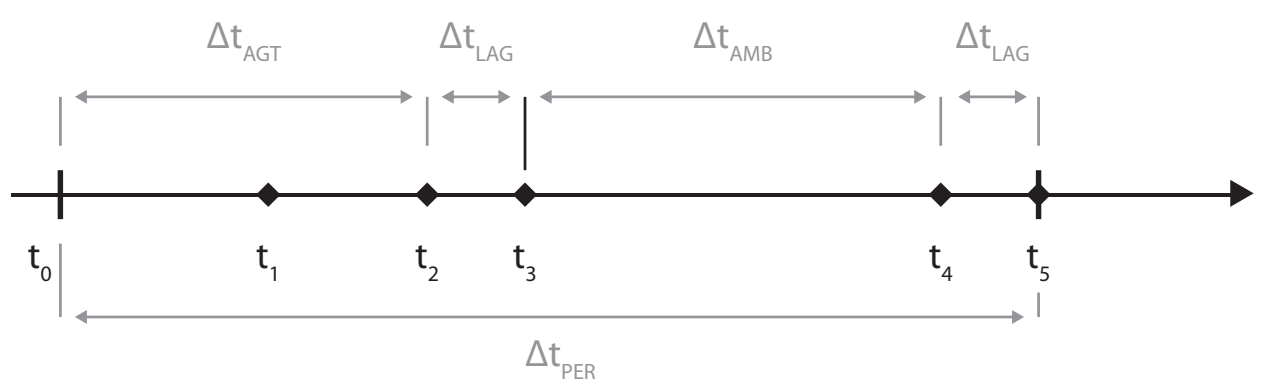

Figura 3.14: Linha do tempo de uma janela na troca de eventos periódicos

O intervalo entre o início do período e o agentDeadline é o tempo que os Agentes Musicais têm para gerar um evento e enviar ao Ambiente, caso queiram participar da próxima rodada de eventos. Caso o valor $t_{1}$ seja igual a zero, o Raciocínio não é avisado e o Atuador considera que o evento estará disponível na Base de Conhecimentos para ser enviado.

Até o prazo $t_{2}$ o evento deve ter sido enviado pelo Atuador, seja de forma automática ou através de uma chamada ao método act() por parte do Raciocínio. No momento do envio, caso o evento disponível não corresponda à janela de trabalho, o Atuador o descarta. Esse caso pode ocorrer quando a janela de trabalho muda sem que o Raciocínio tenha tido tempo de finalizar o seu processamento.

O Ambiente, durante esse período, recebe os eventos e, opcionalmente, pode realizar um préprocessamento à medida que cada evento chega. Por exemplo, no caso de eventos de áudio, o cálculo da atenuação do áudio para cada agente receptor já pode ser calculado, mas não o áudio final que cada agente escutará, pois depende da chegada de todos os eventos.

A partir do momento $t_{3}$, o Servidor de Eventos fecha sua interface de comunicação, rejeitando qualquer evento que possa chegar e inicia o processamento dos eventos recebidos através da execução do método process(). 
Caso esse processamento gere eventos de resposta, o Servidor de Eventos deve enviá-los até o prazo $t_{4}$, sendo o seu método act() chamado automaticamente, para que os Agentes Musicais possam receber os eventos que ocorrem no ambiente na próxima janela. Se o Servidor de Eventos não necessita enviar eventos de resposta aos Agentes Musicais, pode-se definir o prazo $t_{4} \mathrm{com} o$ mesmo valor do $t_{5}$.

O funcionamento da troca se dá através de máquinas de estado presentes tanto nos Atuadores quanto no Servidor de Eventos. A troca de estado é feita no momento em que um prazo é atingido, através do agendamento de tarefas com o Relógio Virtual. A figura 3.15 mostra o diagrama de estados do Servidor de Eventos e do Atuador.
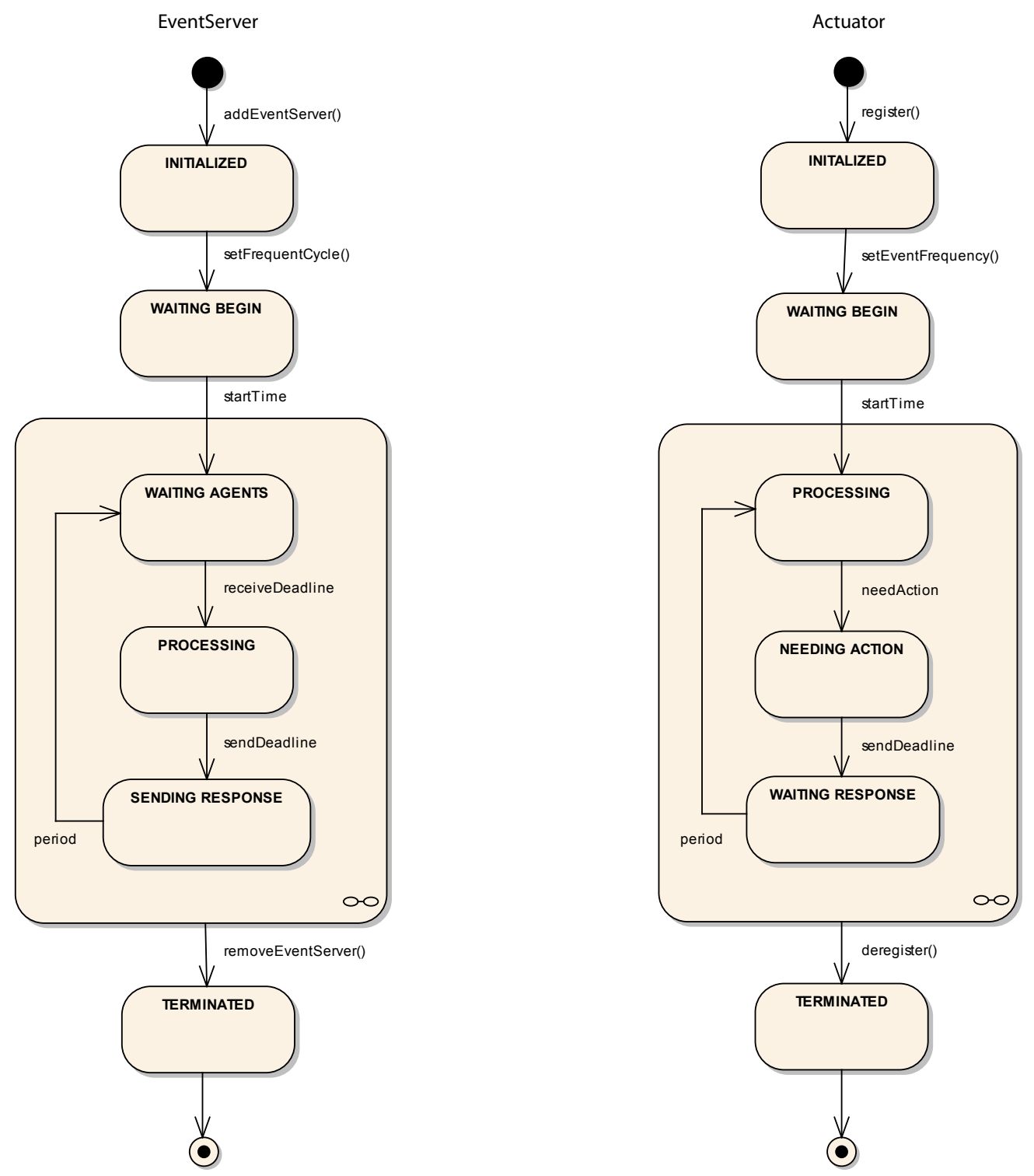

Figura 3.15: Diagrama de estados do Servidor de Eventos e do Atuador na troca de eventos periódicos

O diagrama de sequência da figura 3.16 mostra um ciclo completo de uma troca de eventos periódicos entre um EventServer e um MusicalAgent equipado com um Reasoning, um Actuator e um Sensor, que tratam do mesmo tipo de Evento.

No início de cada janela, existe um período de tempo em que o agente processa qualquer informação que deseja enviar para a próxima janela. Quando o prazo needAction é alcançado, o Actuator executa o método needAction() do Reasoning responsável por escrever na memória do Atuador (ar- 


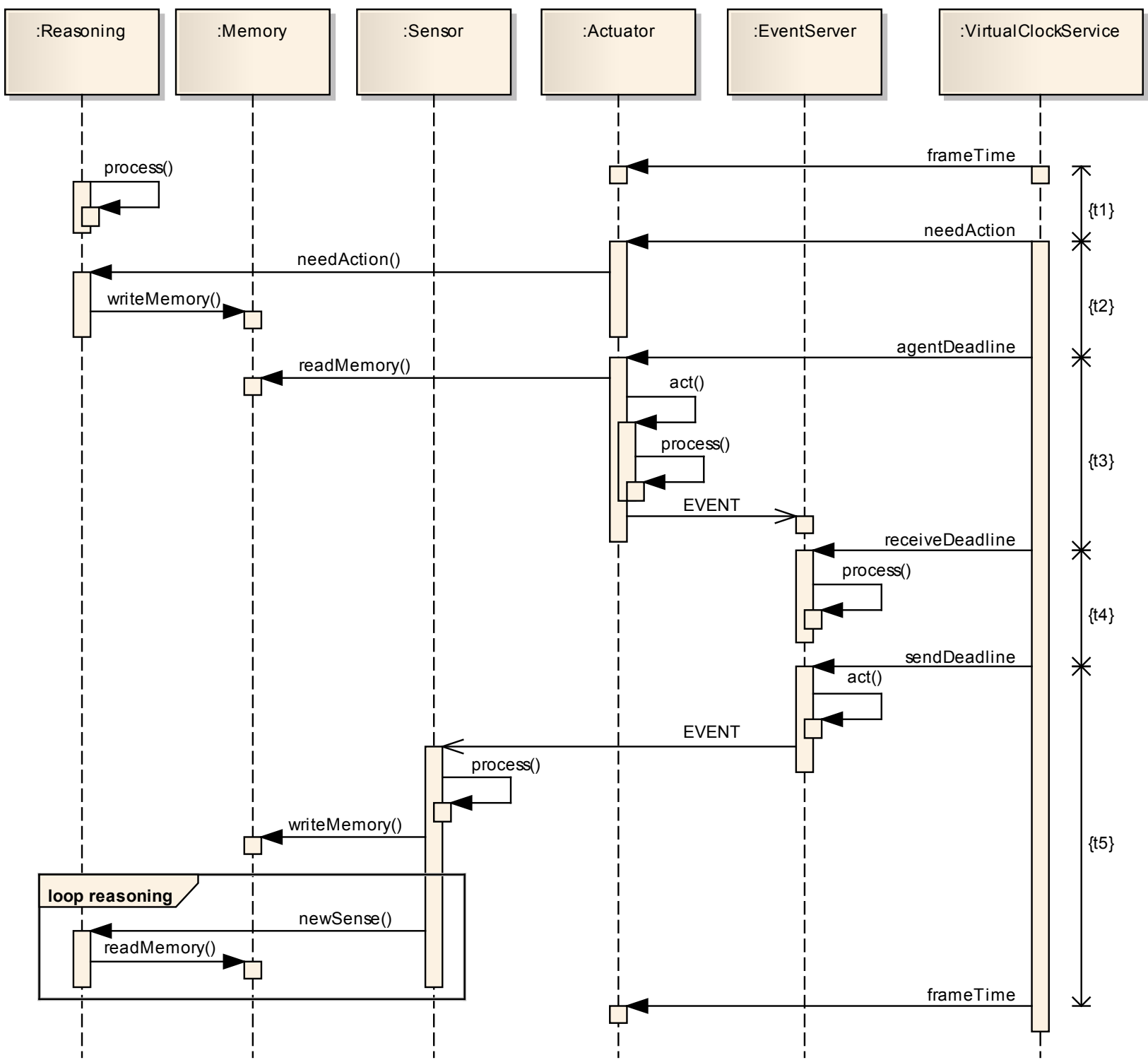

Figura 3.16: Diagrama de sequência de uma troca de eventos periódicos.

mazenada na Base de Conhecimentos) a informação que será enviada. O prazo agentDeadline indica que um Event deve ser enviado através do método act().

O EventServer aguarda a chegada de todos os eventos até o prazo receiveDeadline, quando ele inicia seu método de processamento process(), atualizando o estado do Mundo. Caso existam eventos de resposta a serem enviados aos Sensores registrados, o Servidor de Eventos pode optar por enviá-los um a um à medida que os processa, através do método act(), ou então os armazena em uma fila através do método addOutputEvents(). O prazo para o envio dos eventos de resposta é sendDeadline, momento no qual todos os eventos armazenadas na fila são enviados automaticamente pelo arcabouço.

Quando um Sensor recebe um Evento, ele o armazena em sua respectiva memória na Base de Conhecimento e informa todos os Raciocínios registrados sobre o novo Evento através do método newSense(). Finalmente, em frameTime, um novo ciclo de troca se inicia.

É interessante notar que mudanças no tamanho do fragmento mudam a resposta do sistema, que influi principalmente no caso do sistema multiagente interagir com agentes externos, como um músico. Se o período for muito grande, os agentes demoram mais tempo para responder a um 
evento externo ou ao próprio som gerado por agentes dentro do sistema.

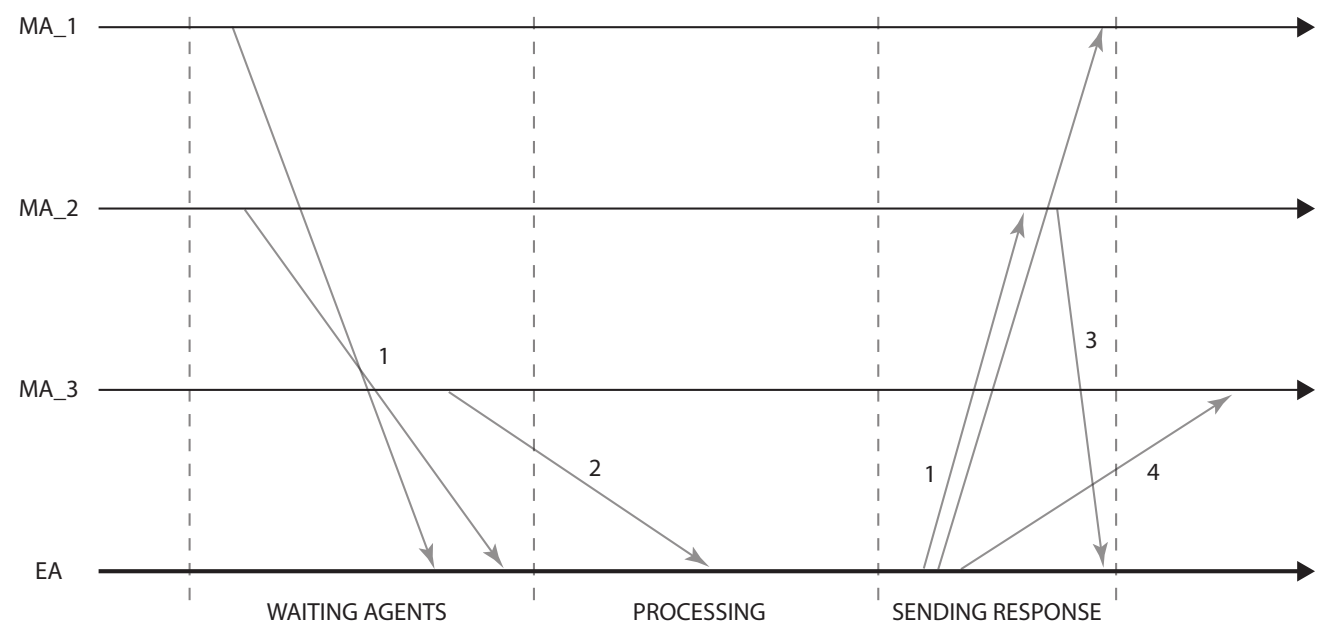

Figura 3.17: Problemas na troca de eventos periódicos

A Figura 3.17 mostra uma troca de eventos entre três Agentes Musicais (MA 1, MA_2 e MA_3) e um Servidor de Eventos (EA) e os problemas que podem surgir caso os prazos não sejam respeitados. Os eventos marcados por 1 estão dentro do funcionamento correto, sendo enviados e chegando dentro do estado correto do Servidor de Eventos. O evento 2, que chega atrasado ao Servidor de Eventos durante o estado de processamento, é descartado. No caso do evento 3, o Agente Musical se antecipa e ele chega ao Servidor de Eventos antes do início da próxima janela, sendo guardado para ser processado. Já no evento 4, a resposta do Ambiente chega atrasada ao Agente Musical, podendo ser utilizada ou descartada.

As causas desses problemas podem ser as seguintes: demora no processamento, fazendo com que o evento seja enviado sem tempo suficiente de chegar no estado correto; latência excessiva no envio, causada por um problema no sistema de comunicação; ou falta de sincronismo entre os estados dos Agente Musical e do Servidor de Evento, uma vez que estes dependem de um relógio global e do mecanismo de agendamento de tarefas da plataforma sendo utilizado, que pode iniciar a execução de uma tarefa antes ou depois do momento correto.

Opcionalmente, caso a plataforma permita, um mecanismo de fallback pode ser incluído para cancelar um processamento que ultrapassou o seu prazo, seja porque o tempo de processamento é grande ou devido a um laço infinito, impedindo que os agentes acumulem tarefas. Esse mecanismo faria com que o agente não participasse da rodada presente, mas permitiria a ele continuar sem problemas na próxima rodada. 


\section{Capítulo 4}

\section{Implementação do Ensemble}

Neste capítulo os pontos mais importantes da implementação da arquitetura são discutidos, baseando-se na arquitetura descrita no capítulo anterior.

A presente implementação do Ensemble foi codificada utilizando a linguagem Java, em sua versão Java SE 6 Update 25 32-bit ${ }^{1}$. Embora as limitações de desempenho e o fraco suporte ao processamento sonoro do Java sejam conhecidos na comunidade, essa escolha foi feita devido à portabilidade oferecida pela linguagem, permitindo que a mesma aplicação musical programada por um usuário seja executada em plataformas distintas.

A arquitetura pressupõe a utilização de um middleware de sistemas multiagentes, como o JADE [BPR99] ou o Saci [HS00], que provê a infra-estrutura necessária para manter o ciclo de vida dos agentes e controlar a troca de mensagens entre eles. Para esta implementação, o middleware JADE, em sua versão $4.0^{2}$ foi escolhido por:

- ser um software gratuito e de código aberto, permitindo a extensão de suas classes e serviços;

- ser bem documentado, com guias de programação e administração, incluindo um livro publicado [BCGC07];

- permitir a execução tanto em sistema local quanto em sistema distribuído;

- ser uma plataforma utilizada em diversos projetos de sistemas multiagentes, com várias extensões já desenvolvidas;

- ser atualizado constantemente pelos seus autores.

O Ensemble utiliza, principalmente, três funcionalidades do JADE para implementar as suas próprias. O serviço de agendamento de tarefas, através dos Behaviours, o mecanismo de troca de mensagem entre os agentes e o serviço de diretório.

No JADE, as tarefas de um agente são executadas através dos Behaviours. Para que o agente execute uma ação, basta criar um objeto da classe Behaviour, implementar o seu método action() e adicioná-lo ao agente através do método addBehaviour(). A execução é iniciada imediatamente e o Behaviour é finalizado quando a execução chegar ao fim do método action(), sendo possível reiniciar o mesmo Behaviour. Cada Behaviour utilizado nessa implementação é uma Thread Java, permitindo assim a simultaneidade de tarefas dentro de um mesmo agente.

\footnotetext{
${ }^{1}$ http://www.oracle.com/technetwork/java/index.html. Este e os demais links foram verificados em 15 de maio de 2011.

${ }^{2}$ http://jade.tilab.com/.
} 
Para a comunicação dos agentes, o JADE disponibiliza um mecanismo para troca de mensagens, gerenciando o conteúdo a ser transmitido e o caminho a ser tomado pela mensagem desde o agente remetente até o destinatário. A troca de mensagens segue as especificações do padrão FIPA, permitindo a interação padronizada com outros sistemas multiagentes [BPR99]. O conteúdo pode ser especificado em um String ou em um vetor de bytes, permitindo ainda a criação de ontologias de forma a especificar uma linguagem de comunicação entre agentes específica para certo domínio. Essa troca pode ser feita entre agentes residindo em uma mesma máquina, ou em um sistema distribuído.

O serviço de diretório $(D S)$ do JADE permite a busca de agentes a partir de seu nome, mesmo que estes residam em outras máquinas em um sistema distribuído. Além disso, é possível que o agente utilize o diretório para registrar um serviço que ele oferece para que os outros agentes, interessados nesse serviço, o encontrem. Na presente implementação do arcabouço, o $D S$ é utilizado para registrar os agentes do sistema, bem como os tipos de evento gerenciados pelo Agente Ambiente e seus Servidores de Evento.

Embora o JADE ofereça essas funcionalidades, importantes para se construir um sistema multiagente, ele foi projetado para ser um sistema multiagente genérico, principalmente voltado para aplicações web e, assim, apresenta algumas limitações. No caso da troca de mensagens entre agentes, o mecanismo utilizado é assíncrono e a recepção é feita através de uma fila (mailbox) sem nenhum tipo de prioridade, o que acrescenta uma latência proibitiva para aplicações que processam áudio. Desta forma, torna-se necessário acrescentar outros mecanismos de troca de mensagens (ver a seção 3.6.3).

\subsection{Memória}

Dois tipos de memórias foram implementadas, baseadas na interface Memory. A figura 4.1 mostra o diagrama de classes das memórias.

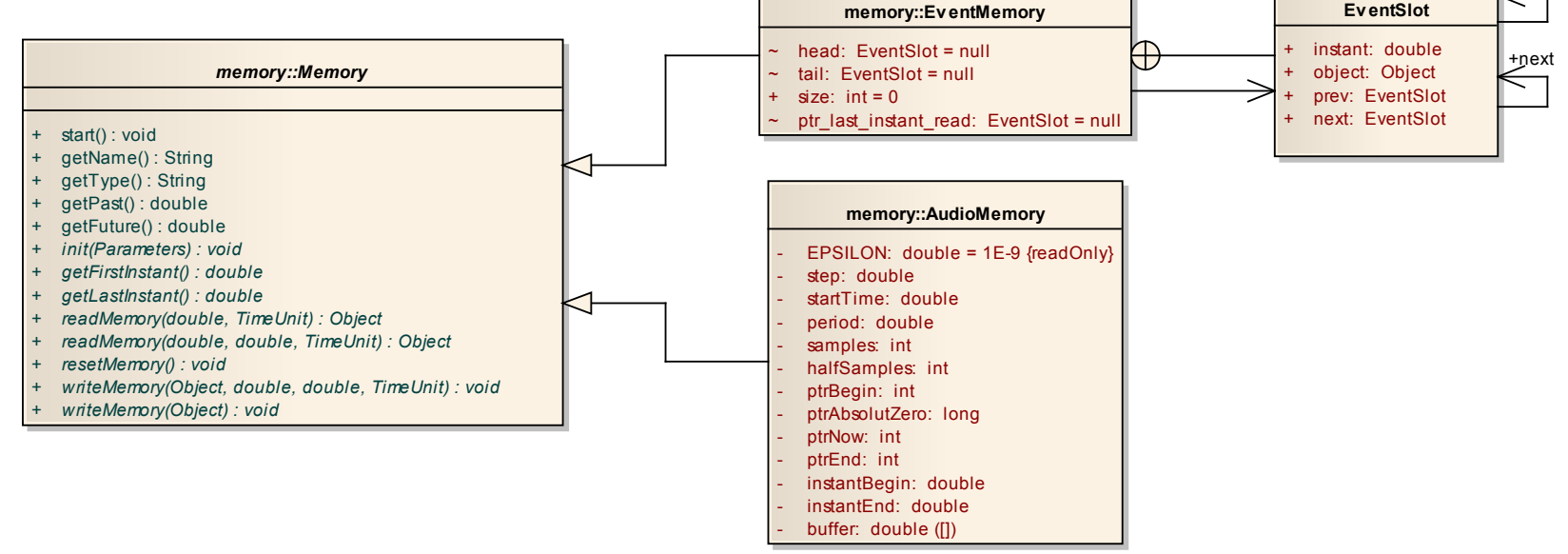

Figura 4.1: Diagrama de classes dos tipos de memória disponiveis no Ensemble

A mais simples é a EventMemory, que armazena objetos do tipo Event em uma lista duplamente ligada, ordenada pelo instante de ocorrência do evento. Ela é uma memória genérica, que não requer periodicidade temporal em suas entradas, e que pode ser usada para armazenar qualquer tipo de informação.

A busca é feita através do método readMemory() que, nesse caso, percorre a lista, de sua cabeça (head) ao seu fim (tail), até encontrar o instante $t_{n}$ solicitado. Caso $t_{n}$ não exista na lista, o método 
retorna o conteúdo do instante existente $t_{n-1}$ imediatamente anterior, considerando que, como não existe o instante buscado, não existiu modificação na memória entre $t_{n}$ e o próximo instante existente $t_{n+1}$.

Como o tempo de busca tende a crescer linearmente com o tamanho da lista, uma heurística simples foi utilizada para melhorar o desempenho em situações comuns. No processamento de áudio ou do movimento (ver as seções 4.2 e 4.3, respectivamente), normalmente o acesso à memória é sequencial, então o último instante buscado é utilizado como ponto de início para os sucessivos acessos (ptr_last_instant_read).

Uma memória especializada em dados de áudio, AudioMemory, foi implementada como um buffer circular de amostras de tipo primitivo double, com uma taxa de amostragem parametrizável pelo usuário. Embora tenha-se uma perda de generalidade, ela permite uma controle mais fino ao acessar seus dados, podendo ser escrita e lida fornecendo-se um instante no tempo ou o índice de uma amostra. Além disso, existe uma economia de memória pois basta armazenar os valores das amostras, e não uma estrutura de dados como os seus eventos.

Uma característica desse tipo de memória é poder ser acessada de forma contínua (usando indíces em ponto-flutuante) pois ela efetua a interpolação de seus valores. A interpolação linear é utilizada como padrão, mas pode-se configurar facilmente o número de pontos a serem utilizados em interpolações polinomiais de grau arbitrário.

Além disso, a memória de áudio é multicanal, ou seja, ela é capaz de armazenar eventos com diversos canais de áudio sincronizados no tempo. Essa característica é essencial no caso da utilização de técnicas de auralização como o Ambisonics (discutido na seção 4.4.3).

Ambas as memórias possuem um mecanismo que as mantêm atualizadas, à medida que o tempo passa, eliminando eventos muito antigos e conservando o espaço reservado na memória do computador pelo usuário ao definir seu horizonte de funcionamento. Essa atualização é executada pelo método updateMemory(), que pode ser configurado para ser executado regularmente, ou somente quando um acesso a memória é feito e um certo intervalo de tempo já passou desde o último acesso.

\subsection{Movimentação do Agente}

Visto que a representação do espaço é um dos pontos principais do trabalho, o Ensemble necessita de um mecanismo que permita aos agentes se locomoverem no mundo virtual. O Servidor de Eventos MovementEventServer é responsável por gerenciar os pedidos de movimentação de um agente, desde que equipados com atuadores de movimento, e atualizar as posições destes no mundo virtual.

Dependendo da definição do Mundo Virtual, os agentes podem usar instruções para mudar instantaneamente sua posição, iniciar um movimento com uma dada velocidade ou, de forma mais realística, definir uma aceleração (como se induzida por uma força física). Fica a cargo do MovementEventServer calcular a trajetória correspondente usando as leis básicas da mecânica (incluindo o atrito entre o atuador e o solo).

Os estados relativos à movimentação de cada agente são armazenados no Mundo Virtual e utilizam uma memória do tipo EventMemory. Os parâmetros de movimento armazenados na memória são posição, velocidade, aceleração, orientação e velocidade angular. Esses parâmetros são objetos do tipo Vector, que armazenam vetores com o mesmo número de dimensões que o definido no Mundo Virtual. 
As instruções oferecidas pelo MovementEventServer estão descritas na tabela 4.1 e são enviadas através de eventos do tipo MovementEvent.

Tabela 4.1: Instruções utilizadas para a interação com Servidor de Eventos de Movimentação

\begin{tabular}{|c|c|c|}
\hline Comando & Parâmetros & Descrição \\
\hline WALK & acc dur & $\begin{array}{l}\text { Desloca o agente, aplicando uma aceleração } a c c \text { du- } \\
\text { rante dur unidades de tempo. }\end{array}$ \\
\hline TURN & vel & $\begin{array}{l}\text { Gira o agente em seu próprio eixo com uma velocidade } \\
\text { angular vel. }\end{array}$ \\
\hline TRANSPORT & pos & $\begin{array}{l}\text { Transporta o agente instantaneamente para a posição } \\
\text { pos do mundo virtual. }\end{array}$ \\
\hline STOP & - & $\begin{array}{l}\text { Interrompe os efeitos dos comandos WALK e TURN, in- } \\
\text { terrompendo o movimento do agente. }\end{array}$ \\
\hline INFO & $\begin{array}{l}\text { [agent] pos vel } \\
\text { acc ori ang }\end{array}$ & $\begin{array}{l}\text { Envia ao agente agent seu estado atual de movimenta- } \\
\text { ção dentro do mundo virtual (pos, vel, acc, ori, ang). }\end{array}$ \\
\hline
\end{tabular}

O Servidor de Eventos, ao receber um evento de movimentação do agente através do método processSense(), deve decidir se é possível ao agente ocupar a nova posição, verificando se existem obstáculos na trajetória do agente, como paredes ou outros agentes, restringindo assim seu movimento.

Caso seja possível, ele recupera o último estado de movimentação do agente e atualiza-o de acordo com o instante de envio do evento através da lei de movimentação. Em seguida, ele modifica o estado baseado na instrução enviada pelo agente, por exemplo, alterando a aceleração do agente, e insere o novo estado na memória do Mundo Virtual.

Para mudar o estado de movimentação de um agente, o servidor utiliza a classe MovementLaw. Se a velocidade ou aceleração forem diferentes de zero, um novo estado é gerado e armazenado na memória do servidor. A lei de movimentação é capaz de aplicar as equações clássicas de movimento uniformemente acelerado e também considera o atrito que a movimentação do agente produz ao se deslocar no mundo. Todos os parâmetros necessários, como a gravidade e os coeficientes de atrito, podem ser configurados na lei de movimentação (a tabela 4.2 indica os parâmetros aceito pelo componente).

Tabela 4.2: Parâmetros aceitos pela lei de movimentação (MovementLaw)

\begin{tabular}{lll}
\hline Parâmetro & Default & Descrição \\
\hline \hline GRAVITY & 9.8 & Valor da gravidade do mundo virtual $\left(\mathrm{em} \mathrm{m} / \mathrm{s}^{2}\right)$ \\
FRICTION_COEFFICIENT & 0 & Coeficiente de atrito dinâmico
\end{tabular}

Agentes que não são dotados de sensores de movimento não conhecem o resultado de suas ações, assim como um robô dotado apenas de esteiras rolantes que, embora as tenha acionado, não sabe se mudou de posição. Existem duas opções nesse caso: ou o agente considera que suas ações obtiveram sucesso e mantém a informação de sua posição, que pode não condizer com a realidade do Ambiente Virtual, ou ele pode ser equipado com um sensor de movimentação, algo como um GPS. 
Nesse último caso, sempre que houver uma modificação no estado de movimentação do agente, o MovementServer envia automaticamente um evento com uma instrução INFO para os sensores de movimentação registrados. Assim, o agente sempre tem a sua correta posição atualizada internamente.

Além dos eventos esporádicos enviados pelos agentes, o servidor atualiza periodicamente todos os estados de movimentação dos agentes. A frequência de atualização pode ser escolhida pelo usuário e depende do tipo de aplicação sendo desenvolvida. Por exemplo, no caso de existir uma interface gráfica que mostra a posição do agente, um período menor ou igual a $100 \mathrm{~ms}$ é desejável para que a movimentação seja percebida de forma contínua.

O servidor também pode ser configurado para enviar mensagens de atualizações de estado para sistemas externos, informando as posições dos agentes e suas atualizações através do comando INFO. Assim, é possível que outros sistemas, como o Pd, possam utilizar essas informações, seja para mostrar os agentes graficamente ou para algum outro tipo de processamento que esteja ligado à posição do agente.

Do lado do Agente Musical, o Ensemble disponibiliza um raciocínio especial MovementReasoning que pode controlar a sua movimentação através de trajetórias pré-definidas. É possível definir os pontos no espaço que devem ser alcançados pelo agente e os limites de tempo que ele deve tentar respeitar para chegar em cada ponto. Também é possível indicar se a movimentação é cíclica, ou seja, se ao chegar no último ponto programado ele pára ou se deve se dirigir ao primeiro ponto, reiniciando a trajetória. Este raciocínio mantém uma fila de waypoints que devem ser atingidos. Para chegar ao próximo ponto, o raciocínio verifica sua posição atual, através da informação colhida pelo sensor de movimentação, e calcula a aceleração que deve ser aplicada, e por quanto tempo, para chegar ao novo ponto. Em seguida, ele envia uma instrução WALK para o servidor, iniciando o deslocamento.

A aceleração máxima de um agente pode ser parametrizada pelo usuário. Assim, em casos em que o limite de tempo para chegar ao próximo ponto é muito pequeno, e a aceleração necessária calculada não é factível, ele irá aplicar a aceleração máxima permitida.

À medida que o agente se movimenta, seu sensor atualiza sua posição e o raciocínio de movimento monitora, de forma periódica, se o agente já atingiu ou passou o seu destino. Caso tenha atingido o destino, dentro de um limite de tolerância também definido pelo usuário, ele envia uma instrução STOP para o servidor, interrompendo o movimento. Se ele passou do ponto, irá calcular uma nova aceleração e enviar uma nova instrução WALK para voltar ao seu destino.

\subsection{Propagação Sonora}

A disponibilização de uma simulação realística e confiável da propagação sonora tridimensional dentro do ambiente virtual é um dos pontos principais no projeto do Ensemble. Assim, cada agente deve escutar exatamente o que ele escutaria em um cenário real, de acordo com as posições de seus sensores e atuadores sonoros no ambiente e suas velocidades e acelerações. Esta simulação é de suma importância quando um projeto sonoro for apresentado em um espaço real de projeção, como uma sala de concerto ou instalação, e a impressão de um espaço sonoro real for desejada.

Existem diversas técnicas computacionais utilizadas para a simulação acústica que podem ser divididas em técnicas geométricas, como o traçado de raios [Kul85] e imagens virtuais [AB79], e técnicas baseadas na resolução numérica da equação de onda [SL01]. A escolha da técnica depende de um compromisso entre o custo de processamento e o realismo, ou seja, quais fenômenos acústicos 
a técnica leva em conta.

Algumas considerações técnicas envolvidas na simulação realística da propagação sonora serão discutidas a seguir. Primeiramente, deve-se mencionar que um som só é percebido em sensores sonoros (e em mais nenhum lugar no espaço), então a simulação da equação de onda em uma grade discretizada representando o espaço seria computacionalmente proibitiva e também inútil na maior parte dos pontos da grade. Assim, a propagação sonora é considerada independente para cada par de sensor/atuador sonoro. Parâmetros globais de simulação, como a velocidade do som e a atenuação devido à distância podem ser alterados pelo usuário.

Na propagação dita realista, o som é codificado como áudio digital, utilizando ponto flutuante de 32 bits (tipo primitivo double), sendo a taxa de amostragem escolhida pelo usuário. Essa taxa pode ser diferente entre os diversos agentes e seus componentes, inclusive a dos eventos sonoros, e pode ser alterada em tempo de execução pelo usuário.

Quando os eventos sonoros são trocados no ambiente, eles são encapsulados em eventos da classe AudioEvent, que contêm os parâmetros da codificação (frequência de amostragem, bits por amostra e número de amostras por fragmento) bem como o fragmento de áudio (um vetor de bytes). A troca de eventos sonoros é do tipo periódico, ou seja, dependendo do tamanho do fragmento de áudio os agentes musicais devem enviar antecipadamente o som que desejam emitir ao ambiente virtual na próxima janela, de forma a permitir um fluxo contínuo de áudio.

Nas seções seguintes, explica-se como é feito o cálculo da propagação sonora dentro do Servidor de Eventos e, em seguida, como funciona a troca de eventos sonoros periódicos dentro do Ambiente Virtual.

\subsubsection{Cálculo da Frente de Onda}

O AudioEventServer executa um processo periódico responsável por calcular e entregar a cada sensor sonoro uma janela de áudio por ciclo (contendo FrameSize amostras), representando todos os sons emitidos pelos atuadores no ambiente que chegam à posição do sensor e considerando que o som se propaga em campo aberto, ou seja, sem reflexões ou difrações. A tabela 4.3 mostra os parâmetros aceitos pelo componente.

Tabela 4.3: Parâmetros aceitos pelo servidor de áudio

\begin{tabular}{|c|c|c|}
\hline Parâmetro & Default & Descrição \\
\hline SPEEED_SOUND & 343.3 & "Velocidade de propagação do som, em m/s. \\
\hline REFERENCE_DISTANCE & 1 & $\begin{array}{l}\text { Distância de referência com relação ao sensor em que o sinal } \\
\text { de áudio não é atenuado (em m). }\end{array}$ \\
\hline ROLLOFF_FACTOR & 1.0 & $\begin{array}{l}\text { Ganho }(<1.0) \text { ou atenuação }(>1.0) \text { aplicado ao som com } \\
\text { relação à atenuação natural baseado na distância da fonte. }\end{array}$ \\
\hline LOOP_HEARING & FALSE & $\begin{array}{l}\text { Indica se o som emitido por um atuador de um agente é } \\
\text { propagado para os sensores do próprio agente. }\end{array}$ \\
\hline POLYNOMIAL_DEGREE & 3 & $\begin{array}{l}\text { Grau do polinômio a ser usado no cálculo do atraso de cada } \\
\text { amostra (0 indica que todos os atrasos serão calculados). }\end{array}$ \\
\hline SAMPLE_RATE & 44100 & Taxa de amostragem utilizada $(\mathrm{em} \mathrm{Hz})$. \\
\hline
\end{tabular}

Como tanto o atuador com o sensor podem estar continuamente em movimento, para cada amostra de áudio em uma janela correspondendo a um instante $t$, o Sensor $S$ tem uma posição 
diferente $S p(t)$, e o mesmo é verdade para cada Atuador sonoro produzindo áudio no ambiente, como mostra a primeira situação da figura 4.2. Considerando que o sensor e o atuador não estão na mesma posição no instante $t$, a onda sonora que chega no sensor foi gerada em algum instante $t_{d}$ no passado, em que o Atuador sonoro estava na posição $A p\left(t_{d}\right)$ com velocidade $A v\left(t_{d}\right)$ como mostra a segunda situação da figura 4.2.
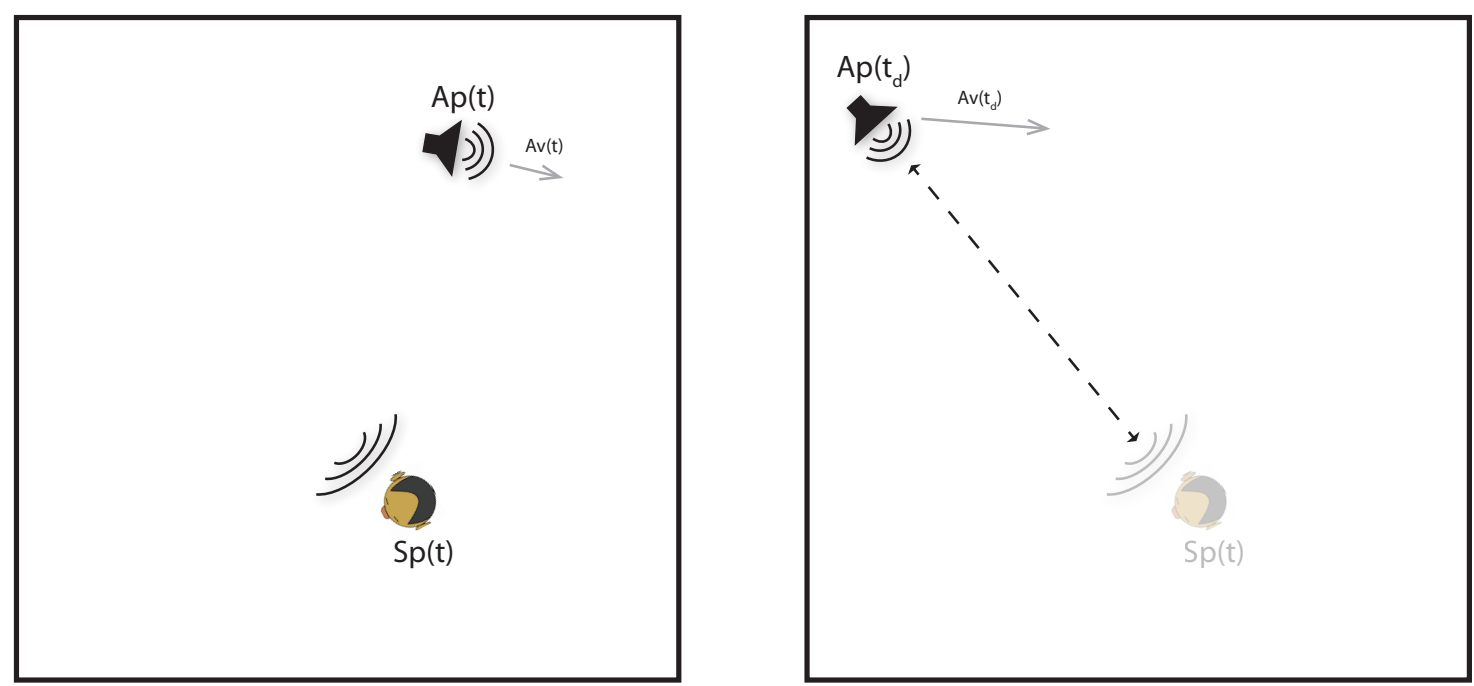

Figura 4.2: Frente de onda sonora em duas situações: momento em que chega no sensor (t) e momento em que foi produzida pelo atuador $\left(t_{d}\right)$

Considerando que o som se propaga em uma linha reta com uma velocidade constante $c_{\text {som }}$, o problema é encontrar esse instante $t_{d}$ no passado de tal forma que o caminho da posição $A p\left(t_{d}\right)$ para $S p(t)$ leva exatamente $t-t_{d}$ unidades de tempo, ou em outras palavras, solucionar a seguinte equação na variável $d$ para cada $t$ dado:

$$
\left\|S p(t)-A p\left(t_{d}\right)\right\|=c_{\text {som }}\left(t-t_{d}\right)
$$

Como as funções $S p(t)$ e $A p(t)$ têm derivadas analíticas simples (de acordo com as equações Newtonianas), o método de Newton-Raphson fornece uma forma rápida para encontrar a solução $t_{d}$ para cada $S, A$ e $t$. Para isto, basta manipular a equação anterior e obter uma função cujo zero deve ser encontrado:

$$
\begin{gathered}
\left\|S p(t)-A p\left(t_{d}\right)\right\|^{2}=\left(c_{\text {som }}\left(t-t_{d}\right)\right)^{2} \\
\phi\left(t_{d}\right)=\left\|S p(t)-A p\left(t_{d}\right)\right\|^{2}-\left(c_{\text {som }}\left(t-t_{d}\right)\right)^{2} \\
\phi^{\prime}\left(t_{d}\right)=2 A v\left(t_{d}\right)\left\|S p(t)-A p\left(t_{d}\right)\right\|-2 c_{\text {som }}\left(t-t_{d}\right)
\end{gathered}
$$

A função $\phi\left(t_{d}\right)$ e sua derivada $\phi^{\prime}\left(t_{d}\right)$ são utilizadas no método de Newton-Raphson. Como chute inicial do método, utiliza-se o atraso entre as posições do atuador e do sensor no instante $t$. Ao encontrar o zero da função $\phi\left(t_{d}\right)$, temos o valor $t_{d}$ procurado. A figura 4.3 ilustra através de um exemplo como esse atraso $\left(t-t_{d}\right)$ varia com relação à distância $\|S p(t)-A p(t)\|$ entre um par Atuador/Sensor. 


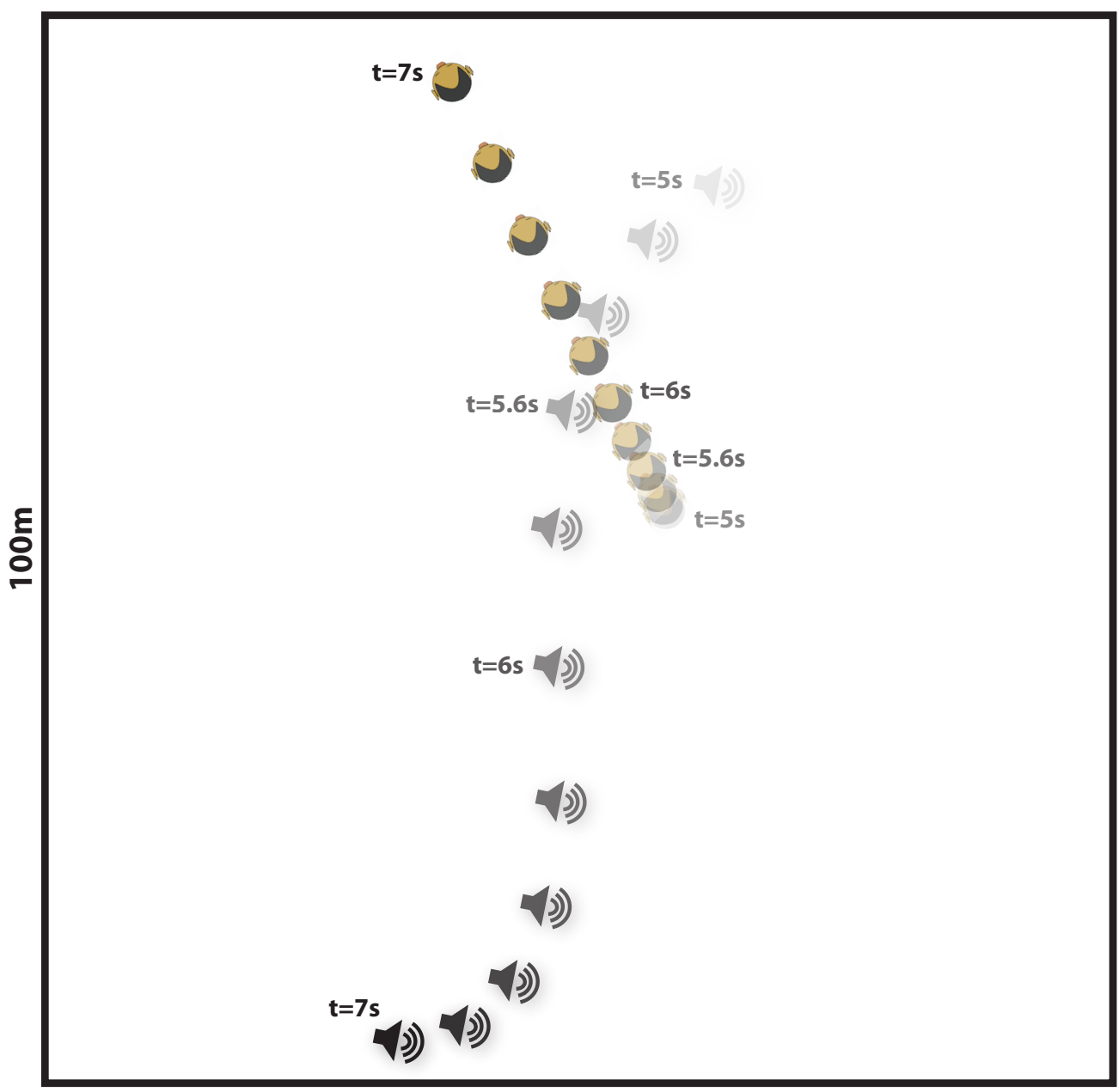

$100 \mathrm{~m}$

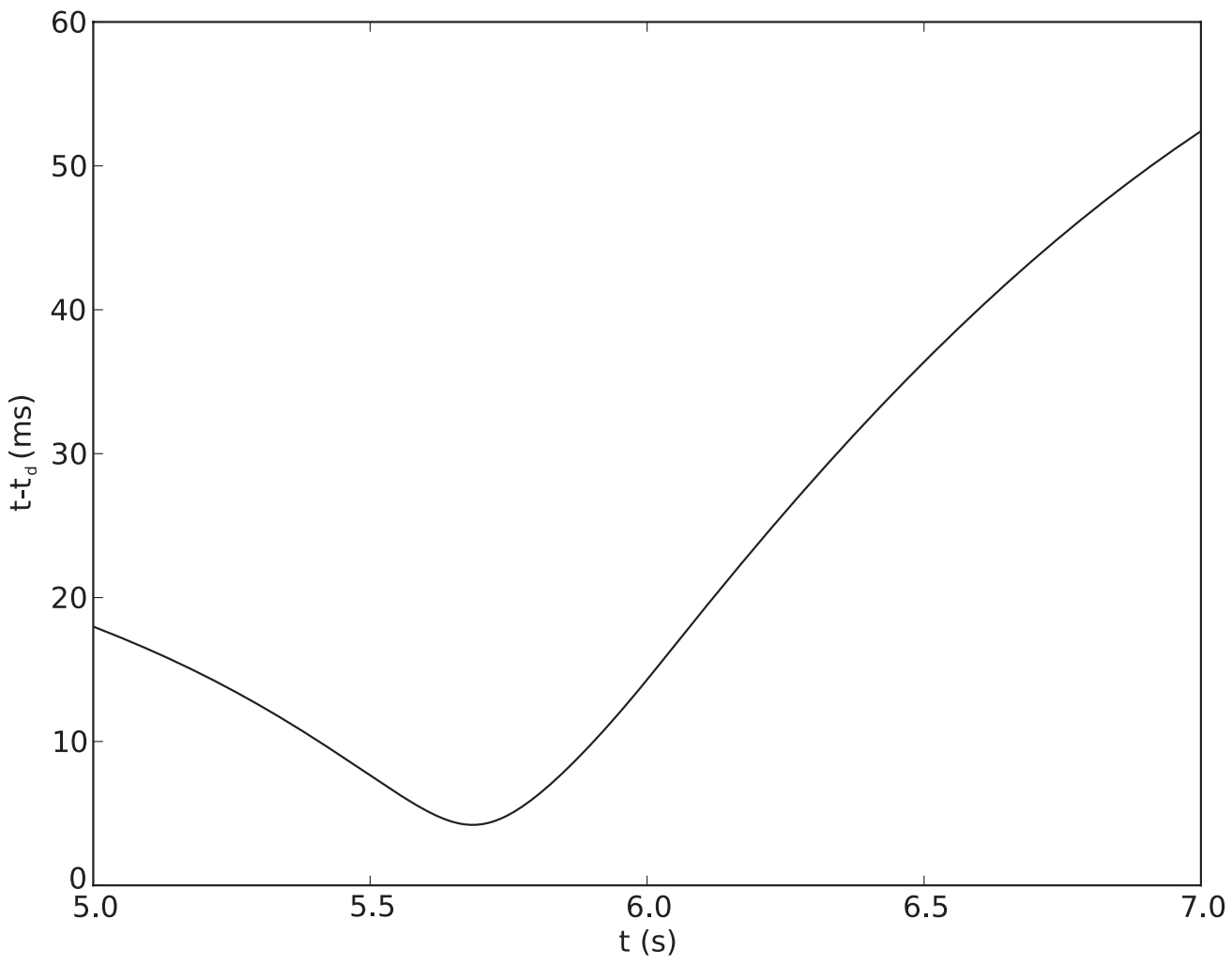

Figura 4.3: Variação do atraso $\left(t-t_{d}\right)$ para um par Atuador/Sensor em movimento 
A solução para o instante $t$ pode ser usada como ponto inicial para encontrar a solução do próximo instante $t+\Delta$, sendo $\Delta$ o valor temporal entre duas amostras, cuja solução $d(t+\Delta)$ provavelmente é próxima de $t_{d}$. Testes experimentais mostraram que, com este chute, o método de Newton-Raphson necessita de aproximadamente quatro iterações para encontrar $t_{d}$ com uma precisão de $10^{-9}$ segundos.

Assim, para cada instante $t$ dessa janela de áudio (a ser entregue para um sensor sonoro em particular), o Servidor de Eventos deve passar por todos os atuadores sonoros presentes no ambiente e descobrir, para cada Atuador $A$ com uma trajetória independente $A p(\cdot)$, em que momento foi produzido o som que chega à posição $S p(t)$ no instante $t$.

Pelas equações anteriores, vê-se que a busca por $t_{d}$ necessita da posição e da velocidade do atuador em diversos instantes. Como visto na seção 4.2, não se armazena os dados de movimentação do agente em todos os instantes, mas sim de acordo com uma taxa definida pelo usuário. Como os valores $t_{d}$ procurados são arbitrários e dependem da busca feita pelo método de Newton-Raphson, deve-se obter na memória de estados de World o primeiro instante disponível anterior a $t_{d}$ e aplicar a mudança de estado através da MovementLaw para o instante desejado.

Alguns problemas podem ocorrer durante a busca, como por exemplo o instante $t_{d}$ não existir mais na memória de eventos do AudioEventServer. Essa situação pode aparecer quando a memória passada é muito curta e/ou o atuador estava muito longe do sensor nesse instante. Nesse caso, o som gerado pelo atuador é ignorado, como se ele estivesse a uma distância tal que suas ondas sonoras chegassem com intensidade praticamente nula.

Uma vez encontrados os valores de $t_{d}$ para todos os instantes $t$ da janela em questão, deve-se calcular a atenuação do sinal causada pela distância da fonte sonora. A atenuação $g(t)$ devida à distância obedece a lei do inverso da distância (por se tratar da pressão sonora, e não da intensidade sonora) e depende simplesmente da distância entre o atuador no instante $t_{d}$ e o sensor no instante $t$. Observe que são considerados dois instantes distintos: o instante em que o som foi gerado no Atuador e o instante em que foi recebido no Sensor.

Como os valores utilizados pelo Ensemble para fazer o cálculo da distância são adimensionais, deve-se utilizar uma distância de referência parametrizável $(R D)$. Para distâncias entre o atuador e a fonte menores que esse valor, o sensor sonoro não experimenta atenuação alguma. Além disso, é possível controlar o nível de atenuação por distância através do parâmetro RF (Roll-off Factor), cujo valor padrão igual a 1 respeita a lei original $(1 / r)$ :

$$
g(t)=\min \left\{1.0, \frac{R D}{R D+\left(R F\left(c_{s o m}\left(t-t_{d}\right)-R D\right)\right)}\right\}
$$

Finalmente, pode-se calcular o som que chega em um sensor $S$ para uma certa janela, que é a mistura dos sinais emitidos pelos $K$ atuadores presentes no ambiente cujos atrasos $t_{d}$ foram calculados para cada $t$ da janela:

$$
S x(t)=\sum_{k=1}^{K} g_{k}(t) * A_{k} x\left(t-t_{d}\right)
$$

Apesar da eficiência do método de Newton-Raphson, é importante frisar que esse problema 
deve ser resolvido para cada amostra de cada sensor sonoro $S$ e cada atuador sonoro $A$, totalizando (\#Sensors) * (\#Actuators $) *($ FrameSize $)$ chamadas ao método.

Por exemplo, em um contexto bem simples com apenas dois sensores e dois atuadores utilizandose um tamanho de janela de $100 \mathrm{~ms}$ com uma taxa de amostragem de $44.1 \mathrm{kHz}$ (FrameSize igual a 4410 amostras), seriam necessárias 17640 chamadas ao método e em torno de 70560 iterações para completar cada ciclo de processamento, o que daria menos de 1,5 $\mu$ s de tempo de processamento para cada iteração, apenas para a propagação sonora. À medida que o número de sensores e atuadores aumenta, a chance do Servidor de Eventos perder o seu prazo de processamento pode ser uma ameaça para a sincronização do sistema.

Para minimizar o problema, um método de interpolação polinomial combinado com o método de Newton-Raphson é utilizado. Essa abordagem encontra os valores precisos de $t_{d}$ para a primeira e a última amostra de cada janela e para o número necessário de pontos espaçados igualmente na janela, de acordo com o grau do polinômio escolhido. Em seguida, interpola-se esses pontos utilizando o algoritmo de Neville para encontrar os $t_{d}$ aproximados das amostras restantes.

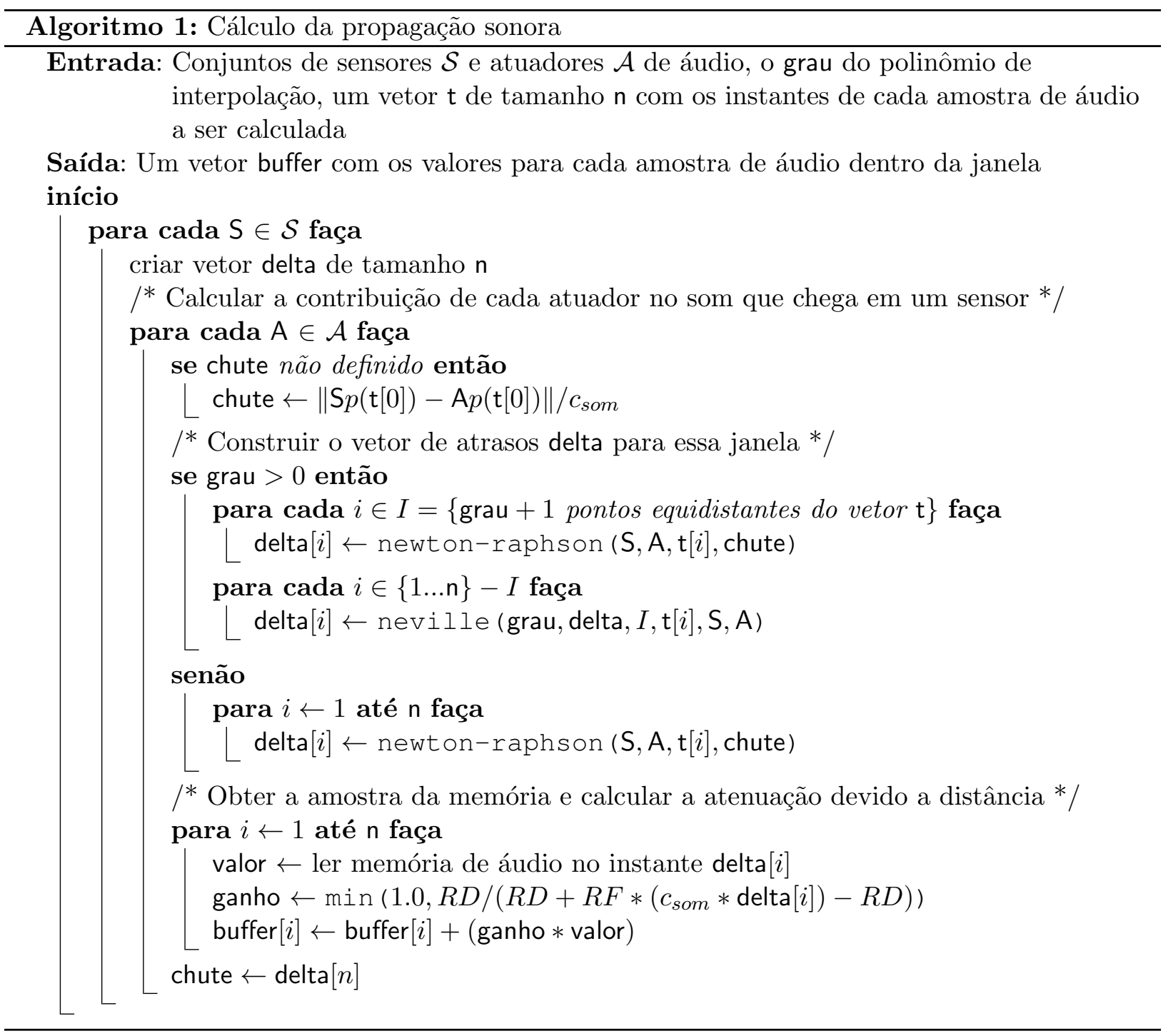

O algoritmo utilizado no processamento para encontrar todas as contribuições sonoras de todos os pares sensor-atuador para todas as amostras de uma janela é mostrado no algoritmo 1. O método de Newton-Raphson necessita das funções $\phi\left(t_{d}\right)$ e $\phi^{\prime}\left(t_{d}\right)$, que por sua vez, necessitam buscar no 
estado do mundo a posição do Sensor e a posição e velocidade de um Atuador em um determinado instante $t$.

A complexidade do algoritmo de Newton-Raphson [BB87], considerando uma boa aproximação inicial, é $O((\log (d)) F(d))$, sendo $F(d)$ o custo para calcular $\phi\left(t_{d}\right) / \phi^{\prime}\left(t_{d}\right)$ com uma precisão de $d$ dígitos, e do algoritmo de Neville é $O\left(m^{2}\right)$, sendo $m$ o grau do polinômio mais um, ou seja, o número de pontos a serem interpolados (nesta implementação, o método de Newton-Raphson utiliza uma precisão de 6 dígitos e o chute inicial é próximo da solução).

No algoritmo 1, caso se utilize a interpolação, o número de execuções das funções newton-raphson e neville depende do grau do polinômio escolhido, que, como veremos a seguir, não necessita ser maior que 3, assim podemos considerar a complexidade constante $O(1)$. Da mesma forma, consideramos o cálculo das funções $\phi(t)$ e $\phi^{\prime}(t)$, que busca a posição do agente, como $O(1)$ devido à heurística utilizada (discutida na seção 4.2).

Finalmente, chega-se à conclusão que a complexidade depende principalmente do número de sensores e atuadores e do número de amostras dentro de uma janela (que, por sua vez, depende do período da janela e da frequência de amostragem sendo utilizada). Assim, os laços internos conferem um limite assintótico de $\Theta(\|A s\| *\|S s\| *$ FrameSize $)$ ao algoritmo.

Teste experimentais com uma janela de 100 ms mostraram que a interpolação quadrática (3 pontos por janela) provê valores de $t_{d}$ com uma precisão maior que $10^{-5}$ segundos, o que corresponde a uma precisão sub-amostral, mesmo quando os sensores e atuadores mudam suas acelerações dentro da janela considerada. A interpolação cúbica (4 pontos por janela) diminui o erro para $10^{-8}$ segundos ou 0.000441 em termos do índice da amostra.

É interessante notar que essa abordagem corresponde a uma simulação da propagação sonora realística que inclui o efeito Doppler, uma vez que os valores $t_{d}$ dependem dos valores de posição e velocidade dos sensores e atuadores, que podem mudar constantemente. Assim, pares de sensores/atuadores que estão se aproximando têm suas frentes de ondas comprimidas e os que estão se distânciando têm suas frentes expandidas. Alterações na frequência são consequências diretas da definição de $t_{d}$ dada acima.

Como cada agente pode ter múltiplos sensores posicionados em diferentes pontos do seu corpo virtual, uma onda sonora tem diferentes instantes de chegada para cada Sensor. Isso permite o uso de agentes ouvintes com múltiplos sensores que capturam um ambiente sonoro tridimensional e o enviam para interfaces de áudio multi-canais. Isso também permite que raciocínios usem essas múltiplas entradas para identificar a posição de fontes sonoras, para separação das fontes, etc.

\subsubsection{Troca de Eventos de Áudio}

De acordo com Laplante [Lap04], podemos classificar a troca de áudio entre os agentes como tempo real soft, uma vez que a perda do prazo por parte dos agentes em entregar um fragmento de áudio não tem consequências catastróficas. Essa perda acarreta um período de tempo em que o agente fica mudo. Já a perda do prazo por parte do agente Ambiente é mais grave, pois seria como se todos os agentes ficassem mudos durante uma janela de áudio. A seguir, discute-se como é feita a troca de eventos de áudio entre um Agente Musical e o Servidor de Eventos de som.

O Raciocínio do Agente Musical responsável por gerar o som é ativado pelas requisições (needAction()) feitas pelo seu Atuador de som. Ao executar este método, o raciocínio deve armazenar na memória (do tipo AudioMemory) do atuador sonoro o buffer de áudio que ele deseja enviar. O atuador recupera os dados e cria um novo evento sonoro AudioEvent, com o fragmento e os 
parâmetros da codificação de áudio, e o envia ao ambiente. Os agentes devem fornecer ao ambiente um fragmento de áudio correspondente ao próximo período de tempo que será ouvido no ambiente; assim, o sistema multiagente está sempre processando no presente um fragmento que será ouvido no futuro, o que introduz um atraso correspondente ao tamanho dos fragmentos de áudio utilizados.

À medida que o AudioEventServer recebe eventos sonoros através do método processSense(), ele armazena na memória do Mundo (também do tipo AudioMemory) a informação sonora dos fragmentos de áudio recebidos referentes a uma janela de áudio em um determinado período de tempo. Assim, posteriormente, é possível recuperar os dados sonoros enviados por um certo atuador sonoro em um certo instante.

Quando o prazo para envio dos fragmentos é atingido (receiveDeadline), o método de processamento é executado (process()) e qualquer evento sonoro que chegue a partir desse instante é automaticamente descartado. O processamento consiste em calcular, para cada sensor sonoro registrado no Ambiente, a contribuição sonora de cada atuador que emitiu som para a janela sendo processada. Para cada par sensor/atuador, o cálculo da propagação da onda sonora é feito através do algoritmo descrito na seção 4.3.1, obtendo o valor de todas as amostras.

No caso do sensor e atuador estarem no mesmo agente, pode-se parametrizar o servidor de eventos para descartar esse par, considerando que o agente sabe o que está emitindo. Alternativamente, pode-se fazer uma cópia direta dos valores, como se ele ouvisse internamente sem atraso algum, ou então permitir a propagação sonora usual, considerando a distância entre o atuador e o sensor no mesmo corpo.

Após a obtenção do sinal misturado que será recebido por um certo sensor, um novo AudioEvent é criado com os valores obtidos, sendo armazenado na lista de eventos a serem enviados, processo este repetido para cada sensor. Ao atingir o prazo para envio dos eventos de resposta (sendDeadline), o servidor de eventos os envia automaticamente.

\subsection{Interfaces Externas}

O Ensemble foi desenvolvido de forma a permitir implementações flexíveis de aplicações multiagentes musicais, com a intenção de generalizar exemplos encontrados na literatura. Mesmo assim, a interface do arcabouço com sistemas externos é benéfica por várias razões: incrementa-se o número de funcionalidades disponíveis do Ensemble, permite-se a reutilização de código e aumenta-se o conforto do usuário, permitindo que parte da aplicação seja desenvolvida utilizando-se uma linguagem ou ambiente de sua escolha.

Esta seção discute como o Ensemble é capaz de se relacionar com o exterior, como bibliotecas especializadas, sistemas genéricos de processamento de som, usuários e ambientes de escuta/captura reais.

\subsubsection{Interface com Bibliotecas Externas}

Seguindo a filosofia do Ensemble, seu usuário deve se preocupar com o projeto de sua aplicação musical, e não com detalhes como a implementação de uma transformada rápida de Fourier ou de um filtro digital. Assim, a interface com bibliotecas de processamento externas, principalmente de áudio digital, nas quais essas funções básicas já foram implementadas e testadas, é essencial para facilitar o uso desse tipo de arcabouço. 
O Ensemble dispõe de um mecanismo simples do ponto de vista do usuário para utilizar essas funções de processamento, através do uso do padrão de programação AbstractFactory. Ele garante que diversas bibliotecas possam ser incorporadas ao arcabouço, à medida que forem necessárias, disponibilizando um grande número de funções e de opções de implementação de cada função.

A figura 4.4 mostra o diagrama de classes do processamento com bibliotecas externas. Como simplificação, apenas uma função de processamento (FFT) é representada.

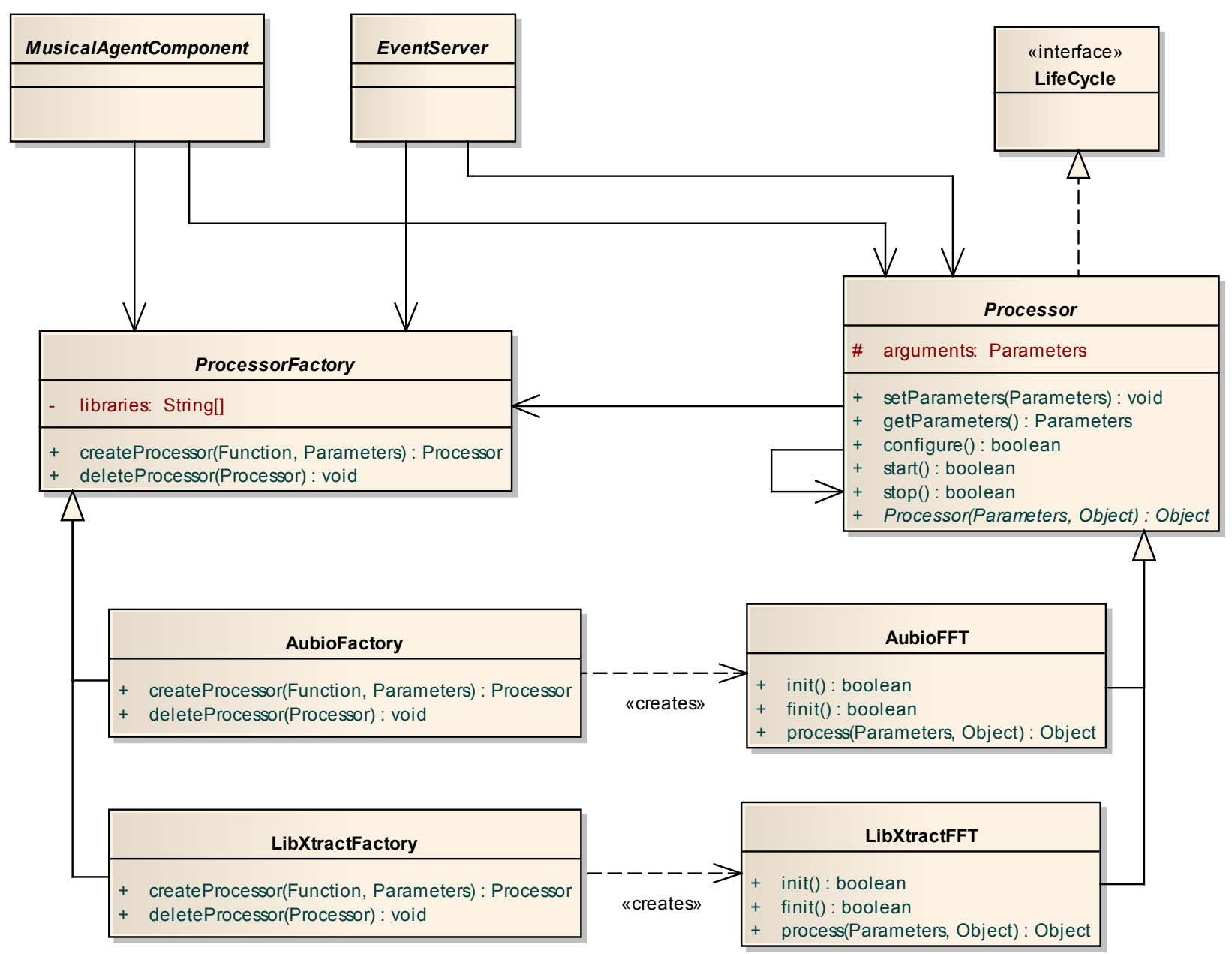

Figura 4.4: Diagrama de classes do processamento através de bibliotecas externas

Um MusicalAgentComponent ou EventServer que deseje usar uma função de biblioteca deve utilizar a fábrica de objetos ProcessFactory através do método createProcessor(), informando o tipo de função desejada (como FFT) e quaisquer parâmetros necessários para a inicialização dessa função (como o tamanho da janela em amostras e o tipo de janelamento do sinal). Opcionalmente, ele pode indicar de qual biblioteca específica ele quer que a função seja utilizada.

Em seguida, caso exista alguma biblioteca com a função disponível, a fábrica irá solicitar a criação de um processador Processor para a fábrica específica da biblioteca em questão, que será repassado ao objeto que o solicitou. Este, por sua vez, irá acessar a função de processamento através do método process(), passando como argumento quaisquer parâmetros necessários para a execução da função e um objeto com o conjunto de dados de entrada, e recebendo um outro objeto com o conjunto de dados processados.

Uma instância do processador pode ser usada durante todo o tempo de vida do componente que o criou, evitando assim que vários processadores sejam criados. Finalmente, ao fim da vida do 
componente, deve-se utilizar o método deleteProcessor() da fábrica para que qualquer finalização necessária, como a liberação da memória, seja feita.

Duas bibliotecas externas de processamento de áudio foram incorporadas ao Ensemble: aubio [Bro06] e LibXtract [BC07]. A biblioteca aubio contém funções de processamento de sinais, como filtros, enquanto a libXtract é mais focada na extração de características do som. Estas bibliotecas estão livremente disponíveis na rede mundial ${ }^{3}$.

$\mathrm{Na}$ figura 4.4, como exemplo, existem duas fábricas das bibliotecas aubio e libXtract, AubioFactory e LibXtractFactory respectivamente. Como as duas bibliotecas oferecem a função FFT, cada uma é responsável por criar o seu objeto de processamento FFT, AubioFFT e LibXtractFFT respectivamente.

Para incluir uma biblioteca no Ensemble, deve-se primeiramente criar uma classe que realize a classe abstrata ProcessFactory e indique todos as funções disponíveis na biblioteca. Em seguida, para cada uma dessa funções, deve-se criar um classe que implemente a interface Processor, cujos objetos serão criados pela fábrica.

Caso a biblioteca não esteja disponível na linguagem Java, o que geralmente é o caso, existe um trabalho extra para criar uma interface que irá ligar o código Java do arcabouço e o código nativo, através da Java Native Interface (JNI). Recomenda-se que versões compiladas dessas interfaces sejam geradas para os três sistemas operacionais mais comuns utilizados por usuários da área de computação musical (MS-Windows, MacOS e Linux), mantendo a portabilidade das bibliotecas.

Tabela 4.4: Comandos utilizados para a interação com Servidor de Eventos de Movimentação

\begin{tabular}{|c|c|}
\hline Função & Descrição \\
\hline BEAT_TRACKING & Detecção de batimentos musicais. \\
\hline $\mathrm{FFT}$ & $\begin{array}{l}\text { Transformada rápida de Fourier, função essencial no proces- } \\
\text { samento de áudio para análise do espectro. }\end{array}$ \\
\hline FEATURE_EXTRACTION & $\begin{array}{l}\text { Extração de características do som, como rms, loudness, kur- } \\
\text { tosis, smoothness etc. (ver [BC07]). }\end{array}$ \\
\hline FILTER_FIR & Filtro digital que utiliza uma resposta ao impulso finita. \\
\hline FILTER_IIR & Filtro digital que utiliza uma resposta ao impulso infinita. \\
\hline RESAMP LE & Conversão de taxa de amostragem. \\
\hline ONSET_DETECTION & $\begin{array}{l}\text { Detecção do ínicio de um som, importante para a definição } \\
\text { de padrões rítmicos. }\end{array}$ \\
\hline PHASE_VOCODER & $\begin{array}{l}\text { Ferramenta para análise e síntese sonora, permitindo mu- } \\
\text { danças de escala no domínio do tempo e da frequência. }\end{array}$ \\
\hline PITCH_DETECTION & Detecção de alturas. \\
\hline
\end{tabular}

As funções implementadas até o momento, baseadas nas bibliotecas aubio e LibXtract, estão listadas nas tabela 4.4 .

\subsubsection{Interface com Sistemas Externos}

A interface do Ensemble com sistemas externos é feita através da troca de mensagens de controle utilizando o protocolo OSC. Também é possível fazer a troca de áudio com sistemas externos,

\footnotetext{
${ }^{3}$ http://aubio.org/ e http://libxtract.sourceforge.net/.
} 
que será detalhada na seção seguinte.

O Open Sound Control (OSC) [WF97] é um protocolo de troca de mensagens especializado em aplicações musicais, atualmente utilizado por uma grande parte dos softwares musicais (Pure Data, CSound, LogicPro, Max/MSP, SuperCollider, Ardour, entre outros). O mecanismo de roteamento do arcabouço também pode ser usado para enviar e receber mensagens OSC.

A figura 4.5 mostra um exemplo de um patch do Pure Data que se comunica com o Ensemble utilizando o protocolo OSC. Dois objetos $\mathrm{Pd}^{4}$ são necessários para a comunicação acontecer: dumpOSC, usado para receber as mensagens OSC, e sendOSC, usado para enviar mensagens. Essas mensagens em formato texto devem ser analisadas, através do objeto OSCroute, e interpretadas pelo patch de acordo com a aplicação do usuário.

Foi implementado um external do $\mathrm{Pd}$, ensemble_gui, que funciona como uma representação gráfica do mundo virtual e interface de usuário. Através da interface, o usuário é capaz de ver os agentes e interagir com estes, enviando mensagens de controle para o arcabouço. Também é possível posicionar seu avatar dentro do ambiente virtual para escutar através de fones de ouvidos uma versão binaural da simulação.

Esse patch processa comandos do tipo INFO enviados pelo MovementEventServer que atualizam a interface gráfica e envia comandos do tipo TRANSPORT, caso o usuário altere a posição de algum agente. A figura também ilustra alguns exemplos de comandos que podem ser enviados ao Ensemble para criar/destruir agentes ou adicionar sensores sonoros, tudo isso em tempo de execução.

Um outro exemplo de uso do OSC para controlar o Ensemble é através de sua integração com o Swarm Orchestra [BNF08]. Este sistema é capaz de gerar complexos padrões de movimentação para seus grupos de agentes. As posições de cada agente são enviadas via OSC, com uma frequência configurável, e podem ser capturadas pelo arcabouço, atualizando a posição dos Agentes Musicais.

\subsubsection{Interface com Espaços de Escuta e Captura Reais}

A utilização do Ensemble não faria sentido se não fosse possível ao usuário, através de algum meio, escutar os eventos sonoros que ocorrem dentro do ambiente virtual durante a simulação. Interfaces gráficas podem ser utilizadas para ver a movimentação dos agentes, como discutido acima, enquanto que técnicas de processamento de imagem mais avançadas poderiam ser consideradas para renderizar representações espaciais do mundo virtual. Mas fazer com que o som saia do ambiente virtual é o objetivo mais importante quando se projeta uma aplicação multiagentes musical.

Da mesma forma, inserir áudio no ambiente virtual é essencial quando o sistema está interagindo com músicos executando um instrumento ou outras fontes sonoras reais. Assim, deve existir uma forma de capturar o som gerado no ambiente externo (através de microfones ou de ligações diretas na interface de áudio) e propagá-lo através de atuadores sonoros dentro do ambiente virtual, onde um agente musical terá o papel de mapear a fonte sonora real.

Uma consequência da abordagem de troca de eventos periódicos é a existência de um atraso na inserção do som no Ensemble, ilustrado na figura 4.6. Além do atraso introduzido pela interface de áudio $\Delta l a t_{i n}$, ao transferir as amostras para o buffer de entrada, no início do processamento de um atuador sonoro em $t_{2}$ (workingFrame 2), ele só pode garantir que o som capturado está disponível até esse instante, ou seja, o som que foi gerado entre $t_{1}$ e $t_{2}$. Como esse fragmento de áudio

\footnotetext{
${ }^{4}$ que fazem parte do pacote Pd-extended, disponível em http://puredata.info.
} 


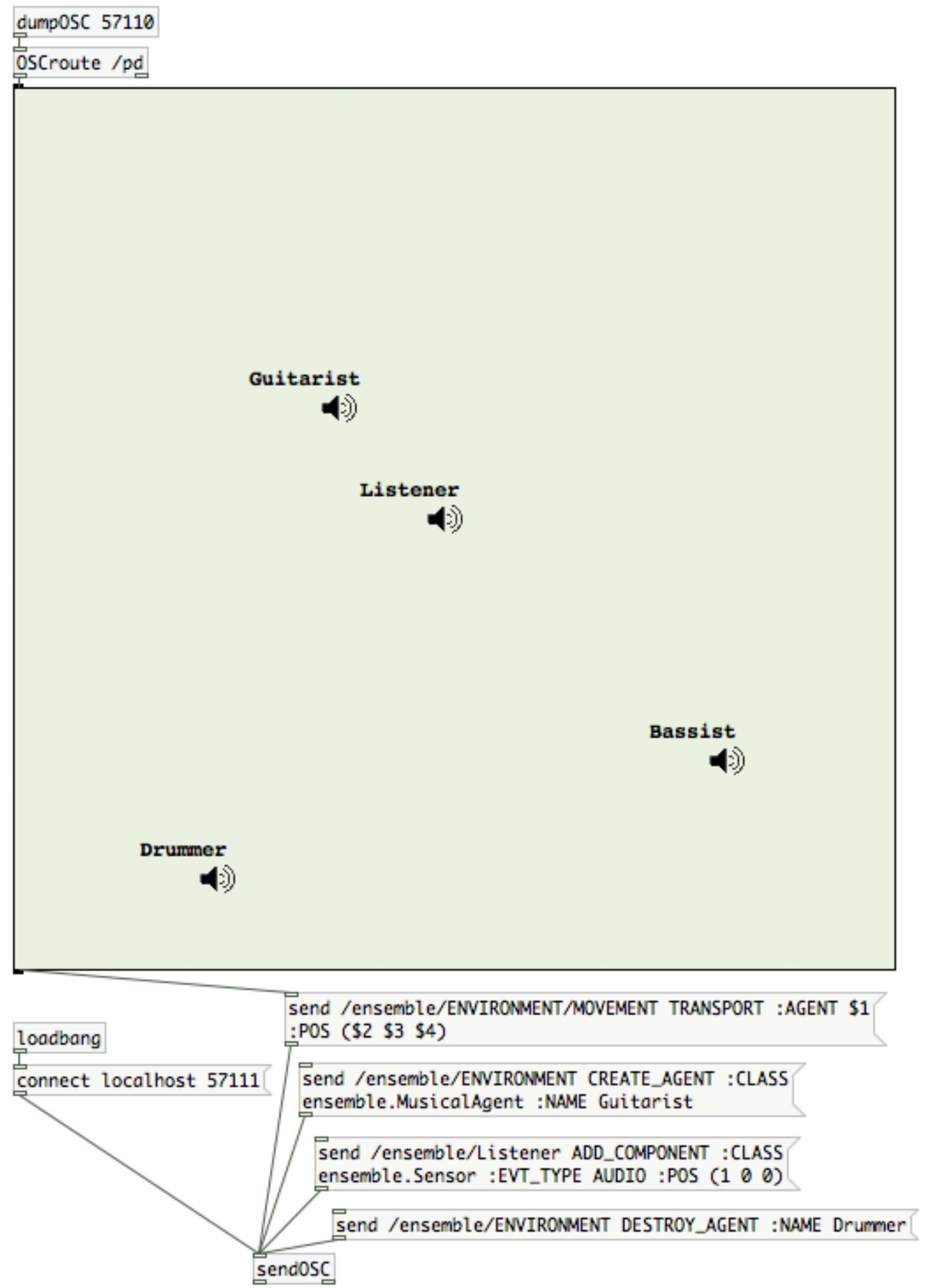

Figura 4.5: Interação entre o Pd e o Ensemble através do protocolo OSC 
será propagado pelo Ambiente durante a working frame 2, ele estará disponível para os sensores sonoros no instante até $t_{3}$, assim o fragmento corresponde ao que se escuta no ambiente durante a working frame 3, introduzindo duas janelas de áudio de atraso. No caso da reprodução, como o fragmento já está disponível, apenas o atraso de saída da interface de áudio ( $\Delta l a t_{\text {out }}$ ) é introduzido. Considera-se que o tamanho do buffer da biblioteca de áudio é muito menor que o período da janela.

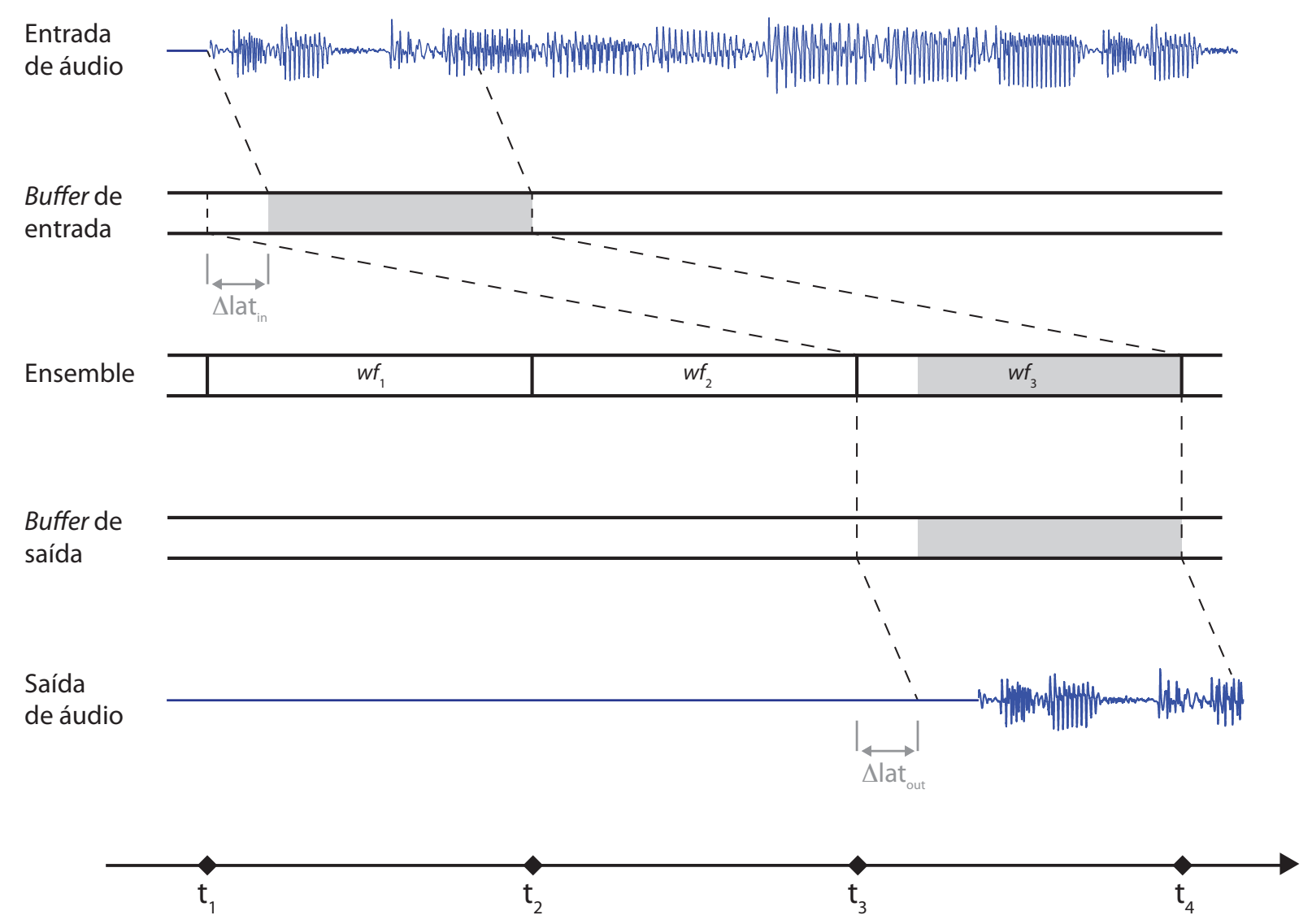

Figura 4.6: Atraso na captura e na reprodução de áudio no Ensemble

Foram implementadas três formas de direcionar o som para as interfaces de áudio do computador, cada qual com suas vantagens e desvantagens, utilizando bibliotecas distintas: o JavaSound, o PortAudio e o Jack. Elas são implementados através de raciocínios que podem ser incluídos em agentes ouvintes, ou avatares. Módulos especiais são usados por esses raciocínios para fazer a interface entre o Ensemble e as bibliotecas nativas.

Cada forma dispõe de dois raciocínios, um para entrada e outro para saída de áudio, que funcionam basicamente da mesma forma. Basta agregar o raciocínio ao agente musical, e configurar a conexão de um sensor sonoro com um canal de áudio. Por exemplo, em um agente com duas "orelhas", basta incluir um raciocínio de saída e indicar que a orelha esquerda está ligada ao canal de áudio esquerdo, e a direita com o canal direito.

A forma mais simples é a utilização do JavaSound, uma biblioteca de áudio disponível em todas as implementações da máquina virtual Java e que faz parte do Java Media Framework ${ }^{5}$ (raciocínios JavaInputReasoning e JavaOutputReasoning). Embora de fácil utilização e disponível em qualquer máquina virtual Java, o JavaSound não permite um controle temporal preciso sobre os fragmentos de áudio que são enviados ou recebidos da interface. Um outro problema é que o JavaSound não

\footnotetext{
${ }^{5}$ http://www.oracle.com/technetwork/java/javase/tech/index-jsp-140239.html.
} 
tem suporte multicanal, o que inviabiliza seu uso no caso de montagens de auralizações com mais de dois canais de áudio, como por exemplo a quadrafônica ou montagens mais avançadas baseadas em Ambisonics [Tho07].

Para contornar essas limitações, a biblioteca PortAudio ${ }^{6}$ [BB01] foi escolhida para oferecer uma segunda forma de acesso à interface de áudio, devido a sua portabilidade e flexibilidade, permitindo um controle fino na sincronia das janelas de áudio, através de funções de callback, e também o uso de múltiplos canais da(s) interface(s) de áudio. O PortAudio pode ser acessado através dos raciocínios PAInputReasoning e PAOutputReasoning.

As duas formas anteriores permitem apenas o acesso aos canais de uma interface de áudio, mas não permitem que um programa externo gere áudio e o introduza no Ensemble, e vice-versa. Essa funcionalidade é essencial para que um programa externo seja utilizado de forma efetiva com o Ensemble, permitindo a troca de áudio entre programas, além da troca de mensagens textuais.

Para solucionar essa demanda, utilizou-se a biblioteca Jack $^{7}$, uma plataforma para entrada e saída de áudio em tempo real, com baixa latência. O Jack funciona em cima de outras bibliotecas de áudio nativas do sistema operacional sendo utilizado, inclusive o PortAudio. Assim, ele oferece as mesmas vantagens do PortAudio com relação ao JavaSound. Os raciocínios JackInputReasoning e JackOutputReasoning implementam a interface com o Jack.

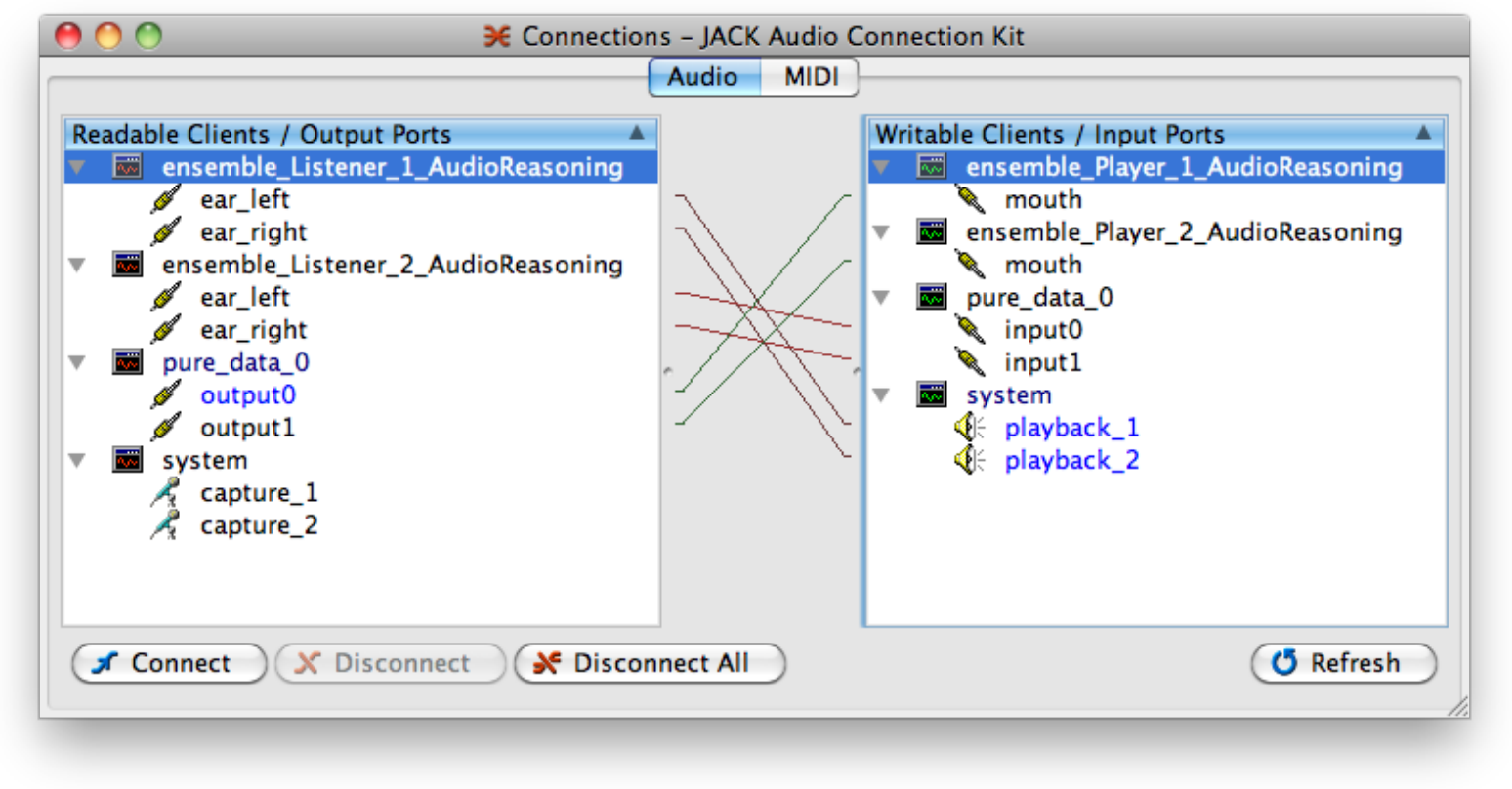

Figura 4.7: Interface entre o Ensemble, o Pd e a interface de áudio feita através do Jack

Com o Jack é possível fazer o roteamento de sinais de áudio entre aplicações que o suportem e entre os canais da interface de áudio. A figura 4.7 mostra um exemplo com os canais de saída do Pd conectados como entrada no Ensemble, diretamente em uma "boca" de um agente, e a "orelha" de um outro agente avatar conectada em uma saída da interface de áudio.

Para conectar um raciocínio a um canal ou outro sistema basta configurar o raciocínio no arquivo de configuração da simulação ou fazer as conexões em tempo de execução, através da in-

\footnotetext{
${ }^{6}$ http://www.portaudio.com/.

${ }^{7}$ http://jackaudio.org.
} 
terface gráfica do Jack. A figura 4.7 mostra uma situação em que existem quatro agentes dentro do ambiente virtual, sendo dois agentes reprodutores (Player_1 e Player_2, capazes de emitir som no ambiente através de atuadores sonoros mouth), e dois agentes ouvintes (Listener_1 e Listener_2, dotados de dois sensores sonoros ear).

A saída de um canal do Pd foi conectada ao Player_1, assim o som produzido na aplicação está sendo reproduzido dentro do ambiente através desse agente. Um canal de entrada, por exemplo um microfone conectado à interface de áudio, foi direcionado para o outro agente reprodutor Player_2. Os agentes ouvintes recebem esses sons, devidamente propagados pelo ambiente de acordo com as posições dos agentes, e redirecionam a saída de volta ao $\mathrm{Pd}$ (Listener_1) e diretamente para os alto-falantes (Listener_2).

O uso das duas bibliotecas, PortAudio e Jack, exigem interfaces de código feitas em JNI, o que significa que as bibliotecas e estas interfaces devem ser compiladas em cada sistema operacional. Na presente implementação, duas interfaces foram desenvolvidas (jportaudio e jjack) e compiladas para os três sistemas operacionais.

Utilizando-se as bibliotecas descritas anteriormente, é possível direcionar o áudio que está sendo escutado por um agente diretamente para uma caixa de som, o que equivale a dizer que o altofalante é o avatar e não a pessoa que o está ouvindo. Embora essa utilização possa dar origem a alguns efeitos interessantes, como, por exemplo, o som gerado por um agente em movimento entre duas caixas ser mais agudo em uma caixa e mais grave na outra devido ao efeito Doppler, o campo sonoro que está sendo recriado não é verossímil do ponto de vista do usuário avatar, diminuindo sua experiência de escuta.

Para poder solucionar esse problema e possibilitar a criação de campos sonoros mais reais, utilizou-se a técnica de auralização Ambisonics [Ger73, MM95]. Esta técnica utiliza o conhecimento das posições das fontes sonoras e do ouvinte para poder codificar a onda sonora recebida em diversos canais que correspondem aos eixos de escuta com relação ao ouvinte, como se microfones com padrão de captura figura-8 estivessem nele posicionados ortogonalmente. Em seguida, um decodificador processa estes canais através de uma matriz de ganhos para uma certa configuração de alto-falantes, recriando o campo sonoro. Um aspecto interessante desta técnica é o total desacoplamente entre a codificacão do sinal e a matriz de alto-falantes que será utilizada para a reprodução, permitindo sua utilização em diversas situações.

A partir de trabalhos anteriores na área [Tho07], incorporou-se ao Servidor de Eventos de áudio um codificador Ambisonics de terceira ordem, que é capaz de codificar o sinal recebido por um sensor de áudio. No momento do registro do sensor, basta que este solicite o envio de canais ambisonics codificados através do parâmetro AMBISONICS, indicando a ordem desejada. Também foi criado um raciocínio (AmbisonicsOutputReasoning) capaz de decodificar esses canais em diversas configurações de alto-falantes, inclusive tridimensional, como mostra a figura 4.8.

Finalmente, além das opções de transmissão de áudio citadas anteriormente, também é possível que arquivos de áudio sejam utilizados como entrada e saída do sistema através do raciocínio AudioFileReasoning. Com esse componente, pode-se controlar a leitura e escrita de arquivos de áudio não compactados (no formato WAVE), direcionando sua entrada/saída para um sensor/atuador. No processamento em lote, essa é a única opção disponível para capturar e reproduzir sons no ambiente. 


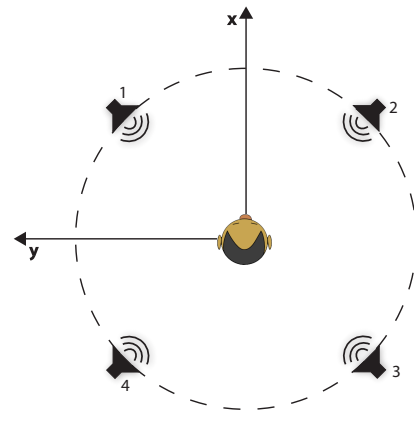

Quadrado

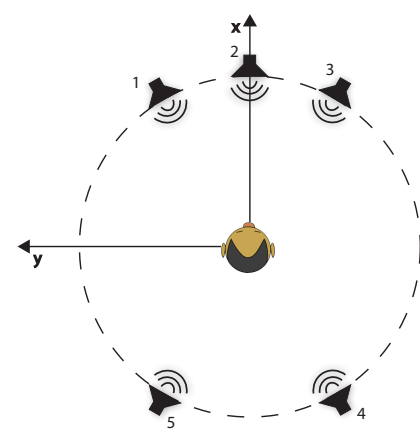

Surround

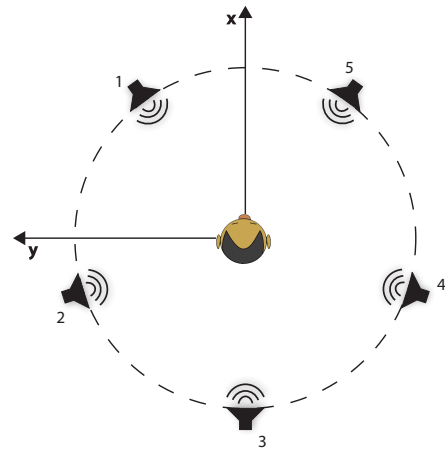

Pentágono

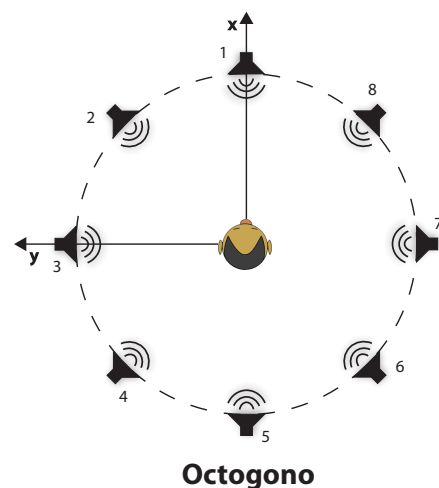

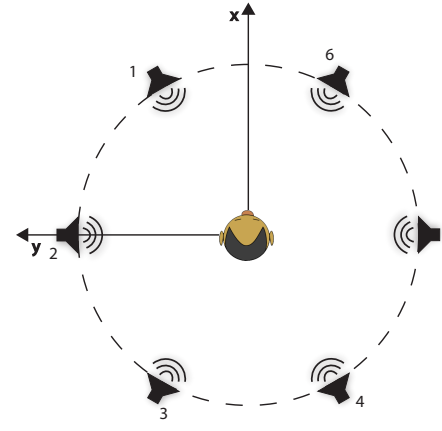

Hexágono

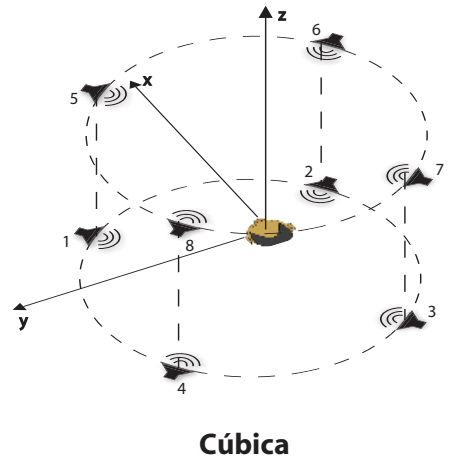

Figura 4.8: Configurações de alto-falantes disponíveis para a recriação de campo sonoro através de Ambisonics

\subsubsection{Interface de controle}

Uma interface gráfica Sniffer, mostrada na figura 4.9, foi concebida para controlar o sistema e monitorar seu estado atual, de forma similar ao agente Sniffer disponível no JADE. A interface permite o envio de mensagens customizadas para um determinado componente do sistema, a criação e destruição de agentes musicais, e a inserção e remoção de componentes e de servidores de eventos. Além disso, é possível visualizar todos os agentes e componentes registrados, e seus estados internos, bem como alterar qualquer um de seus parâmetros.

\subsection{Análises Experimentais}

Testes experimentais foram conduzidos no Ensemble de forma a verificar o desempenho do sistema e o seu limite operacional. Neste contexto, os dois pontos mais sensíveis são a troca de eventos periódicos e o processamento necessário para a simulação da propagação sonora. Nas seções seguintes são detalhados os testes conduzidos e seus resultados são discutidos.

Todos os experimentos foram realizados em um computador MacBook Pro com um processador 2.7 GHz Intel Core 2 Duo e 4 GB de memória, rodando o sistema operacional Mac OS X 10.6 e utilizando a máquina virtual Java HotSpot 64-Bit Server VM, versão 19.1-b02-334.

\subsubsection{Troca de Eventos Periódicos}

A troca de eventos periódicos depende da sincronia entre os Atuadores e Servidores de Eventos envolvidos (processo descrito na seção 3.6.5.2). Caso algum problema aconteça, como a sobrecarga do processamento ao tratar um evento ou a lentidão na sua entrega, a sincronia é perdida e os 


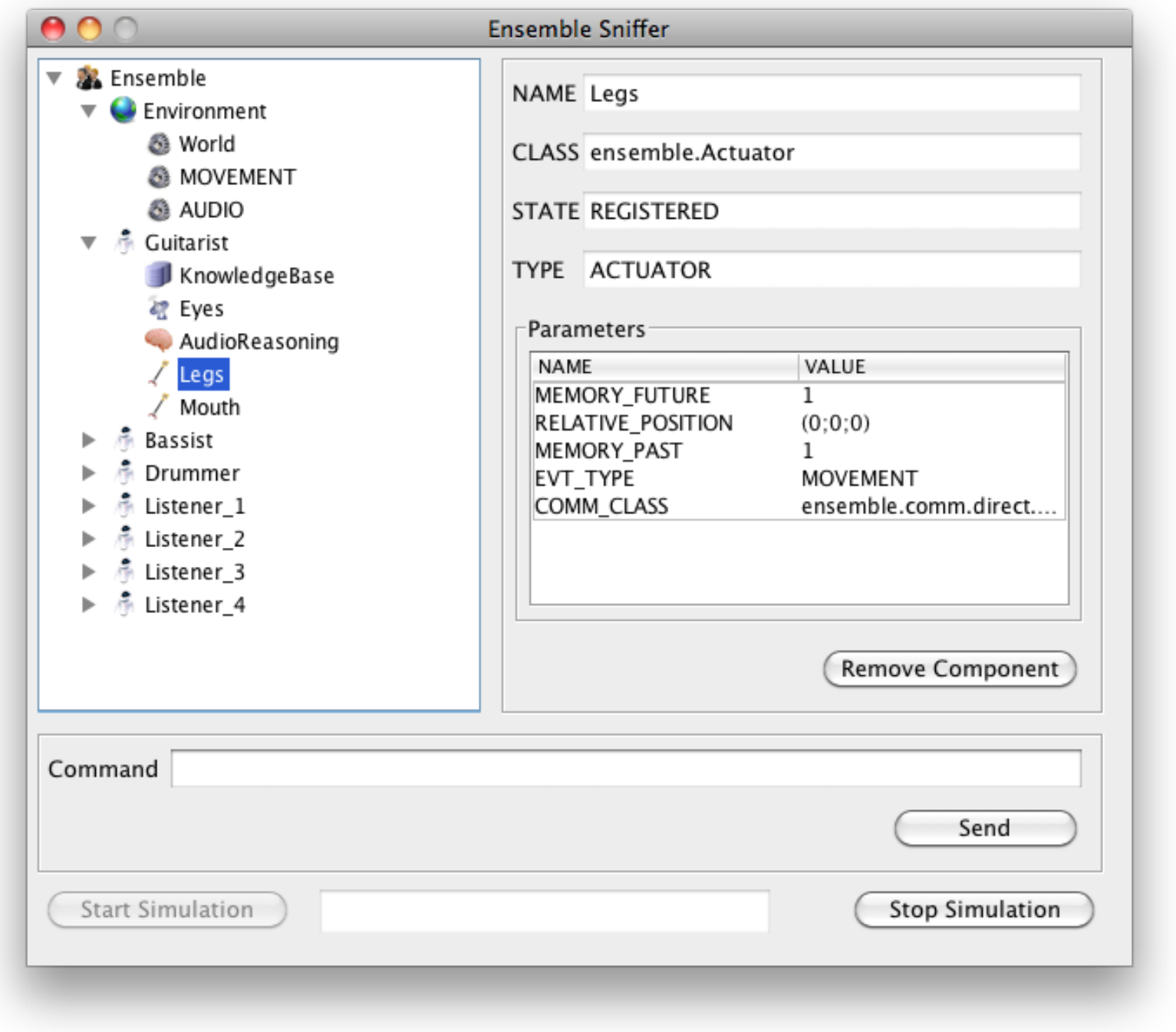

Figura 4.9: Interface de controle gráfica do Ensemble

eventos são descartados. Assim, é importante para o usuário saber quais são os limites no número de Atuadores e na frequência a ser utilizada em uma troca de eventos.

Para avaliar o desempenho do sistema, testes com uma versão preliminar do arcabouço foram feitos para estimar a taxa de eventos perdidos [TQ09]. Nesse experimento, variou-se o número de agentes envolvidos e o número de amostras em fragmentos de áudio durante a execução de 25 segundos de áudio. A Tabela 4.5 mostra a porcentagem de eventos sonoros, enviados pelos Agentes Musicais, que foram recebidos pelo Servidor de Eventos para cada combinação de número de agentes e amostras em um fragmento. Os resultados que aparecem com asteriscos foram aqueles em que o sistema, devido ao processamento excessivo, não foi capaz de manter o sincronismo e enviar uma taxa constante de áudio para a interface de áudio.

Os resultados obtidos mostram uma queda no desempenho à medida que o número de agentes aumenta e o tamanho da janela diminui. A partir destes resultados, gargalos no processamento foram identificados e melhorias foram incorporadas ao Ensemble, que serão descritas na seção 6.1. Em seguida, um novo teste foi concebido para estimar a nova taxa de eventos perdidos.

Neste experimento, o Agente Musical utilizado é composto apenas de um par Sensor/Atuador e um Raciocínio responsável por enviar um evento a cada solicitação do método needAction(). Ne- 
Tabela 4.5: Taxa de sucesso no envio de eventos sonoros pelos Agentes Musicais

\begin{tabular}{cccccccc}
\hline & & \multicolumn{7}{c}{ Número de Agentes Musicais } \\
\cline { 3 - 8 } Amostras & Período & $\mathbf{1}$ & $\mathbf{5}$ & $\mathbf{1 0}$ & $\mathbf{2 5}$ & $\mathbf{5 0}$ & $\mathbf{1 0 0}$ \\
\hline \hline 22050 & $500 \mathrm{~ms}$ & $100,0 \%$ & $100,0 \%$ & $100,0 \%$ & $100,0 \%$ & $98,3 \%$ & $76,7 \%$ \\
11025 & $250 \mathrm{~ms}$ & $100,0 \%$ & $100,0 \%$ & $100,0 \%$ & $96,9 \%$ & $75,3 \%$ & $*$ \\
4096 & $90 \mathrm{~ms}$ & $100,0 \%$ & $100,0 \%$ & $99,9 \%$ & $86,2 \%$ & $*$ & $*$ \\
1024 & $23 \mathrm{~ms}$ & $100,0 \%$ & $100,0 \%$ & $92,9 \%$ & $*$ & $*$ & $*$ \\
512 & $11 \mathrm{~ms}$ & $100,0 \%$ & $100,0 \%$ & $66,5 \%$ & $*$ & $*$ & $*$ \\
256 & $5 \mathrm{~ms}$ & $100,0 \%$ & $90,0 \%$ & $*$ & $*$ & $*$ & $*$ \\
\hline
\end{tabular}

nhum tipo de processamento foi feito no Agente Musical ou no Servidor de Eventos, assim o tempo gasto estava limitado ao tempo de envio e recebimento de eventos.

Os eventos enviados pelos Atuadores, ao chegarem no Servidor de Eventos, eram armazenados na memória do Servidor e, chegado o prazo correspondente, eram reenviados cada qual para o Sensor do Agente de origem. Assim, pode-se perder eventos tanto no envio pelo Agente Musical como no envio pelo Servidor de Eventos. Considerou-se que um evento foi transmitido com sucesso se ele conseguia fazer o percurso de ida e volta.

A intenção deste experimento é mostrar os limites de desempenho do sistema no caso da troca de eventos periódicos, considerando uma certa divisão de tempo de processamento entre Agentes Musicais e o Ambiente. Assim, o usuário, conhecendo os requisitos computacionais (em tempo de processamento) tanto dos processos internos dos Agentes Musicais como dos Servidores de Eventos periódicos envolvidos na sua aplicação, pode ter de antemão uma limite máximo tanto para o período da janela como para o número de agentes que poderão participar em sua simulação.

No experimento, variou-se o número de agentes envolvidos (de 1 a 500 agentes) e o período da troca de eventos (em 10, 25, 50, 75, 100, 250, 500, 750 e 1000 milissegundos). Além disso, variou-se também o tempo disponível para o processamento no Agente Musical, ou seja, a fração de um período completo do Servidor destinada ao processamento e envio do evento por parte do Agente Musical (de 10\% a $90 \%$ do tempo total, em passos de 10\%).

Os resultados podem ser visto na figura 4.10. Os gráficos em escala de cinza representam a taxa de eventos recebidos com sucesso, sendo que o branco representa $100 \%$ e o preto $0 \%$. Para a construção destes gráficos, os valores obtidos no experimento foram interpolados linearmente.

Como esperado, o desempenho do sistema diminui quanto maior o número de Agentes, uma vez que o número de processos aumenta e, consequentemente, aumenta a demanda por tempo de processamento e memória.

A escolha do período do Servidor de Eventos, ou equivalentemente do tamanho do fragmento de áudio, determina o intervalo de tempo disponível para os agentes gerarem seus eventos e para o ambiente processá-los, propagando-os no ambiente. Essa escolha é essencial no caso da troca de eventos de áudio, pois o tamanho da janela influi diretamente na latência do sistema, que será percebida por um ouvinte e, principalmente, por um músico que esteja tocando junto com o sistema.

A diminuição do tamanho da janela também aumenta a taxa de perda de eventos, pois o tempo disponível para o processamento por parte dos Agentes Musicais e do Agente Ambiente se torna muito pequeno. Como a resolução temporal utilizada na implementação do Ensemble é da ordem de milissegundos e os prazos de envio de eventos são muito próximos, a falta de precisão temporal acaba por fazer com que alguns atuadores percam o prazo para o envio do evento. Janelas maiores 


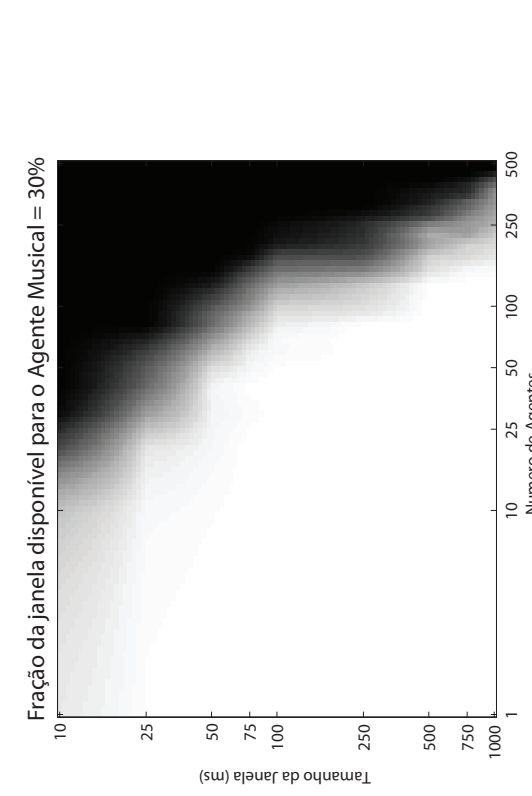

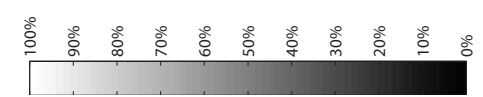
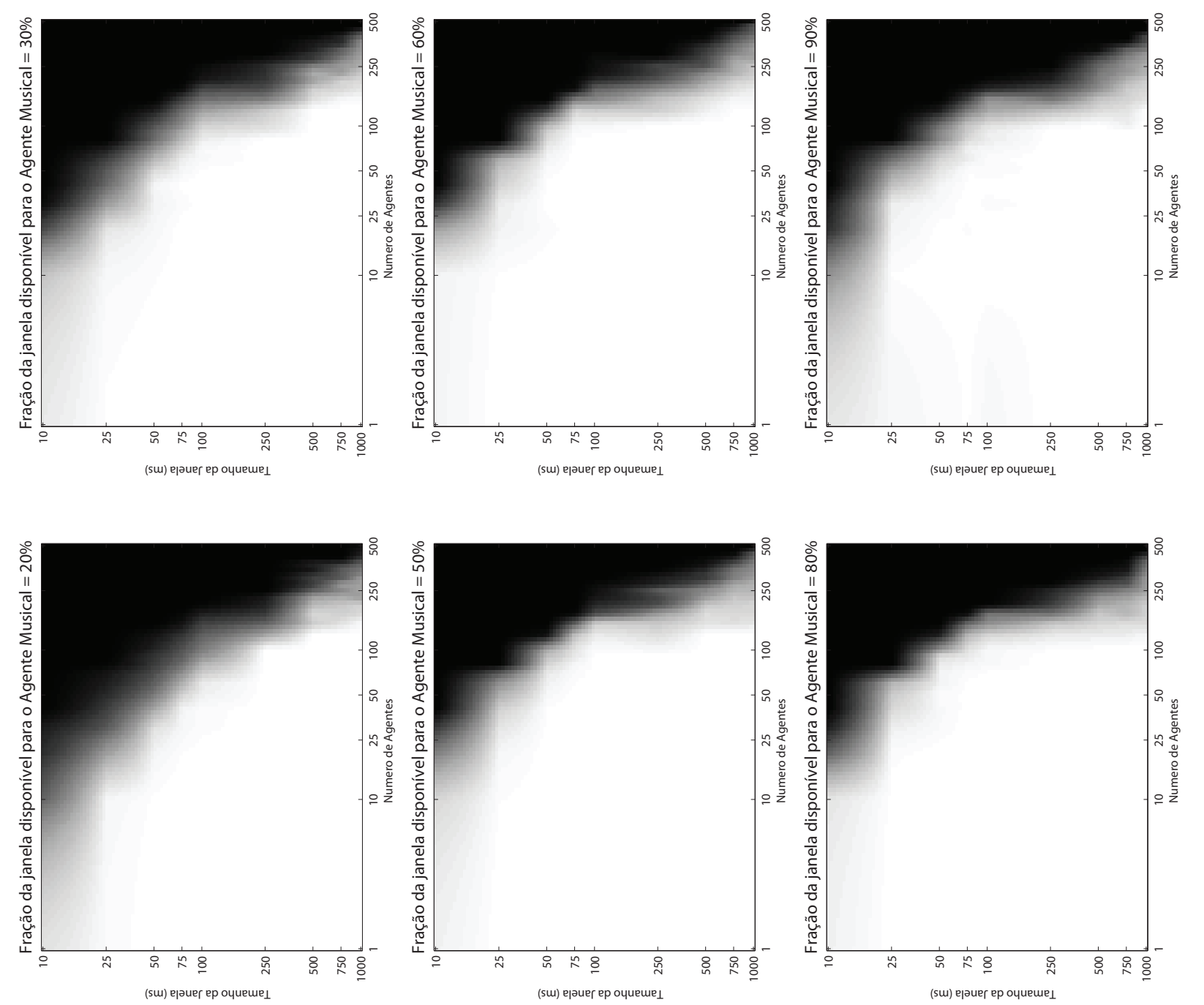

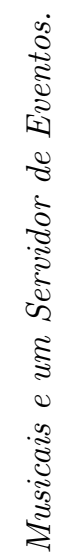
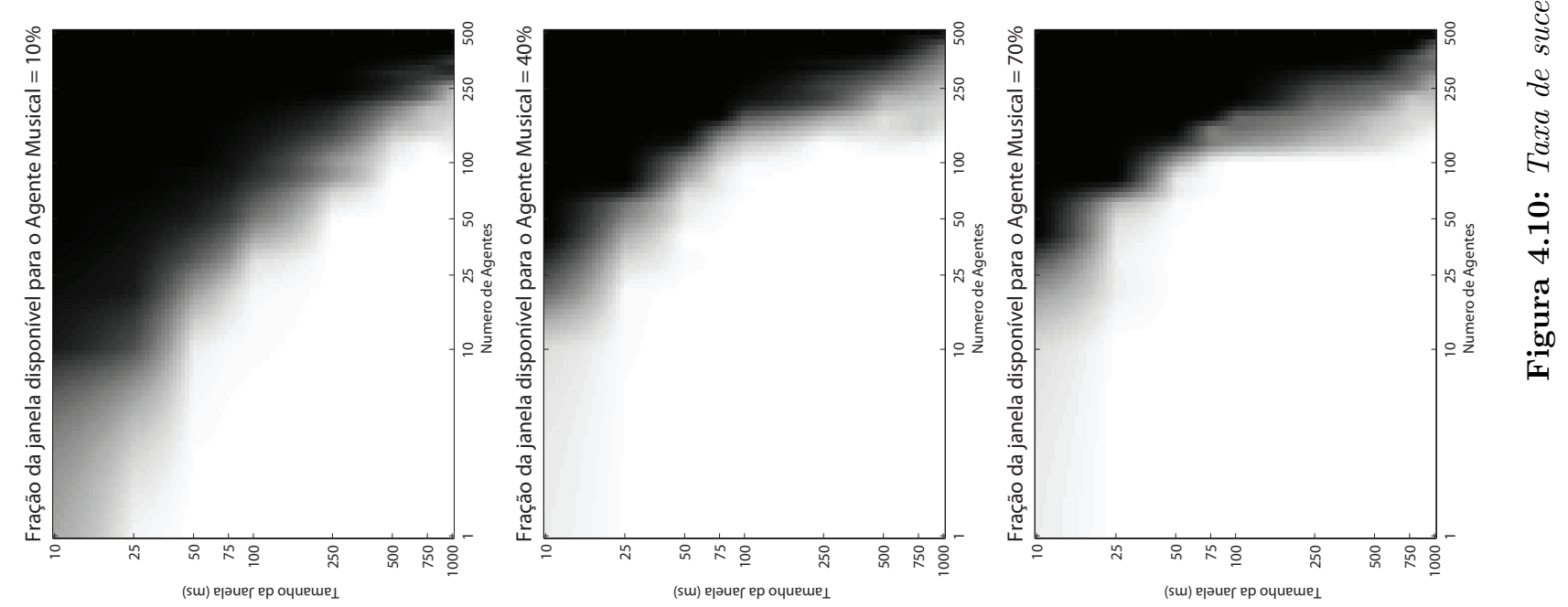
disponibilizam mais tempo para o processamento do agente e por isso são menos influenciadas por imprecisões temporais.

Com relação à divisão do tempo de processamento entre os agentes e o ambiente, é interessante notar que um menor tempo de processamento para os Agentes Musicais (10\% e 20\%) penaliza mais o sistema do que um correspondente menor tempo para o Servidor de Eventos. Isso ocorre porque cada Atuador tem o seu processo separado, concorrendo pelos recursos do computador, enquanto que o Servidor de Eventos trata todos os eventos em um mesmo processo.

Em linhas gerais, o arcabouço se mostrou robusto para uma grande parte dos casos testados. Todavia, visto que o seu principal objetivo é a troca de áudio, o que geralmente exige baixa latência (menor que $100 \mathrm{~ms}$ ), o número de agentes é o principal fator limitante no uso do sistema. Uma maneira de contornar esta limitação é usar agentes que representem coletividades, como no caso de Swarm Orchestra, onde um mesmo processo poderia controlar um grande número de indivíduos através um laço.

Os resultados representam os limites operacionais do sistema, por se tratar de uma troca de eventos sem processamento. Eles podem ser ser utilizados pelo usuário como ponto de partida para melhor configurar sua aplicação, a partir da aferição do tempo de processamento dos seus Agentes Musicais e dos Servidores de Evento. Utilizando os gráficos, é possível verificar qual seria a melhor divisão de tempo, qual o número máximo de agentes que ele pode inserir no ambiente com aquele volume de processamento, e qual o menor período de troca possível.

\subsubsection{Propagação Sonora}

Uma das tarefas do Ensemble que mais demanda processamento computacional é a simulação da propagação sonora. Um experimento foi concebido especificamente para poder avaliar o desempenho do AudioEventServer [TQ11].

Neste experimento, um Agente Musical dotado de um Atuador sonoro gera uma onda senoidal, enviando eventos de áudio para o Ambiente Virtual, enquanto vários outros Agentes Musicais dotados de Sensores sonoros, posicionados em locais aleatórios do espaço, recebem os eventos correspondentes. Além do Servidor de Eventos de áudio, também estava presente o Servidor de Eventos de movimentos.

Para este teste, variou-se o número de pares Atuador/Sensor (entre 1 e 100) e o período de troca de eventos ou tamanho da janela de áudio (com 50, 100, 250, 500 e 1000 ms). Durante a condução do teste, o prazo correspondente ao tempo de processamento da janela foi ajustado manualmente, de acordo com o tamanho da janela e com o número de agentes envolvidos, através de uma medição prévia do tempo de processamento utilizado pelo AudioEventServer para cada combinação destes parâmetros.

A figura 4.11 mostra a medida do desempenho do Ensemble. Esses valores correspondem ao tempo dedicado ao cálculo da propagação sonora entre um Atuador e $N$ Sensores, expresso como uma fração do tamanho da janela. O cálculo foi feito utilizando uma interpolação polinomial cúbica.

Como esperado, o valor cresce de forma praticamente linear em função de (\#Sensors) * (\#Actuators) para cada tamanho de janela, até que o limite de operabilidade é atingido e o sistema fica congestionado, ou seja, nem todos os sons produzidos pelos Atuadores são propagados para cada sensor. Esse limite de operabilidade (indicado na figura por pequenas caixas) aumenta com o tamanho da janela; para o equipamento utilizado nesse experimento, janelas com tamanhos entre $100 \mathrm{~ms}$ e $250 \mathrm{~ms}$ parecem oferecer a melhor relação entre baixa latência e estabili- 
dade para $(\#$ Sensors $) *(\#$ Actuators $) \leq 40$.

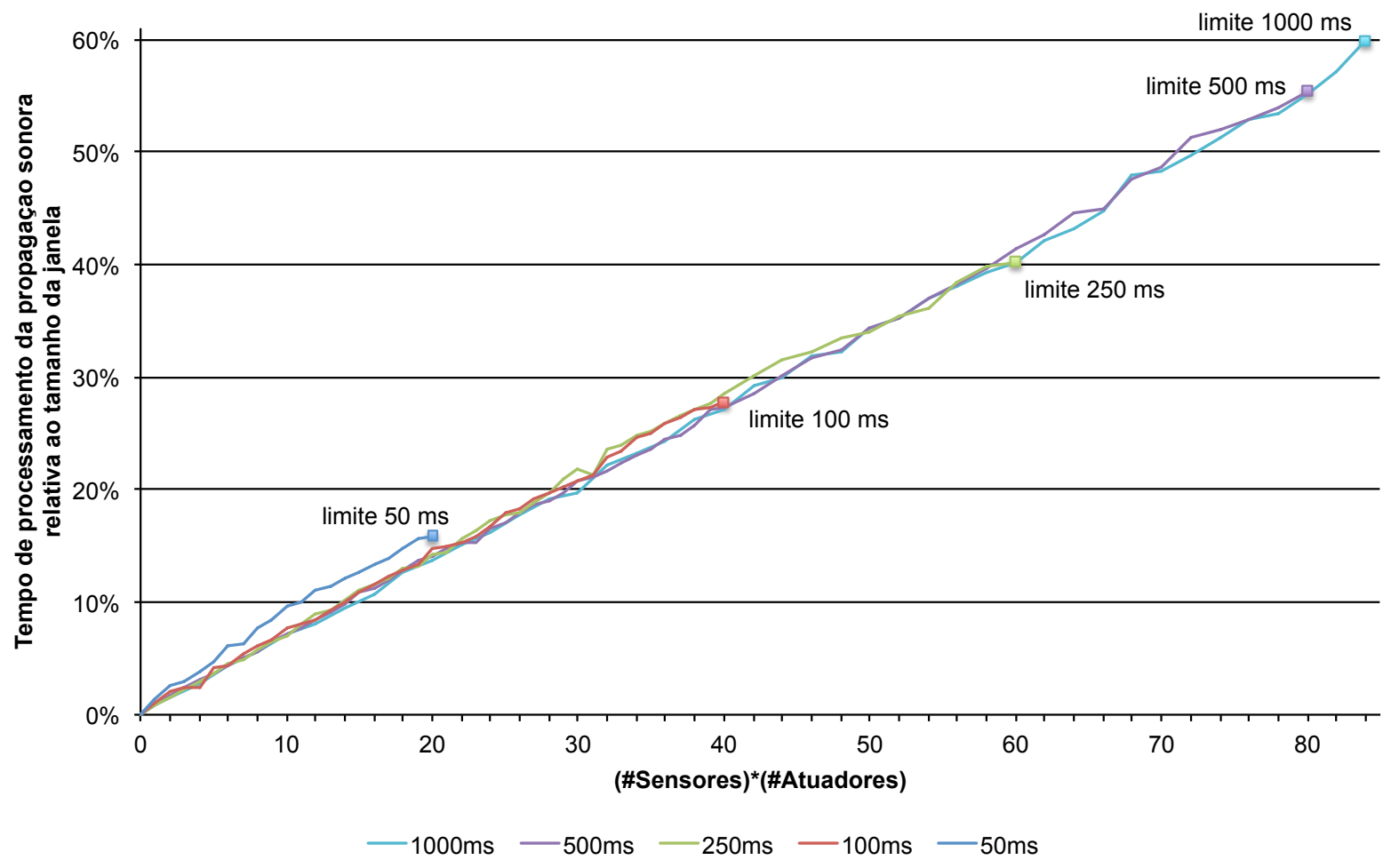

Figura 4.11: Tempo gasto para o cálculo da propagação sonora relativo ao tamanho da janela. 


\section{Capítulo 5}

\section{Estudos de Caso}

Para testar as principais funcionalidades do Ensemble e o objetivo proposto de generalidade do sistema, dois estudos de caso foram concebidos. O primeiro, Living Melodies, é um mapeamento de um sistema existente e que utiliza o modo de execução em lote. O segundo é uma nova aplicação baseada na peça Clapping Music, que utiliza as funcionalidades descritas no capítulo anterior de simulação de propagação sonora, movimentação e acesso a bibliotecas externas.

\section{$5.1 \quad$ Living Melodies}

O Living Melodies é um sistema musical com características emergentes, em que a constante interação entre seus agentes, através de instruções inicialmente aleatórias, gera padrões sonoros que evoluem com o tempo. O usuário pode registrar a saída musical do sistema e utilizá-la como material composicional.

Seu ambiente virtual é habitado por criaturas que interagem através do som e do contato, movimentando-se no ambiente enquanto cantam e ouvem. Essas criaturas são dotadas de um material genético que indica as instruções que elas devem executar dentro do ambiente, e qual é a sua afinidade com as diversas notas musicais produzidas por outras criaturas. Através de interações físicas, elas podem se reproduzir, compartilhando e recombinando seus materiais genéticos ao dar origem a novas criaturas. Uma característica desse sistema é que as criaturas são dotadas de uma característica "emotiva", o seu nível de prazer, que é alterado à medida que notas consideradas interessantes tenham sido escutadas.

O mapeamento para o Ensemble aqui descrito foi baseado no artigo de Dahlstedt e Nordahl [DN01] e na utilização e observação da implementação do sistema original ${ }^{1}$. Detalhes ou parâmetros internos que não estavam disponíveis nem no artigo nem na interface foram ou deduzidos a partir do uso ou deixados para configuração pelo usuário.

O modo de execução do sistema é em lote, pois na definição do Living Melodies os agentes atuam de forma sequencial e cíclica, cada um executando uma instrução pré-programada por turno. Assim, o ambiente deve aguardar a atuação de todos os agentes e atualizar o estado do ambiente, para que os agentes possam agir novamente. Todos os eventos do sistema são do tipo esporádico.

O Living Melodies contém uma grande quantidade de parâmetros, que definem vários aspectos da vida dos agentes, das características do ambiente e de como o som gerado é apresentado para o usuário. Esse parâmetros são definidos em uma classe especial LM_Constants, e o ajuste fino desses parâmetros é imprescíndivel para se obter um resultado musical similar ao do sistema original.

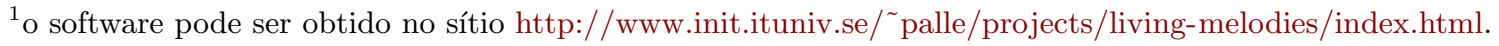




\subsubsection{Agente Musical}

A aplicação musical Living Melodies possui apenas um tipo de Agente Musical, baseado na classe LM_MusicalAgent, com várias instâncias existentes durante a simulação. O diagrama de classes da figura 5.1 mostra o agente e seus componentes musicais.

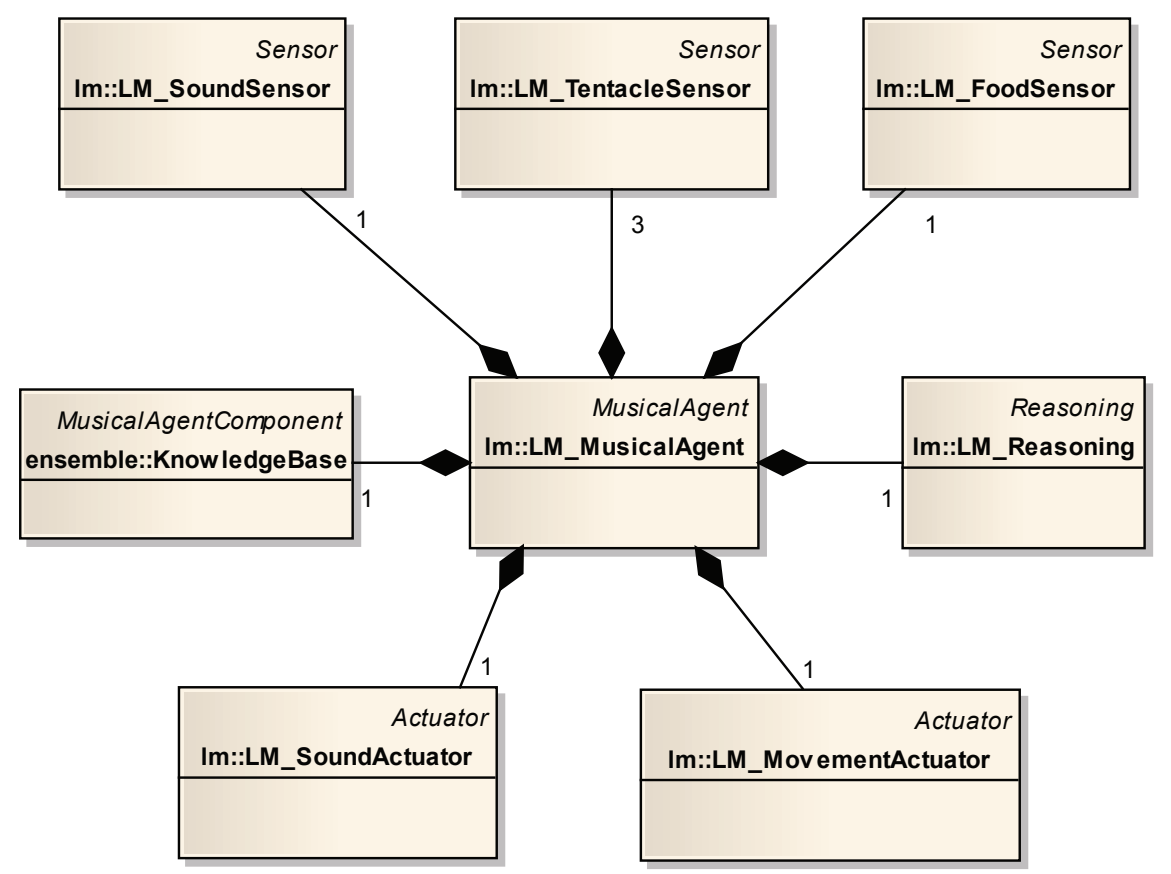

Figura 5.1: Diagrama de classes do Agente Musical da aplicação Living Melodies

Uma base de conhecimento (KnowledgeBase) é usada para armazenar o seu genoma, que é composto de uma parte sonora, que identifica a espécie da criatura (que é associada a uma nota musical) e consiste em uma lista de notas ou intervalos musicais favoritos, além de uma parte procedural, que descreve uma sequência de ações do agente, como se movimentar e cantar. Além disso, o agente mantém em sua base fatos públicos que indicam sua idade, seu nível de energia e seu nível de prazer.

A criatura é dotada de um sensor sonoro (LM_SoundSensor), que recebe o som que está presente no ambiente, mais especificamente na posição do tabuleiro que ela ocupa. Ela também possui três tentáculos (LM_TentacleSensor) que funcionam como sensores de aproximação, posicionados à frente e aos lados do seu corpo, indicando a presença de outras criaturas próximas. Um sensor (LM_FoodSensor) é responsável por receber a energia vinda do consumo de alimentos (que é feito automaticamente, quando uma criatura atinge uma posição do mundo que tenha alimentos).

A comunicação musical do agente é feita através de um atuador sonoro (LM_SoundActuator), capaz de emitir a nota musical correspondente à espécie do agente. Finalmente, para se locomover, a criatura dispõe de um atuador (LM_MovementActuator).

Todos estes sensores e atuadores são controlados por um único raciocínio da criatura (LM_Reasoning). Tal como o processador de um computador, ele é responsável por interpretar o seu genoma procedural e executar as instruções ali programadas (uma a cada turno de processamento). É possível, além de usar instruções para acionar os atuadores, utilizar elementos de linguagens de programação como laços e comandos condicionais, comparando informações e sensores e valores literais. 


\subsubsection{Agente Ambiente}

O Agente Ambiente (LM_Environment) é composto por diversos servidores, que serão detalhados nas seções seguintes, e um Mundo Virtual. A figura 5.2 mostra o diagrama de classes do Agente Ambiente do Living Melodies.

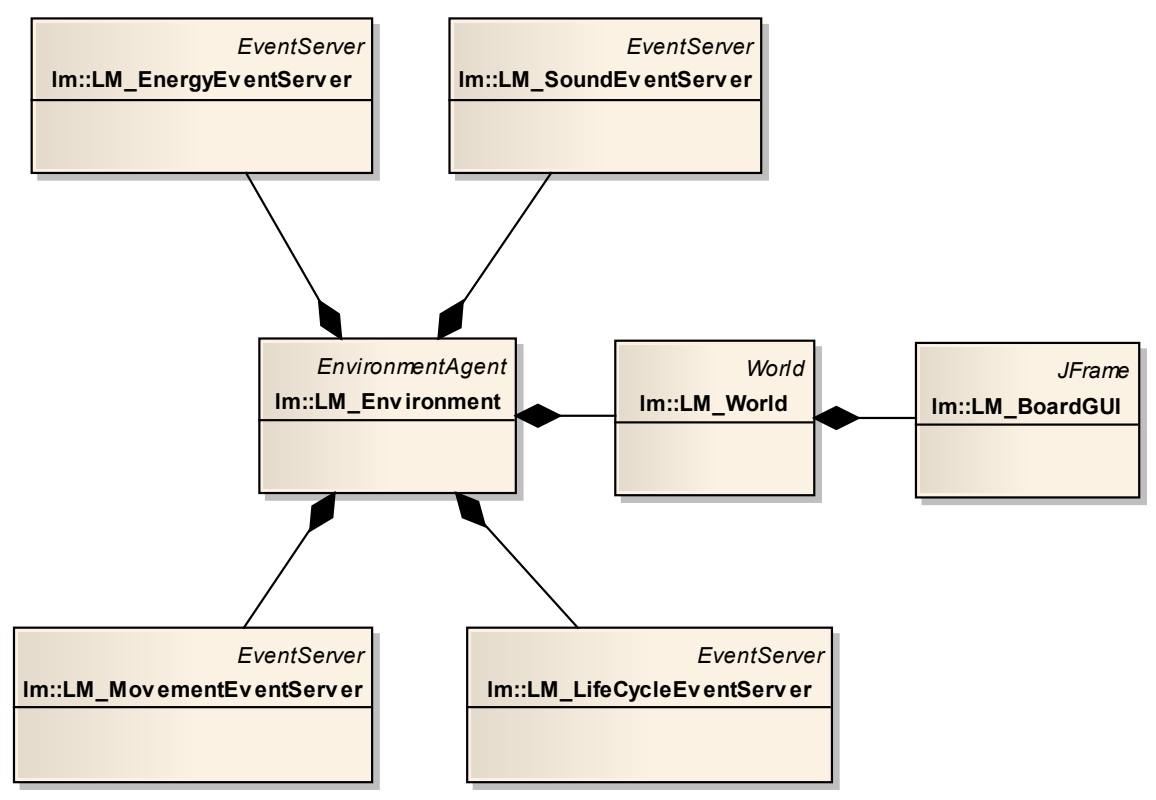

Figura 5.2: Diagrama de classes do Ambiente Virtual da aplicação Living Melodies

O mundo virtual da simulação do Living Melodies é definido como um tabuleiro bidimensional, limitado e com um número finito de posições. A classe $L M_{-}$World armazena o estado de cada posição desse tabuleiro, indicando a presença de uma criatura (seu nome, direção e última nota cantada), de alimento (quantidade de energia) e de som (nota musical, amplitude e direção de propagação).

O sistema possui uma interface gráfica, implementada pela classe LM_BoardGUI, que mostra um tabuleiro bidimensional representando o mundo virtual, onde as criaturas são representadas por triângulos vermelhos, indicando sua posição e direção. Uma posição do tabuleiro que contenha som é preenchida por uma cor correspondente à nota musical. A cada mudança de turno, a interface gráfica é atualizada com as novas posições dos agentes e a propagação das frentes de ondas sonoras, através do método preUpdateClock(). A Figura 5.3 mostra a interface gráfica em um turno da simulação, com os agentes musicais e as frentes de onda correspondentes à propagação sonora.

\subsubsection{Movimentação}

O mundo em que as criaturas podem se movimentar corresponde a um tabuleiro composto por quadrados, em que o movimento pode ser feito em qualquer uma das oito direções. A criatura sempre está apontada para uma destas direções e, quando executa uma instrução de movimentação em um turno, desloca-se uma posição na direção apontada.

O LM_MovementEventServer é o Servidor de Eventos responsável pela movimentação das criaturas no ambiente. Este, ao receber o registro de um novo Agente Musical, o coloca aleatoriamente no tabuleiro em alguma posição vazia (ou então em uma posição pré-definida, caso um parâmetro de posição inicial tenha sido passado). 


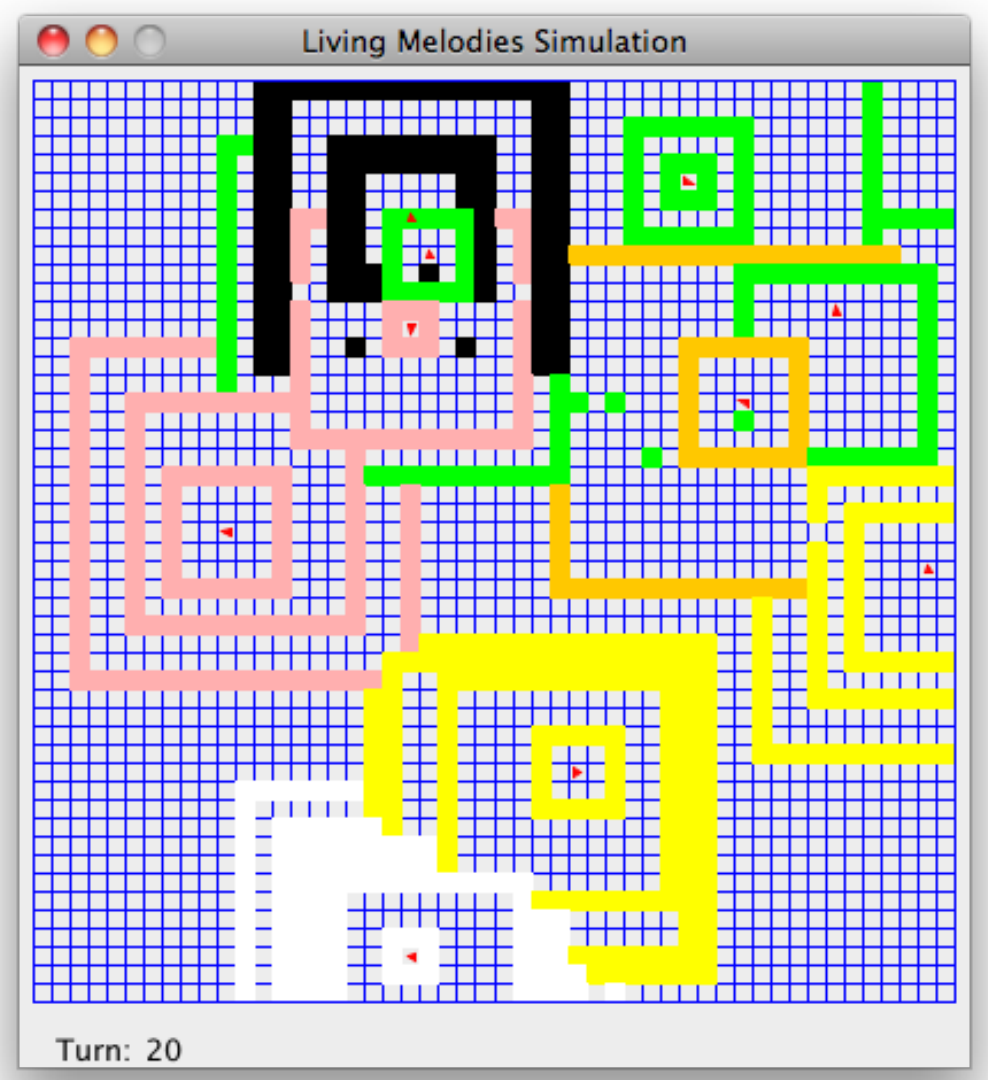

Figura 5.3: Interface gráfica na simulação do Living Melodies

$\mathrm{O}$ atuador de movimento da criatura gera no ambiente um evento com uma instrução de movimento solicitada pelo raciocínio naquele turno, que pode ser andar (W), virar no sentido horário $(\mathrm{T}+)$ ou virar no sentido anti-horário $(\mathrm{T}-)$. A cada evento de movimento recebido durante um turno, o método processEvent() atualiza a posição do Agente Musical, de acordo com a instrução de movimentação recebida. Caso já exista uma criatura na posição pretendida, o pedido de movimento é descartado.

A cada fim de turno, o método process() verifica se existem criaturas em posições adjacentes e, caso existam, envia para os sensores de presença (tentáculos) de cada Agente Musical a nota musical que representa a espécie da criatura próxima.

\subsubsection{Som}

O Servidor de Eventos responsável pela propagação sonora no ambiente é o LM_SoundEventServer. No momento da inicialização, um canal MIDI é aberto para que as notas emitidas pelas criaturas sejam renderizadas na interface de áudio padrão e ouvidas pelo usuário.

Ao receber uma instrução de canto de uma criatura (S), o método processSense() armazena a nota correspondente em uma lista, para posterior propagação, e a toca no canal MIDI disponível. Ao fim do turno, o método process() é responsável por propagar o som presente no ambiente. Para tornar a saída do sistema para o usuário menos profusa, o ambiente decide quais notas emitidas pelos agentes serão efetivamente reproduzidas de acordo com um limiar referente ao nível de prazer 
da criatura no momento da emissão do som.

Visto que o artigo não dá muitos detalhes sobre a propagação do som no ambiente, inferiu-se a maior quantidade possível de informações a partir da observação da execução do sistema implementado pelos autores. As frentes de onda expandem-se na forma de um quadrado em torno do ponto de emissão da nota. A cada turno, a frente de onda perde amplitude linearmente. Quando duas frentes de onda se encontram em uma posição do tabuleiro, a de maior amplitude prevalece, destruindo a propagação da mais fraca, que desaparece. O usuário pode configurar qual o raio máximo de propagação da frente de onda e qual a amplitude inicial da emissão.
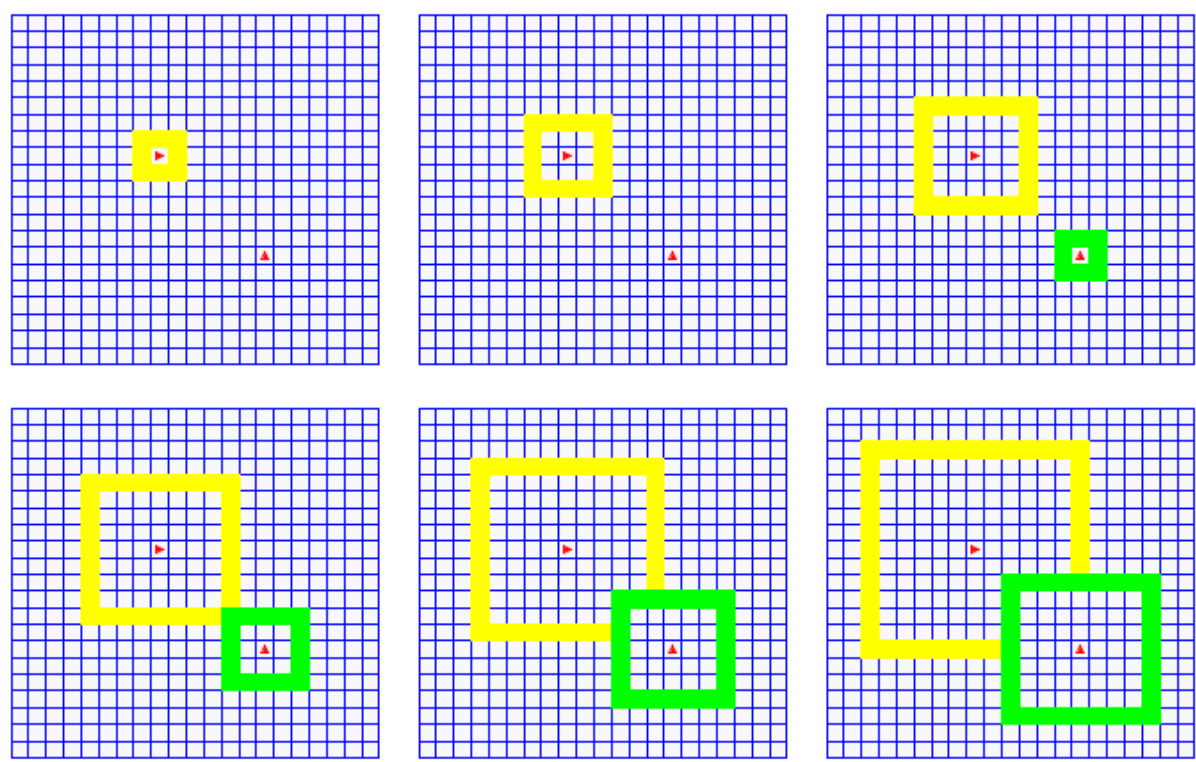

Figura 5.4: Propagação do som na simulação do Living Melodies

A Figura 5.4 mostra a propagação do som emitido por duas criaturas, durante seis turnos. Inicialmente, o primeiro Agente Musical emite um som, cuja nota é representada pela cor amarela da frente de onda sonora. No instante 3, o segundo Agente Musical emite um som, representado pela cor verde. Em seguida, no instante 4, quando as duas ondas se encontram, a que foi emitida por último tem uma amplitude maior e, portanto, nos pontos em que se encontra com a outra onda, age de forma destrutiva.

Após propagar o som, o método verifica quais criaturas encontram-se em uma posição que tenha som, enviando então um evento para este agente contendo a nota, sua amplitude e a direção de propagação do som.

\subsubsection{Ciclo de Vida}

O Servidor de Eventos LM_LifeCycleEventServer é responsável pelo nascimento e morte das criaturas. Diferentemente de outros servidores, ele não envia nem recebe eventos, mas executa o seu processamento ao fim de cada turno (através do método process()), baseando-se nos fatos públicos dos agentes musicais.

No momento da inicialização do sistema, indica-se qual é a quantidade de criaturas a serem criadas. Elas assumem posições aleatórias no mundo virtual, assim como seus genomas são gerados aleatoriamente. Decidiu-se por essa implementação pois nem o artigo nem o software original dão indicações de como é feita a inicialização. 
Quando duas criaturas estão em posições adjacentes, elas podem se reproduzir, dependendo de alguns parâmetros como sua idade, energia disponível e nível de prazer, que depende dos sons escutados recentemente. O Servidor de Eventos verifica essas condições ao fim de cada turno e, sempre que a reprodução é possível, cria um novo agente que é posicionado aleatoriamente no mundo virtual, retirando energia dos pais e realizando o crossover dos genomas musical e procedural.

Um agente morre quando ele atinge uma certa idade (medida em turnos) ou quando sua energia chega a zero. A cada turno, o Servidor de Eventos LM_LifeCycleEventServer verifica o estado de cada criatura do ambiente e, se for o caso, mata a criatura através do Agente Ambiente.

\subsubsection{Energia}

A energia presente no ambiente, que é mantida constante durante toda execução de uma simulação, está distribuída entre as criaturas e espalhada pelo mundo na forma de alimento. A criatura gasta energia para se manter viva, a cada vez que canta e quando se reproduz. Os valores gastos são fixos e, assim como o valor total de energia no ambiente, podem ser configurados pelo usuário em LM_Constants.

O Servidor de Eventos responsável pelo controle da energia no ambiente é o LM_EnergyEventServer. Durante a inicialização do ambiente, após reservar a quantidade de energia necessária que será dada às criaturas iniciais, ele distribui a energia restante aleatoriamente no ambiente, em forma de alimento presente nos quadrados do tabuleiro. A cada fim de turno, o método process() verifica a posição de todas as criaturas e, caso exista alimento presente, realiza a troca de eventos correspondente à transferência da energia contida no alimento para o Agente Musical.

O sensor LM_FoodSensor presente em cada Agente Musical é responsável por receber os eventos enviados pelo LM_EnergyEventServer, indicando a quantidade de energia consumida, e atualizar em sua base de conhecimentos o seu nível de energia.

\subsubsection{Discussão}

O Living Melodies é um sistema complexo, em que os agentes musicais possuem diversas habilidades e diversos detalhes de implementação. A arquitetura desacoplada do Ensemble traz uma complexidade maior na implementação de algumas funcionalidades, que no sistema original, devido à sua estrutura monolítica, provavelmente foram implementadas de forma mais simples. Um exemplo disto é o sequenciamento de ações dos agentes musicais. Na realidade, foi o mapeamento deste sistema em uma plataforma multiagentes, onde as trocas de mensagens são assíncronas e cada agente tem uma linha de execução (thread), que mostrou a necessidade da criação de um modo de execução em lote na especificação do arcabouço.

Devido ao grande número de parâmetros, cujos valores no sistema original não eram conhecidos, e à aleatoriedade da inicialização, houve uma certa dificuldade em ajustar os parâmetros para que a saída musical fosse idêntica à do sistema original. Embora os autores relatem a existência da maior parte dos parâmetros, nem o artigo original nem o software dão uma indicação precisa de quais são os valores destes parâmetros responsáveis por gerar uma certa saída musical. Esses parâmetros incluem, por exemplo, o valor mínimo de prazer da escuta para que a nota emitida pelo agente seja efetivamente tocada na saída para o usuário, bem como os diversos fatores envolvidos na reprodução do agente. 
Apesar disso, o resultado obtido é bastante próximo do sistema original, recriando um panorama sonoro que, pouco a pouco, converge a certos padrões rítmicos e a certos intervalos musicais (devido principalmente à reprodução e à utilização do nível de prazer como critério para filtrar notas). Dependendo das condições iniciais e das interações aleatórias, o sistema apresenta uma textura musical complexa com sequências rápidas de notas curtas ou então em uma textura rarefeita, com poucas notas de longa duração.

\subsection{Clapping Music}

De forma a testar algumas funcionalidades mais avançadas do Ensemble em um contexto musical, um estudo de caso mais complexo foi desenvolvido. Como ponto de partida utilizou-se uma peça musical chamada Clapping Music, escrita em 1972 pelo compositor Steve Reich. Essa peça percussiva trabalha com pequenas variações feitas sobre um padrão rítmico de origem africana, que dá origem a um intrincado jogo contrapontístico durante sua execução.

Nesta peça minimalista, um pequeno padrão rítmico, ilustrado na figura 5.5, é executado repetidamente através de palmas por dois músicos (ou dois grupos de músicos). Enquanto o primeiro fica repetindo exatamente o mesmo padrão, o segundo defasa o começo de cada repetição, antecipando o início em uma colcheia, a cada 8 ou 12 repetições do tema principal, até que eles estejam novamente sincronizados após 96 ou 144 repetições.

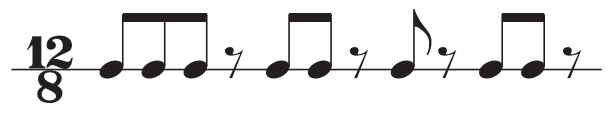

Figura 5.5: Padrão rítmico utilizado na peça Clapping Music, de Steve Reich

$\mathrm{Na}$ adaptação da peça em uma aplicação musical multiagentes, algumas hipóteses complicadoras foram introduzidas. Primeiramente, a peça não é conhecida de antemão por todos os músicos, mas apenas um músico, o líder, conhece o padrão rítmico que será executado e o seu andamento. O padrão rítmico pode ser o mesmo sugerido por Reich, mas também pode ser aleatoriamente criado pelo agente líder ou definido pelo usuário.

Os outros músicos presentes, os seguidores, devem descobrir qual o padrão através da escuta das primeiras execuções feitas pelo líder e só em seguida irão iniciar a execução de suas partes. Eles podem ter entradas e quantidade de defasagem independentes para cada versão defasada do padrão, parâmetros estes que são controlados pelo usuário.

Para tornar a aplicação mais interessante do ponto de vista da exploração das funcionalidades do Ensemble, os agentes aqui definidos não têm a possibilidade de se comunicarem por nenhuma outra forma que não o áudio, ou seja, exclui-se a possibilidade de auxílios visuais ou mensagens simbólicas que facilitariam a sincronização entre agentes. Todo o raciocínio do agente é baseado na análise do áudio presente no ambiente, seja para encontrar o primeiro ataque do padrão rítmico, deduzir este padrão, bem como o instante em que o agente deverá começar a tocar.

\subsubsection{Agente Musical}

Dois tipos de agentes musicais foram implementados: um agente músico (Musician), responsável pela execução da peça musical; e um agente ouvinte (Listener), que funciona como um avatar 


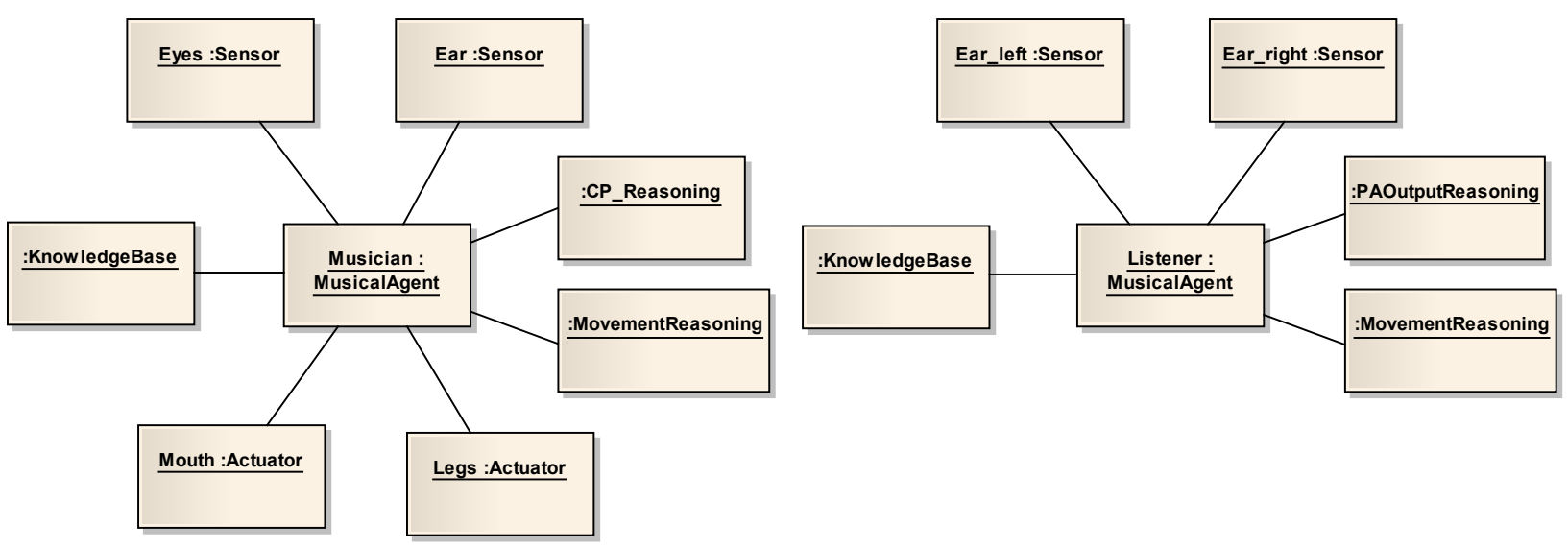

Figura 5.6: Diagrama de objetos com os dois tipos de Agente Musical do Clapping Music

e joga a produção sonora do ambiente na interface de áudio para ser escutada pela usuário.

A figura 5.6 mostra um diagrama de objetos dos dois tipos agentes. Diferentemente do Living Melodies, onde todos os componentes foram desenvolvidos especialmente para aquela aplicação, os agentes do Clapping Music usam componentes genéricos e já disponíveis no Ensemble, com exceção de um único raciocínio (CP_Reasoning), construído especificamente para esta aplicação. Os sensores e atuadores dos agentes tem seus nomes indicados na figura, mostrando as funções sonora (Ear e Mouth) e de movimentação (Eyes e Legs). O controle da movimentação é feito através do raciocínio MovementReasoning.

Uma particularidade do agente Listener é a presença de dois sensores sonoros (Ear_right e Ear_left), posicionados em locais diferentes do agente para permitir a reprodução em estéreo. Para redirecionar o som do ambiente captado pelos seus sensores, ele utiliza um raciocínio PAOutputReasoning, que faz a interface com a biblioteca PortAudio.

O agente Musician pode assumir o papel de líder (Leader) ou de seguidor (Follower), dependendo do parâmetro role indicado pelo usuário. Diversos aspectos específicos de cada agente músico, líder ou seguidor, podem ser controlados por outros parâmetros, descritos na tabela 5.1.

O raciocínio $C P \_$Reasoning do agente músico pode assumir dois estados, o de análise e de reprodução. O funcionamento de seus métodos depende do papel que o agente músico assumiu. Ao iniciar-se a simulação, o método init() irá obter os parâmetros de inicialização e colocar o líder no estado de reprodução e o seguidor no estado de análise.

Quando em reprodução, o raciocínio estará agindo de forma reativa e apenas o método needAction() é executado. O padrão é armazenado na base de conhecimentos como uma sequência de instantes de ataque (beats). Para cada janela de áudio, este método verifica se alguma nota do padrão deve ser produzida dentro do intervalo da janela e, caso positivo, gera um evento de áudio inserindo a wavetable na posição correspondente da janela.

Durante a reprodução, o líder acentua a primeira nota do padrão a cada repetição, fornecendo assim uma dica do início do padrão aos outros agentes. Estratégias mais complexas para descobrir os padrões poderiam ser implementadas sem o uso da acentuação, mas qualquer estratégia baseada exclusivamente nos instantes de ataque inevitavelmente dificultaria o uso de padrões que contenham repetições de padrões menores ou motivos, como padrões na forma $\mathrm{AA}$ ou $\mathrm{AAB}$, por exemplo.

Quando um agente músico assume o papel de seguidor, seu raciocínio CP_Reasoning é iniciado 
Tabela 5.1: Parâmetros da aplicação Clapping Music

\begin{tabular}{|c|c|}
\hline Parâmetro & Descrição \\
\hline wavetable & $\begin{array}{l}\text { Arquivo de áudio que será executado para cada nota do agente. Se não for } \\
\text { informado, o agente utiliza um arquivo de som padrão de palmas. }\end{array}$ \\
\hline role & Papel do agente no ambiente, líder (leader) ou seguidor (follower). \\
\hline \multicolumn{2}{|c|}{ Parâmetros específicos do papel leader } \\
\hline bpm & $\begin{array}{l}\text { O andamento da peça em batidas (ou cada colcheia da peça original) por } \\
\text { minuto. } \mathrm{O} \text { valor padrão é de } 120 \mathrm{bpm} \text {. }\end{array}$ \\
\hline pattern & $\begin{array}{l}\text { Padrão rítmico que será utilizado, indicado por uma sequência de 0's e 1's } \\
\text { representando as notas ou pausas. O valor padrão é o definido por Reich } \\
\text { (111011010110). Se o padrão não for informado, um padrão é escolhido } \\
\text { aleatoriamente. }\end{array}$ \\
\hline \multicolumn{2}{|c|}{ Parâmetros específicos do papel follower } \\
\hline begin & $\begin{array}{l}\text { O número de repetições do padrão pelo agente líder que o agente seguidor deve } \\
\text { esperar antes de iniciar sua execução. O valor padrão é } 2 \text {. }\end{array}$ \\
\hline shift & $\begin{array}{l}\text { A quantidade de repetições do líder que o agente deve esperar a cada defasa- } \\
\text { gem. O valor padrão é } 1 .\end{array}$ \\
\hline phase & $\begin{array}{l}\text { A quantidade de figuras rítmicas que o agente deve defasar a cada shifting. O } \\
\text { valor padrão é } 1 \text {. }\end{array}$ \\
\hline
\end{tabular}

no estado de análise. Nesse caso, a sequência beats ainda vai ser preenchida, pois o agente seguidor não conhece o padrão a priori. O processamento no estado de análise é feito de forma paralela nos métodos newSense() e process().

O primeiro destes métodos é responsável por, a cada janela de áudio recebida, buscar a existência de ataques/notas (usando técnicas de detecção de onsets), armazenando o instante correspondente e a intensidade do ataque. Uma função de detecção de onset está disponível na biblioteca aubio, que utiliza o método proposto por Brosser et al. [BBP04]. Decidiu-se pela utilização desse método por oferecer uma alta taxa de acertos para sons percussivos e estar apto a trabalhar em sistemas de baixa latência.

O segundo método, que é executado de forma periódica (com um período default de $50 \mathrm{~ms}$ ), verifica se o padrão já foi encontrado. Assim que a segunda repetição do padrão é detectada, através da comparação das intensidades de cada ataque, a sequência beats é criada, usando os instantes de ataque obtidos até o momento, e o raciocínio do agente passa para o estado de reprodução. Como a troca de eventos periódicos implica que o áudio só pode ser gerado para a próxima janela, o agente deve esperar pelo menos a terceira repetição para poder entrar em sincronia com o líder.

O seguidor utiliza dois parâmetros para efetuar a defasagem, um que indica de quantos em quantos compassos ele deve defasar (shift), e o outro que indica o número de figuras rítmicas que devem ser defasadas (phase). Para melhor ilustrar o processo de defasagem, a figura 5.7 mostra a partitura da execução da peça com dois seguidores. O agente Seguidor 1 tem como parâmetros shift=1 e phase=1, enquanto que o Seguidor 2 tem shift=2 e phase=1. Os dois agentes iniciam a execução no compasso 3, após os dois compassos necessários para a identificação do padrão. No compasso 15, o primeiro agente entra em sincronia com o agente líder, reiniciando o seu ciclo. Apenas no compasso 27 é que o segundo agente completa seu ciclo e todos os agentes estão em sincronia novamente.

Algumas pequenas mudanças nas repetições feitas pelos agentes seguidores foram feitas para 
Clapping Music

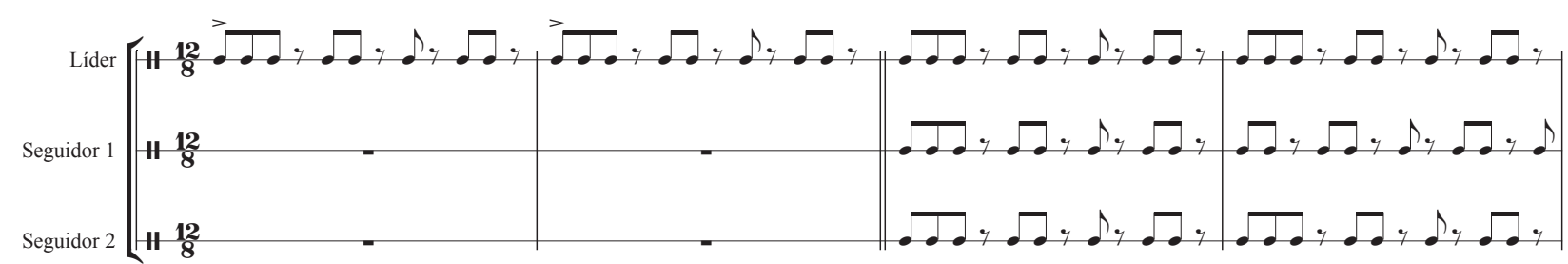

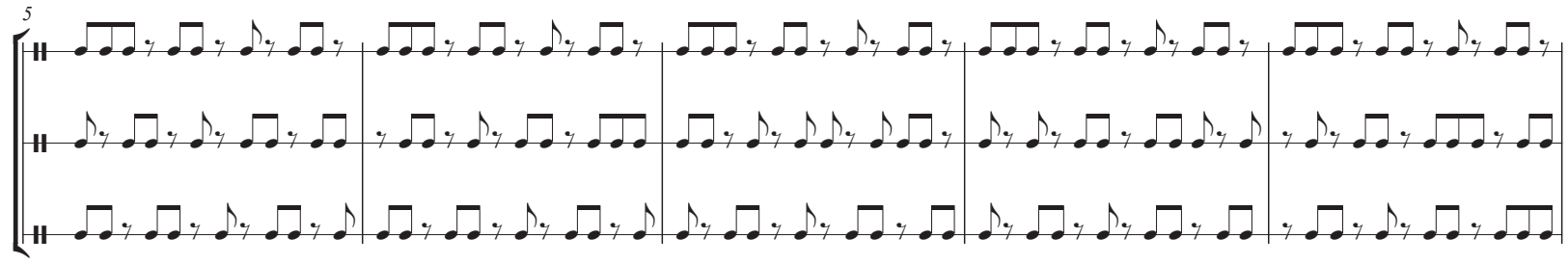

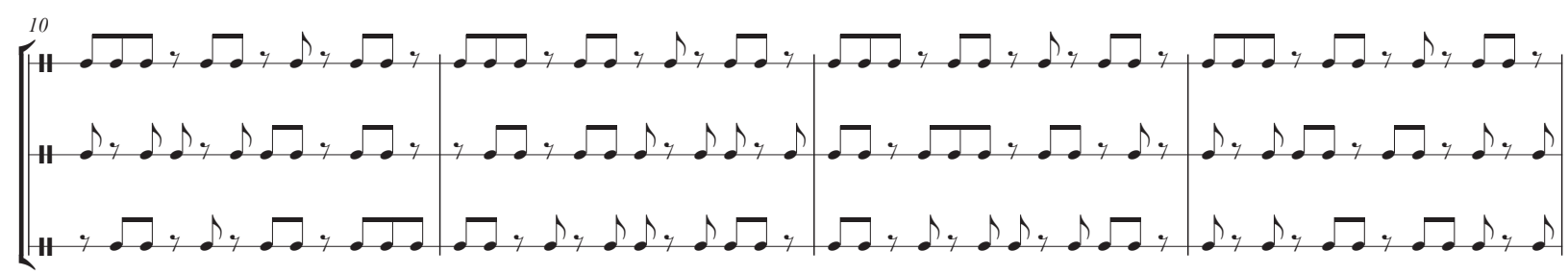

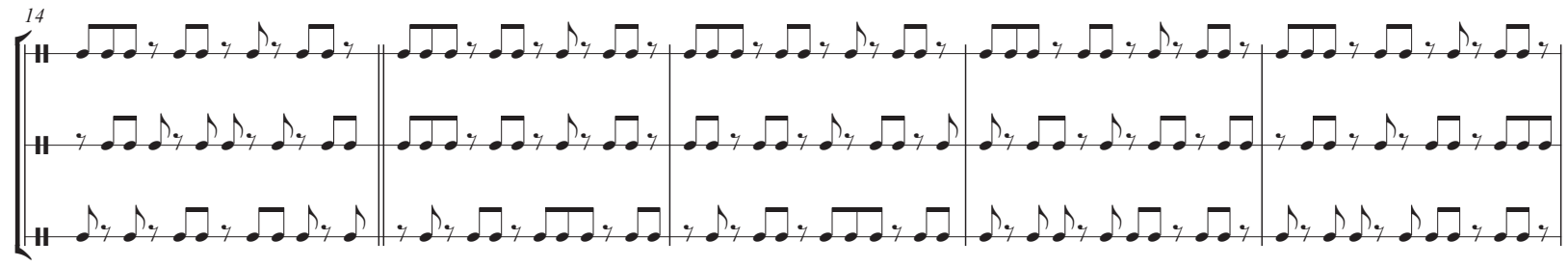

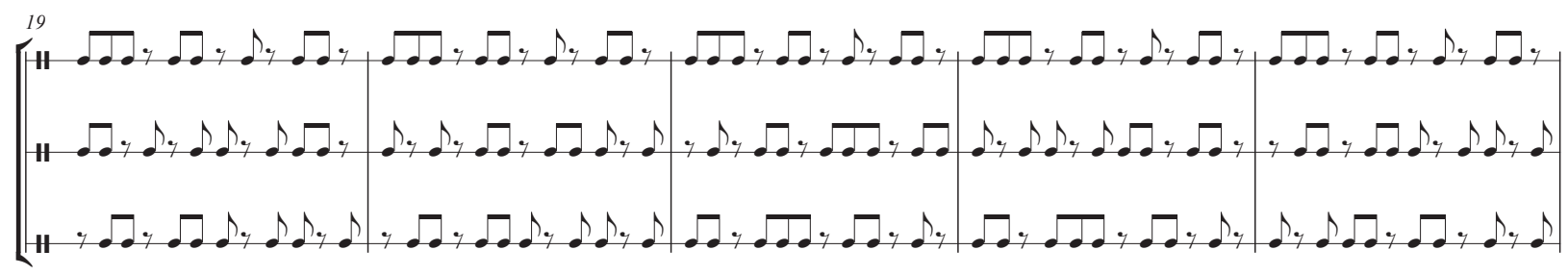

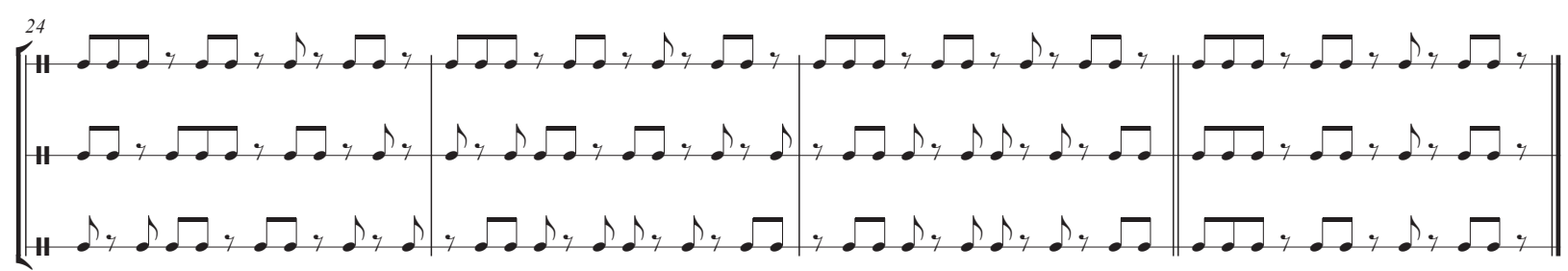

Figura 5.7: Execução de um ciclo completo do padrão do Clapping Music, onde a segunda voz defasa uma colcheia a cada compasso 


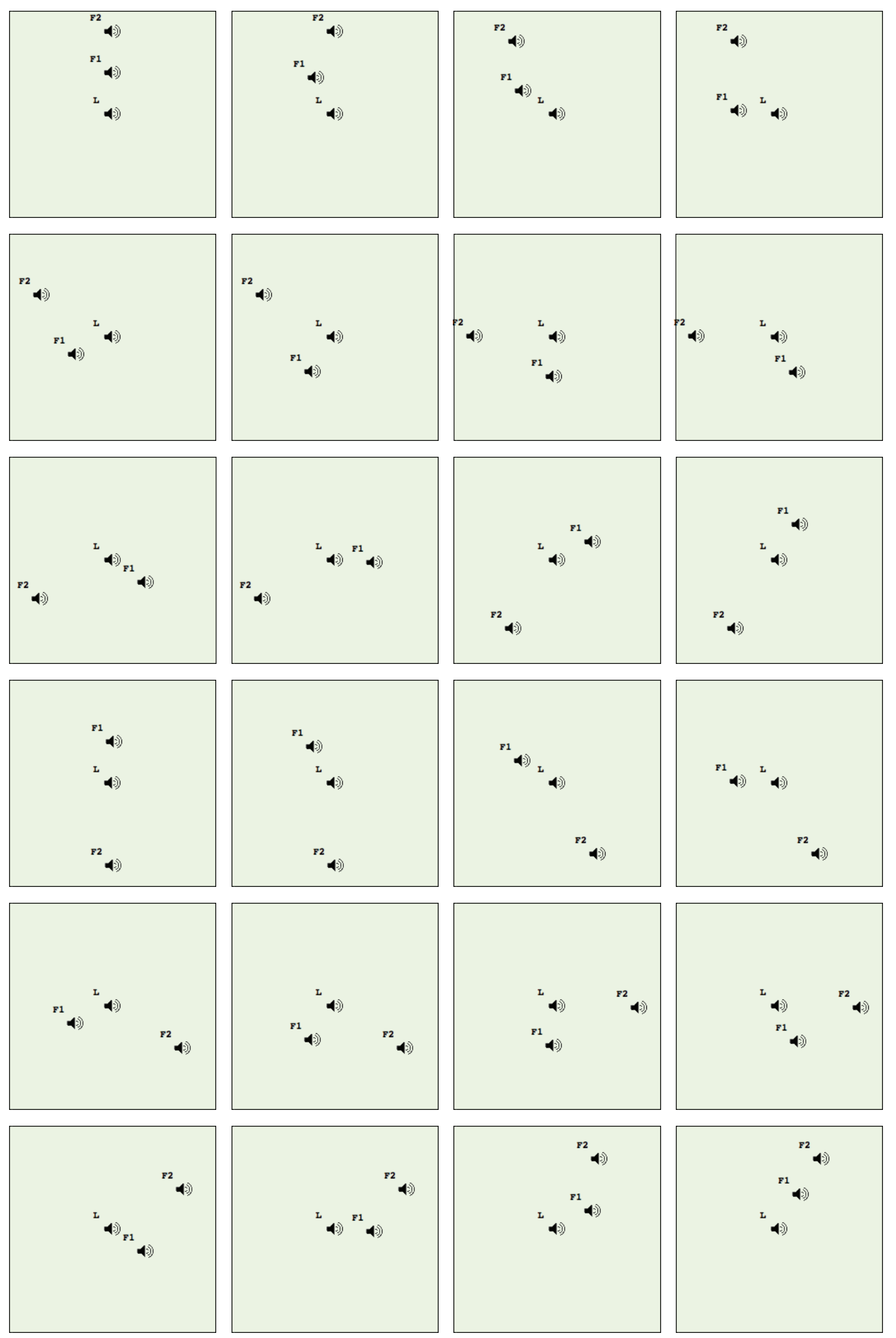

Figura 5.8: Posicão dos agentes a cada compasso na execução do Clapping Music utilizando o exemplo da figura anterior (sendo L o lider, F1 o Seguidor 1 e F2 o Seguidor 2) 
deixar a simulação um pouco mais natural. O instante dos ataques varia aleatoriamente, dentro de um pequeno intervalo definido pelo usuário, de forma a deixar a performance menos mecânica. Também é possível aplicar um filtro ao som utilizado, de forma a dar um timbre diferente para agentes que utilizam o mesmo arquivo de áudio. Além disso, é possível inserir um efeito de reverberação na aplicação, aplicável a todos os agentes, de forma a simular a execução em um ambiente fechado.

A movimentação dos agentes foi definida de forma a ilustrar graficamente o esquema de defasagem de cada agente seguidor em relação ao líder. Enquanto o líder se localiza no centro do espaço virtual, os seguidores se movimentam em torno dele seguindo uma órbita circular definida pelos valores de defasagem. Sempre que um agente seguidor inicia uma nova repetição com uma nova defasagem, ele anda até uma nova posição orbital, e todos os agentes estarão novamente alinhados quando um ciclo é completado (o que pode levar muito mais do que as 144 repetições do padrão na peça original).

A figura 5.8 mostra o movimento orbital de dois agentes seguidores, baseados no exemplo da figura 5.7. Cada quadro equivale a um compasso, iniciando no compasso 3 , momento em que os agentes estão sincronizados, até o compasso 26. Em seguida, o ciclo de repetições e de movimentações se reinicia. Essas posições influenciam a forma como o usuário, através de seu avatar (agente Listener), irá perceber a peça, uma vez que a propagação considera todas as posições dos agentes, com o devido atraso e atenuação.

\subsubsection{Agente Ambiente}

O Agente Ambiente na aplicação Clapping Music utiliza apenas componentes já existentes no Ensemble para movimentação e propagação sonora. A figura 5.9 mostra o diagrama de objetos do Agente Ambiente.

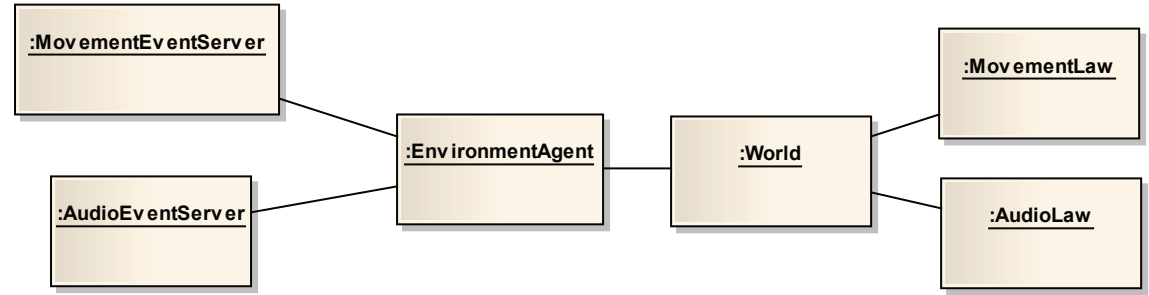

Figura 5.9: Diagrama de objetos com o Agente Ambiente do Clapping Music

A interação com o usuário é feita através do $\mathrm{Pd}$, utilizando o componente ensemble_gui e a comunicação via OSC, que mostra a posição dos agentes no mundo virtual (ver figura 5.8). Através dessa interface, o usuário é capaz de alterar diretamente a posição dos agentes utilizando o mouse. Uma instrução do tipo TRANSPORT é enviada ao Servidor de Eventos de movimentos, que irá atualizar a posição do agente.

\subsubsection{Discussão}

A parte mais complexa da tarefa do seguidor é detectar o padrão rítmico. Se ele estiver muito longe do líder, ou algum problema acontecer na detecção da nota acentuada, ele pode se perder e encontrar um padrão completamente diferente (ou nunca encontrá-lo). Testes feitos com diversos andamentos e posições mostraram que sempre foi possível detectar corretamente o padrão. Obviamente, o agente seguidor deve estar a uma distância suficientemente próxima do mestre, considerando os parâmetros físicos da propagação sonora da simulação em questão, para que seja 
possível detectar as batidas e diferenciar a primeira batida do compasso das outras. Uma vez detectado o padrão, os seguidores puderam executar a peça sem perda de sincronia ou quaisquer outras dificuldades.

Uma limitação do sistema é que agentes seguidores inseridos durante a simulação dificilmente serão capazes de detectar o padrão rítmico correto devido a interferência dos outros agentes seguidores, que provavelmente estarão defasados com relação ao líder. Para contornar essa limitação, algum outro tipo de indicação poderia ser dada ao agente seguidor para que ele prestasse atenção somente ao líder, seja sonoramente utilizando um timbre específico ou através de alguma informação simbólica.

Aglomerados de grupos líder-seguidores podem ser criados, cada um com seu padrão rítmico, desde que a distância entre esses grupos seja grande o suficiente para que o som gerado por um grupo não interfira no outro. Outras situações interessantes podem ser criadas, por exemplo fazendo uma simulação usando dois líderes com padrões diferentes, e um seguidor que provavelmente encontrará um terceiro padrão devido à interferência, gerando texturas rítmicas mais complexas.

Um efeito que deriva da espacialização dentro do ambiente virtual é a imprecisão no pulso dos agentes seguidores que estão mais distantes do líder. Como a propagação da onda sonora gerada pelo líder leva um certo tempo para chegar até o agente seguidor, este detectará o padrão com um certo atraso e, consequentemente, executará o padrão com o mesmo atraso. O agente ouvinte pode apreciar este efeito especialmente quando a distância entre o líder e o seguidor é grande e eles utilizam timbres diferentes para gerar seus padrões rítmicos. Este efeito poderia ser compensado com algum tipo de comunicação visual entre os agentes, de tal modo que um agente seguidor poderia inferir a sua distância em relação ao líder, e antecipar a sua execução para que seu som chegasse em sincronia com o som do líder em alguma posição específica (a do líder ou a do ouvinte, por exemplo).

É interessante notar que, embora se trate de uma aplicação razoavelmente complexa, envolvendo a troca e processamento de áudio, foi necessário desenvolver apenas um componente e criar um único arquivo de configuração. O componente $C P_{-}$Reasoning contém menos de 400 linhas de código, incluindo comentários. 


\section{Capítulo 6}

\section{Conclusões e Trabalhos Futuros}

\subsection{Limitações do Java}

A escolha da linguagem Java, motivada pelo fato desta ser uma linguagem independente de plataforma e de uso genérico com uso difundido na comunidade, também apresenta desvantagens, algumas das quais eram previsíveis, enquanto outras só foram detectadas durante a implementação do Ensemble.

Por ser uma linguagem multi-plataforma, em princípio todo código em Java é interpretado por uma máquina virtual Java, responsável pela tarefa de interpretação em cada plataforma diferente. Como a interpretação do código pode tornar a execução mais lenta, as máquinas virtuais Java mais recentes utilizam um mecanismo de compilação em tempo de execução (Just-in-time Compilation). Este mecanismo analisa o código à medida que ele é interpretado, compilando as seções computacionalmente mais custosas.

Mesmo com esse mecanismo, as primeiras execuções de cada método são mais lentas do que as subsequentes, uma vez que o interpretador do Java só decide compilar o código nativamente após detectar que ele está sendo repetido intensivamente. Esse problema foi contornado através de rotinas de aquecimento para métodos com processamento intensivo, executadas antes da inicialização da simulação e forçando a compilação nativa do código.

A abordagem de programação orientada a objetos utilizada na modelagem e implementação da arquitetura implica em um grande número de objetos sendo constantemente criados e destruidos, em vários níveis de abstração. Essas operações são de certa forma caras para a máquina virtual Java, uma vez que deve-se alocar memória e executar os construtores e destrutores para cada um destes objetos. Alguns métodos com restrição de tempo de execução e que trabalham com uma grande quantidade de dados, como a simulação da propagação sonora, são severamente atingidos por esse fato. De forma a melhorar o desempenho do sistema, foram utilizadas técnicas como a reutilização de objetos quando possível e o uso de padrões de programação (patterns).

Um dos grandes problemas encontrados na implementação foi o mecanismo de gerenciamento automático de memória do Java (Garbage Collector). Ele causa interrupções esporádicas em operações do arcabouço cujo prazo de execução é restrito temporalmente, como a troca de eventos periódicos, ou em importantes operações de processamento de áudio, como a simulação de propagação sonora. Como não se pode controlar o funcionamento do coletor de lixo, pelo menos em sua versão padrão do Java, o arcabouço está fadado a perder janelas durante a troca de eventos sempre que o sistema ficar sobrecarregado.

Finalmente, a implementação atual do JavaSound é extremamente simples e não direcionada para aplicações de áudio profissionais. Assim, problemas como a latência e a impossibilidade de 
acesso a interfaces de áudio multicanais tiveram que ser contornados com o uso de outras bibliotecas de som (PortAudio e Jack).

\subsection{Considerações Finais}

O presente trabalho descreveu o desenvolvimento e implementação do Ensemble, um arcabouço genérico para a criação de aplicações musicais baseadas em sistemas multiagentes musicais. Embora outros trabalhos tenham sido feitos na área, este é o primeiro trabalho que generaliza o problema e trata de maneira detalhada a espacialização no ambiente virtual e a troca de áudio entre agentes musicais.

Como se pode constatar nos experimentos realizados, o Ensemble é capaz de suportar um grande número de agentes funcionando de forma independente. Com relação à troca de eventos periódicos, os testes mostraram que utilizando-se o mecanismo de sincronização proposto é possível realizar a troca de áudio entre agentes mantendo uma taxa de áudio constante.

A implementação dos dois estudos de caso propostos (Living Melodies e Clapping Music) mostrou que o estágio atual do desenvolvimento do arcabouço é capaz de abranger sistemas de requisitos distintos, como a replicação de sistemas existentes baseados em MIDI e/ou que necessitem de troca de áudio digital em tempo real. As funcionalidades disponibilizadas pelo Ensemble permitem ao usuário do sistema focar o seu trabalho na resolução do problema musical específico, sem se preocupar com problemas de baixo nível como a comunicação entre agentes e a sincronização.

O Ensemble oferece ao usuário diversas funcionalidades que não estão disponíveis de forma integrada em nenhum outro sistema: o gerenciamento do ciclo de vida de Agentes Musicais; a troca de mensagens e o roteamento de comandos entre os agentes e seus componentes; a troca de eventos e a sua sincronização; o acesso a interfaces e sistemas externos (como bibliotecas de processamento de áudio e programas de áudio); e componentes padrões para o tratamento da propagação sonora e da movimentação dos agentes.

O usuário com pouca experiência, ou que necessite somente de componentes existentes, pode criar seu sistema multiagente musical simplesmente através de um arquivo de configuração, em formato texto, que é interpretado pelo Ensemble e executa a simulação. Já o usuário avançado, com habilidades de programação, e que necessite de componentes com características especiais, pode estender o Ensemble programando novos componentes utilizando Java, da mesma forma como foram feitos os componentes básicos descritos nesse trabalho.

A versão atual do kernel do Ensemble tem em torno de 20.000 linhas de código de programação em Java, que permitem ao usuário criar uma aplicação como o Clapping Music com apenas um arquivo de 400 linhas.

O Ensemble foi concebido para ser um projeto de longa duração e mutável, e incentiva a contribuição de usuários e programadores ao seu código original, estendendo suas funcionalidades. O código do arcabouço, assim como exemplos de aplicações musicais, está aberto e disponível na página do projeto ${ }^{1}$. Adotou-se a licença GNU General Public License ${ }^{2}$ versão 3 para a sua publicação, permitindo que outros desenvolvedores possam acessar livremente o código, alterá-lo e utilizá-lo. Um tutorial passo-a-passo, explicando como montar uma aplicação musical através do uso do arcabouço, bem como a documentação do código (Javadoc) também estão disponíveis neste sítio.

\footnotetext{
${ }^{1}$ http://code.google.com/p/musicalagents/

${ }^{2}$ http://www.gnu.org/licenses/gpl.html
} 


\subsection{Trabalhos Futuros}

Os trabalhos futuros mais imediatos correspondem a melhorar o desempenho geral do sistema, seja através de sintonia fina de seus mecanismos de controle e processamento ou, caso necessário, através da completa reimplementação de certos módulos. Esses trabalhos estão sobretudo relacionados ao consumo da memória e ao sincronismo das máquinas de estado. As melhorias permitirão ao Ensemble trabalhar com latências menores e um número ainda maior de agentes.

Com relação à perda de fragmentos na troca de eventos periódicos, deve-se adaptar o mecanismo para que o sistema trabalhe em sincronismo mesmo com períodos pequenos (menores que $50 \mathrm{~ms}$ ). A utilização do modelo de agendamento baseado em um relógio global é simples, mas mecanismos adicionais de sincronização, mesmo que adicionem certa latência, podem ser necessários para garantir a sincronização entre os Atuadores e o Servidor de Eventos no caso de fragmentos pequenos. Além disso, deve-se otimizar o código do Ensemble em todos os aspectos, encontrando os atuais gargalos e diminuindo o processamento requerido pelas suas partes, além de verificar quais métodos são executados simultaneamente dentro de um mesmo agente e que podem apresentar problemas de concorrência.

Alguns pontos importantes a serem considerados nas próximas atualizações do Ensemble são:

- Realismo do Ambiente Virtual

Os componentes existentes devem ter suas funções ampliadas para aumentar o realismo da representação, o que inclui: definições mais flexíveis do espaço virtual (como espaços fechados não necessariamente retangulares/cúbicos), possibilidade de incluir obstáculos no mundo virtual e estes influenciarem no movimento e na propagação sonora, novos algoritmos para o raciocínio de movimentação do agente e a inclusão de efeitos acústicos no simulador de propagação sonora;

- Novo escalonador de tarefas

O uso do Real-Time Java Specification (RTJS) [BG00] em uma nova implementação do arcabouço pode levar a uma melhora considerável de desempenho. O RTJS provê um relógio de alta resolução (em nanosegundos) e a possibilidade do agendamento de tarefas com essa resolução. Além disso, ele permite controlar de forma mais precisa o início e o prazo de conclusão das tarefas agendadas e disporia de um maior controle sobre o gerenciamento de memória automático da máquina virtual Java (Garbage Collector), aumentando a confiabilidade da máquina de estados da troca de eventos periódicos. O uso do RTJS implica na utilização de um sistema operacional em tempo real (como o Solaris ou o SUSE Linux), o que diminuiria consideravelmente o público alcançado pelo Ensemble. Por esse motivo, espera-se manter as duas versões do Ensemble disponíveis, de forma a não impor requerimentos de sistemas operacionais não-acessíveis ao usuário comum.

Uma outra opção é a utilização do Jack como escalonador de tarefas, uma vez que ele utiliza o clock da interface de áudio e tem acesso a threads prioritárias dentro do sistema operacional que o executa. Essa adaptação, se viável, permitiria ao arcabouço dispor de um agendador de tarefas mais confiável que o disponível na versão padrão da máquina virtual Java sem exigir do usuário a instalação de um sistema operacional de tempo real.

- Nova implementação do JavaSound

Um trabalho complexo, mas extremamente útil para a comunidade Java que trabalha com áudio, seria a implementação de uma biblioteca de áudio nativa baseada na API do JavaSound. 
Essa implementação serviria como substituto à implementação distribuida com a máquina virtual Java, e teria como principal objetivo superar as limitações da implementação atual, discutidas anteriormente (como o acesso a interfaces multicanais e um controle mais preciso do fluxo de áudio).

\section{- Documentação}

Espera-se ampliar a documentação com textos voltados ao usuário mais avançado, explicando como criar seu próprio componente através da API do Ensemble.

- Validação da arquitetura com usuários

Como forma de melhor validar o arcabouço aqui proposto, espera-se que ele possa ser utilizado de forma sistemática por um grupo de usuários para criar sistemas multiagentes musicais. Essa validação pode ser feita de forma controlada através de trabalhos propostos a uma turma de estudantes de ciência da computação, definindo-se o projeto de aplicações musicais a serem desenvolvidas por pequenos grupos de alunos. Através do acompanhamento constante da evolução do trabalho, dos resultados finais (código fonte, demonstração e documentação da aplicação) e de questionários de avaliação do arcabouço, será possível avaliar sua generalidade, a facilidade de uso e a carga de programação exigida do usuário.

- Aplicação musical: Piano Preparado

Uma aplicação musical baseada na ideia do piano preparado de John Cage está sendo desenvolvida com o auxílio de Michelle Agnes, no âmbito do projeto MOBILE ${ }^{3}$. A ideia da aplicação é que diversos agentes musicais, de características sonoras diferentes, ocupem a cauda de um piano virtual e interajam com os sons produzidos pelo intérprete humano. Os agentes musicais estendem as funções de alguns itens básicos encontrados no piano tradicional, como o abafador e o pedal de sustentação, e no piano preparado, como a utilização de elementos acoplados às cordas. Aproveitando-se da capacidade de processamento do sistema, as limitações físicas desses elementos são extrapoladas, possibilitando a criação de novos materiais sonoros. Esse mundo virtual deverá ter uma representação gráfica que será projetada na tampa do piano verdadeiro, para que o público (e o músico) possa acompanhar visualmente a ação dos agentes.

\footnotetext{
${ }^{3}$ http://www.cmu.eca.usp.br/mobile/.
} 


\section{Apêndice A}

\section{Tutorial}

Este tutorial mostra de uma forma passo-a-passo como deve-se proceder para criar uma aplicação musical customizada a partir da utilização de componentes prontos do Ensemble e da criação de novos componentes.

\section{A.1 Requisitos do Ensemble}

Para a execução do Ensemble é necessário que os seguintes sistemas/bibliotecas estejam disponíveis e configurados em sua máquina e sejam acessíveis através do PATH/CLASSPATH:

- Máquina Virtual Java versão 6 ou superior $^{1}$;

- Jade 4.0 ou superior (biblioteca acompanha a distribuição do Ensemble);

- NetLib (biblioteca acompanha a distribuição do Ensemble).

Além disso, algumas bibliotecas podem ser necessárias caso o usuário deseje utilizar alguma funcionalidade extra do Ensemble:

- Jack $2.0^{2}$;

- $\operatorname{aubio}^{3}$;

- LibXtract ${ }^{4}$.

A princípio, o Ensemble pode ser executado em qualquer máquina que tenha disponível uma máquina virtual Java 6 . Caso seja necessário utilizar alguma interface JNI compilada para acessar bibliotecas nativas (como o Jack, aubio etc.), deve-se ter as interfaces compiladas para o seu sistema.

O Ensemble disponibiliza interfaces compiladas para os seguintes sistemas operacionais: Linux, Mac OS X e Windows (todas de 32-bits). Caso o seu sistema operacional não seja suportado, você mesmo pode compilar a interface. No caso de máquinas 64-bits, é mais fácil utilizar uma máquina virtual de 32-bits do que recompilar a interface.

\footnotetext{
${ }^{1}$ http://www.java.com/

${ }^{2}$ http://www.jackaudio.org/

${ }^{3}$ http://aubio.org/

${ }^{4}$ http://libxtract.sourceforge.net/
} 


\section{A.2 Configurando uma aplicação musical}

Uma aplicação utilizando o Ensemble necessita de um arquivo de configuração XML que especifica os parâmetros de inicialização do arcabouço. Este arquivo é dividido em três partes: a definição do agente ambiente, das classes de agentes musicais e suas instâncias.

Primeiramente, devemos criar uma aplicação musical do Ensemble através do elemento de mais alto nível no XML (ENSEMBLE), dando um nome para a aplicação (NAME) e definindo dois parâmetros globais, que são o modo de operação do relógio interno CLOCK_MODE (pode assumir os valores CLOCK_CPU no caso do relógio ser controlado pelo clock interno do computador ou CLOCK_USER no caso de ser controlado pelo usuário) e o modo de execução EXECUTION_MODE (com os valores REAL_TIME para o processamento em tempo real ou BATCH para o processamento em lote).

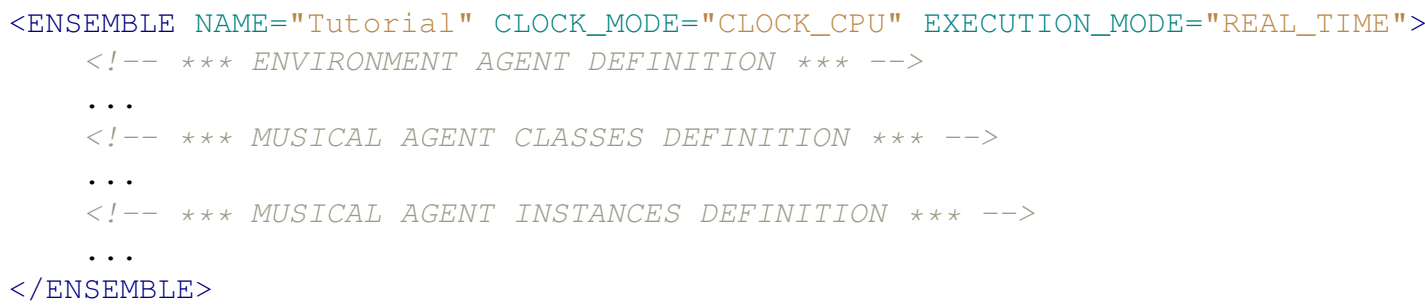

Em seguida, devemos definir o ambiente virtual através da criação de um Agente Ambiente (ENVIRONMENT_AGENT), configurando a classe (CLASS) que o define. Esta classe pode ser a padrão do arcabouço (ensemble.EnvironmentAgent) ou alguma outra classe estendida criada pelo usuário (o mesmo vale para os outros agentes e componentes que iremos criar na aplicação).

Dentro deste Agente Ambiente iremos inserir um mundo virtual (elemento WORLD), que irá abrigar fisicamente nossos agentes musicais. Neste ponto podemos passar parâmetros para qualquer agente ou componente (através do elemento PARAM), indicando o nome (NAME) e o valor do parâmetro (VALUE). Neste caso, estamos informando que o nosso mundo terá três dimensões, será contínuo e terá forma de um cubo com aresta de tamanho 100 (embora os valores sejam adimensonais, vamos considerar a unidade básica de comprimento o metro).

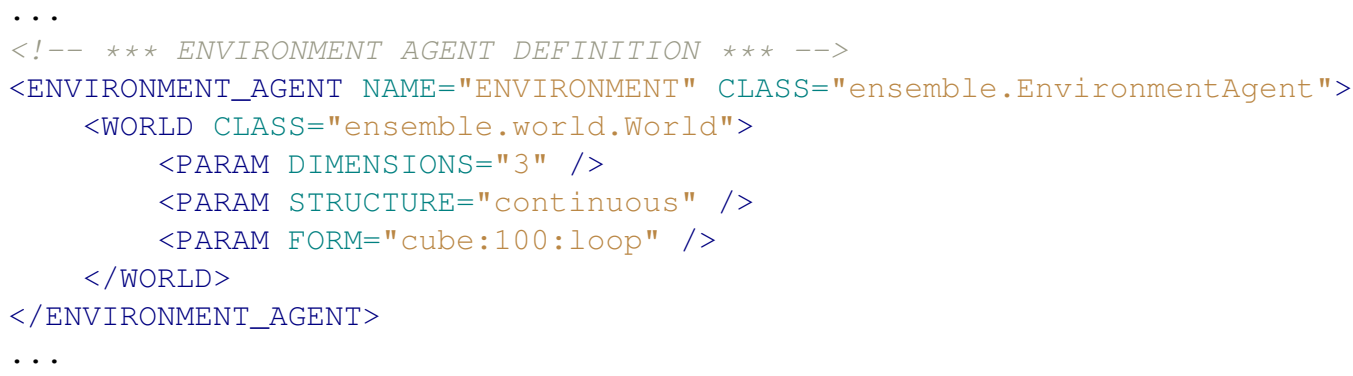

A partir deste ponto, já temos um Ambiente Virtual definido e é possível executar a simulação através do carregador do Ensemble, embora não tenhamos definido nenhum Agente Musical. Para executar o sistema, basta chamar o carregador do Ensemble informando o arquivo XML de entrada através do seguinte comando:

java -cp lib/ensemble.jar:lib/jade.jar:lib/NetUtil.jar ensemble.Loader -f tutorial.xml

Certifique-se que a máquina virtual Java esteja no $P A T H$ do seu sistema operacional e ajuste o classpath $(-\mathrm{cp})$ caso necessário. Se tudo correr bem, você verá uma janela do Sniffer mostrando que o ambiente está rodando apenas com o Agente Ambiente. 


\section{A.2.1 Criando um agente músico}

Vamos deixar nosso ambiente virtual mais interessante com a inserção de alguns agentes músicos. Como exemplo, vamos definir um agente musical capaz de ler um arquivo de áudio e reproduzir seu conteúdo no ambiente virtual, emitindo sinais de áudio através de um atuador sonoro. Essa definição é feita através do elemento MUSICAL_AGENT_CLASS, com o qual iremos agregar componentes ao Agente Musical, como sensores, atuadores e raciocínios. Esta classe de agente servirá como um modelo para criar agentes musicais deste tipo. Da mesma forma que o Agente Ambiente, podemos usar a classe padrão do arcabouço (ensemble.MusicalAgent) ou então uma classe customizada.

Todo Agente Musical deve ter uma base de conhecimento, definida pelo elemento KB, na qual podemos inserir fatos (FACT indicando seu nome, valor e se ele é visível pelo outros agentes). Em seguida, inserimos um sensor e um atuador sonoro (elementos SENSOR e ACTUATOR), dando um nome para eles e indicando o tipo de evento que irão tratar (nessa caso, AUD IO) e o tipo de interface de comunicação que irão utilizar (ensemble.comm.direct.CommDirect).

Para reproduzir o arquivo de áudio no ambiente utilizaremos um raciocínio disponível no Ensemble (ensemble.audio.file.AudioFileInputReasoning). Este raciocínio abre o arquivo de áudio no formato WAVE, cujo nome é armazenado como um fato na base de conhecimentos, e redireciona o seu conteúdo para os atuadores de áudio presentes no Agente Musical (nesse caso, temos apenas um atuador de áudio chamado Mouth).

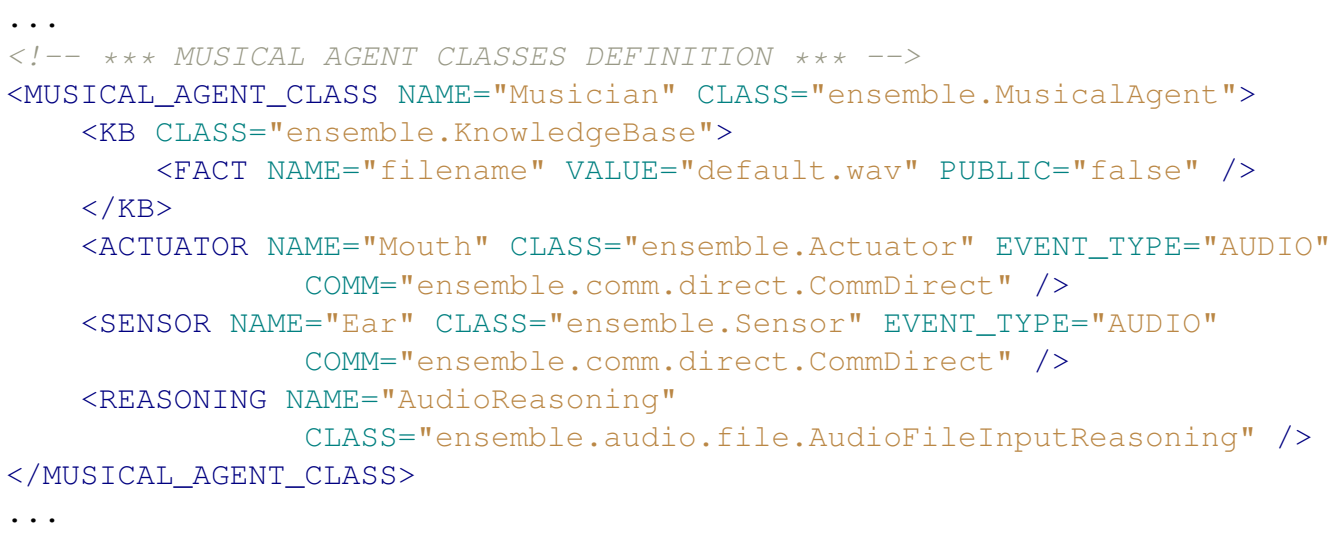

A partir desses modelos de agentes podemos criar agentes individuais através do elemento MUSICAL_AGENT. É interessante ressaltar que todas as definições de agentes do arcabouço podem ser feitas também ao se estender a classe básica (como veremos mais abaixo). Uma vez definida a classe do Agente Musical, podemos criar suas instâncias através da configuração a seguir, na qual três agente músicos são definidos, com seus respectivos arquivos de áudio e posições iniciais.

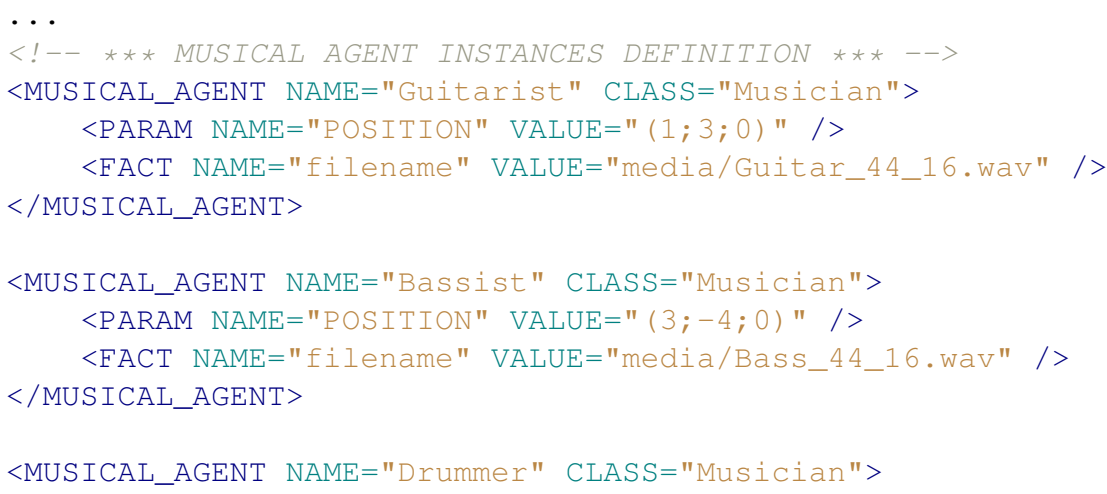




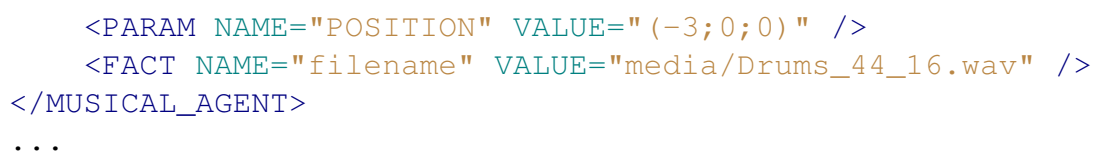

Alguém precisa processar o áudio que está sendo gerado pelos Agentes Musicais e esse papel cabe a um Servidor de Eventos capaz de receber esses eventos de áudio e propagar o som dentro do Ambiente Virtual. O Ensemble dispõe de um Servidor de Eventos chamado ensemble.audio.AudioEventServer responsável pela troca de eventos de áudio e de uma lei de propagação de áudio (ensemble.audio.AudioLaw), que simula uma propagação sonora realística, considerando que o som se propaga em campo aberto e sem reflexões, difrações etc.

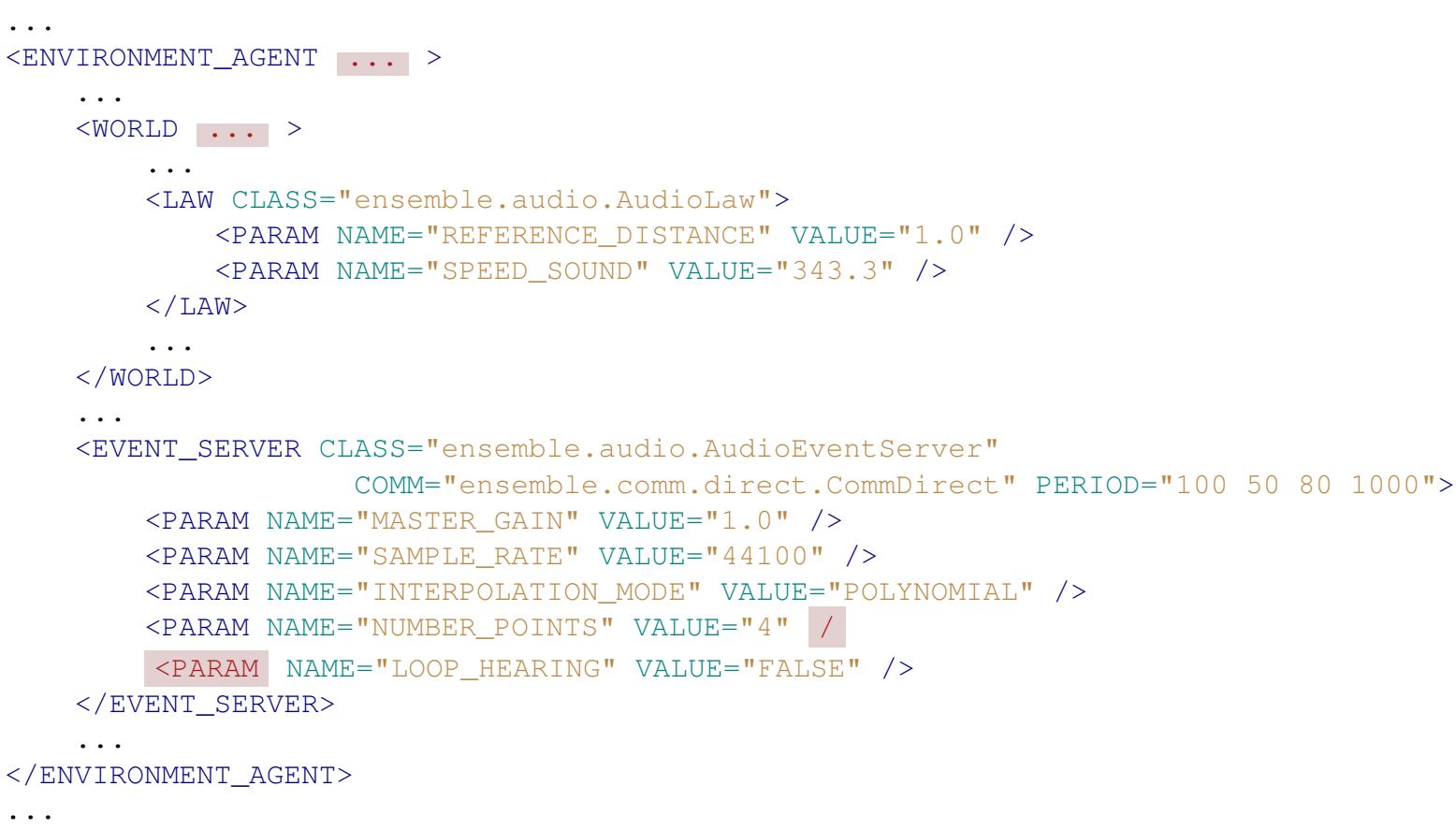

No caso do AudioEventServer, devemos parametrizar a frequência com que os agentes deverão gerar um fragmento de áudio, o que influencia diretamente na latência observada na simulação. Se usarmos valores baixos, como janelas de 50 ou $100 \mathrm{~ms}$, a latência se torna menos perceptível mas a carga de processamento é maior. Para configurar a frequência utilizamos o parâmetro PERIOD, indicando em milissegundos qual a duração de um fragmento de áudio, o tempo desse fragmento que é reservado para o processamento dos agentes musicais, o tempo reservado para o processamento do Servidor de Eventos e o tempo de espera antes de iniciar a troca de áudio.

A lei de propagação sonora pode ser parametrizada indicando a velocidade do som no ambiente (SPEED_SOUND) e a distância de referência de um sinal de áudio sem que haja atenuação (REFERENCE_DISTANCE).

\section{A.2.2 Ouvindo o que acontece no ambiente virtual}

Ainda não estamos ouvindo o que está sendo produzido dentro do ambiente virtual, pois necessitamos de um agente Avatar capaz de receber o som que está sendo propagado no ambiente e direcioná-lo para uma saída da interface de áudio. Para isso, criaremos uma nova classe de agentes, compostos por dois sensores de áudio (Ear_left e Ear_right), simulando dois ouvidos em posições distintas, e um raciocínio (Speaker), que processa o som recebido pelo sensor e o redireciona para 
a saída de áudio. Em seguida, basta criar uma instância dessa classe de agente, nosso Avatar.

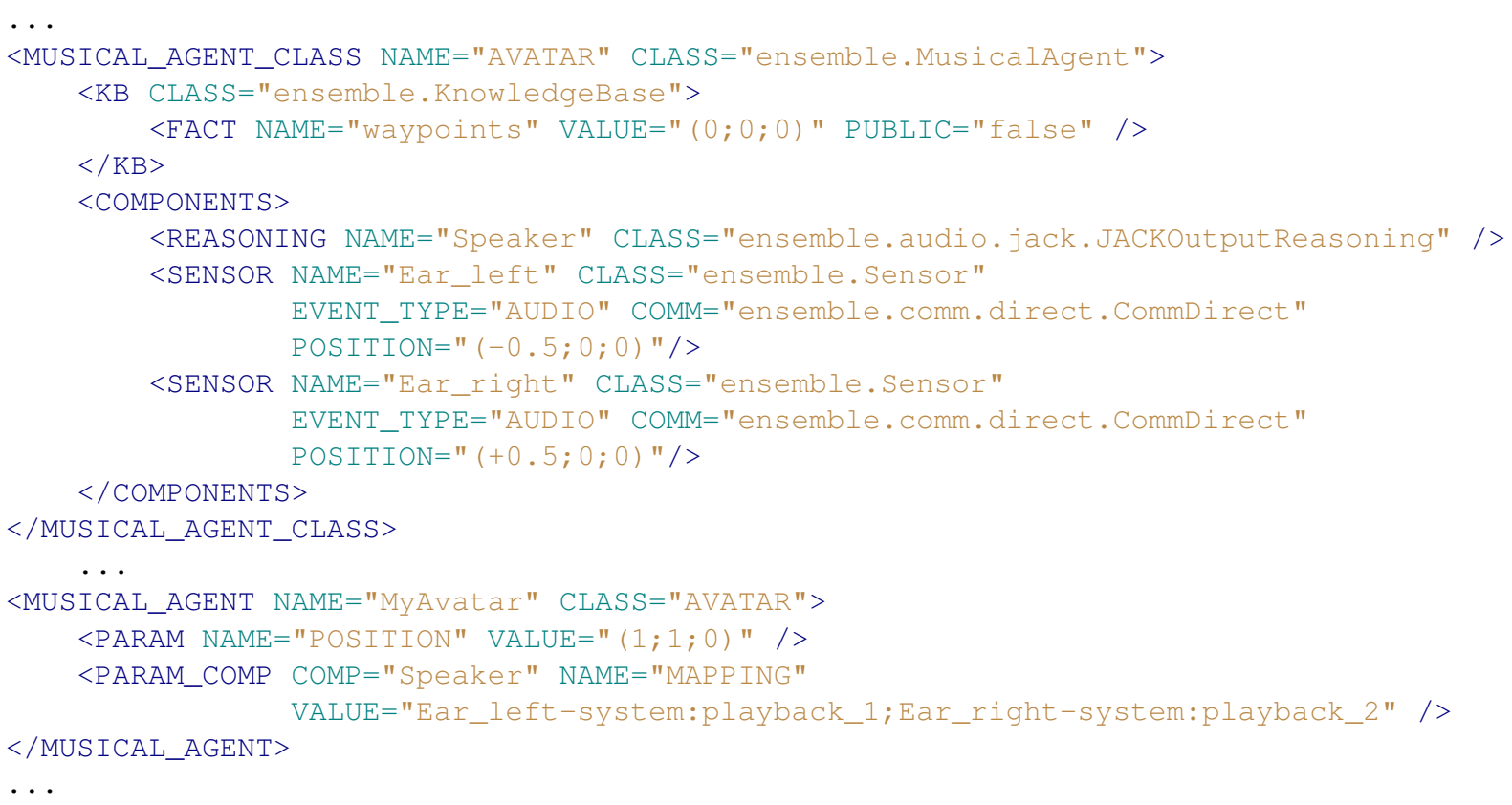

Duas diferenças importantes aparecem nesta definição com relação aos agentes Musician, a primeira é o posicionamento do sensor relativo ao centro do agente musical, através do parâmetro POSITION. Dessa forma, podemos espaçar os dois sensores e, como consequência, o som chegará em instantes diferentes neles. No caso do exemplo esse espaçamento é de 1 metro no eixo x. Este recurso também pode ser utilizado com os atuadores.

A segunda é o uso da biblioteca Jack para acessar a interface de áudio, através do raciocínio JACKOutputReasoning. Para isso, você deve ter certeza que o servidor Jack está executando em sua máquina e que existem portas de saída disponíveis (veja a documentação/tutorial do Jack caso tenha alguma dúvida).

O parâmetro MAPPING indica qual sensor de áudio será conectado a uma certa porta do Jack. Neste caso, estamos conectando o sensor Ear_left à porta system:playback_1 e o sensor Ear_right à porta system:playback_2. Atenção aos separadores utilizados no mapeamento (';' para cada mapeamento sensor/porta e '-' para indicar qual sensor é ligado a certa porta, sendo ':' reservado pelo Jack).

\section{A.2.3 Movimentando os agentes}

Uma outra funcionalidade básica do arcabouço é permitir que os agentes se movimentem dentro do mundo virtual. Para isso, da mesma forma que criamos um Servidor de Eventos que trata a propagação sonora, precisamos de um servidor que irá tratar a movimentação, trocando eventos deste tipo com os Agentes Musicais.

Além disso, precisamos de uma lei de movimentação que irá criar os novos estados de posicionamento dos agentes a partir de suas requisições. A lei MovementLaw implementa as equações clássicas de movimento uniformemente acelerado, incluindo o atrito. Os parâmetros que podem ser configurados são o coeficiente de atrito (friction_coefficient) e a gravidade (gravity) do mundo virtual. 


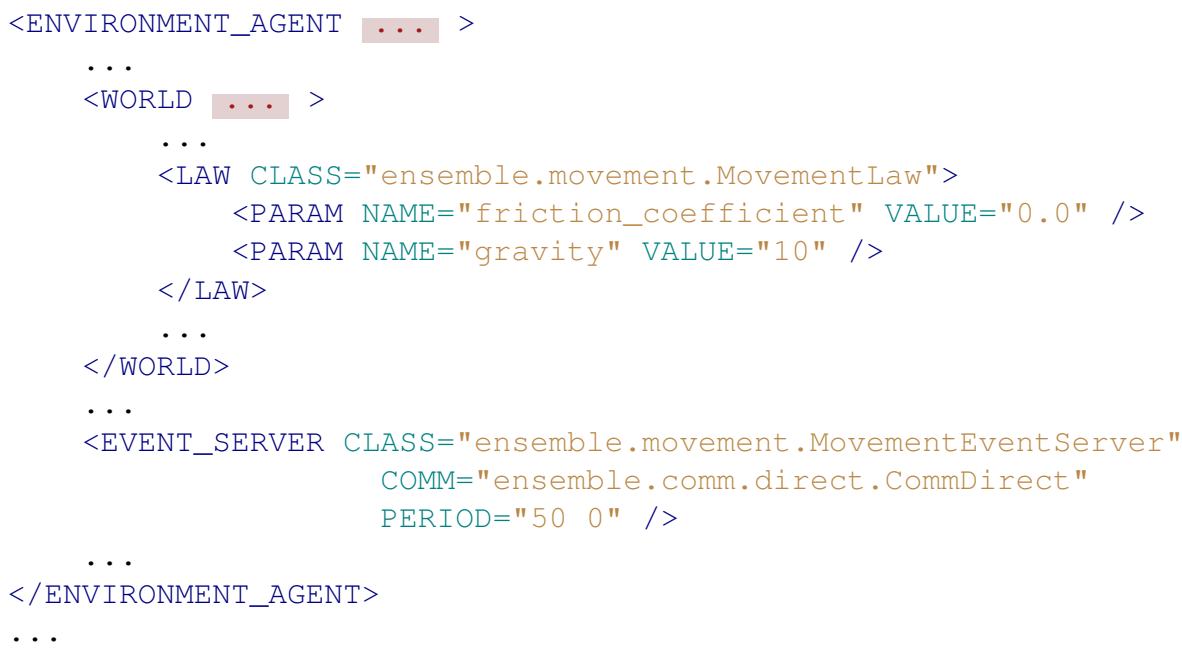

Os agentes musicais também precisam de uma atualização em sua composição para serem capazes de se movimentar no ambiente. Para isso, inserimos um atuador de movimentação (Legs), que irá enviar pedidos de movimentação como andar e parar para o ambiente, e um sensor de movimentação (Eyes), que funciona como um GPS recebendo a posição atual do agente. O raciocínio MovementReasoning é capaz de receber instruções de outros raciocínios do agente e enviar eventos de movimentação para o ambiente.

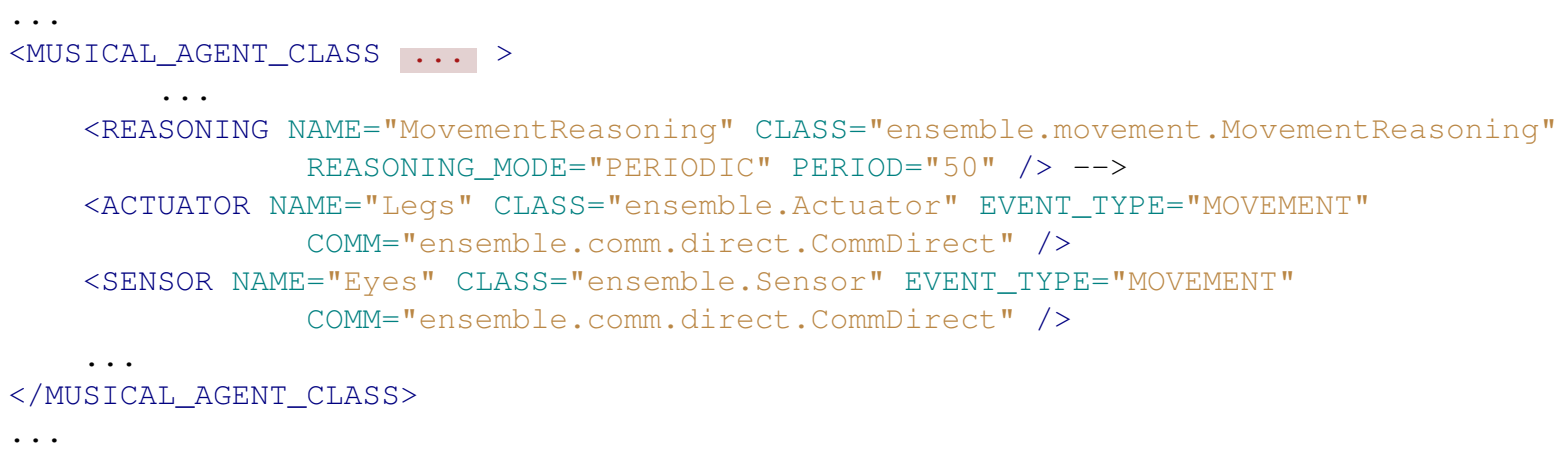

\section{A.2.4 Tocando junto com os agentes}

Finalmente, vamos utilizar os canais de entrada da interface de áudio para tocar junto com os agentes presentes no ambiente. De forma similar à primeira forma de escuta demonstrada, vamos utilizar um raciocínio capaz de direcionar, através do Jack, um canal de entrada da interface de áudio a um atuador de áudio.

Para isto, vamos adicionar à classe de agente AVATAR um raciocínio do tipo JACKInputReasoning chamado Microphone e um atuador de áudio chamado Mouth. Veja que o mapeamento é feito agora para a porta de captura do Jack (system:capture_1).

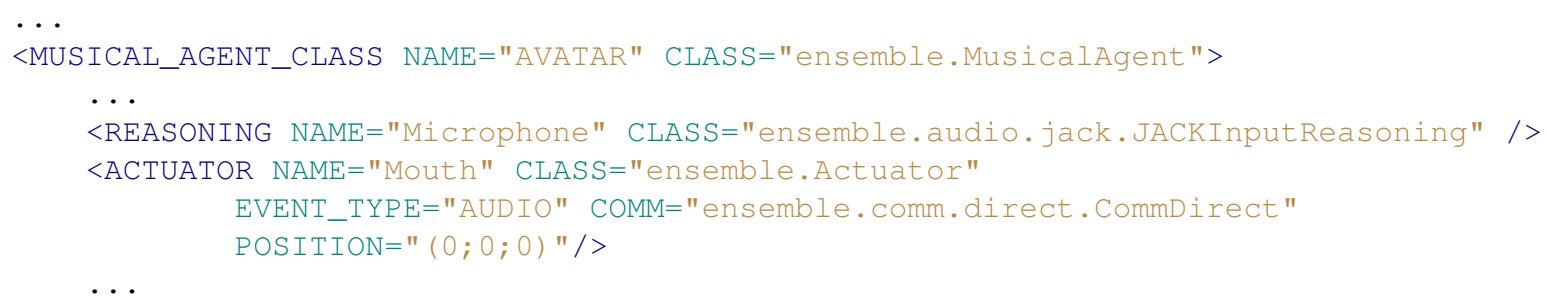




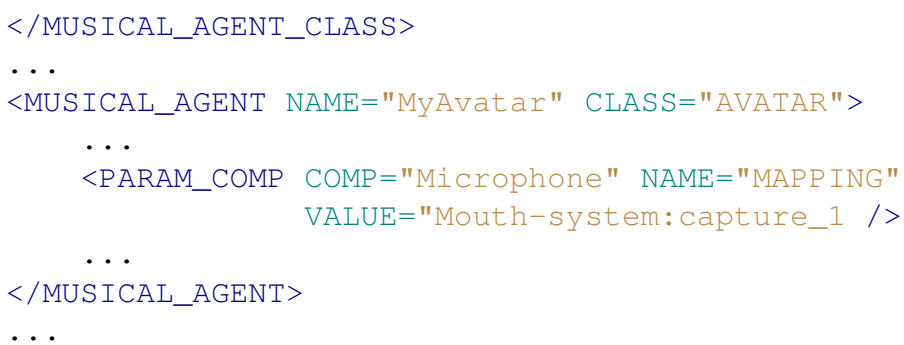

Agora todo o som capturado pela interface de áudio será redirecionado para o agente MyAvatar que o emitirá no Ambiente Virtual e será recebido pelos outros agentes. Um atraso de duas janelas de áudio é intrínseco ao sistema devido à forma como o som é sincronizado entre os agentes, então configurações do servidor de áudio com janelas menores terão um atraso menor.

\section{A.2.5 Recriando um campo sonoro de escuta}

O agente ouvinte representa apenas uma saída na interface de áudio, mas para ter uma situação mais realista, seria interessante poder recriar o campo sonoro através de um conjunto de alto-falantes. Para isso utilizamos a técnica chamada Ambisonics (para mais detalhes, veja a seção 4.4.3).

Basta alterar o sensor do agente ouvinte, informando-o que ele deve receber eventos de áudio no formato Ambisonics e qual a ordem através do parâmetro AMBISONICS (essa informação será automaticamente repassada para o servidor de eventos de áudio). Também precisamos configurar um novo tipo de memória a ser utilizada pelo sensor (MultichannelAudioMemory), pois o formato Ambisonics utiliza pelo menos 4 canais de áudio (Ambisonics de primeira ordem).

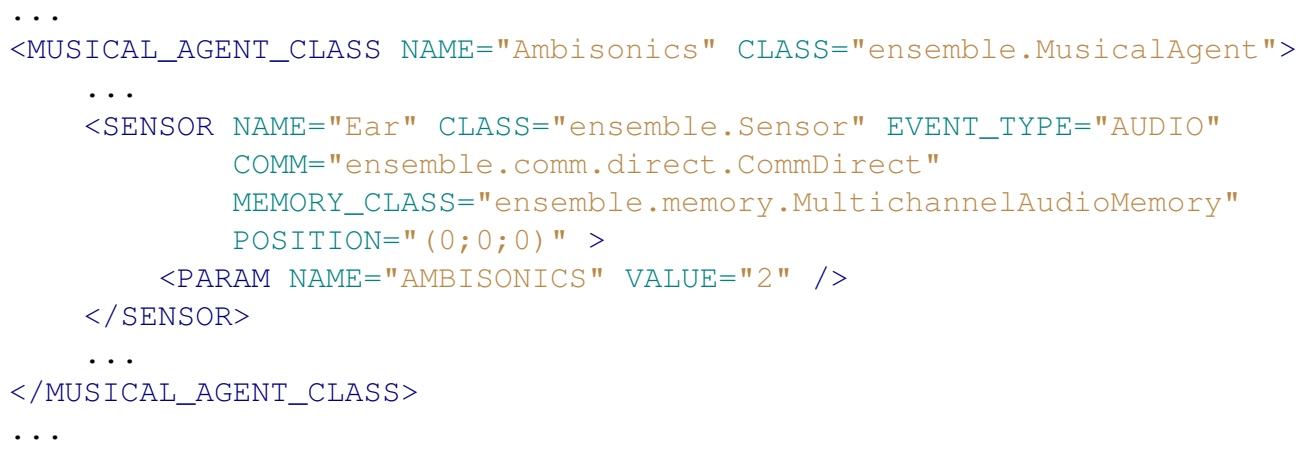

Além disso, precisamos trocar o raciocínio Speaker do agente para que ele trate esses canais de forma especial (AmbisonicsAudioOutputReasoning), decodificando o sinal Ambisonics em uma certa configuração de alto-falantes. Nesse exemplo, vamos utilizar uma configuração estéreo através do parâmetros SPEAKERS_LAYOUT, mas outras configurações são possíveis (ver figura 4.8).

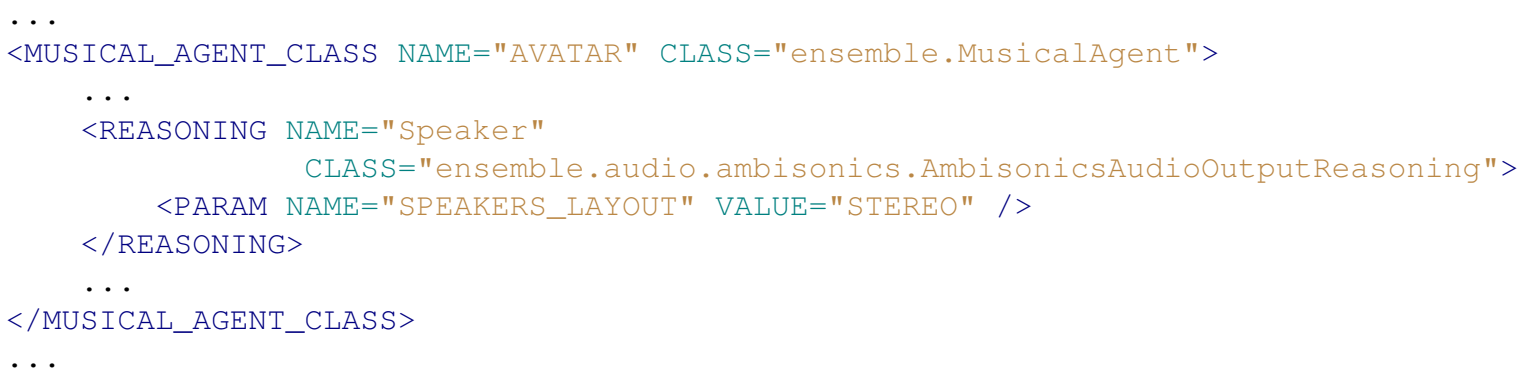


Os canais serão configurados automaticamente para as saídas disponíveis no Jack, mas também é possível fazer o mapeamento dos canais dos alto-falantes de forma individual através do parâmetro MAPPING.

\section{A.3 Próximos passos}

Este tutorial cobriu algumas das construções elementares usando componentes prontos do Ensemble. Mais exemplos de construções em XML podem ser encontrados na documentação que acompanha o código. O usuário interessado em estender as classes do arcabouço para implementar raciocínios ou servidores de eventos em Java poderá consultar o código dos estudos de caso ou a documentação em Javadoc. 


\section{Referências Bibliográficas}

[AB79] J. B. Allen e D. A. Berkley. Image method for efficiently simulating small-room acoustics. J. Acoust. Soc. Am, 65(4):943-950, 1979. 61

[B ${ }^{+}$00] R.C. Boulanger et al. The Csound Book, volume 309. MIT press, 2000. 19

[BB87] J.M. Borwein e P.B. Borwein. Pi and the AGM: a study in the analytic number theory and computational complexity. Wiley-Interscience, 1987. 67

[BB01] R. Bencina e P. Burk. PortAudio-an open source cross platform audio API. Em Proc. 2001 Intl. Computer Music Conf.(ICMC-01), 2001. 74

[BBP04] P. Brossier, J.P. Bello, e M.D. Plumbley. Real-time temporal segmentation of note objects in music signals. Em Proceedings of the International Computer Music Conference, 2004. 91

[BC07] J. Bullock e U.C.E.B. Conservatoire. Libxtract: A lightweight library for audio feature extraction. Em Proceedings of the International Computer Music Conference, 2007. 70

[BCGC07] F. Bellifemine, G. Caire, D. Greenwood, e Ebooks Corporation. Developing multi-agent systems with JADE. Springer, 2007. 57

[Bey07] P. Beyls. Interaction and Self-organisation in a Society of Musical Agents. Em Proceedings of ECAL 2007 Workshop on Music and Artificial Life, 2007. 3, 5, 13

[BG00] G. Bollella e J. Gosling. The real-time specification for Java. Computer, 33(6):47-54, 2000. 99

[BNF08] D. Bisig, M. Neukom, e J. Flury. Interactive Swarm Orchestra-A Generic Programming Environment for Swarm Based Computer Music. Em Proceedings of the International Computer Music Conference. Belfast, Ireland, 2008. 4, 5, 9, 19, 71

[BP89] J. Brown e M. Puckette. Calculation of a Narrowed Autocorrelation Function. Journal of the Acoustical Society of America, 85(4):1595-1601, 1989. 17

[BPR99] F. Bellifemine, A. Poggi, e G. Rimassa. Jade - a fipa-compliant agent framework. Proceedings of PAAM, 99:97-108, 1999. 57, 58

[Bro06] P. Brossier. Automatic annotation of musical audio for interactive applications. Tese de Doutorado, Centre for Digital Music, Queen Mary University of London, 2006. 70

[CDK00] A. T. Cemgil, P. Desain, e B. Kappen. Rhythm quantization for transcription. Computer Music Journal, 24(2):60-76, 2000. 9, 18

$\left[\mathrm{CDPF}^{+} 05\right]$ A. Camurri, G. De Poli, A. Friberg, M. Leman, e G. Volpe. The mega project: Analysis and synthesis of multisensory expressive gesture in performing art applications. Journal of New Music Research, 34(1):5-21, 2005. 19 
[Cho71] J. M. Chowning. The simulation of moving sound sources. Journal of the Audio Engineering Society, 19(1):2-6, 1971. 13

$\left[\mathrm{CHR}^{+} 00\right]$ A. Camurri, S. Hashimoto, M. Ricchetti, A. Ricci, K. Suzuki, R. Trocca, e G. Volpe. Eyesweb: Toward gesture and affect recognition in interactive dance and music systems. Computer Music Journal, 24(1):57-69, 2000. 19

[Cop00] D. Cope. The Algorithmic Composer. AR Editions, Inc., 2000. 16

[CVM08] L.L. Costalonga, R.M. Vicari, e E.M. Miletto. Agent-based guitar performance simulation. Journal of the Brazilian Computer Society, 14:19-29, 2008. 2, 3, 9

[Dan93] R. B. Dannenberg. Music representation issues, techniques, and systems. Computer Music Journal, 17(3):20-30, 1993. 9, 12

$\left[\mathrm{DBT}^{+} 04\right]$ R. B. Dannenberg, W. P. Birmingham, G. Tzanetakis, C. Meek, N. Hu, e B. Pardo. The musart testbed for query-by-humming evaluation. Computer Music Journal, 28(2):3448, 2004. 9, 18

[Dix00] S. Dixon. A lightweight multi-agent musical beat tracking system. PRICAI 2000: Proceedings of the Pacific Rim International Conference on Artificial Intelligence, página 778-788, 2000. 2, 9

[DN01] P. Dahlstedt e M. G. Nordahl. Living melodies: Coevolution of sonic communication. Leonardo, 34(3):243-248, 2001. 2, 3, 5, 9, 12, 13, 15, 16, 20, 21, 22, 23, 83

[Dre05] K. Dressler. Extraction of the melody pitch contour from polyphonic audio. Proceedings of the 2005 Music Information Retrieval Exchange, 2005. 9, 18

[Dre06] K. Dressler. Sinusoidal extraction using an efficient implementation of a multiresolution FFT. Em Proc. of the Int. Conf. on Digital Audio Effects (DAFx-06), Montreal, Quebec, Canada, páginas 247-252, 2006. 17

[EP06] D.P.W. Ellis e G.E. Poliner. Classification-based melody transcription. Machine Learning, 65(2):439-456, 2006. 17

[ES04] D.H. Eberly e K. Shoemake. Game physics. Morgan Kaufmann, 2004. 12

[Fuj98] I. Fujinaga. Machine recognition of timbre using steady-state tone of acoustic musical instruments. Proc. International Computer Music Conference-ICMC'98, 1998. 18

[GD05] F. Gouyon e S. Dixon. A review of automatic rhythm description systems. Computer Music Journal, 29(1):34-54, 2005. 9, 18

[Ger73] M.A. Gerzon. Periphony: With-height sound reproduction. J. Audio Eng. Soc, 21(1):210, 1973. 75

[GMJ06] M. Gimenes, E.R. Miranda, e C. Johnson. The development of musical styles in a society of software agents. Em Proceedings of the International Conference on Music Perception and Cognition, 2006. 3, 5

[HS00] J. F. Hubner e J. S. Sichman. Saci: Uma ferramenta para implementação e monitoração da comunicação entre agentes. Proceedings of the International Joint Conference, "7th Ibero-American Conference on AI, 15th Brazilian Symposium on AI (Open Discussion Track), página 47-56, 2000. 57

[Jen93] N. R. Jennings. Commitments and conventions: The foundation of coordination in multi-agent systems. The Knowledge Engineering Review, 8(3):223-250, 1993. 1 
[JF88] R. E. Johnson e B. Foote. Designing reuseable classes. Journal of Object-Oriented Programming, 1988. 2, 25

[KMMG87] R. Kronland-Martinet, J. Morlet, e A. Grossmann. Analysis of sound patterns through wavelet transforms. International Journal of Pattern Recognition and Artificial Intelligence, 1(2):273-302, 1987. 17

[Kol93] J. Kolodner. Case-based reasoning. Morgan Kaufmann Publishers Inc. San Francisco, CA, USA, 1993. 15

[Kul85] A. Kulowski. Algorithmic representation of the ray tracing technique. Applied Acoustics, 18(6):449-469, 1985. 61

[Lan95] C. G. Langton. Artificial Life: An Overview. Mit Press, 1995. 3, 13

[Lap04] P. A. Laplante. Real-Time Systems Design and Analysis. Wiley-IEEE Press, 2004. 67

[LCN90] H. J. Levesque, P. R. Cohen, e J. H. T. Nunes. On acting together. Proceedings of the Eighth National Conference on Artificial Intelligence (AAAI-90), página 94-99, 1990. 1

[LJ83] F. Lerdahl e R. Jackendoff. A Generative Theory of Tonal Music. MIT Press, 1983. 15

[McC01] J. McCormack. Eden: An evolutionary sonic ecosystem. Advances in Artificial Life, páginas 133-142, 2001. 5, 9, 13

[Mir01] R. Miranda. Composing Music with Computers. Focal Press, 2001. 9, 16, 19

[Mir02] E. R. Miranda. Emergent sound repertoires in virtual societies. Computer Music Journal, 26(2):77-90, 2002. 2, 5, 9, 12, 20, 21, 23

[Mir03] E. R. Miranda. On the music of emergent behavior: What can evolutionary computation bring to the musician? Leonardo, 36(1):55-59, 2003. 3

[MM95] D. G. Malham e A. Myatt. 3-d sound spatialization using ambisonic techniques. Computer Music Journal, 19(4):58-70, 1995. 2, 75

[MM03] S. Muller e G. Mazzola. The extraction of expressive shaping in performance. Computer Music Journal, 27(1):47-58, 2003. 19

[MMH99] K. McAlpine, E. Miranda, e S. Hoggar. Making music with algorithms: A case-study system. Computer Music Journal, 23(2):19-30, 1999. 9, 13

[Moo73] J. A. Moorer. The heterodyne filter as a tool for analysis of transient waveforms, Memo AIM-208, 1973. 17

[MR07] D. Murray-Rust. Musical Acts and Musical Agents: theory, implementation and practice. Tese de Doutorado, University of Edinburgh, 2007. 2, 4, 15, 16, 18, 19

[MRS05] D. Murray-Rust e A. Smaill. Musical acts and musical agents. Proceedings of the 5th Open Workshop of MUSICNETWORK: Integration of Music in Multimedia Applications, 2005. 12

[MRSE06] D. Murray-Rust, A. Smaill, e M. Edwards. MAMA: An architecture for interactive musical agents. Em Proceeding of the 2006 conference on ECAI 2006: 17th European Conference on Artificial Intelligence August 29-September 1, 2006, Riva del Garda, Italy, páginas 36-40. IOS Press, 2006. 5, 9, 12 
[ON98] PD O'Brien e RC Nicol. FIPA — towards a standard for software agents. BT Technology Journal, 16(3):51-59, 1998. 3

[PAG95] R. D. Patterson, M. H. Allerhand, e C. Giguere. Time-domain modeling of peripheral auditory processing: A modular architecture and a software platform. JOURNALACOUSTICAL SOCIETY OF AMERICA, 98:1890-1890, 1995. 17

[PB02] B. Pardo e W. P. Birmingham. Algorithms for chordal analysis. Computer Music Journal, 26(2):27-49, 2002. 18

[PMC06] R. P. Paiva, T. Mendes, e A. Cardoso. Melody detection in polyphonic musical signals: Exploiting perceptual rules, note salience, and melodic smoothness. Computer Music Journal, 30(4):80-98, 2006. 9, 17

[Puc96] M. Puckette. Pure data: another integrated computer music environment. Proceedings of the Second Intercollege Computer Music Concerts, páginas 37-41, 1996. 4, 32

[Pul97] V. Pulkki. Virtual sound source positioning using vector base amplitude panning. Journal of the Audio Engineering Society, 45(6):456-466, 1997. 2

[Ris91] J.C. Risset. Timbre analysis by synthesis: representations, imitations, and variants for musical composition. Em Representations of musical signals, páginas 7-43. MIT Press, 1991. 18

[RK06] M. Ryynanen e A. Klapuri. Transcription of the singing melody in polyphonic music. Em Proc. 7th International Conference on Music Information Retrieval, 2006. 17

[RN03] Stuart J. Russell e Peter Norvig. Artificial intelligence : a modern approach. Prentice Hall series in artificial intelligence. Prentice Hall/Pearson Education, Upper Saddle River, N.J., 2nd edição, 2003. 2003269366 Stuart J. Russell and Peter Norvig ; contributing writers, John F. Canny ... [et al.]. ill. ; $27 \mathrm{~cm}$. Includes bibliographical references (p. 987-1043) and index. 10, 15

[Roa96] C. Roads. The Computer Music Tutorial. Mit Press, 1996. 13, 18

[Roe99] J.G. Roederer. The perception of music by the human brain: An introductory course. The Journal of the Acoustical Society of America, 105:1054, 1999. 20

[Row92] R. Rowe. Machine listening and composing with cypher. Computer Music Journal, 16(1):43-63, 1992. 15

[RRG99] G. L. Ramalho, P. Y. Rolland, e J. G. Ganascia. An artificially intelligent jazz performer. Journal of New Music Research, 28(2):105-129, 1999. 2, 3, 5, 9, 15, 16

[RS04] C. Raphael e J. Stoddard. Functional harmonic analysis using probabilistic models. Computer Music Journal, 28(3):45-52, 2004. 9, 18

[SB68] R. Smith-Brindle. Serial Composition, 1968. 15

[SGVT04] S. Schertenleib, M. Gutierrez, F. Vexo, e D. Thalmann. Conducting a virtual orchestra. Multimedia, IEEE, 11(3):40-49, 2004. 9, 23

[SL01] L. Savioja e T. Lokki. Digital waveguide mesh for room acoustic modelling. ACM SIGGRAPH and Eurographics Campfire: Acoustic Rendering for Virtual Environments. Utah, USA, 2001. 61

[Spi04] M. Spicer. AALIVENET: an agent based distributed interactive composition environment. Em International Computer Music Conference, páginas 1-6, 2004. 4, 5 
[STR05] P. Sampaio, P. Tedesco, e G. Ramalho. Cinbalada: um laboratório multiagente de geração de ritmos de percussão. Em X Brazilian Symposium on Computer Music, Belo Horizonte, MG, 2005. 3, 9

[Sup01] M. Supper. A few remarks on algorithmic composition. Computer Music Journal, 25(1):48-53, 2001. 9, 16

[SZM06] N. Scaringella, G. Zoia, e D. Mlynek. Automatic genre classification of music content. Signal Processing Magazine, IEEE, 23(2):133-141, 2006. 18

[TC02] G. Tzanetakis e P. Cook. Musical genre classification of audio signals. Speech and Audio Processing, IEEE Transactions on, 10(5):293-302, 2002. 9, 15

[Tho07] Leandro F. Thomaz. Aplicação à música de um sistema de espacialização sonora baseado em ambisonics. Dissertação de Mestrado, Universidade de São Paulo, 2007. $2,74,75$

[TQ09] L. F. Thomaz e M. Queiroz. A framework for musical multiagent systems. Em Proceedings of the SMC 2009 - 6th Sound and Music Computing Conference, páginas 119-124, Porto, Portugal, 2009. 77

[TQ11] L. F. Thomaz e M. Queiroz. Ensemble: Implementing a musical multiagent system framework. Em Proceedings of the SMC 2011 - 8th Sound and Music Computing Conference, páginas 198-205, Padova, Italia, 2011. 80

[TW99] P. M. Todd e G. M. Werner. Frankensteinian methods for evolutionary music composition. Musical Networks: Parallel Distributed Perception and Performance, 1999. 2, 9

[UK04] L.K. Ueda e F. Kon. Mobile musical agents: the andante project. Em Conference on Object Oriented Programming Systems Languages and Applications, páginas 206-207. ACM New York, NY, USA, 2004. 2, 3, 9

[VE90] B. Vercoe e D. Ellis. Real-time CSOUND: Software synthesis with sensing and control. ICMC Glasgow, páginas 209-211, 1990. 4

[Wei99] Gerhard Weiss. Multiagent systems: a modern approach to distributed artificial intelligence. MIT Press, Cambridge, Mass., 1999. 98049797 edited by Gerhard Weiss. 26 $\mathrm{cm}$. Includes bibliographical references and index. 1

[WF97] M. Wright e A. Freed. Open sound control: A new protocol for communicating with sound synthesizers. Em Proceedings of the 1997 International Computer Music Conference, páginas 101-104, 1997. 71

[Wha05] I. Whalley. Software Agents and Creating Music/Sound Art: Frames, Directions, and Where to From Here. Em Proceedings of International Computer Music Conference, páginas $691-5,2005.1$

[Wid96] G. Widmer. Learning expressive performance: The structure-level approach. Journal of New Music Research, 25(2):179-205, 1996. 19

[WNV03] R. D. Wulfhorst, L. Nakayama, e R. M. Vicari. A multiagent approach for musical interactive systems. Proceedings of the second international joint conference on Autonomous agents and multiagent systems, páginas 584-591, 2003. 2, 3, 9, 12, 16, 18, 19, 23

[Woo02] Michael J. Wooldridge. An introduction to multiagent systems. J. Wiley, New York, 2002. 10,16 
[ZA02] U. Zölzer e X. Amatriain. DAFX: digital audio effects. John Wiley \& Sons Inc, 2002. 20

[Zha01] T. Zhang. Instrument classification in polyphonic music based on timbre analysis. Proceedings of SPIE, 4519:136, 2001. 18 